FÁBIO FERRAZ JÚNIOR

\title{
ARQUITETURA PARA MONITORAMENTO E SUPERVISÃO INTEGRADOS DE PROCESSOS DE USINAGEM EM MÁQUINAS COM CONTROLE NUMÉRICO ABERTO
}

Tese apresentada à Escola de Engenharia de São Carlos, da Universidade de São Paulo, para obtenção do título de Doutor em Engenharia Mecânica.

Área de Concentração: Engenharia Mecânica

Orientador: Prof. Dr. João Fernando Gomes de Oliveira 
Candidato: ERgenheiro FÁ

Candidato: Epgenheiro FA

Tese defendida e julgafa em 14/08/2007 perante a Comissão Julgadora:

rof. Titular JOÁO FERNANDO GOMES DE OLIVEIRA (Orientador)
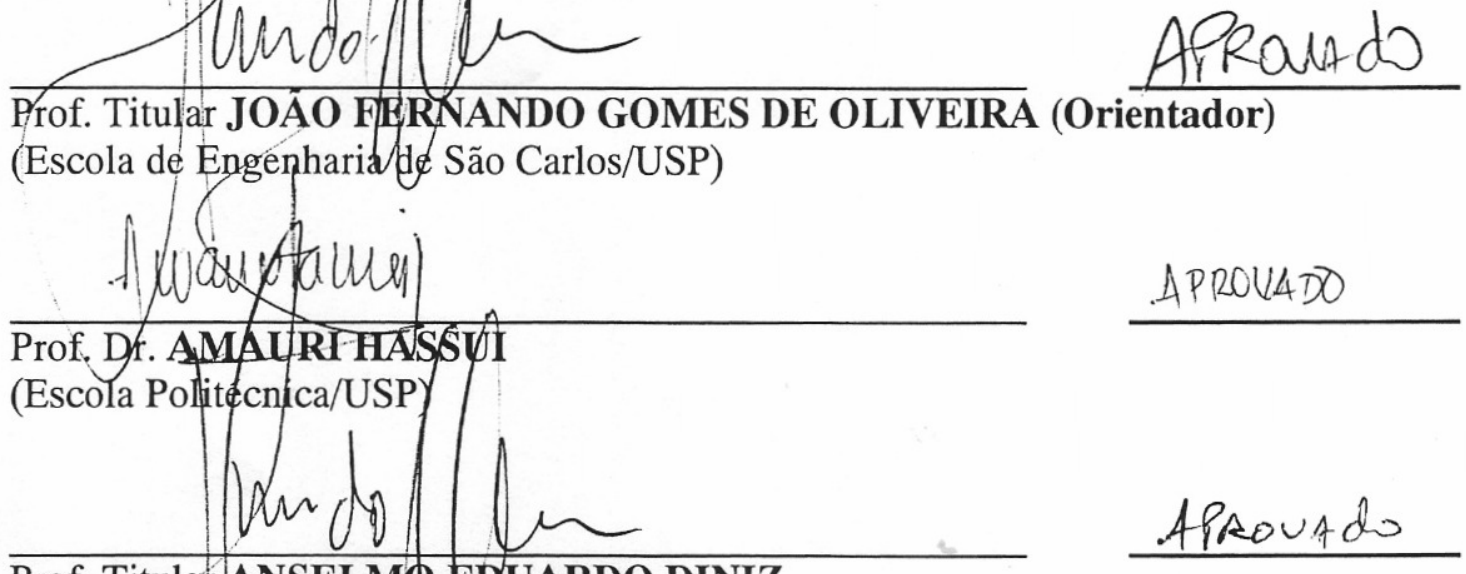

Prof. Titular ANSELM $\phi$ EDUARDO DINIZ

(Universidade Estadual de Campinas/UNICAMP)

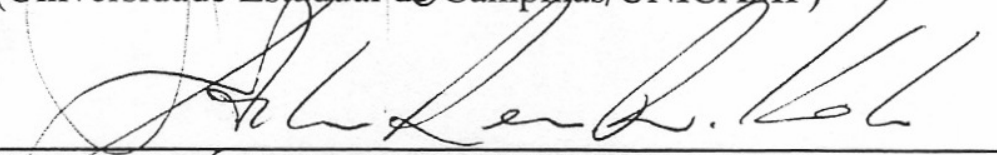

Ptof.Dr. EDÍLSON REIS RODRIGUES KATO

(Universidade Federal de São Carlos/UFSCar)

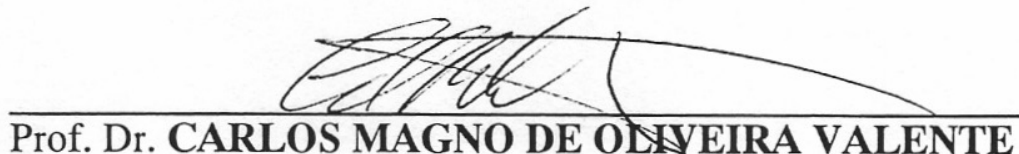

APROUADO

Prof. Dr. CARLOS MAGNO DE OLYVEIRA VALENTE

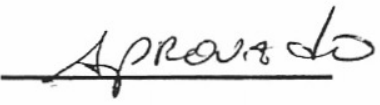

(Centro Universitário de Araraquara/UNIARA)

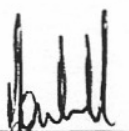

Prof. Associado JONAS DE CARVALHO

Coordenador do Programa de Pós-Graduação em Engenharia Mecânica

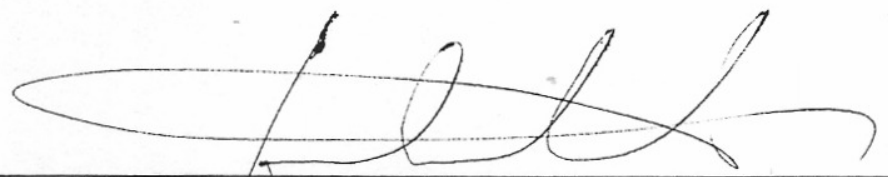

Prof. Associado GERALDO ROBERTO MARTINS DA COSTA

Presidente da Comissão da Pós-Graduação da EESC 


\section{DEDICATÓRIA}

Aos meus pais, Fábio e Antonia, fonte de inspiração e conforto, exemplos de dignidade e amor.

Aos meus irmãos, Fabrício e Lúcio, exemplos de pessoas e de profissionais, das quais eu sempre me guiarei; e a minha irmã Jéssica.

A Camilinha, com amor e gratidão por sua compreensão, carinho e apoio para a realização deste trabalho. 


\section{AGRADECIMENTOS}

À Deus - razão de toda a existência, fonte de esperança e amor -, por ter me guiado para alcançar mais esta graça.

Ao professor João Fernando Gomes de Oliveira, pela confiança, pela orientação deste trabalho, pela amizade, paciência e conselhos que contribuíram para o meu crescimento científico e intelectual.

À Dona Irene, pela disponibilidade e atenção em todos os momentos.

A toda "família" do laboratório OPF (Otimização de Processsos de Fabricação) do NUMA (Núcleo de Manufatura Avançada), pelo apoio, convivência e momentos de descontração. Agradecimentos especiais para Carlos Magno (Dinho) e Eraldo Jannone pelos trabalhos realizados na EMBRAER.

Ao colega e amigo Anderson Yoshizato, pela confiança e oportunidade de desenvolver parte deste trabalho na EMBRAER.

À todos os funcionários do Departamento de Engenharia Mecânica e do Departamento de pós-graduação da EESC-USP, pela atenção e cooperação.

À Fundação de Amparo à Pesquisa do Estado de São Paulo (FAPESP) pela concessão da bolsa de doutorado e pelo apoio financeiro para a realização desta pesquisa.

À todas as pessoas que de alguma forma contribuíram de forma direta ou indireta para a realização deste trabalho. 


\section{EPÍGRAFE}

\section{Exigência}

Não pense mal de mim.

A minha luta, o meu esforço...

Aquilo por que mais torço,

é uma batalha sem fim.

Não pense que idealizo

Para nós a perfeição.

Mas brigo por isso, antemão,

Sabendo que não realizo.

A vida é luta constante.

E se o querer-subir não vem,

A decadência intervém,

E leva a todos rasante.

Por isso brado com gosto,

- Para ficarmos no meio -

Querendo, com todo anseio,

O idealismo proposto.

\section{Fábio Ferraz}

( "Exigência", pág. 23 do livro "Mente Corpo Coração" ) 


\section{RESUMO}

FERRAZ JUNIOR, F. Arquiteturas para monitoramento e supervisão integrados de processos de usinagem em máquinas com controle numérico aberto. 2007. 163 f. Tese (Doutorado) - Escola de Engenharia de São Carlos, Universidade de São Paulo, São Carlos, 2007.

Empreendimentos industriais requerem o completo e preciso acompanhamento de dados de máquinas em tempo real, integrando as atividades do chão de fábrica com a engenharia,

suporte e de negócios. É reconhecido que sistemas de monitoramento são fundamentais para melhorar a qualidade do produto, reduzir os tempos e para a adaptação rápida às mudanças de produção. Os sensores de processos possuem altos custos, não são compactos e são de difícil implementação. Portanto, seria estratégico desenvolver sistemas de monitoramento que utilizem ao máximo os recursos já existentes nas máquinas ferramentas e que não representem custos adicionais de implementação. O uso de CNC's de arquitetura aberta nas indústrias é crescente. Estes se mostram como potenciais ferramentas para atender a estas exigências. Possuem os recursos necessários para a aquisição de informações administrativas e tecnológicas e para o desenvolvimento de sistemas de monitoramento. O objetivo do presente trabalho é pesquisar arquiteturas de monitoramento e supervisão para processos de usinagem que tenham como base informações disponíveis em CNC's de arquitetura aberta. Tais sistemas, apesar de todo o potencial existente, ainda não tem sido explorados nem desenvolvidos adequadamente para os processos de usinagem. O presente trabalho é multidisciplinar nas áreas de automação e usinagem. Está dividido em partes em que são analisados tanto os elementos tecnológicos dos CNC's abertos, bem como os processos de monitoramento e supervisão da usinagem. São apresentadas propostas no sentido de integrar as duas áreas pelo desenvolvimento de arquiteturas de software dedicadas. Os sistemas desenvolvidos foram testados em laboratório e também nas empresas parceiras. Os resultados mostram que o uso de CNC's abertos para monitoramento e supervisão de processos é viável e proporciona funções de monitoramento/supervisão que não eram possíveis com os sistemas convencionais e sem a necessidade de recursos adicionais, como hardware, sensores e instalação. A implementação de protótipo em empresa parceira foi bem sucedida e deverá ser expandida no futuro.

Palavras-chave: CNC de arquitetura aberta, monitoramento, supervisão, usinagem. 


\section{ABSTRACT}

\section{FERRAZ JUNIOR, F. Integrated monitoring and supervision architectures applied to} machining process controlled by open CNC systems. 2007. 163 f. Thesis (Doctoral) Escola de Engenharia de São Carlos, Universidade de São Paulo, São Carlos, 2007.

Manufacturing enterprises require complete real time and accurate monitoring of machine tool data for integrating the shop floor with other company activities, as engineering, maintenance and business. It is acknowledged that monitoring systems capabilities are unavoidable to improve product quality, to reduce production time, and to the rapid adaptation in the changes of production. The use of external sensors gives high costs and do not have the advantages of compactness and the ease of use. Therefore, it is extremely advantageous to develop monitoring systems maximizing the use of the resources already existent in the machine tools and without additional costs of implementation. The use of open CNC's on industries is growing. This kind of control has been a great tool to attend these present requirements. It has the necessary resource to get managerial and technological information, and to develop monitoring systems. The objective of this work is to research monitoring and supervision architectures for machining process, based on information already available in open CNC's. Such systems, in spite of the whole existent potential, have not still been explored nor developed appropriately for the machining processes. The present work is multidisciplinary in the automation and machining areas. It is divided in parts where the technological elements of open CNC's are analyzed, as well as the monitoring and supervision systems of the machining processes. An architecture is proposed in the sense of integrating both monitoring and supervision. The developed systems were tested in laboratory and also in the partner companies. The results show that the use of open CNC's for monitoring and supervision of processes is viable and provides monitoring/ supervision functions which were not possible with the conventional systems and without the need of additional resources, as hardware and sensor installation. The prototype tested in a partner company succeeded and should be expanded in the future.

Keywords: open CNC, monitoring system, supervisory system, machining. 


\section{LISTA DE FIGURAS}

FIGURA 2.1 - Constituição básica de uma máquina CNC

FIGURA 2.2 - Estruturas de CNCs - passado, atualidade e tendência (PRITSCHOW et al, 2001 -

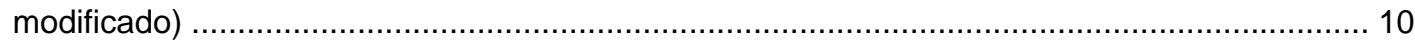

FIGURA 2.3 - CNC hardware e software - tendência atual (PRITSCHOW et al, 2001 - modificado) . 11

FIGURA 2.4 - Benefícios do uso de sistemas de controles abertos (PRITSCHOW et al, 2001 modificado).

FIGURA 2.5 - interfaces externas e internas de sistemas de controle (PRITSCHOW et al, 2001 modificado).

FIGURA 2.6 - Arquitetura básica de um sistema de controle OSACA (OSACA, 2004 - modificado). 17

FIGURA 2.7 - Esquema da plataforma de sistema da OSACA (OSACA, 2004 - modificado)........... 18

FIGURA 2.8 - Esquema da plataforma de sistema de controle convencional (OSACA, 2004 modificado).

FIGURA 2.9 - Variações de estruturas de hardware e software de CNCs (PRITSCHOW et al, 2001 modificado).

FIGURA 2.10 - Critério de sistemas de controle aberto (PRITSCHOW et al, 2001 - modificado)...... 23

FIGURA 2.11 - Níveis de abertura de sistemas de controle (OSACA, 2004 e PRITSCHOW et al, 2001 - modificado)

FIGURA 2.12 - Decomposição das funcionalidades de controle (PRITSCHOW et al, 2001 modificado).

FIGURA 2.13 - Infraestrutura de sistemas de controle aberto modulares (PRITSCHOW et al, 2001 modificado).

FIGURA 2.14 - Critérios de abertura de sistemas de controle (PRITSCHOW et al, 2001 - modificado).

FIGURA 2.15 - Características de sistemas de controle abertos (PRITSCHOW et al, 2001 modificado). 28

FIGURA 2.16 - Visão geral de sistemas CNC comerciais (PRITSCHOW et al, 2001 - modificado)... 29

FIGURA 3.1 - Funções de sistemas de monitoramento (TÖNSHOFF et al, 2002 - modificado) ........ 32 FIGURA 3.2 - Elementos de um ciclo de controle de processo (TÖNSHOFF et al, 2002 - modificado)

FIGURA 3.3 - Guia para o processamento de sinal de sensor (DU et al, 1995 - modificado) .......... 40 FIGURA 3.4 - Método convencional de tomada de decisão (TÖNSHOFF et al, 2002 - modificado) 42 FIGURA 3.5 - Limites fixos ao longo do ciclo e ao longo do tempo ........................................42

FIGURA 3.6 - Limites fixos ao longo do ciclo, porém flutuante ao longo do tempo.....................43

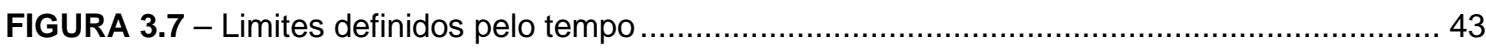




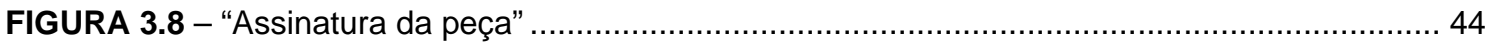

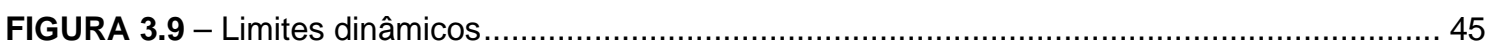

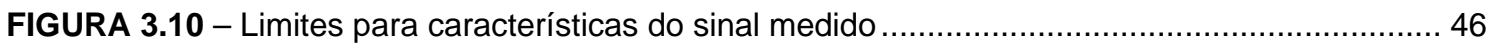

FIGURA 3.11 - Método por modelagem de processo para tomada de decisão (TÖNSHOFF et al,

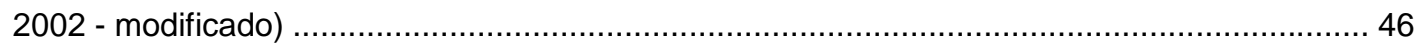

FIGURA 3.12 - Métodos de modelagem (TÖNSHOFF et al, 2002 - modificado) …........................ 47

FIGURA 3.13 - Possibilidades de integração de sistemas de monitoramento em máquinas ferramenta

FIGURA 3.14 - Controle de máquina ferramenta e de processos (LIANG et al, 2004; SIEMENS, 2000

- modificado)..... 50

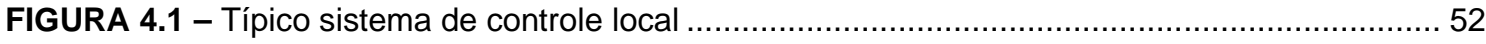

FIGURA 4.2 - Exemplo de central de controle de um sistema SCADA ............................................. 54

FIGURA 4.3 - Arquitetura de hardware típica de um sistema SCADA .............................................. 56

FIGURA 4.4 - Arquitetura de software genérica de um sistema SCADA (DANEELS \& SALTER, 1999)

57

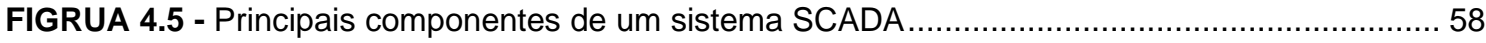

FIGURA 4.6 - Equipamentos de campo (em destaque) de um sistema SCADA …............................. 59

FIGURA 4.7 - Sistema de comunicação (em destaque) de um sistema SCADA ................................ 63

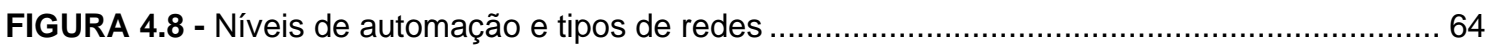

FIGURA 4.9 - Diferença entre redes de cabos paralelos e fieldbus (FERRAZ JR., 2002) .................. 66

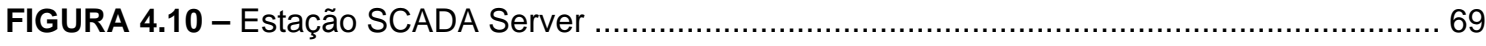

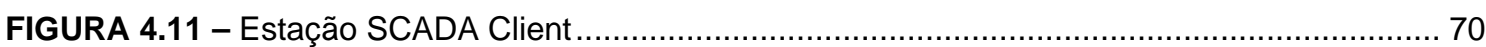

FIGURA 4.12 - Exemplos de telas de supervisão (FERRAZ JR., 2002) …..................................... 72

FIGURA 4.13 - Esquema das possíveis configurações de máquinas de chão de fábrica................... 74

FIGURA 5.1 - Níveis de resolução de tempo para a aquisição de informações de chão de fábrica... 76

FIGURA 5.2 - Arquitetura tradicional de sistema de monitoramento........................................... 77

FIGURA 5.3 - Níveis de resolução de tempo para sistemas de supervisão, micromonitoramento da

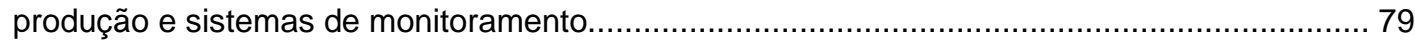

FIGURA 5.4 - Arquitetura proposta abrangendo todos os níveis de resolução de tempo de aquisição de informações.

FIGURA 5.5 - Exemplos de aplicações da arquitetura proposta: sistema de monitoramento e supervisão

FIGURA 5.6 - Arquitetura proposta com sistema de automação em PC externo interligado à rede interna de controle.

FIGURA 5.7 - Arquitetura proposta com sistema de automação em PC externo interligado via PC da IHM. 85

FIGURA 5.8 - Arquitetura proposta com o sistema de automação no próprio PC da IHM. ................ 86

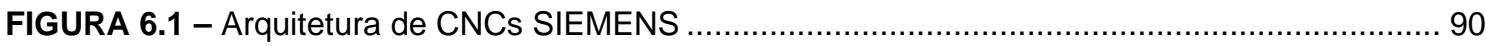

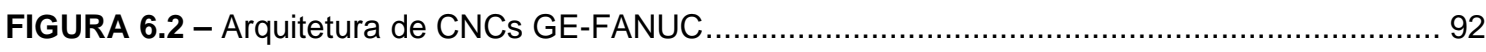

FIGURA 6.3 - Arquitetura de comunicação via rede Ethernet (TCP/ IP) e protocolo NetDDE ........... 94 
FIGURA 6.4 - Exemplo de arquitetura de supervisão com CNCs SIEMENS Sinumerik 810D/ 840D 95 FIGURA 6.5 - Arquitetura de comunicação via rede RS-485 (MPI/ OPI) e protocolo DDE, utilizando um PC externo 96

FIGURA 6.6 - Arquitetura de comunicação via rede RS-485 (MPI/ OPI) e protocolo DDE, no próprio $\mathrm{PC}$ da HMI

FIGURA 6.7 - Arquitetura de comunicação via rede Ethernet e protocolo FOCAS1 para sistema de monitoramento e/ou supervisão 98

FIGURA 6.8 - Exemplo de arquitetura de supervisão com CNCs GE-FANUC serie XX0i 98

FIGURA 6.9 - Arquitetura de comunicação via rede HSSB de fibra óptica e protocolo FOCAS1, no próprio PC da IHM

FIGURA 6.10 - Corpo de prova de perfil complexo: a-) foto do corpo de prova b-) modelo geométrica utilizado no CAM 102

FIGURA 6.11 - Comparação entre arquiteturas de comunicação com CNC SIEMENS. 103

FIGURA 7.1 - Arquitetura de comunicação do sistema de supervisão com CNCs SIEMENS Sinumerik 8X0D

FIGURA 7.2 - Front end principal do sistema de supervisão (informações de produção das máquinas ferramenta) 109

FIGURA 7.3 - Front end de informações do torno INDEX 110

FIGURA 7.4 - Front end de informações do centro de usinagem ROMI ................................ 110

FIGURA 7.5 - Front end de informações do centro de usinagem HERMLE............................ 111

FIGURA 7.6 - Estratégia para definição de status a serem registrados .................................... 112

FIGURA 7.7 - Arquitetura de comunicação do projeto piloto EMBRAER-CEEHM ........................ 114

FIGURA 7.8 - Front end da tela principal do projeto EMBRAER-CEEHM (informações gerais das

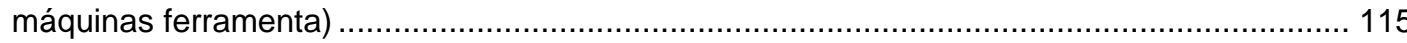

FIGURA 7.9 - Front end de uma das telas de informações detalhadas das máquinas ferramenta.. 116 FIGURA 7.10 - Front end do aplicativo local (LOG LOCAL) das máquinas ferramenta com CNC ECS

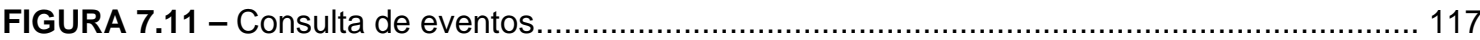

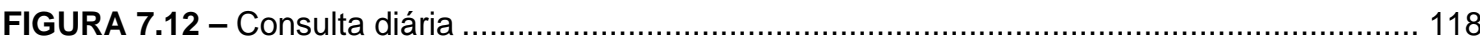

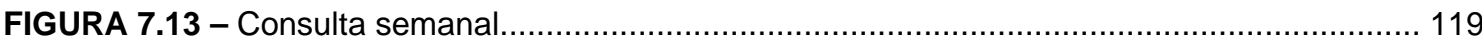

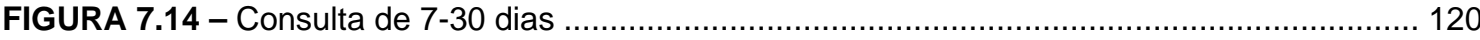

FIGURA 7.15 - Arquitetura de comunicação do sistema de monitoramento com CNC SIEMENS

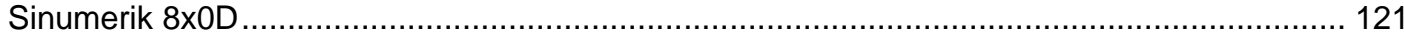

FIGURA 7.16 - Front end do sistema de monitoramento do processo de fresamento ................. 125

FIGURA 7.17 - Front end do sistema de monitoramento do processo de fresamento .................. 125

FIGURA 7.18 - Gráfico do sinal de "LOAD" spindle ao longo do processo de fresamento para cada ensaio 126

FIGURA 7.19 - Gráfico da média do sinal de "LOAD" spindle em cada ensaio de usinagem ......... 127

FIGURA 7.20 - Detalhe da detecção de limite de desgaste da ferramenta de corte ultrapassado... 128 FIGURA 7.21 - Análise de velocidades de avanço (real e de setpoint) ao longo do corpo de prova 129 
FIGURA 7.22 - Análise de forças de corte ao longo do corpo de prova........... 


\section{LISTA DE TABELAS}

TABELA 3.1 - Métodos para o monitoramento do estado de ferramentas de corte .............................. 39

TABELA 6.1 - Exemplos de arquiteturas de comunicação para sistemas de monitoramento e supervisão....... 93

TABELA 7.1 - Máquinas ferramenta do projeto EMBRAER-CEEHM........................................ 112

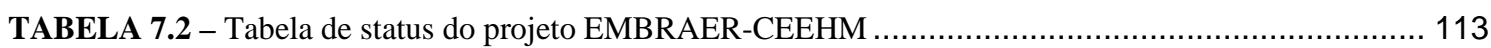

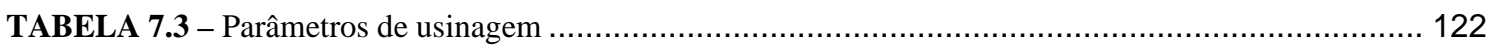

TABELA 7.4 - Desgastes da ferramenta de corte nos quatro ensaios de usinagem ........................... 123 


\section{LISTA DE ABREVIATURAS E SIGLAS}

API - Application Programming Interface

BOP - Basic Operation Package

CAM - Computer Aided Manufacturing

CEP - Controle Estatístico de Processo

CEEHM - Coleta Eletrônica de Eventos Hora Máquina

CLP - Controlador Lógico Programável

CNC - Comando Numérico Computadorizado

CN - Comando Numérico

COM - Component Object Model

CPU - Central Processing Unit

DCOM - Distributed Component Object Model

DCS - Distributed Control System

DDE - Dynamic Data Exchange

DLL - Dynamic Linking Libraries

DNC - Distributed Numerical Control

ERP - Enterprise Resource Planning

FDDI - Fiber Distributed Data Interface

FOCAS - Fanuc OpenFactory CNC API Specification

FSSB - Fanuc Serial Servo Bus

FTP - File Transmission Protocol

HMI - Human Machine Interfacing

HSSB - High Speed Serial Bus

HTML - HyperText Markup Language

HTTP - HyperText Transfer Protocol

IEC - International Electrotechnical Commission

IEEE - Institute of Electrical and Electronics Engineers

IHM - Interface Homem Máquina

I/O - Input/ Output

IP - Internet Protocol

ISA - The Instrumentation, Systems and Automation Society 
ISO - International Organization for Standardization

LAN - Local Area Networking

LVDT - Linear Variable Differential Transformer

MES - Manufacturing Execution System

MMC - Man Machine Interface

MMI - Man Machine Interfacing

MPI - MultiPoint Interface

NetDDE - Network Dynamic Data Exchange

ODBC - Open Database Connectivity

OEM - Original Equipment Manufacturer

OLE - Object Linking and Embedding

OPC - OLE for Process Control

OPI - Operator Panel Interface

PC - Personal Computer

PDF - Probability Density Functions

PMC - Programmable Machine Control

RMS - Root Mean Square

RTU - Remote Terminal Unit ou Remote Telemetry Unit

SCADA - Supervisory Control And Data Acquisition

SDCD - Sistemas Digitais de Controle Distribuídos

SDC - Sistemas Distribuído de Controle

SQL - Structured Query Language

TCP - Transmission Control Protocol

TI - Tecnologia de Informação

WAN - Wide Area Networking

WIP - Work In Process 


\section{SUMÁRIO}

RESUMO i

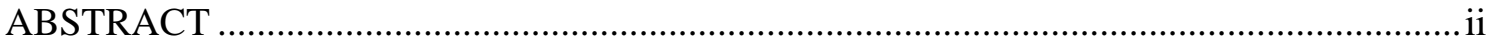

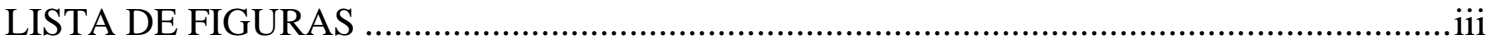

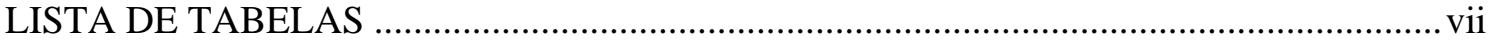

LISTA DE ABREVIATURAS E SIGLAS …....................................................................viii

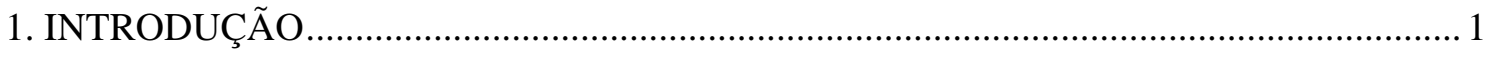

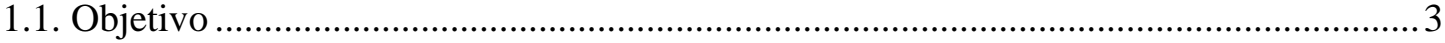

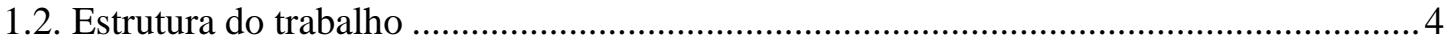

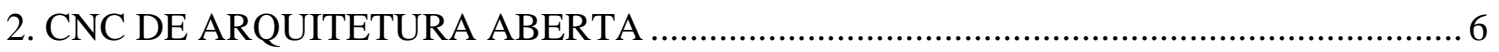

2.1. Benefícios de CNCs de Arquitetura Aberta ..................................................................... 13

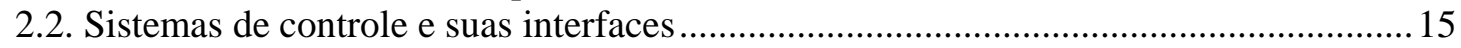

2.3. Estrutura de hardware e software de sistemas de controle ...........................................19

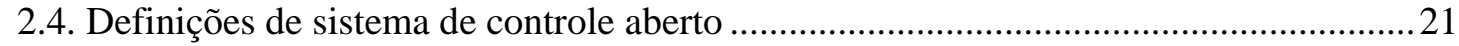

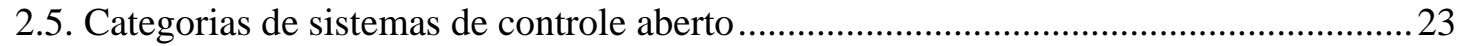

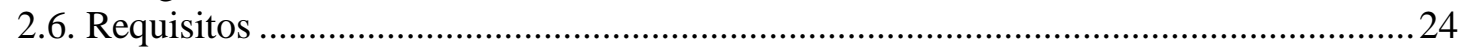

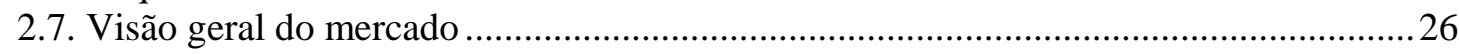

3. SISTEMAS DE MONITORAMENTO DE PROCESSOS DE USINAGEM...................... 30

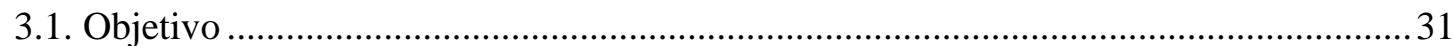

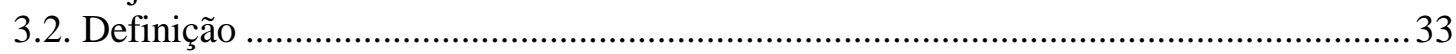

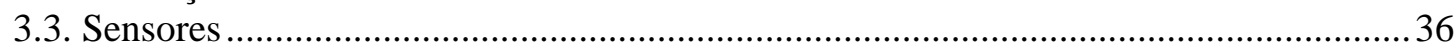

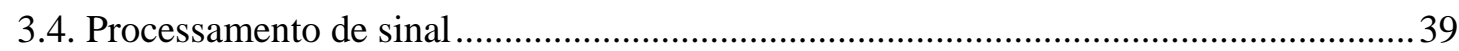

3.5. Interpretação e tomada de decisões (estratégia de monitoramento) .............................41

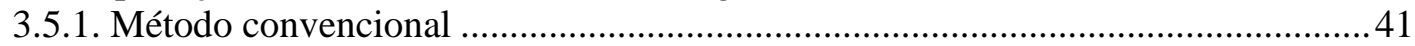

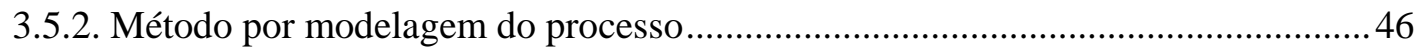

3.6. Integração de sistemas de monitoramento em máquinas ferramenta ...............................48

3.6.1. Controle de processos de usinagem.................................................................... 49

4. SISTEMAS DE SUPERVISÃO E CONTROLE DE PROCESSOS ..................................... 52

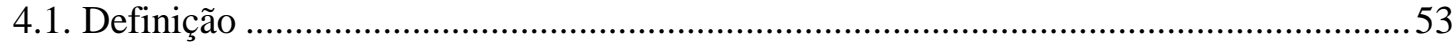

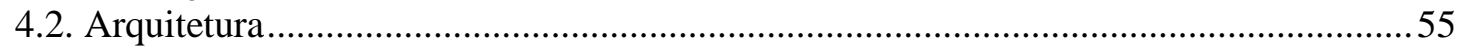

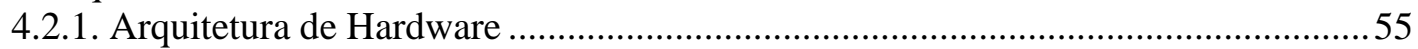

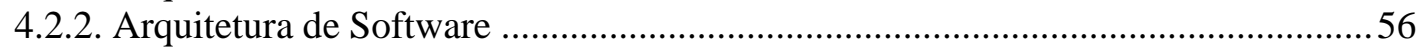

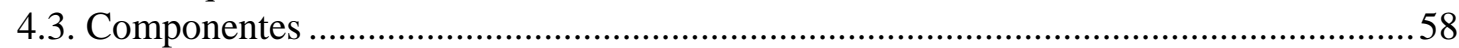




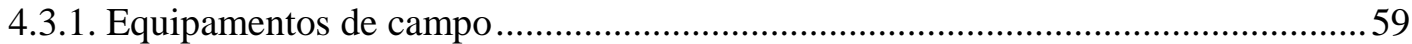

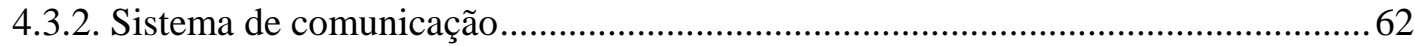

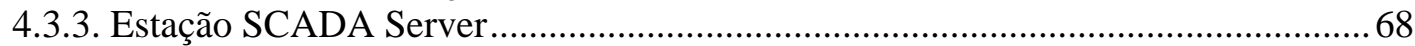

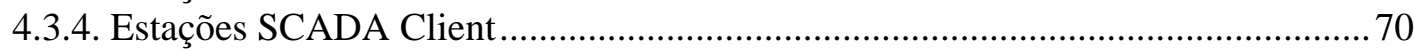

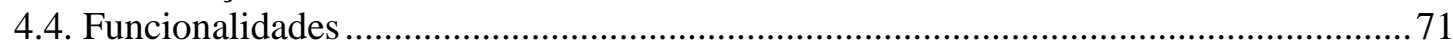

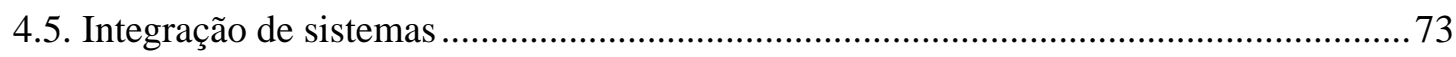

5. PROPOSTA DE ARQUITETURA DE MONITORAMENTO E SUPERVISÃO EM OPEN

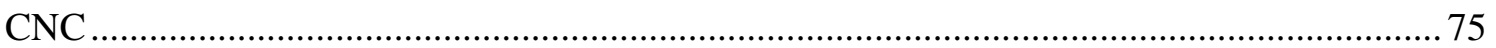

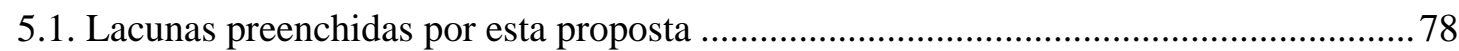

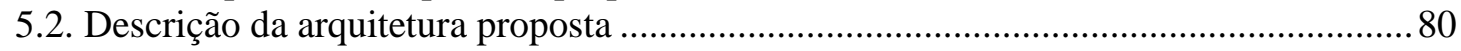

5.2.1. Opção 1: Sistema de automação em PC externo interligado à rede interna de

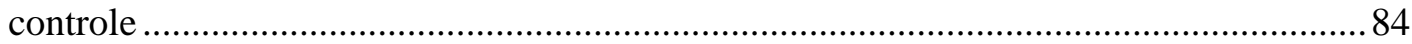

5.2.2. Opção 2: Sistema de automação em PC externo interligado via PC da IHM .........85

5.2.3. Opção 3: Sistema de automação no próprio PC da IHM........................................ 86

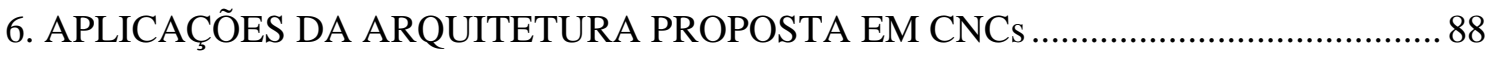

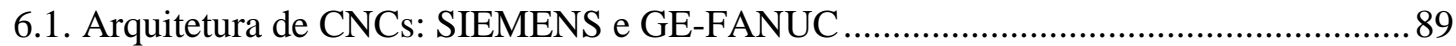

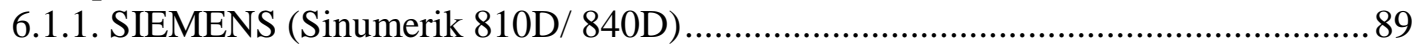

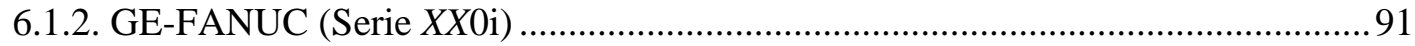

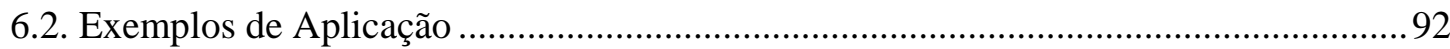

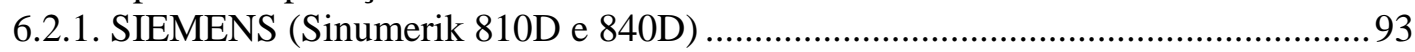

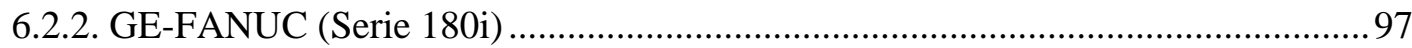

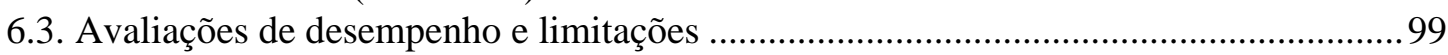

6.3.1. Comunicação com CNC SIEMENS (Sinumerik 810D/ 840D)............................. 100

6.3.2. Comunicação com CNC GE-FANUC (serie 180i) ….......................................... 103

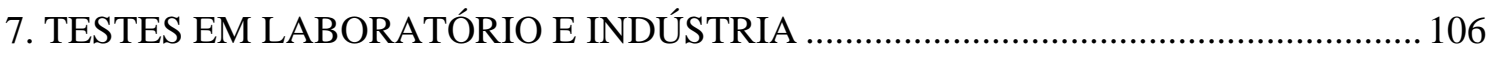

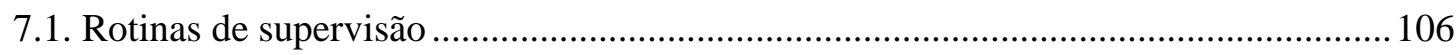

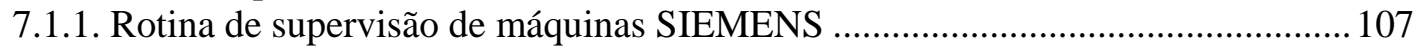

7.1.2. Rotina de supervisão de máquinas GE-FANUC ….............................................. 111

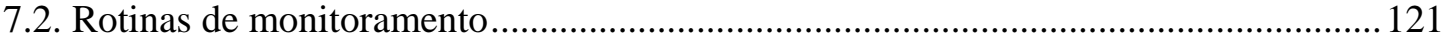

7.2.1. Rotina de monitoramento da ferramenta de corte para processos de fresamento 121

7.2.2. Rotina de aquisição de sinais para o estudo de fenômenos de usinagem .............. 129

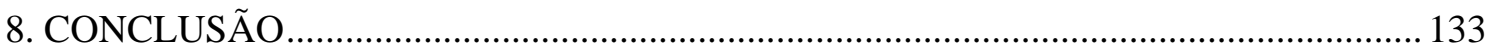

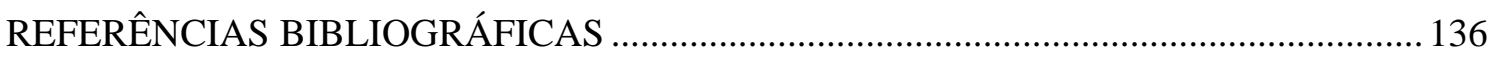

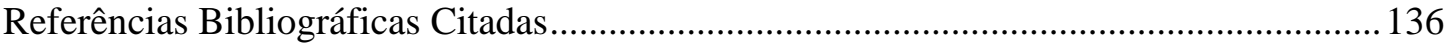

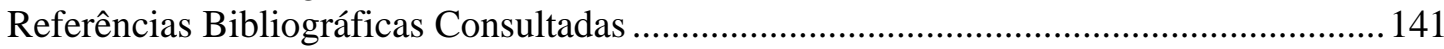

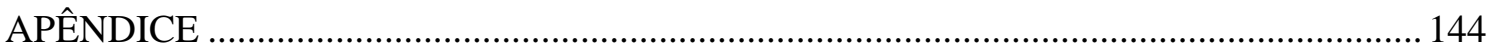

CONFIGURAÇÃO PARA COMUNICAÇÃO VIA REDE MPI/ OPI (SIEMENS) ......... 144

ROTINA DE SUPERVISÃO DE MÁQUINAS FERRAMENTA COM CNC SIEMENS

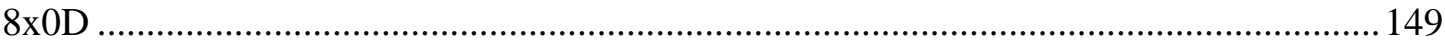

ROTINA DE MONITORAMENTO DA FERRAMENTA DE CORTE PARA

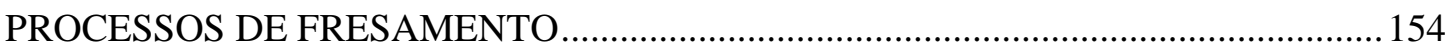




\section{INTRODUÇÃO}

São vários os fatores, tais como custos, qualidade, flexibilidade e tempo de resposta, que são diferenciais de competitividade nas indústrias. No ramo metal-mecânico, esses fatores estão intimamente ligados ao sistema de produção, especificamente ao chão de fábrica e à sua gestão. Se a gestão da produção não estiver suficientemente preparada com informações precisas, detalhadas e em tempo real, esses fatores de competitividade podem ser afetados negativamente. Entender a verdadeira capacidade do sistema de manufatura é essencial para balancear demandas de consumidores em curto tempo, e atender lotes com tamanhos variados e a baixo custo, afirma ROCKWELL (2004). O meio para se fazer isso é a troca de informações entre o chão de fábrica e os demais níveis superiores onde decisões gerenciais são realizadas. A coleta manual de informações mostra-se deficiente quanto à confiabilidade, velocidade de atualização, detecção de não conformidades e outros fatores prejudiciais à produção, além de gerarem redundância de trabalho na coleta e alimentação de banco de dados. Conseqüentemente, as informações geradas a partir desses apontamentos podem criar uma percepção diferente da realidade, e com um retardo suficiente para impossibilitar decisões críticas a partir das mesmas, conclui MINTCHELL (2001). Assim, o fluxo de informações entre os sistemas de Tecnologia de Informação (TI) dos altos níveis gerenciais e dos níveis de automação de chão de fábrica é altamente desejável. Portanto, um sistema automático de aquisição de informações de chão de fábrica, compartilhando informação localmente e remotamente ao longo do empreendimento, é altamente estratégico como ferramenta de apoio à gestão do sistema produtivo. Com esses sistemas, conhecidos como 
sistemas de supervisão, empreendimentos podem rapidamente se adaptar às mudanças de mercado, melhorar atendimento aos clientes, e reduzir custos operacionais. Os sistemas de supervisão são amplamente utilizados nos processos contínuos e por bateladas. No entanto, ainda não são aplicados para os processos discretos, nos quais se encaixam os processos de usinagem. Empreendimentos de manufatura cada vez mais requerem que seus equipamentos sejam integrados com os demais sistemas de TI, exigindo um completo e preciso monitoramento de máquinas ferramenta em tempo real (MINTCHELL, 2000; KRAR \& GILL, 2002; WIENDAHL \& LUTZ, 2002). No entanto, até o momento, tem havido poucos fluxos úteis de informações, devido a controles proprietários que limitam o acesso ou o tipo de dados a serem adquiridos (ROCKWELL, 2004; KRAR \& GILL, 2002). Gerentes ainda vêm tomando decisões estratégicas baseadas em dados de produção incompletos e desatualizados, ROCKWELL (2004).

Adicionalmente, segundo LANDERS \& ULSOY (1998), sistemas de monitoramento são inevitáveis para melhorar a qualidade de produtos, reduzirem tempos de produção e para a rápida adaptação às mudanças da produção. Contudo, trata-se de uma tarefa árdua escolher sensores apropriados e condicionadores/ amplificadores de sinais. Em muitos casos, os sensores têm altos custos, não são compactos, podendo até mesmo perturbar as áreas de trabalho, e não são de fácil utilização. Seus sinais contêm ruídos, os quais para extrair componentes desejáveis de informação, têm-se a necessidade de escolher apropriados condicionadores e amplificadores de sinais, bem como os seus parâmetros de configuração. Assim, é extremamente vantajoso desenvolver sistemas de monitoramento usando somente os recursos já disponíveis nas máquinas ferramenta (sensores, rede de comunicação, condicionadores e amplificadores de sinais, CPU, etc), que são resistentes a sujeiras, cavacos, influências eletromagnéticas e mecânicas, sem custos adicionais e sem redução da área de trabalho. 
CNC de arquitetura aberta tem-se mostrado como uma grande ferramenta para atender à estas necessidades. Dentre as diversas configurações de CNC de arquitetura aberta, tem-se a chamada arquitetura híbrida, ou open HMI (Human Machine Interface). Nesta arquitetura, o cerne do CNC permanece fechado, no entanto a sua HMI (ou IHM - Interface Homem Máquina) é baseada em PC (Personal Computer) com padrões e recursos abertos (não proprietários) para a integração e implementação de aplicativos. Ele tem os recursos necessários para a aquisição de informações gerenciais e tecnológicas de máquinas ferramenta, permitindo melhor fluxo de informação entre o chão de fábrica e os demais níveis superiores de uma empresa (engenharia, suporte, negócios, etc), bem como o desenvolvimento de sistemas de monitoramento.

\subsection{Objetivo}

O objetivo do presente trabalho é pesquisar e propor arquiteturas inovadoras de monitoramento e supervisão para processos de usinagem que tenham como base informações disponíveis em CNC's de arquitetura aberta. Tais sistemas, apesar de todo o potencial existente, ainda não têm sido explorados nem desenvolvidos adequadamente para os processos de usinagem. A aplicação das arquiteturas pesquisadas e propostas neste trabalho deve promover melhorias nos atuais sistemas de monitoramento e supervisão de processos de usinagem. O presente trabalho é multidisciplinar nas áreas de automação e usinagem. Está dividido em partes em que são analisados tanto os elementos tecnológicos dos CNC's abertos, bem como os processos de monitoramento e supervisão da usinagem.

Os sistemas pesquisados visam não somente servirem como fontes de informações para posteriores otimizações de processos de usinagem, mas também detectar possíveis falhas de 
funcionamento de seus componentes (máquina, peça, ferramenta e processo) e executar ações de prevenção e/ou correção. Assim, dentre as diversas técnicas de monitoramento e supervisão, o presente projeto de doutorado utiliza as vantagens das arquiteturas abertas e ambientes PCs de CNCs modernos, que disponibilizam uma infinidade de recursos ainda poucos explorados no meio acadêmico e industrial brasileiro. Com base nos resultados obtidos, poder-se-á apresentar uma visão geral das possibilidades de monitoramento e supervisão para os processos de usinagem com máquinas ferramenta de CNC de arquitetura aberta.

\subsection{Estrutura do trabalho}

Este documento - apresentado à Escola de Engenharia de São Carlos, da Universidade de São Paulo, como parte dos requisitos para a defesa de tese de doutorado do departamento de Engenharia Mecânica - está dividido em 9 capítulos:

- Capítulo 1: introdução, com o intuito de situar o leitor dentro do panorama em que se encontra o presente trabalho; apresenta também esta estrutura da tese, que faz breve descrição dos capítulos que compõem o documento.

- Capítulo 2: revisão bibliográfica sobre CNC de arquitetura aberta.

- Capítulo 3: revisão bibliográfica sobre sistemas de monitoramento de processos de usinagem.

- Capítulo 4: revisão bibliográfica sobre sistemas de supervisão e controle de processos. 
- Capítulo 5: apresentação de propostas de arquiteturas de sistemas de monitoramento e supervisão em open CNC.

- Capítulo 6: implementações de soluções de monitoramento e supervisão em open CNC de acordo com as propostas apresentadas no capítulo 5.

- Capítulo 7: apresentação de testes, da arquitetura proposta, em laboratório e indústria.

- Capítulo 8: conclusões finais do presente trabalho.

- Referências bibliográficas utilizadas e citadas que deram suporte a confecção do presente documento.

- Apêndice, para dar suporte esclarecedor relativo ao conteúdo do trabalho. 


\section{CNC DE ARQUITETURA ABERTA}

São vários os tipos de controles de máquinas ferramenta encontrados em chão-defábrica; desde controles mais simples baseados em lógicas aos relés e contatores, passando por controles através de CLPs, e finalmente controles mais sofisticados utilizando-se de CNCs, dentre os quais possuem uma infinidade de tipos e padrões.

Uma máquina CNC é constituída basicamente por (vide ilustração na figura 2.1):

- Programa CN

Série de instruções codificadas simbolicamente (segundo normas DIN66025 e ISO/105R) que levam a máquina a realizar uma seqüência específica de operações.

- Controle

- CNC (Controle Numérico Computadorizado): responsável pela interpretação do programa CN e tradução em comandos que são enviados ao CLP e aos Drivers para o acionamento interpolado dos eixos e spindle, de acordo com valores atuais de posição vindos de transdutores de posição (encoders, etc).

- CLP (Controlador Lógico Programável): responsável pela execução de tarefas seqüenciais e de intertravamento (segurança, troca de ferramentas, acionamentos, etc), e pelo gerenciamento da interface da máquina com o operador - display, botões, acionadores, etc.

- Drivers: responsáveis pelos loops de controle da velocidade e da corrente dos motores, baseando-se em dados vindos do CNC (velocidade desejada), do 
motor (corrente, etc) e de transdutores de velocidade. Permitem que os motores (servo-motores, motores de passo, spindle, etc) girem na velocidade e tempo necessários para que cada eixo atinja os valores de posição e velocidades estipulados em cada bloco do programa CN.

- IHM (Interface Homem Máquina): sistema de hardware/software que serve de interface entre o operador e a máquina ferramenta. Basicamente, possibilita o referenciamento e movimento dos eixos da máquina, troca e setup de ferramentas, manipulação de programas CN (armazenar, gerar, editar, simular e executar), e acompanhamento de tarefas e situação (alarmes, mensagens, etc) da máquina.

\section{- Máquina}

Partes mecânicas da máquina ferramenta que garantem a precisão dos movimentos e rigidez. Composta basicamente por: barramento, mesa, guias, porta-ferramentas e eixo-árvore.

Lista de instruções

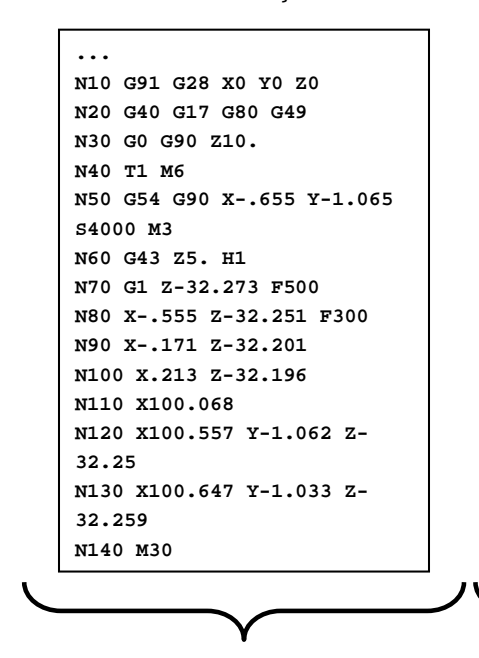

PROGRAMA CN
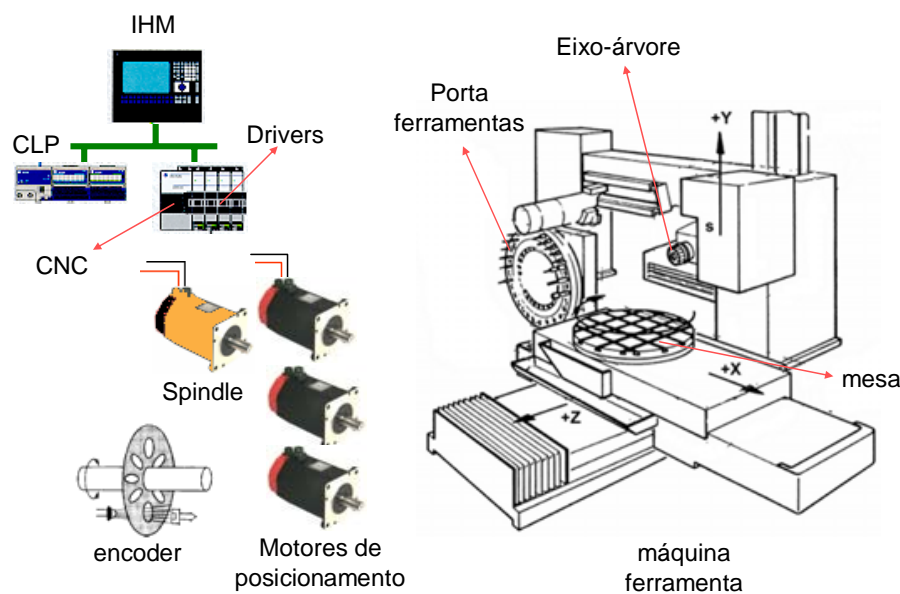

ferramenta

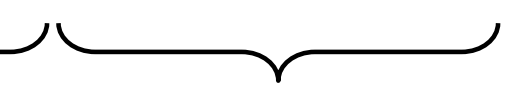

CONTROLE

MÁQUINA

FIGURA 2.1 - Constituição básica de uma máquina CNC 
Segundo GONÇALVES FILHO (1994), com o advento de novos materiais, difíceis de usinar, juntamente com exigências de qualidade com tolerâncias na faixa de 1 a $2 \mu \mathrm{m}$, os melhores operadores de máquinas chegaram ao limite de suas habilidades ou possibilidades. Esses requisitos, aliados com a necessidade de flexibilidade de fabricação, levaram a uma forma de controle automático de máquina conhecido pelo nome genérico de Comando Numérico (CN).

No início da década de 70, com a prática do conceito CAM (Computer-Aided Manufacturing), aumentou-se a ênfase do uso do computador na manufatura, levando o surgimento de novas formas de Comando Numérico, como o CNC (Comando Numérico Computadorizado). Desde então, o CNC vem sofrendo melhorias contínuas e aumento do seu emprego na produção.

\section{Conforme INSTITUT FÜR ANGEWANDTE ORGANISATIONSFORSCHUNG} (1984), pode-se dizer que o CNC é um equipamento eletrônico capaz de receber informações através de uma entrada de dados própria, tratar estas informações e transmiti-las em forma de comando à máquina-ferramenta de modo que esta, sem a intervenção do operador, realize as operações na seqüência programada. De forma geral, os CNCs podem receber informações através de leitora de fitas (os mais antigos), manualmente pelo painel de controle da máquina e através de outros microcomputadores ligados em redes locais ou através da Internet, de qualquer parte do globo.

Tanto nos ambientes industriais quanto nos acadêmicos, notam-se crescentes discussões a respeito da evolução dos comandos numéricos, na qual vêm despontando os chamados CNCs de arquitetura aberta, cujo principal objetivo é fornecer um ambiente neutro e padronizado para facilitar a implementação e integração de aplicações específicas através de aberturas de interfaces e configurações de métodos. Isto resulta em uma redução de custos e 
aumento de flexibilidade, pois softwares podem ser reusados e algoritmos específicos de usuários ou aplicações podem ser integrados.

Segundo PRITSCHOW et al (1993 e 2001), inicialmente o mercado de CNC foi dominado por heterogeneidades e sistemas orientados à equipamentos, com componentes de hardware e software proprietários, o que levou à sistemas inflexíveis e complexos, conforme ilustrado na figura 2.2, sendo estes tipos de CNCs ainda comercializados. Neste tipo de controle, a ampliação de suas funções muitas vezes é impossível, ou só é possível de um modo complicado e principalmente com ajuda do fabricante do controle. A transição de um sistema de controle de um fabricante para o de outro ou até mesmo uma transição de família de um sistema de controle de um mesmo fabricante só é realizável com grandes dificuldades, conclui PRITSCHOW et al (1993). No passado, esses sistemas proprietários permitiram que fabricantes criassem controles com características únicas e desejáveis, embutindo-os em arquiteturas proprietárias para torná-los mais difíceis de serem copiados. Este método de proteção de segmento de mercado funcionou bem por vários anos, quando o ciclo de vida da tecnologia dos controles era em torno de 4 à 5 anos. Agora que o ciclo de vida é bem menor (em torno de 6 à 8 meses para tecnologia de processadores), fabricantes de controles de sistemas proprietários estão percebendo que o tempo necessário para incorporar novas tecnologias em sistemas proprietários é maior que o próprio ciclo de vida destas tecnologias. Para manterem-se competitivos em custo e tecnologia, fabricantes de CNC buscam o melhor caminho para integrarem as novas tecnologias que vem surgindo aos seus controles (HERRIN, 2001).

Atualmente, alguns modernos CNCs, visando alta qualidade e flexibilidade, utilizamse de ambientes homogêneos baseado em PC, sistemas orientados à software e interfaces abertas, buscando-se atingir uma arquitetura aberta e suas vantagens. 


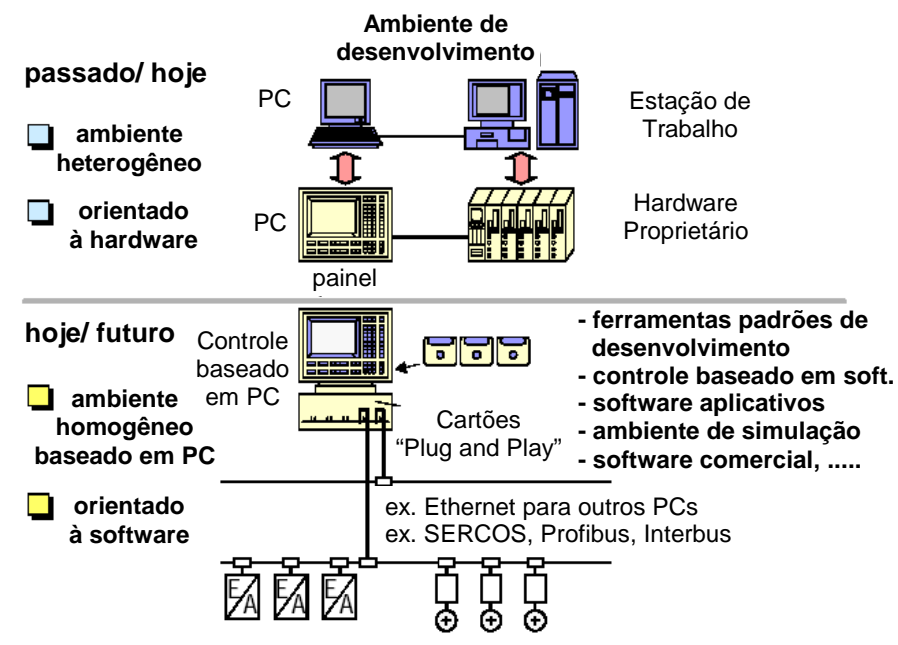

FIGURA 2.2 - Estruturas de CNCs - passado, atualidade e tendência (PRITSCHOW et al, 2001 - modificado)

Companhias estão começando a identificar quais produtos levam ao sucesso no ambiente industrial de hoje. Tal setor empresarial sofre pressões competitivas, como demandas de cliente para leadtimes menores, pressões para qualidade mais alta e ofertas de produtos mais flexíveis. Estes fatores estão forçando fabricantes a um grau mais alto de agilidade para satisfazer necessidades específicas de seus clientes. Com este novo cenário industrial vem o aumento de demandas por máquinas e controles mais flexíveis. O controle de arquitetura aberta baseado em PC representará, indiscutivelmente, um papel significante para a introdução de companhias para a idade do "Agile Manufacturing” (HERRIN, 2001). Adicionalmente, com o grande número de máquinas de propósitos especiais exigindo altos níveis de automação e o aumento de custos para o desenvolvimento de softwares, tem-se um aumento considerável da necessidade da utilização desses controles de arquitetura aberta. Estes crescentes aumentos de custos com softwares para aplicações especiais no desenvolvimento de máquinas podem ser notados desde a década de 80 , conforme ilustrado na figura 2.3. 


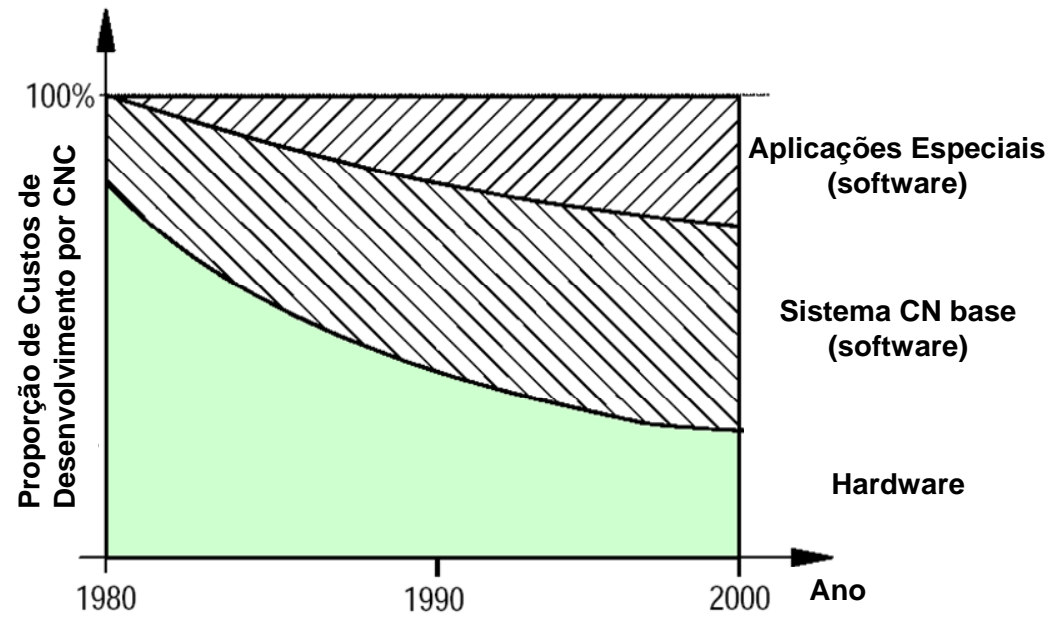

FIGURA 2.3 - CNC hardware e software - tendência atual (PRITSCHOW et al, 2001 - modificado)

Conforme apresentado, existem, portanto, basicamente três razões para a demanda por controles de arquitetura aberta: flexibilidade, proteção de investimento e redução de custos. Além disso, afirma PRITSCHOW et al (1993), dois argumentos adicionais têm que ser levados em conta para um número crescente de fabricantes de máquinas ferramenta: a proteção de conhecimentos em tecnologias específicas, bem como as possibilidades para diferenciação de produto (neste caso, de máquinas-ferramenta).

Grandes esforços vêm sendo realizados para atender as novas exigências de mercado. Vários projetos no mundo estão voltados para o estudo e definição de um controle de arquitetura aberta, destacando-se, segundo PRITSCHOW et al (2001) e LIANG et al (2004), o OSACA (Open System Architecture for Controls within Automation Systems) na Europa, o OSEC (Open System Environment for Manufacturing) e o JOP (Japanese Open Promotion Group) no Japão, e o OMAC (Open Modular Architecture Controllers) nos Estados Unidos, entre outros.

Paralelamente às fases de tecnologias de automação e controle industrial, houve uma evolução vertiginosa de computadores pessoais (PC) que passaram a invadir o ambiente industrial. Inicialmente empregados na administração e supervisão de tarefas “off-line”, 
passaram a ser utilizados para coleta de dados de chão de fábrica, interligação em redes, e, mais recentemente, em lugar de CPUs de CNCs e substituindo totalmente tarefas antes desempenhadas por CLPs, afirma BUZATTO (1999).

Essa evolução dos PCs vem permitindo que modernos CNC busquem alcançar uma alta qualidade e flexibilidade, utilizando-se de sistemas orientados à softwares e ambientes homogêneos baseados em PC (PRITSCHOW et al, 2001).

As implementações baseadas em PC possuem diversas configurações. Desde sistemas cuja única CPU é o processador do PC (por exemplo, o sistema comercializado pela empresa MDSI), na qual toda a arquitetura do CNC é construída em software, passando por sistemas cujas funções do PC são complementadas por cartões dedicados, cada qual com sua própria CPU, até finalmente às arquiteturas híbridas, na qual o cerne do CNC permanece fechado e algumas áreas são abertas, como, em geral, as interfaces homem-máquina (IHM) com ambiente PC (BUZATTO, 1999; MINTCHELL, 1998; MINTCHELL, 2000; MDSI, 2003; NOURSE, 2001).

As arquiteturas na qual o cerne do CNC permanece fechado e a interface homemmáquina é de ambiente PC são as mais comumente encontradas em chão de fábrica. Nestes sistemas, os controles de movimento e de seqüências de operações são tipicamente manuseados por hardware dedicados, sendo o PC usado somente para prover a interface de operação, o armazenamento de programas CNC e a execução de tarefas de comunicação (TURNER, 1994). É importante salientar que apenas a característica de se ter um CNC com ambiente PC não o torna um CNC de arquitetura aberta. Para tal, necessita-se ao menos disponibilizar protocolos e tecnologias abertas (não proprietárias) para a troca de dados, tais como o DDE (Dynamic Data Exchange), NetDDE (Network Dynamic Data Exchange), OPC (OLE for Process Control), ActiveX, entre outras, e redes de comunicação padrões como as redes Ethernet TCP/ IP, SERCOS, Profibus, etc. Assim, pode-se ter um CNC com a interface 
externa aberta, no entanto mantendo o seu cerne (interface interna) fechado, caracterizando-o como uma arquitetura híbrida. Sistemas baseados em PC podem ter um grau maior ou menor de abertura (MMSOnline, 2001). Todos ou parte dos componentes de hardware e/ou software podem ser proprietários ou não, assim como as interfaces entre o CNC e as demais unidades do sistema de controle, tais como os servos sistemas (MMSOnline, 2001).

A interface externa, objeto de foco do presente trabalho, é caracterizada por conectar o sistema de controle com unidades superiores (estações CAD/CAM, sistemas MES e ERP) através de redes LAN (Local Area Network), com unidades subordinadas (servo-motores, drivers, painéis de operação, etc) utilizando-se de redes de campo, e com usuários (tanto para a operação, quanto para a programação) através de normas para a elaboração de programas CNC (linguagens “G” - DIN 66025) e para a programação de CLP (IEC 61131-3).

\subsection{Benefícios de CNCs de Arquitetura Aberta}

Há vários benefícios para fornecedores e usuários de sistemas de controle aberto. Projetistas de CNC e acadêmicos beneficiam-se do alto grau de abertura que cobre as interfaces internas do CNC. Para os usuários finais de CNC, a abertura externa é mais importante (PRITSCHOW et al, 2001).

Na figura 2.4, tem-se um esquema dos benefícios dos sistemas de controles abertos tanto para os fornecedores dos mesmos, quanto para os fornecedores de máquinas e usuários finais. Nota-se que a grande vantagem em comum é a redução geral de custos. 


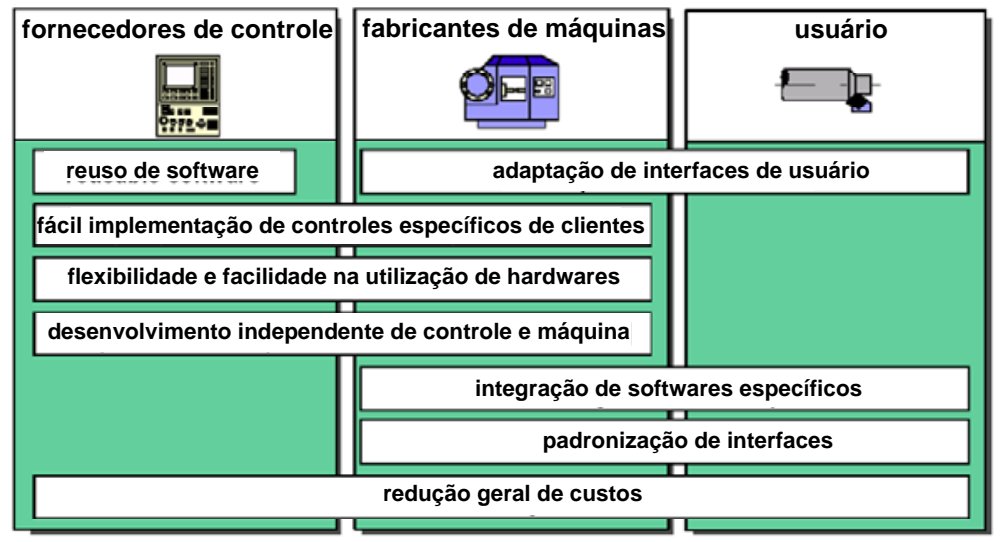

FIGURA 2.4 - Benefícios do uso de sistemas de controles abertos (PRITSCHOW et al, 2001 - modificado).

Para os fornecedores de controles e de máquinas ferramenta, a arquitetura aberta permite o reuso de softwares, facilita a implementação de controles específicos de clientes, possibilita maior flexibilidade e facilidade na utilização de hardwares, utilizando-os de forma mais eficiente e de acordo com os interesses de seus clientes. Quanto aos usuários finais e ainda aos fornecedores de máquinas ferramenta, tem-se como vantagens a capacidade de adaptação de interfaces de usuários e padronização das mesmas, além da possibilidade de integração de softwares específicos, tais como sistemas de monitoramento capazes de trocar informações on-line com os sistemas de controle, e sistemas de coleta e geração de históricos de informações (de máquina, de processo, etc) com capacidade de compartilhá-las via Intranet e/ou Internet. Segundo KRAR \& GILL (2002), os CNC de arquitetura aberta tornam-se geradores de informações, registrando e exibindo milhares delas sobre a máquina-ferramenta, produção e o processo de usinagem, o que é essencial para a integração com sistemas de gerenciamento da produção e administração corporativa, tais como sistemas MES (Manufacturing Execution Systems) e ERP (Enterprise Resource Planning).

Particularmente, a arquitetura de CNC baseada em PC traz muitos benefícios, destacando-se a flexibilidade, conectividade, integração, redução de custos, capacidade de armazenamento e recursos de multimídia. Através de um ambiente PC, tem-se no mundo do CNC um ambiente neutro para a utilização de softwares e hardwares que não necessitam 
obrigatoriamente serem provenientes do fabricante do CNC, reduzindo custos de atualizações e de mão de obra especializadas. Permite a fácil conectividade e a integração com outros sistemas, máquinas e aplicações específicas. O ambiente PC possibilita a utilização de muitos recursos de multimídia, além da alta capacidade de armazenamento e manipulação de dados, facilitando a operação através da utilização de interfaces gráficas, podendo ser personalizadas conforme a necessidade de cada usuário (MINTCHELL, 2001; MMSOnline, 2001; KRAR \& GILL, 2002; HERRIN, 2001).

\subsection{Sistemas de controle e suas interfaces}

Controles são sistemas altamente sofisticados devido às várias exigências rigorosas em relação ao processamento em tempo real e confiabilidade. Para controlar a complexidade dos sistemas de hardware e software, as interfaces são os meios essenciais.

As interfaces de sistemas de controle podem ser divididas em dois grupos, conforme esquema da figura 2.5: interface externa e interface interna.

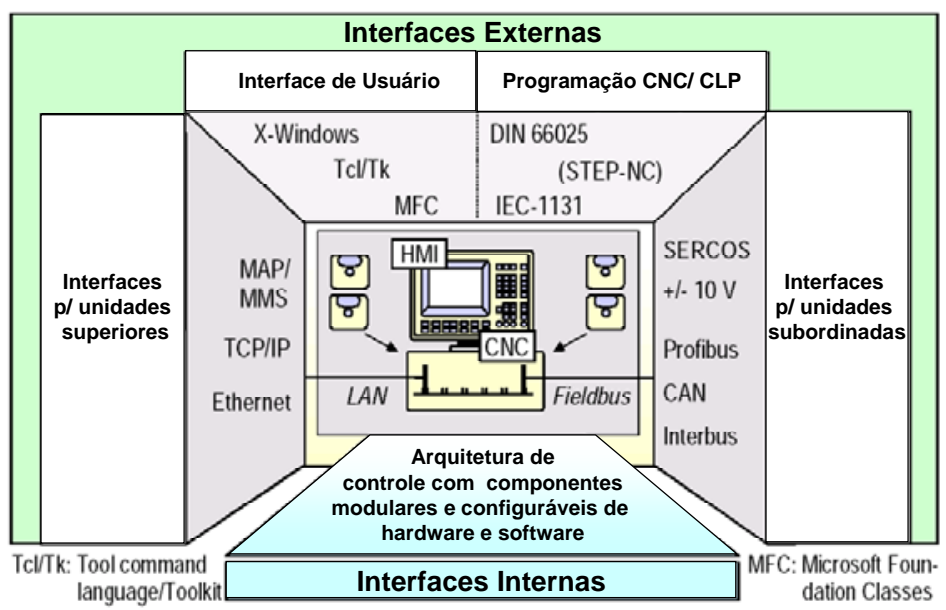

FIGURA 2.5 - interfaces externas e internas de sistemas de controle (PRITSCHOW et al, 2001 - modificado). 
- Interface externa

Essas interfaces conectam o sistema de controle com unidades superiores, com unidades subordinadas e com o usuário (tanto para operação, quanto para programação). Elas podem ser divididas em interfaces de programação/operação para os usuários, e interfaces de comunicação para as unidades.

Na interface para o usuário, para programação, têm-se padrões internacionais, tais como as normas DIN 66025 para a elaboração de programas CNCs (linguagens “G”), e a IEC 61131-3 (International Electrotechnical Commission) para a programação de CLPs. Quanto às interfaces para o usuário para operação, chamadas de IHM ou do inglês de HMI, estas são implementadas em plataformas, e desenvolvidas em ambientes de programação (toolkits). Exemplos que vêm sendo muito utilizados comercialmente são as interfaces desenvolvidas em ambientes de programação para o Windows e implementadas no mesmo ambiente, por exemplo o Visual Basic, utilizando-se de tecnologias de troca de dados, tais como o DDE, OPC, ActiveX, entre outras.

As interfaces de comunicação são também fortemente influenciadas por padrões. Sistemas de redes de campo como o SERCOS, Profibus ou DeviceNet são usados como interfaces para drivers e unidades I/Os, ou seja, para a comunicação com sistemas subordinados. São redes caracterizadas por serem determinísticas (tempo de ciclo fixo) e por terem tempos de resposta curtos, cujo uso específico é para a comunicação entre dispositivos de controle e seus periféricos. Nas interfaces para sistemas superiores são comumente utilizadas redes LAN (Local Area Networking), principalmente baseadas no Ethernet e TCP/ IP. São redes estocásticas (tempo de ciclo variável), mas com capacidade de manipular grandes quantidades de informação em tempo não crítico. São de uso específico para a comunicação entre PCs. 
- Interfaces internas

São usadas para a interação e troca de dados entre componentes que fazem parte do sistema central de controle. Um importante critério nesta área é o suporte para mecanismos de tempo real. Para alcançar um controle re-configurável e adaptável, a arquitetura interna do sistema de controle é baseada em um conceito de plataforma. Os principais objetivos são esconder os detalhes específicos de hardware e dos componentes de software, e estabelecer um definido, mas flexível, meio de comunicação entre os componentes de software. Uma API (Application Programming Interface) assegura estes requerimentos. A funcionalidade inteira do sistema de controle é subdividida em vários componentes de software. Estes componentes de softwares são encapsulados e modulados, e se interagem através de uma definida API (PRITSCHOW et al, 2001).

Utilizando-se como exemplo deste tipo de interface, para melhor entendimento, tem-se a arquitetura OSACA. Ela é dividida em duas principais partes: o software aplicativo e a plataforma de sistema (vide figura 2.6). O software aplicativo incorpora todas as funcionalidades que são específicas para um sistema de controle. Independentes módulos, os então chamados objetos de arquitetura (do inglês, AO - Architecture Objects), usam as interfaces API da OSACA (OSACA-API) e, portanto, podem ser executadas em diferentes plataformas de sistemas que são compatíveis com a OSACA (OSACA, 2004).

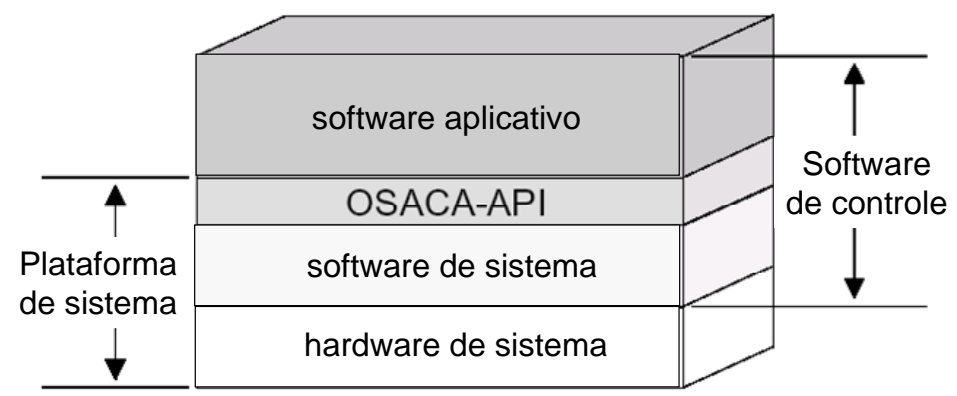

FIGURA 2.6 - Arquitetura básica de um sistema de controle OSACA (OSACA, 2004 - modificado). 
A própria plataforma de sistema consiste em hardware e software de sistema, que não é necessariamente um controle específico, mas que é exigida para habilitar a execução do software aplicativo.

O hardware de sistema inclui componentes eletrônicos, como processadores e módulos de I/O, considerando que o software de sistema inclui, por exemplo, um sistema operacional, um sistema de comunicação e drivers de equipamentos. A plataforma de sistema oferece seus serviços através de uma padronização de interface de programação de aplicação (API Application Programming Interface). Esta API esconde a atual implementação dos serviços da plataforma e, portanto, permite a portabilidade de AOs para diferentes ambientes, conforme ilustrado na figura 2.7 (OSACA, 2004).

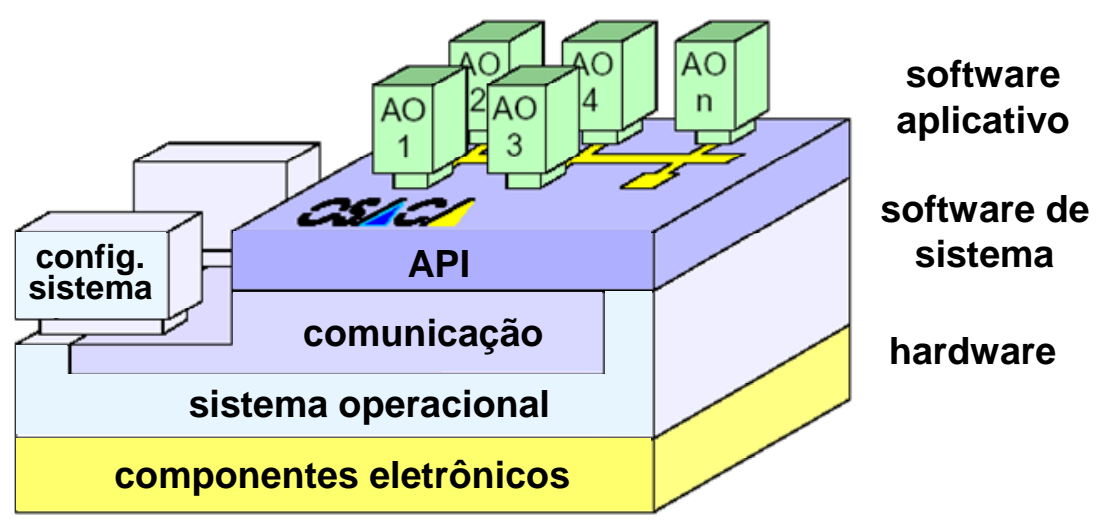

FIGURA 2.7 - Esquema da plataforma de sistema da OSACA (OSACA, 2004 - modificado).

Contrariamente aos sistemas de arquitetura aberta, os sistemas de controles convencionais comportam-se como “caixas pretas”, sem interfaces para a implementação, o reuso e a adaptação de softwares aplicativos (figura 2.8). 


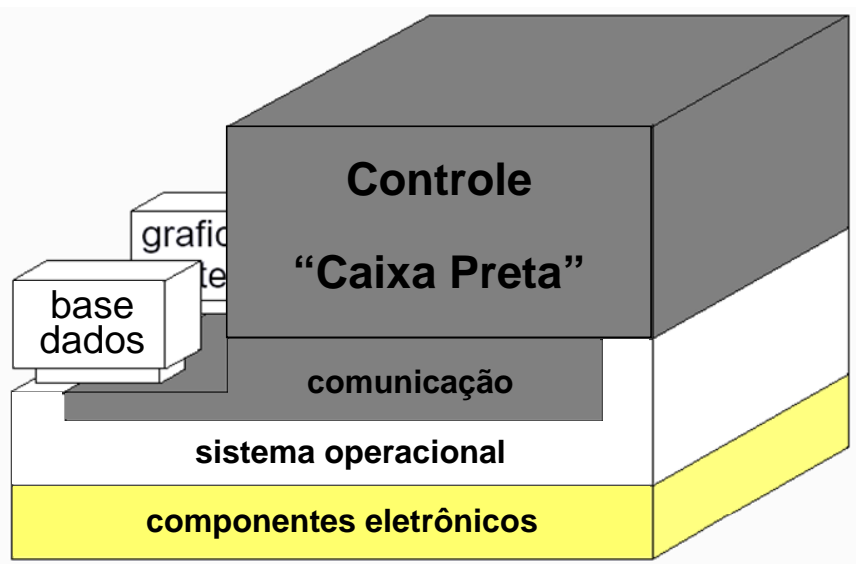

FIGURA 2.8 - Esquema da plataforma de sistema de controle convencional (OSACA, 2004 - modificado).

\subsection{Estrutura de hardware e software de sistemas de controle}

A figura 2.9 mostra as diferentes variações para estruturas de hardware de sistemas de controle. Para melhor entendimento dessas variações, tem-se na figura 2.9 uma divisão de processadores por áreas: área de usuário, de controle e de drivers.

\begin{tabular}{|c|c|c|c|c|}
\hline & $\begin{array}{l}\text { a) convencional, } \\
\text { drivers analógicos }\end{array}$ & \multicolumn{2}{|c|}{$\begin{array}{l}\text { b) concentração em áreas } \\
\text { de drivers, interface digita }\end{array}$} & $\begin{array}{l}\text { c) concentração em ár } \\
\text { de usuário ("Soft-CNC }\end{array}$ \\
\hline $\begin{array}{l}\text { Processador } 1 \\
\text { (área usuário) }\end{array}$ & HMI, PROG & \multicolumn{2}{|r|}{ HMI, PROG } & $\begin{array}{l}\text { HMI, PROG } \\
\text { TP, TG, PLC, PR }\end{array}$ \\
\hline $\begin{array}{l}\text { Processador } 2 \\
\text { (área controle) }\end{array}$ & \begin{tabular}{|l|} 
TP,TG, \\
$\mathrm{LR}$
\end{tabular} & & & \\
\hline \multicolumn{5}{|l|}{$\begin{array}{l}\text { Processador } 3 \\
\text { (área controle) }\end{array}$} \\
\hline \multicolumn{5}{|l|}{\begin{tabular}{|l} 
Processador 4 \\
(área controle)
\end{tabular}} \\
\hline \multirow{4}{*}{$\begin{array}{l}\text { Processador } 5 \\
\text { (área drivers) }\end{array}$} & & \multicolumn{2}{|r|}{ TP, TG, PLC, PR } & LR \\
\hline & DR & \multirow{2}{*}{\multicolumn{2}{|c|}{$\frac{\mathrm{LR}+\mathrm{DR}}{\text { Controle Corrente }}$}} & DR \\
\hline & Controle Corrente & & & Controle Corrente \\
\hline & Amplific. Potência & \multicolumn{2}{|r|}{ Amplific. Potência } & Amplific. Potência \\
\hline \multicolumn{3}{|c|}{ 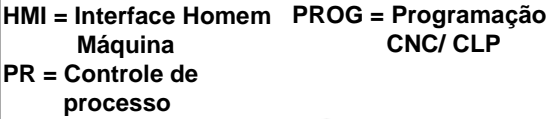 } & 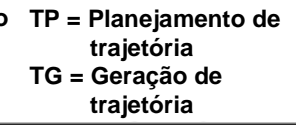 & $\begin{aligned} \mathrm{LR}= & \text { Controle de pos } \\
\mathrm{DR}= & \text { Controle de } \\
& \text { velocidade }\end{aligned}$ \\
\hline
\end{tabular}

FIGURA 2.9 - Variações de estruturas de hardware e software de CNCs (PRITSCHOW et al, 2001 modificado). 
A - Estrutura convencional, com interfaces de drivers analógicos:

Esta estrutura é composta por drivers analógicos interfaceando com controles de posição em um sistema central de controle. Cada módulo nesta estrutura usa seu próprio processador, levando a uma larga variedade de hardwares específicos (PRITSCHOW et al, 2001).

Na área de usuário, tem-se um processador encarregado somente para a interface de operação da máquina (HMI) e de programação de CN e PLC (PROG).

$\mathrm{Na}$ área de controle empregam-se três processadores. Um para o planejamento de trajetória (TP), geração de trajetória (TG) e controle de posição (LR). Os demais são empregados no PLC e no controle de processo (PR).

Finalmente, na área de drivers tem-se um processador encarregado no controle de velocidade (DR), envolvendo o controle de corrente e a amplificação de potência.

\section{$\underline{B}$ - Concentração de módulos na área de drivers, com interfaces de drivers digitais:}

Trata-se de uma combinação de módulos levando a uma significativa redução de número de processadores. Drivers digitais inteligentes, com funcionalidades de controle integrados, que resultam em alta capacidade, miniaturização e alto desempenho de processadores (Pritschow et al, 2001).

Nota-se nesta estrutura que a área de usuário mantém as mesmas funções. No entanto tem-se uma grande modificação da área de controle, tendo todas as suas tarefas migradas para a área de drivers, ou seja, a eliminação dos processadores da área de controle e uma concentração de tarefas no processador da área de drivers. 
C - Concentração de módulos na área de usuário (Soft-CNC):

Estrutura conhecida como Software-CNC (Soft-CNC ou SW CNC), ou seja, CNC baseado em software. Trata-se de uma solução através de processador único, baseado em PC, com extensão de tempo-real do sistema de operação. Todas as funções de controle são executadas como tarefas de softwares em um ambiente de tempo-real baseado em PC, sendo necessário apenas complementar o hardware do PC com módulos dedicados para leitura de transdutores de posição e outros sinais de campo (PRITSCHOW et al, 2001; BUZATTO, 1999).

Nota-se nesta estrutura uma concentração de tarefas no processador da área de usuário, a eliminação da área de controle, e uma redução nas tarefas da área de drivers em relação à estrutura anterior. A área de usuário, além de manter as tarefas antes executadas nas outras estruturas (interface de operação e programação - HMI e PROG), agora acumula também as tarefas de planejamento de trajetória (TP), geração de trajetória (TG), PLC e controle de processo (PR). As demais tarefas, controle de posição (LR) e velocidade (DR), passaram para a área de drivers.

\subsection{Definições de sistema de controle aberto}

O “Technical Committee of Open Systems” do IEEE define um sistema aberto como: “Um sistema aberto provê capacidades que permitem aplicações apropriadamente implementadas serem executadas em uma variedade de plataformas de múltiplos fornecedores, operarem com outras aplicações de sistema e apresentarem um estilo consistente de interação com o usuário (IEEE 1003.0)” (OSACA, 2004; PRITSCHOW et al, 1993 e 2001). 
Um controle de arquitetura aberta deverá ser flexível em hardware, bem como em seu software, para todos os níveis de controle, afirma WRIGHT et al (1996) apud ASATO et al (2002). Um controle de arquitetura aberta deverá ser padrão para permitir o desenvolvimento de hardware e software por diferentes fabricantes, e a sua integração com outros controles e sistemas de planejamento de alto nível, conclui SCHOFIELD (1996) apud ASATO et al (2002). PRITSCHOW et al (1993) e ALTINTAS \& MUNASINGHE (1994) afirmam que um sistema de CNC de arquitetura aberta deverá permitir a integração modular de independentes programas aplicativos, sensores e hardwares de diferentes fabricantes, sistemas de controle e de monitoramento de processos de usinagem, sem a necessidade de modificações do sistema de hardware e software.

Segundo PRITSCHOW et al (1993 e 2001), para estimar a abertura de um controle, o seguinte critério pode ser aplicado, conforme ilustrado na figura 2.10:

- Portabilidade: permite operar componentes de sistema em diferentes plataformas. Módulos de aplicação (AM) podem ser usados em diferentes plataformas, sem qualquer mudança em suas capacidades.

- $\quad$ Extensibilidade: um variado número de AM pode rodar em uma plataforma sem qualquer conflito.

- Interoperabilidade: esta especificação somente será garantida usando semântica de dados padronizada e mecanismos de comunicação e interação. AM trabalham juntos em um modo consistente e podem trocar dados através de um meio definido.

- Escalabilidade: dependendo das requisições do usuário, funcionalidades do AM, desempenho e tamanho do hardware podem ser adaptados. Permite aos usuários aumentarem ou diminuírem funcionalidades do sistema simplesmente através de mudanças de componentes específicos. 
- Intercambialidade: permite substituir um componente com outro sem alteração de desempenho do sistema.

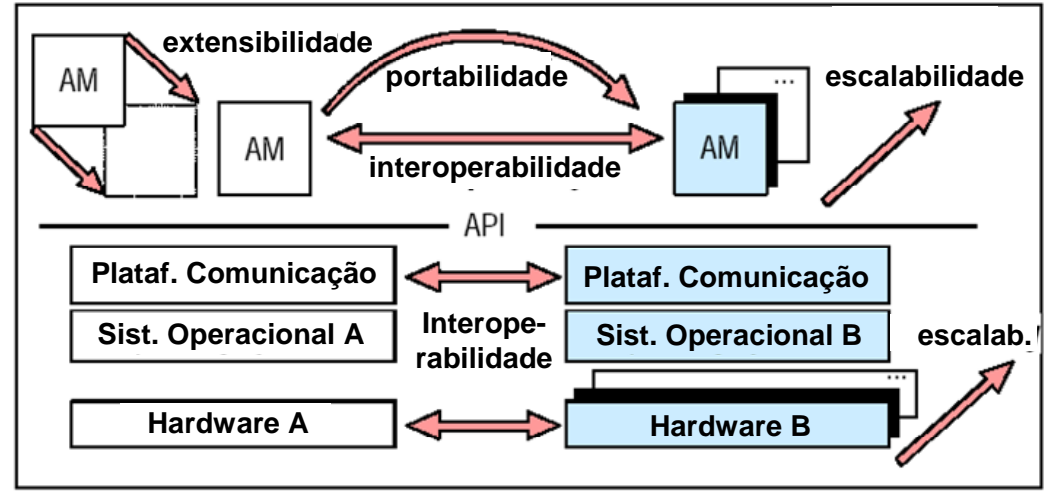

FIGURA 2.10 - Critério de sistemas de controle aberto (PRITSCHOW et al, 2001 - modificado).

\subsection{Categorias de sistemas de controle aberto}

Segundo PRITSCHOW et al, 2001, as seguintes categorias podem ser identificadas, conforme ilustrado na figura 2.11:

- IHM aberta: as aberturas são restritas para as tarefas que não são de tempo real. Adaptações podem ser feitas em aplicações orientadas ao usuário.

- Kernel com aberturas restritas: o kernel de controle tem uma topologia fixa, mais oferece interfaces para inserir filtros específicos de usuário, bem como funções de tempo real.

- Sistema de controle aberto: topologia que oferecem extensibilidade, intercambialidade, escalabilidade, portabilidade e interoperabilidade. 


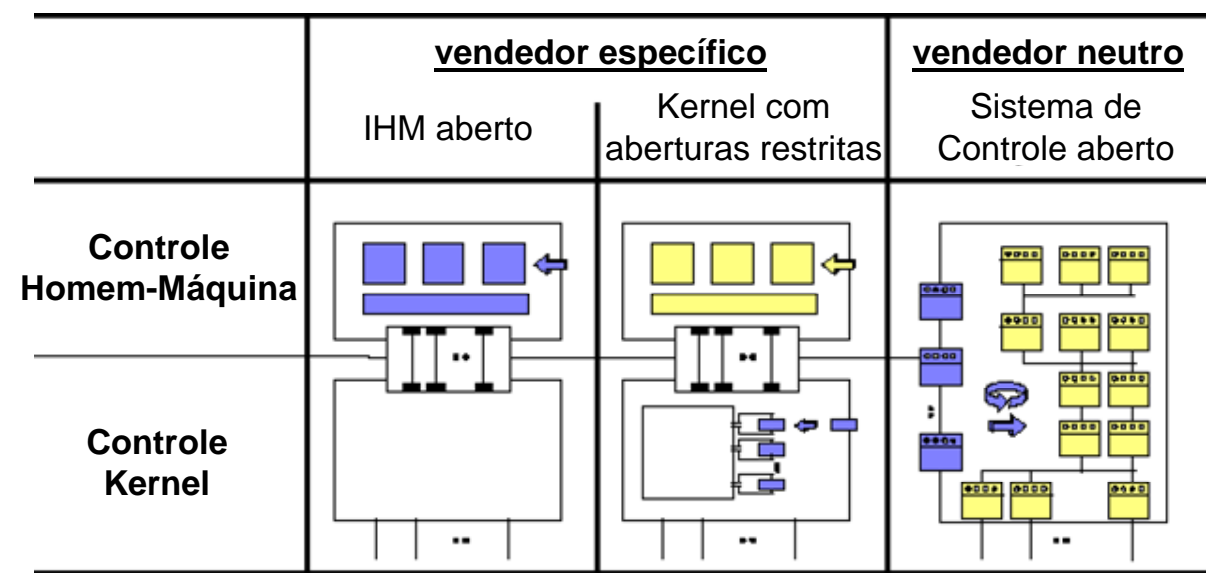

FIGURA 2.11 - Níveis de abertura de sistemas de controle (OSACA, 2004 e PRITSCHOW et al, 2001 modificado)

\subsection{Requisitos}

Os requerimentos para que um sistema de controle seja aberto é ter suas funcionalidades de controle subdivididas em unidades funcionais e ter interfaces bem definidas entre as mesmas, conforme ilustrado na figura 2.12. Assim, modularidade pode ser identificada como a chave para um sistema de arquitetura aberta (PRITSCHOW et al, 2001). Na determinação do nível de modularidade, há um ponto ótimo a ser definido na relação entre o grau de abertura e o custo de integração. Pequenos módulos permitem altos níveis de abertura e mais opções, mas aumentam a complexidade e o custo de integração. Além disso, este aumento de complexidade pode interferir no desempenho de tempo real de todo o sistema. Assim, sistemas de controle deixam de ser vistos como uma caixa preta (sistema proprietário), e passam a ser compreendidos como um sistema lógico decomposto em unidades funcionais (módulos), com interfaces que permitem a interação entre os mesmos, a adaptação e reuso de funções, e a implementação de novos softwares aplicativos. 

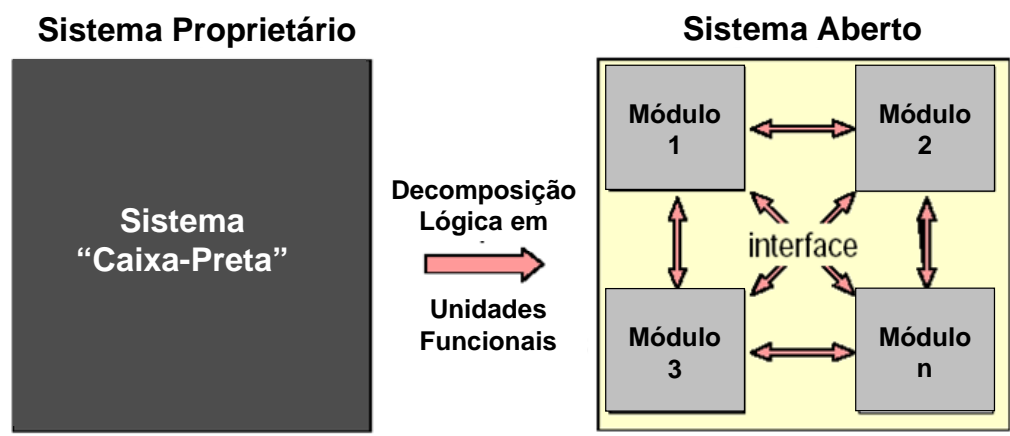

FIGURA 2.12 - Decomposição das funcionalidades de controle (PRITSCHOW et al, 2001 - modificado).

Para os sistemas de controle comerciais neutros abertos, as interfaces precisam ser padronizadas e amplamente reconhecidas. Devido à complexidade de sistemas modulares, a definição de uma arquitetura de sistema é recomendável e de grande ajuda, o que levou à introdução das chamadas plataformas de sistema, conforme ilustrado na figura 2.13. Além disso, seus principais objetivos são encapsular os detalhes específicos de hardware (componentes eletrônicos) e de software, e estabelecer um definido, mas flexível, meio de comunicação com e entre os módulos de softwares aplicativos. Assim, facilita a portabilidade de software aplicativos e também a interoperabilidade de módulos de aplicação, bem como a distribuição dos mesmos em ambientes heterogêneos.

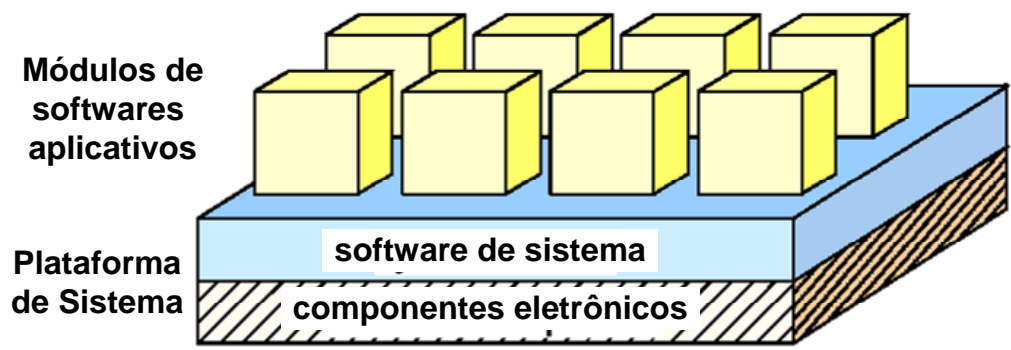

FIGURA 2.13 - Infraestrutura de sistemas de controle aberto modulares (PRITSCHOW et al, 2001 modificado).

Resumidamente, para se ter um sistema de controle aberto, é preciso que o mesmo seja composto por módulos (funcionalidades subdivididas em unidades funcionais), ter interfaces bem definidas entre os mesmos (APIs), e ter uma infraestrutura que crie um meio comum para 
os softwares aplicativos, tornando-os independentes das características dos sistemas de hardware e de software do controle (plataforma de sistema).

\subsection{Visão geral do mercado}

Segundo PRITSCHOW et al (1993, 2001), MMSOnline (2001) e MDSI (2003), quase todos fabricantes de controle oferecem ou anunciam seus produtos como "sistemas abertos". No entanto, somente os sistemas que seguem as especificações segundo a IEEE 1003.0 podem ser descritos como sistemas abertos. Muitos sistemas, apesar de revelarem seus princípios de construção e interfaces internas, permanecem com características específicas e proprietárias, não podendo, por isso, serem considerados sistemas abertos.

Os controles disponíveis no mercado possuem diferentes níveis de abertura, de acordo com o critério mostrado na figura 2.14. Apesar de muitos dos controles atuais oferecerem aberturas nas funções de controle relacionadas com operador (HMI), somente poucos controles permitem aos usuários modificarem seus algoritmos de controle de baixo nível que influenciam nas funções de controle relacionadas com a máquina (CNC). Um importante critério é o uso de plataformas computacionais padronizadas (isto é, hardware, sistema operacional e middleware) como um ambiente para executar o software HMI e CNC (MINTCHELL, 2000; MINTCHELL, 2001; PRITSCHOW et al, 2001; MMSOnline, 2001 e MDSI, 2003). Assim, utilizando-se de API, pode-se integrar software aplicativos específicos (third party software) com as funções de controles relacionadas com o operador (IHM) e com a máquina (CNC). Adicionalmente, a conectividade do CNC para os demais níveis (alto e baixo) do chão-de-fábrica deve ser garantida. Exemplos disto são as conectividades de CNC com níveis altos, como sistemas DNC, estações CAD/CAM, sistemas MES/ERP, etc, através 
de redes LAN, e com níveis baixos, como comunicação com drivers, módulos I/O, painéis e teclados de controle, etc, através de redes fieldbus (PRITSCHOW et al, 2001 e MINTCHELL, 2000).

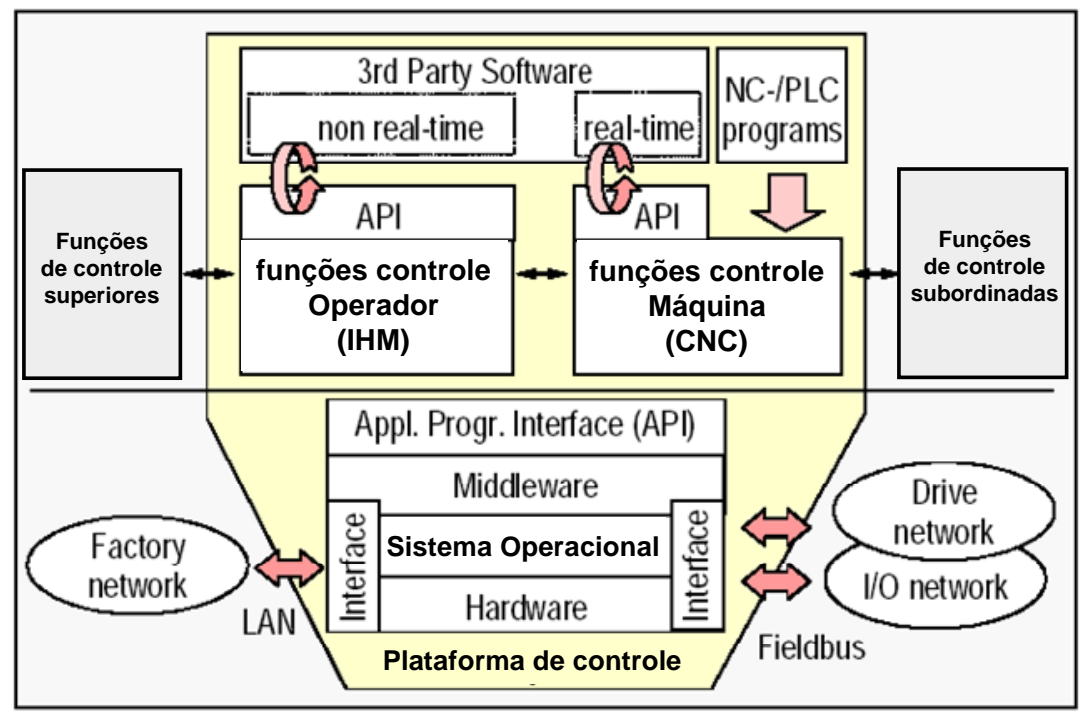

FIGURA 2.14 - Critérios de abertura de sistemas de controle (PRITSCHOW et al, 2001 - modificado).

A figura 2.15 mostra uma visão geral das características dos sistemas de controle atuais em relação ao grau de abertura.

Apesar de muitos sistemas de controle possuirem interfaces abertas para integração de software (por exemplo, o OPC), não há ainda uma definição comum de dados que são passados de um lado para outro pela interface de programação. Portanto, os sistemas de controle disponíveis no mercado hoje não suportam implicitamente características "plug-andplay”. Para melhorar esta situação, os sistemas de redes de campo podem servir como modelo. A variedade de diferentes sistemas de redes de campo conduziu a um grande consenso para harmonizar as interfaces, orientando-as às aplicações, o que é desejável para esconder a pluralidade e a complexidade dos sistemas para o usuário. A maioria das organizações de redes de campo está já usando os denominados perfis de equipamentos para 
suportar a intercambialidade dos equipamentos de diferentes fabricantes. Por exemplo, a interface padrão SERCOS (IEC61491) para as comunicações cíclicas e determinísticas entre CNCs e drivers tem definido a semântica para aproximadamente 400 parâmetros descrevendo drive e funções de controle que são usados por equipamentos de diferentes fornecedores.

\begin{tabular}{|c|c|c|c|}
\hline & Critério & Características & Exemplo \\
\hline \multirow{3}{*}{ 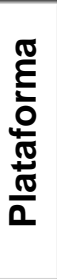 } & Hardware & $\begin{array}{c}\text { Hardware e sistema } \\
\text { de barramento padrões }\end{array}$ & $\begin{array}{c}\text { Controle } \\
\text { baseado PC }\end{array}$ \\
\hline & $\begin{array}{c}\text { Sistema } \\
\text { Operacional }\end{array}$ & $\begin{array}{c}\text { Sistema operacional } \\
\text { padrão }\end{array}$ & $\begin{array}{l}\text { VxWorks, } \\
\text { Windows }\end{array}$ \\
\hline & Middleware & $\begin{array}{l}\text { Middleware } \\
\text { padrão }\end{array}$ & $\begin{array}{l}\text { DCON, } \\
\text { CORBA }\end{array}$ \\
\hline \multirow{3}{*}{ 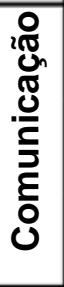 } & $\begin{array}{l}\text { Factory } \\
\text { network }\end{array}$ & $\begin{array}{c}\text { Meio físico padrão + } \\
\text { protocolo comunicação }\end{array}$ & $\begin{array}{l}\text { Ethernet } \\
\text { TCPI IP }\end{array}$ \\
\hline & $\begin{array}{c}\text { Drive } \\
\text { network }\end{array}$ & \begin{tabular}{|c|} 
Meio físico padrão + \\
protocolo comunicação
\end{tabular} & $\begin{array}{l}\text { Interface } \\
\text { SERCOS }\end{array}$ \\
\hline & $\begin{array}{c}\text { I/O } \\
\text { network }\end{array}$ & $\begin{array}{c}\text { Meio físico padrão + } \\
\text { protocolo comunicação }\end{array}$ & $\begin{array}{l}\text { Profibus, } \\
\text { DeviceNet }\end{array}$ \\
\hline \multirow{4}{*}{ 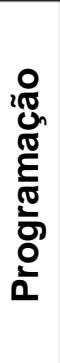 } & $\underset{\text { CNC }}{\text { Programação }}$ & $\begin{array}{c}\text { Linguagem padrão } \\
\text { de programação CNC }\end{array}$ & $\begin{array}{c}\text { DIN 66025, } \\
\text { RS-274 }\end{array}$ \\
\hline & $\underset{\text { CLP }}{\text { Programação }}$ & $\begin{array}{l}\text { Linguagem padrão } \\
\text { de programação CLP }\end{array}$ & IEC 61131-3 \\
\hline & \begin{tabular}{|} 
Integração \\
software IHM
\end{tabular} & API padrão & OPC \\
\hline & \begin{tabular}{|c|} 
Integração \\
software CNC
\end{tabular} & API padrão & $\begin{array}{c}\text { Ciclos } \\
\text { Compilados }\end{array}$ \\
\hline
\end{tabular}

FIGURA 2.15 - Características de sistemas de controle abertos (PRITSCHOW et al, 2001 - modificado).

Atualmente no mercado, encontram-se diversas configurações de CNC baseadas em PC, conforme exposto na figura 2.16. Tem-se desde sistemas cuja única CPU é o processador do PC, chamados de Soft-CNC ou SW CNC, na qual toda a arquitetura do CNC é construída em software, sendo necessário apenas complementar o hardware do PC com módulos dedicados para leitura de transdutores de posição e outros sinais de campo. Um exemplo de empresa que adotou este caminho é a MDSI, com um sistema concentrado no Windows NT, com extensões para tempo real. Uma segunda configuração bastante empregada é utilizar sistemas cujas funções do PC são complementadas por cartão dedicado, às vezes chamado de 
processador de código G. Este cartão tipicamente contém uma CPU dedicada, entradas para transdutores de posição e sinais de comandos analógicos e digitais para a máquina. Nestes casos, a interface homem-máquina é executada no ambiente PC, enquanto o interfaceamento com a máquina é dedicado. Um exemplo da utilização desta configuração são os produtos da Delta Tau. E, finalmente, tem-se as chamadas arquiteturas híbridas, cujo cerne do CNC permanece fechado, e algumas áreas foram abertas à participação do fabricante da máquina para alterações visando melhor adaptação aos seus conceitos e estratégias. Em geral, esta área é a interface homem-máquina (IHM). Exemplos de empresas que adotaram este caminho são: Siemens, GE Fanuc, Rockwell, Indramat, Allen Bradley e ECS (BUZATTO, 1999).

\begin{tabular}{|c|c|c|c|c|c|c|c|}
\hline \multirow[b]{2}{*}{ CNC } & \multirow{2}{*}{\begin{tabular}{|c|} 
IHM \\
$\begin{array}{c}\text { Plataforma } \\
\text { (HW, SO) }\end{array}$
\end{tabular}} & \multirow{2}{*}{\begin{tabular}{|c|} 
CNC \\
$\begin{array}{l}\text { Plataforma } \\
\text { (HW, SO) }\end{array}$ \\
\end{tabular}} & \multicolumn{2}{|c|}{$\begin{array}{c}\text { Interfaces } \\
\text { programação }\end{array}$} & \multicolumn{3}{|c|}{$\begin{array}{c}\text { Interfaces } \\
\text { comunicação }\end{array}$} \\
\hline & & & $\begin{array}{l}\text { IHM } \\
\text { API }\end{array}$ & $\begin{array}{l}\text { CNC } \\
\text { API }\end{array}$ & LAN & DRIVE & $1 / 0$ \\
\hline $\begin{array}{l}\text { Fanuc } \\
210 \mathrm{i} / 210 \text { is }\end{array}$ & \begin{tabular}{|c} 
PC with \\
WinCE/NT
\end{tabular} & $\begin{array}{c}-- \\
\text { proprietary }\end{array}$ & $\begin{array}{c}+\mathbf{+} \\
\text { WinAPI }\end{array}$ & \begin{tabular}{|c|}
-- \\
proprietary
\end{tabular} & $\begin{array}{c}\mathbf{+}+ \\
\text { Ethernet }\end{array}$ & $\begin{array}{c}-- \\
\text { proprietary }\end{array}$ & $\begin{array}{c}+\mathbf{+} \\
\text { Fieldbus }\end{array}$ \\
\hline $\begin{array}{l}\text { Indramat } \\
\text { MTC200 }\end{array}$ & $\begin{array}{l}\text { PC with } \\
\text { WinNT }\end{array}$ & $\underset{\text { Psos }}{\mathbf{0}}$ & $\begin{array}{c}+\mathbf{+} \\
\text { WinAPI }\end{array}$ & \begin{tabular}{|c|}
$-\boldsymbol{-}$ \\
proprietary
\end{tabular} & $\begin{array}{c}\mathbf{4} \\
\text { Ethernet }\end{array}$ & $\begin{array}{c}\mathbf{+} \\
\text { SERCOS }\end{array}$ & $\begin{array}{c}\mathbf{y +} \\
\text { Fieldbus }\end{array}$ \\
\hline $\begin{array}{l}\text { MDSI } \\
\text { Open CNC }\end{array}$ & \multicolumn{2}{|c|}{$\begin{array}{c}\text { PC with WinNT+RTX } \\
\text { (SoftCNC) }\end{array}$} & $\begin{array}{c}+\mathbf{+} \\
\text { WinAPI }\end{array}$ & $\begin{array}{c}+千 \\
\text { RT API }\end{array}$ & $\begin{array}{c}\mathbf{+} \\
\text { Ethernet }\end{array}$ & $\begin{array}{c}\mathbf{+} \\
\text { SERCOS }\end{array}$ & $\begin{array}{c}\mathbf{+}+ \\
\text { Fieldbus }\end{array}$ \\
\hline $\begin{array}{l}\text { Robert Bosch } \\
\text { Typ3 osa }\end{array}$ & $\begin{array}{l}\text { PC with } \\
\text { WinNT }\end{array}$ & $\underset{\text { PxRos }}{\mathbf{0}}$ & $\begin{array}{c}\mathbf{+} \\
\text { WinAPI }\end{array}$ & $\begin{array}{c}\mathbf{+ +} \\
\text { Job Cycles }\end{array}$ & $\begin{array}{c}\mathbf{+} \\
\text { Ethernet }\end{array}$ & $\begin{array}{c}\mathbf{+} \\
\text { SERCOS }\end{array}$ & $\begin{array}{c}++ \\
\text { Fieldbus }\end{array}$ \\
\hline $\begin{array}{l}\text { Allen Bradley } \\
\text { 9/PC }\end{array}$ & $\begin{array}{l}\text { PC with } \\
\text { WinNT }\end{array}$ & $\begin{array}{c}-- \\
\text { proprietary }\end{array}$ & $\begin{array}{c}++ \\
\text { WinAPI }\end{array}$ & $\begin{array}{c}+ \\
\mathrm{OCl} \\
\end{array}$ & $\begin{array}{c}\mathbf{+} \\
\text { Ethernet }\end{array}$ & $\begin{array}{c}\mathbf{+} \\
\text { SERCOS }\end{array}$ & $\begin{array}{c}++ \\
\text { Fieldbus }\end{array}$ \\
\hline $\begin{array}{l}\text { Siemens E\&A } \\
\text { 840D/840Di }\end{array}$ & \begin{tabular}{|c} 
PC with \\
Win95/NT
\end{tabular} & $\begin{array}{c}\text {-- } \\
\text { proprietary }\end{array}$ & $\begin{array}{c}\mathbf{4}+ \\
\text { WinAPI }\end{array}$ & $\begin{array}{c}\mathbf{+} \\
\text { Cpl. Cycles }\end{array}$ & $\begin{array}{c}\mathbf{y} \\
\text { Ethernet }\end{array}$ & $\begin{array}{c}-\boldsymbol{-} \\
\text { proprietary }\end{array}$ & $\begin{array}{c}\mathbf{y} \\
\text { Fieldbus }\end{array}$ \\
\hline
\end{tabular}

FIGURA 2.16 - Visão geral de sistemas CNC comerciais (PRITSCHOW et al, 2001 - modificado). 


\section{SISTEMAS DE MONITORAMENTO DE PROCESSOS DE USINAGEM}

Segundo BLUM et al (1988), GONÇALVES FILHO (1994) e LIANG et al (2004), o surgimento de novos materiais de difícil usinagem (cujos comportamentos ainda são desconhecidos), e como conseqüência o surgimento de novos materiais de ferramentas (de alto custo), juntamente com as exigências de alta produção de produtos e lotes variados, faixas de tolerâncias cada vez mais estreitas, e baixo custo de produção, têm extrapolado os limites e habilidades de operadores de máquinas. Além desses fatores, de acordo com BYRNE et al (1995), tem-se o surgimento de tendências e desenvolvimento de novas tecnologias de usinagem e de máquinas ferramenta, como, por exemplo, os processos de usinagem em altas velocidades de corte, os torneamentos “duros”, etc. Sendo seus parâmetros tecnológicos ainda não totalmente conhecidos e dominados, contribuem para o agravamento das dificuldades encontradas no chão de fábrica.

Máquinas CNC já realizam diversas funções antes executadas pelo homem (aproximação, afastamento e posicionamento da ferramenta, regulagem do avanço e velocidade de corte, etc), porém permanecendo ainda algumas sob responsabilidade do operador (troca da ferramenta, inspeção da peça, otimização do processo, etc), enfatizam DINIZ \& PIGARI (1995) e LIANG et al (2004). Segundo LIANG et al (2004), controles de máquinas ferramenta podem ser classificados em três níveis, de acordo com suas áreas de operação: ciclo de controle de servo-mecanismo, de interpolação e de controle adaptativo (ou controle de processo). O controle de processo é responsável pelo ajuste automático de 
parâmetros de processos (por exemplo, avanços e velocidades) com o intuito de aumentar a produtividade e melhorar a qualidade de produtos. No entanto, este ainda não é comumente integrado às máquinas ferramentas atuais. Poucas máquinas e condições de processos são monitorados continuamente em um equipamento de produção, afirma ZHOU et al (2000).

Assim, de acordo com DU et al (1995), tem-se dois importantes alvos de pesquisas em processos de manufatura. Um é o desenvolvimento integrado e auto-ajustável de sistemas capazes de produzir vários produtos com a mínima supervisão e assistências de operadores. O outro é melhorar a qualidade de produtos e reduzir custos de produção. Sistemas de monitoramento e controle de processos de usinagem buscam atender essa necessidade, minimizando e/ou auxiliando a atuação do homem nas máquinas ferramentas.

\subsection{Objetivo}

Resumidamente, segundo BYRNE et al (1995), o monitoramento de sistemas industriais é exigido para que seja obtido e assegurado o desempenho ótimo desses sistemas. Assim, o foco do monitoramento pode estar na máquina, na ferramenta, na peça ou no processo.

De acordo com TÖNSHOFF et al (2002), as funções de um sistema de monitoramento podem ser resumidamente esquematizadas na figura 3.1. 


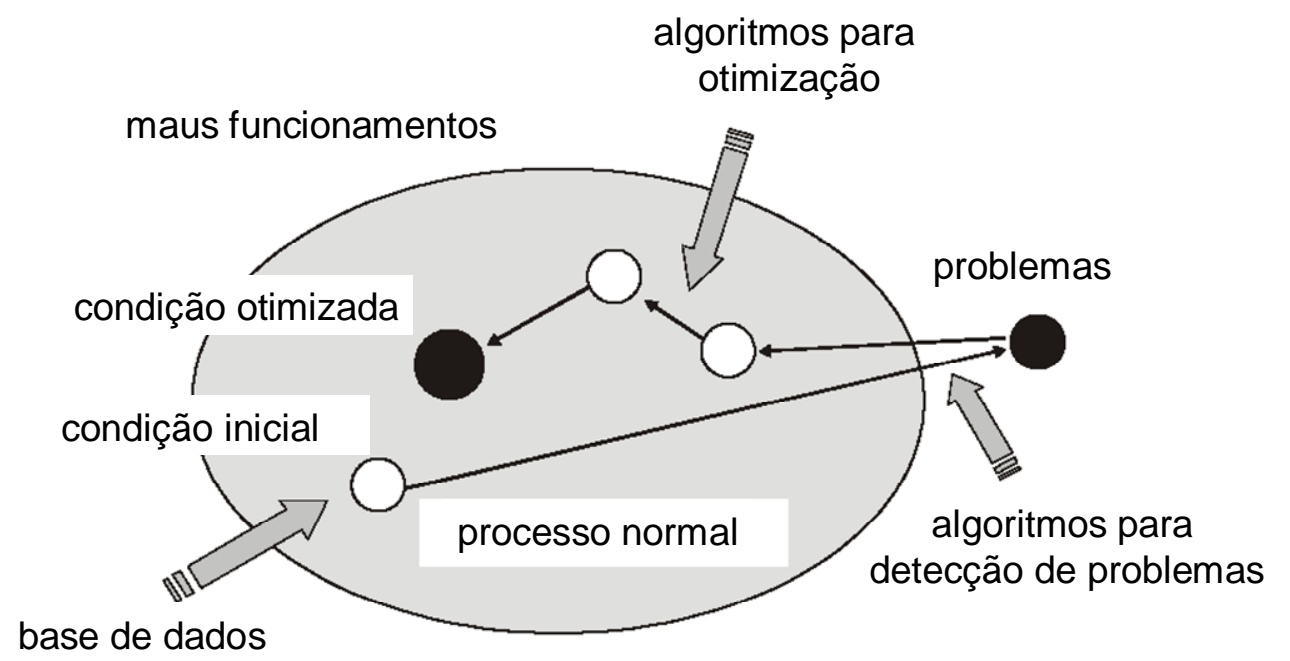

FIGURA 3.1 - Funções de sistemas de monitoramento (TÖNSHOFF et al, 2002 - modificado)

Primeiro, ele deverá ser capaz de detectar qualquer inesperado mau funcionamento que poderá ocorrer no processo. Segundo, informações relacionadas aos parâmetros de processo obtido com o sistema de monitoramento poderão ser utilizadas para otimizar o processo. Terceiro, o sistema de monitoramento tornará possível obter as causalidades de entrada (ex., configurações de parâmetros de usinagem) e saída (ex., características da peça usinada) do processo, que serão úteis para o estabelecimento de base de dados particulares para cada processo monitorado.

Sendo assim, os principais objetivos de sistemas de monitoramento são, TÖNSHOFF et al (2002):

- adquirir dados e conhecimentos para documentações de qualidade, banco de dados técnicos e representações de conhecimentos. Contribuem na garantia de qualidade, “rastreabilidade” e documentação. Este propósito ganha cada vez mais importância devido a leis de responsabilidade de fornecedores e de produtos. 
- manter limites e especificações de produtos (acuracidades geométricas, tolerâncias, etc), processo (exigências de estabilidade), máquina (capacidades mecânicas) e ambiente (por exemplo, emissões de ruídos).

- otimizar o processo com relação a ritmo de produção, custos e qualidade de produtos.

\subsection{Definição}

Existem vários termos ambíguos relacionados para o monitoramento, tais como inspeção, diagnóstico, diagnose e detecção de falha, afirma DU et al (1995). De acordo com DU et al (1995) e ZHOU et al (2000), o objetivo do monitoramento é detectar falhas, enquanto diagnose refere-se à localização e identificação da falha. Monitoramento é geralmente aplicado em equipamentos e processos de usinagem em que falhas podem ser prognosticadas. Diagnose provê a informação que descreve o estado do elemento afetado, conclui ZHOU et al (2000).

Quando o processo é operado por humanos, ele é monitorado com órgãos sensitivos, tais como a visão, audição, tato, olfato e paladar, afirma TÖNSHOFF et al (2002). O operador observa o processo de corte, analisa os sons e vibrações da usinagem ou qualitativamente avalia os produtos fabricados, SOKOLOWSKI e KOSMOL (2001). Algumas vezes, informações obtidas através de múltiplos órgãos sensitivos são fundidas e processadas pelo cérebro para a tomada de decisões, TÖNSHOFF et al (2002). Assim, baseado na experiência, o operador estima se o processo está em seu estado normal, e se a qualidade desejada do produto será alcançada, conclui SOKOLOWSKI e KOSMOL (2001). 
Na tentativa de se construir um algoritmo do comportamento humano do operador, é assumido que a observação do processo está relacionada à medição de certos sinais. Sendo assim, os órgãos sensitivos seriam substituídos por sensores, SOKOLOWSKI e KOSMOL (2001).

Os diferentes elementos de um processo de monitoramento são descritos a seguir, conforme a ilustração da figura 3.2.

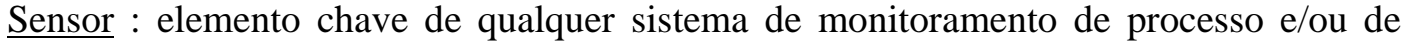
ferramenta, afirma JEMIELNIAK (1999). Detecta a mudança em um estímulo físico, transformando-o em um sinal que pode ser medido e gravado, conclui TÖNSHOFF et al (2002). Para propósitos de medições, seis tipos de sinais são importantes: radiante, mecânico, térmico, elétrico, magnético, e químico. TÖNSHOFF e INASAKI (2001), e USHER (1985), apud TÖNSHOFF et al (2002).

Processamento de sinal : responsável pela extração de dados relevantes a partir dos sinais de sensores. Ou seja, obtêm-se os índices do monitoramento que descrevem as características das diferentes condições do processo, DU et al (1995). Segundo TÖNSHOFF et al (2002), sua tarefa basicamente consiste no processamento de sinais analógicos (amplificação, filtragem, transformações matemáticas, etc.), conversão de sinais analógicos para digitais, e processamento de sinais digitais (seleção de processamentos no domínio do tempo, de freqüência, ou outros, como transformações wavelet).

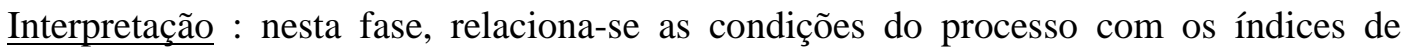
monitoramento obtidos durante o processamento de sinal, como, por exemplo, sinais de emissão acústica relacionados com a quebra e/ou o desgaste de ferramentas.. Esta relação pode ser descrita de diversos modos, tais como através de padrões e limites de sinais, lógicas fuzzy, redes neurais, entre outros métodos, afirma DU et al (1995). 
Resposta : de acordo com TÖNSHOFF et al (2002), a resposta do processo de monitoramento é uma declaração se existe algum mau funcionamento no processo. A razão para o mau funcionamento poderia estar obscura até este ponto.

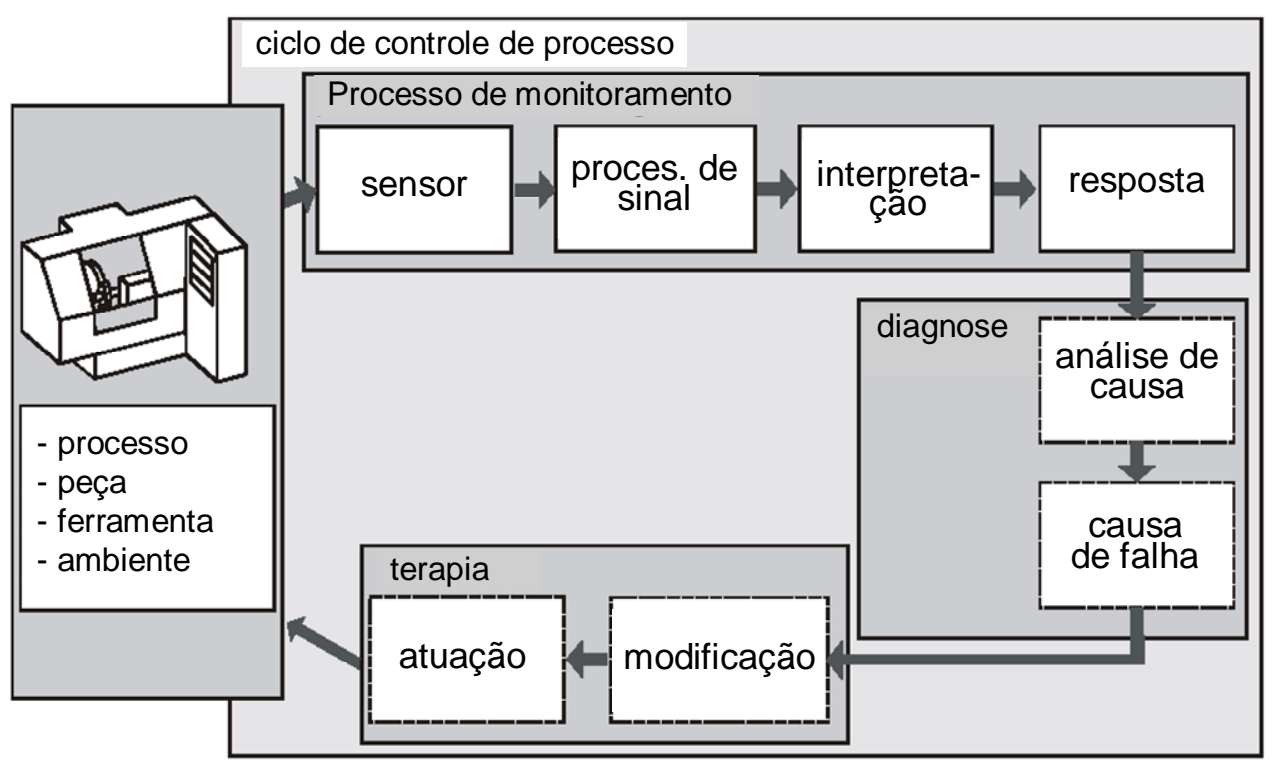

FIGURA 3.2 - Elementos de um ciclo de controle de processo (TÖNSHOFF et al, 2002 - modificado)

Em caso de um mau funcionamento, é desejável interagir com o processo para novamente alcançar sua condição normal. Assim, conforme esquematizado na figura 3.2., após a detecção do mau funcionamento (processo de monitoramento), tem-se a análise de causa e a localização e identificação de falha (diagnose), para posterior procedimento de recuperação que identifica qual dos parâmetros de processo precisa ser modificado para a ação de controle apropriada (terapia), DU et al (1995), ZHOU et al (2000) e TÖNSHOFF et al (2002). Segundo DU et al (1995), em geral, o mau funcionamento de processos pode ser classificado em duas categorias: irrecuperável e recuperável. O mau funcionamento irrecuperável pode somente ser corrigido por vistoria ou troca de novos itens. Por exemplo, a quebra ou o desgaste severo de ferramentas podem somente ser corrigidos pela troca das mesmas. Por outro lado, o mau funcionamento recuperável pode ser corrigido por reajustes das condições de trabalho do processo e/ou por controles dinâmicos. Por exemplo, em um 
processo de usinagem, a trepidação pode ser eliminada através da mudança da profundidade de corte e/ou velocidade de corte. E, controle dinâmico do avanço e/ou velocidade de corte podem ser utilizados para maximizar a taxa de remoção de material, afirmam ULSOY, KOREN e RASMUSSEN (1983) apud DU et al (1995).

A seguir, serão detalhados os principais elementos de um processo de monitoramento, que fazem parte do ciclo de controle de processo, como esquematizado na figura 3.2.:

- $\quad$ sensores

- processamento de sinal

- interpretação

\subsection{Sensores}

Altos níveis de automação de máquinas ferramenta para automação de processos são utilizados para maximizar a remoção de material e ao mesmo tempo minimizar o desgaste e/ou quebra de ferramentas, para manter especificações de qualidade de produtos, afirma LIANG et al (2004). Para este fim, são exigidos sensores confiáveis para identificarem falhas e comportamentos da máquina, ferramenta, processo e produtos, conclui LIANG et al (2004).

Falhas relacionadas com variáveis de estado discreto incluem falhas de operação e de CNC, enquanto falhas relacionadas com variáveis de estado contínuo geralmente referem-se para falhas de equipamento e processo, afirma ZHOU et al (2000). As falhas de variáveis de estado discreto (falhas de operação e de CNC) podem ser localizadas utilizando-se de sinais de estado discreto de controles de máquinas ferramentas, como CNCs e CLPs. Quanto às falhas de variáveis de estado contínuo (falhas de equipamento e processo), estas são identificadas através de medições de variáveis de estado contínuo. Assim, um dos requerimentos principais para o desenvolvimento de sistemas de monitoramento é a utilização 
de sensores capazes de descrever comportamentos da máquina, ferramenta, processo e peça, e identificação de falhas. Os sensores são os elementos chaves de muitos sistemas de monitoramento de processos e ferramentas, afirma JEMIELNIAK (1999). De acordo com BYRNE et al (1995), devido ao ambiente agressivo das máquinas ferramentas, os requerimentos adicionais para os sensores são:

- medições próximas ao ponto de usinagem, o quanto for possível;

- não redução da rigidez estática e dinâmica da máquina;

- não restrição de área de trabalho e de parâmetros de corte;

- livre de desgaste e manutenção, facilidade de mudanças e baixos custos;

- resistência à sujeiras, cavacos, e influencias mecânica, elétrica e térmica;

- funções independente de ferramentas e peça;

- adequadas características metrológicas;

- transmissão confiável de sinais;

Segundo LIANG et al (2002), LIANG et al (2004), BLUM et al (1988) e BYRNE et al (1995), em geral os sensores podem ser categorizados em sistemas contínuos (in-process ou on-line) e sistemas intermitentes (in-cycle ou off-line). Um sistema contínuo monitora durante o processo de usinagem, enquanto um sistema intermitente examina os atributos periodicamente, como, por exemplo, nos intervalos da usinagem de cada peça. Adicionalmente, técnicas de sensoriamento podem ser classificadas em medições diretas e indiretas. Em técnicas indiretas, a informação é obtida depois do processamento do sinal e interpretação baseada em modelos (por exemplo, a utilização de sensores de emissão acústica para detectar quebra ou desgastes de ferramentas). Quanto às técnicas diretas, a informação é obtida diretamente do sinal (por exemplo, sistemas de visão para a medição direta de desgastes, ou detecção de quebras de ferramentas), afirma LIANG et al (2004). 
Particularmente, quanto às ferramentas, sabe-se que suas avarias e desgastes são os maiores fatores que influem a qualidade e o ritmo de produção, BLUM et al (1988). Além disso, segundo DINIZ \& PIGARI (1995), com o emprego de ferramentas de corte de alto custo, sua utilização otimizada torna-se imprescindível; entretanto, vêm-se utilizando, em processos convencionais de usinagem, métodos estatísticos para trocas de ferramentas, que são ineficientes por não garantir a utilização total de sua vida.

As funções de um sistema de monitoramento da ferramenta em um processo de usinagem consistem em: detectar falhas de funcionamento da ferramenta utilizada na máquina (avarias e desgastes); e executar ações de prevenção ou correção (compensações do desgaste, ou interrupção do avanço, da rotação, e retração da ferramenta) para proteger a ferramenta, máquina e peça, minimizando os danos (TANGUY, 1993, e KLUFT, 1994).

JEMIELNIAK (1999) afirma que muitos sensores têm sido inventados e aplicados em laboratórios, mas somente poucos vêm sendo usados comercialmente. Na TABELA 3.1, temse alguns dos principais sensores utilizados em sistemas de monitoramento de condições de ferramentas de corte, com o respectivo método empregado, segundo MATHEW \& DAN (1990) apud SOUZA (1999), JEMIELNIAK (1999)*1, BYRNE et al (1995)*1, BLUM et al $(1988) * 2$. 
TABELA 3.1 - Métodos para o monitoramento do estado de ferramentas de corte

\begin{tabular}{|c|c|c|c|}
\hline MÉTODO & PROCEDIMENTO & MEDIDA & SENSOR \\
\hline DIRETO & $\begin{array}{l}\text { Óptico } \\
\text { Partículas do desgaste e } \\
\text { radioatividade } \\
\text { Resistência peça- } \\
\text { ferramenta } \\
\text { Tamanho da peça } \\
\text { Distância peça-ferramenta }\end{array}$ & $\begin{array}{l}\text { Forma ou posição da borda } \\
\text { Tamanho da partícula de } \\
\text { concentração } \\
\text { Alteração na resistência } \\
\text { elétrica da junção } \\
\text { Dimensão da peça sendo } \\
\text { usinada }\end{array}$ & $\begin{array}{l}\text { Câmera de TV, sensor } \\
\text { óptico, espectrofotômetro, } \\
\text { cintilador } \\
\text { Medidor de radioatividade } \\
\text { Ohmímetro } \\
\begin{array}{l}\text { Apalpador, sensor: } \\
\text { eletromagnético, ultra- } \\
\text { sônico, óptico } \\
\text { Micrômetro, medidor de } \\
\text { deslocamento (LVDT) }\end{array}\end{array}$ \\
\hline INDIRETO & $\begin{array}{l}\text { Força de Corte } \\
\text { Emissão Acústica } \\
\text { Som e Ultra-som } \\
\text { Vibração } \\
\text { Temperatura } \\
\text { Potência } \\
\text { Rugosidade } \\
\text { Torque *1 } \\
\text { Velocidade de rotação *2 }\end{array}$ & $\begin{array}{l}\text { Alterações na Força } \\
\text { Energia nas ondas de } \\
\text { deformação ou stress } \\
\text { Ondas acústicas } \\
\text { Vibração da ferramenta/ } \\
\text { porta-ferramenta } \\
\text { Variação da temperatura } \\
\text { no ponto de corte } \\
\text { Corrente ou consumo de } \\
\text { potência do motor de } \\
\text { acionamento } \\
\text { Rugosidade da peça } \\
\text { Alterações de Torque } \\
\text { Alterações devido às } \\
\text { variações de torques }\end{array}$ & $\begin{array}{l}\text { Dinamômetro, strain gage } \\
\text { Transdutor piezoelétrico } \\
\text { Microfone } \\
\text { Acelerômetro } \\
\text { Termopar, Pirômetro } \\
\text { Amperímetro, sensor de } \\
\text { corrente (efeito Hall) } \\
\text { Agulha mecânica, sensor } \\
\text { ótico, laser } \\
\text { Sensor de torque } \\
\text { Tacômetro }\end{array}$ \\
\hline
\end{tabular}

\subsection{Processamento de sinal}

O processamento de sinal, no monitoramento de processos, objetiva extrair as características dos sinais de sensores (chamados de índices de monitoramento) que descrevem 
as condições do processo, afirma DU et al (1995). Segundo o mesmo, diferentes técnicas de processamento podem ser utilizadas dependendo dos sinais de sensores. Uma diretriz geral de uso de diferentes técnicas de processamento de sinais é apresentada na figura 3.3.

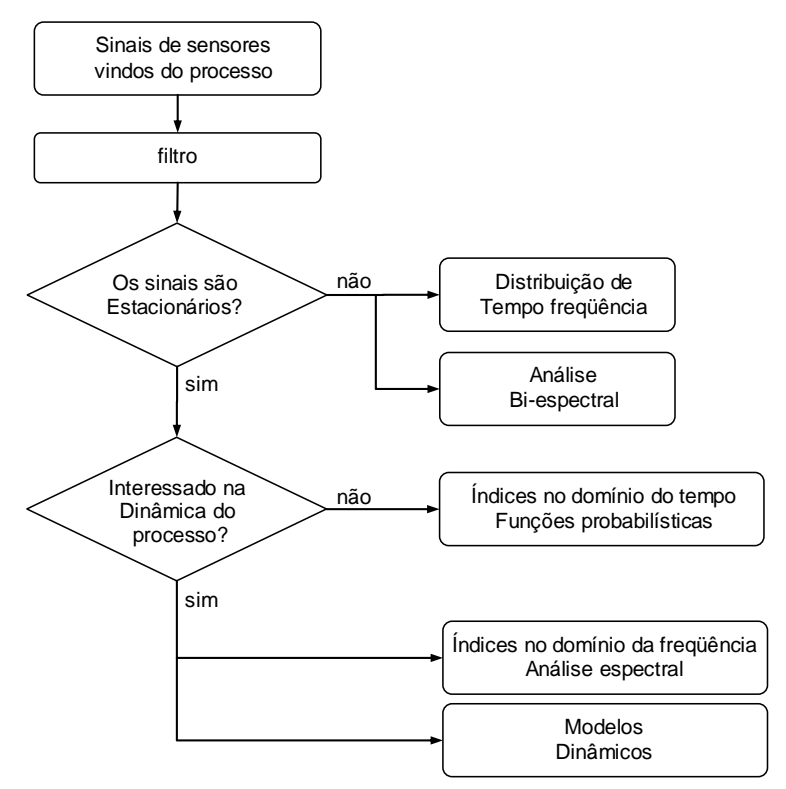

FIGURA 3.3 - Guia para o processamento de sinal de sensor (DU et al, 1995 - modificado)

Em geral, o primeiro passo de um processamento de sinal é a filtragem. Ele pode reduzir a influência de várias perturbações de ruídos, e pode amplificar a informação em gamas de freqüência desejadas.

Segundo DU et al (1995), dado um sinal de sensor, $x(t)$, se sua média $\mu(t)$ não depende do tempo $t$, e se sua variância $\sigma\left(t_{1}, t_{2}\right)$ é uma função somente da diferença de tempo $/ t_{1}-t_{2} /$, então este sinal é chamado de estacionário. Caso contrário, ele é não estacionário.

Resumidamente, as seguintes regras são recomendadas para o uso das diferentes técnicas de processamento de sinais em monitoramento de processos de fabricação, DU et al (1995):

1. se um sensor é estacionário, utilize-se de índices das funções de densidade de probabilidade (PDF - Probability Density Functions) e do domínio de tempo, tais como médias, variâncias, RMS (Root Mean Square), etc; 
2. Se os sinais de sensores são estacionários e deseja-se estudar a dinâmica do processo, utilize-se de análises espectrais;

3. Se os sinais dos sensores são não estacionários, utilize-se de distribuições de tempo freqüência e/ou de espectros de alta ordem.

\subsection{Interpretação e tomada de decisões (estratégia de monitoramento)}

Existem basicamente duas estratégias para interpretação e tomada de decisões. Uma utiliza-se de técnicas de aquisição de sinais, na qual sinais de saída mostram alguma relação com as características do processo. Assim, pode-se determinar sinais que representam um estado normal do processo e compará-los com sinais posteriores, com o intuito de detecção de inconformidades. A outra utiliza-se de modelos que relacionam os sinais de saída com os mecanismos do processo. Assim, utilizando-se desses modelos, juntamente com as informações dos sensores, pode-se prognosticar o comportamento do processo, afirma BYRNE et al (1995).

A seguir, é exposta uma breve revisão desses dois métodos para a tomada de decisões.

\subsubsection{Método convencional}

Os valores distintivos dos sinais processados são comparados com limiares (thresholds) predeterminados para identificar o estado do processo, conforme esquematizado na figura 3.4. 


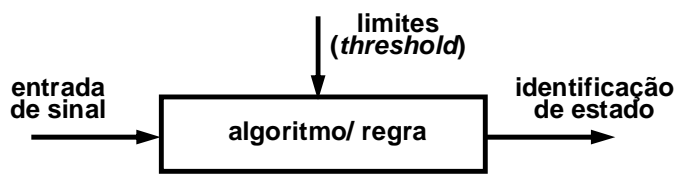

FIGURA 3.4 - Método convencional de tomada de decisão (TÖNSHOFF et al, 2002 - modificado)

Assim, segundo BYRNE et al (1995), se o limite é cruzado pelo sinal, tal fato deve-se a algum distúrbio do processo, como colisões, quebra de ferramentas, etc. Algumas das principais estratégias de monitoramento são, conforme JEMIELNIAK (1999) e BYRNE et al (1995):

\section{- Limites estáticos}

São estratégias que utilizam limites fixos ao longo do ciclo e ao longo do tempo (figura 3.5), ou limites fixos ao longo do ciclo, porém flutuantes ao longo do tempo, havendo um ajuste dos thresholds de acordo com o número de ciclos realizados (figura 3.6). Esta última técnica é utilizada quando há variações da amplitude do sinal medido ao longo do tempo. Assim, conforme mencionado antes, o cruzamento de um destes limites deve-se a um determinado fato no processo monitorado. Uma desvantagem deste método é a necessidade de ajustes manuais de limites.
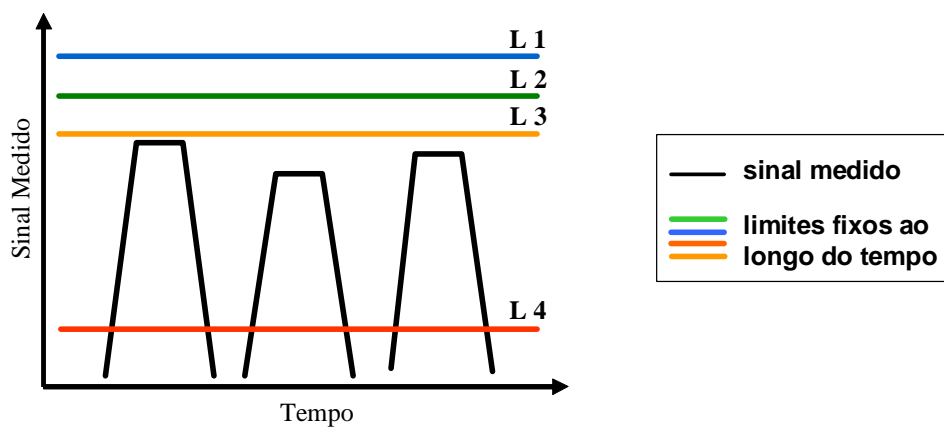

FIGURA 3.5 - Limites fixos ao longo do ciclo e ao longo do tempo 


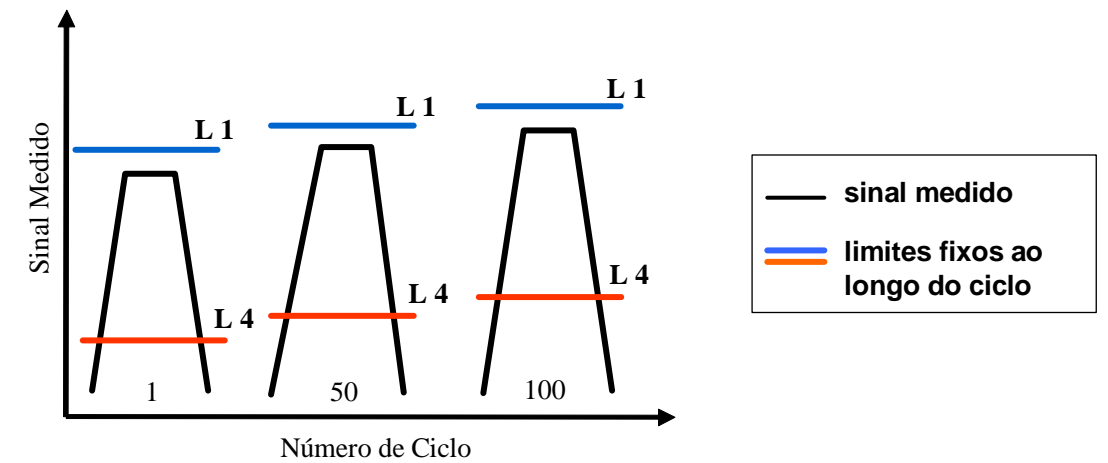

FIGURA 3.6 - Limites fixos ao longo do ciclo, porém flutuante ao longo do tempo

- Limites definidos pelo tempo

São limites que variam ao longo do ciclo (com o tempo do ciclo de corte), para monitorar diversas situações (por exemplo, início e fim do ciclo de corte, quebra e desgaste de ferramentas de corte, etc) em regiões características do processo (figura 3.7). Também possui a desvantagem da necessidade de ajustes manuais de limites.

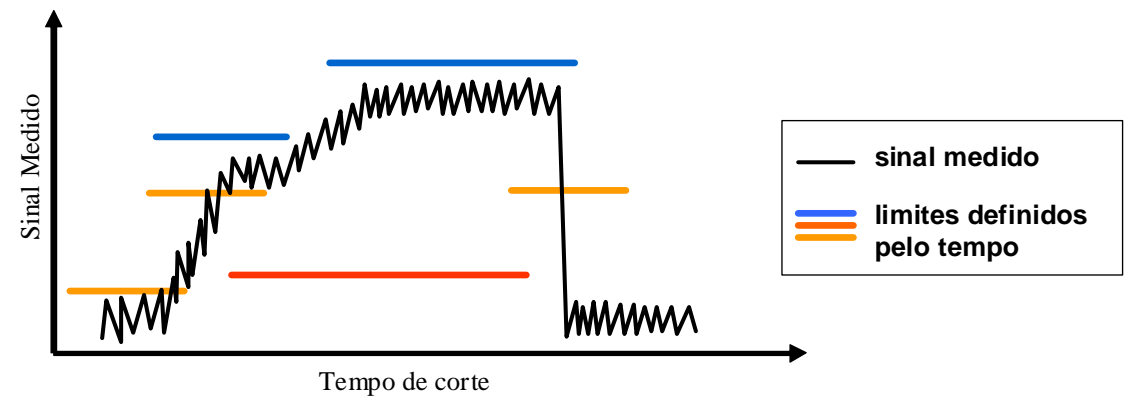

FIGURA 3.7 - Limites definidos pelo tempo

- "Assinatura da peça”

Este método é baseado na comparação do sinal medido com um sinal armazenado, BYRNE et al (1995). Cria-se então uma referência flutuante com limites circunvizinhos do sinal armazenado, como um tubo apertado, no qual o sinal medido deverá permanecer dentro. Esses limites podem variar no decorrer do 
tempo de corte ou da posição da peça, dividindo o processo de corte em segmentos, que podem ter valores particulares de limites (figura 3.8). Essa técnica, conhecida como “assinatura da peça”, permite um melhor acompanhamento de ciclos de corte complexos do que o uso de um simples conjunto de limites fixos (JEMIELNIAK, 1999). A desvantagem desta estratégia é a necessidade de ciclo de "aprendizagem” (“teach-in”), ou seja, a necessidade de um ciclo em estado normal do processo para servir de base para comparações com outros ciclos a serem monitorados.

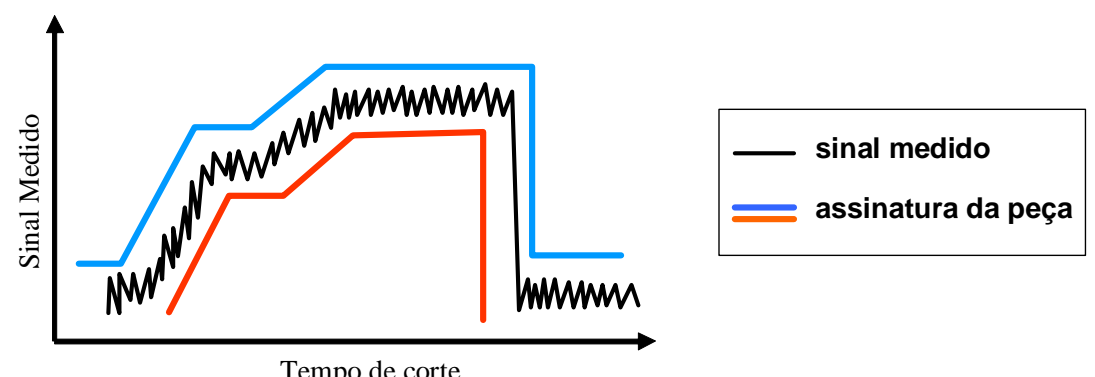

FIGURA 3.8 - “Assinatura da peça”

- Reconhecimento de padrão

Inicialmente, tem-se o armazenamento de diversos padrões que indica uma determinada situação (por exemplo, a quebra da ferramenta de corte) para posterior comparação com o sinal medido do processo. O sistema, que utiliza essa técnica, continuamente monitora o sinal comparando com os padrões armazenados. Quando um ou mais padrões são identificados, a situação que representa tal padrão é declarada, como por exemplo, a quebra da ferramenta de corte. Essa estratégia também tem a desvantagem da necessidade de ciclos de “teach-in”.

- Limites dinâmicos 
Desde que o método dos limites estático trabalha somente quando todas as restrições (profundidade de corte, material da peça, etc) permanecem constantes, o uso de limites dinâmicos torna-se mais apropriado em muitos casos, segundo KLUFT (1983) apud BYRNE et al (1995). O sistema de monitoramento calcula um limite on-line à partir do sinal original (figura 3.9). Assim, esse limite dinâmico calculado permanecerá com um determinado tempo de atraso em relação ao sinal original. Mudanças lentas do sinal poderão ocorrer sem a violação do limite. Contudo, no instante de uma quebra de ferramenta, o limite dinâmico será cruzado e, seguindo uma verificação de confirmação do aumento brusco do sinal (o sinal deverá permanecer acima do limite por um determinado tempo), a quebra é confirmada e assinalada (BYRNE et al, 1995).

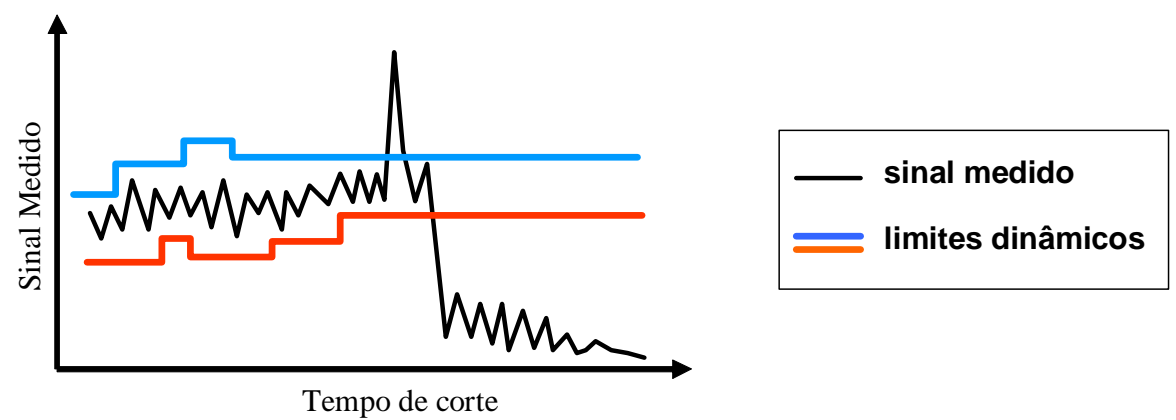

FIGURA 3.9 - Limites dinâmicos

- Limites por características calculadas de sinais de sensores

A variação contínua das propriedades do material da peça, das condições de corte, etc. pode mascarar ou confundir a detecção de situações, como um desgaste de ferramenta, devido a mudanças imprevistas no sinal medido. Tal fato limita o alcance de aplicabilidade ou requer um extenso treinamento em determinados sistemas de monitoramento. Assim, torna-se extremamente importante a extração de características do sinal medido que não sejam afetadas por tais variações, para 
posterior comparações com limites que venham detectar situações do processo (figura 3.10). Tais características são adquiridas utilizando-se diversas técnicas de processamento de sinal, como filtros, ferramentas estatísticas, etc.

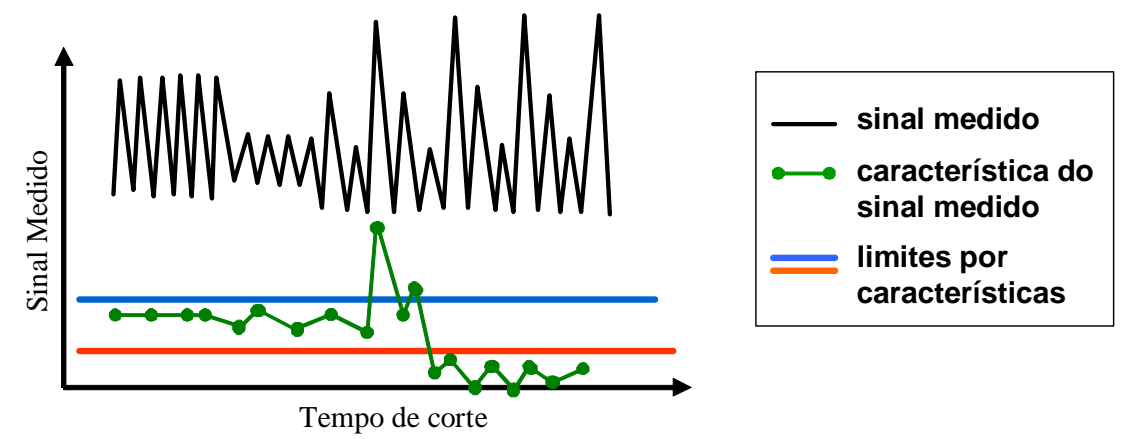

FIGURA 3.10 - Limites para características do sinal medido

\subsubsection{Método por modelagem do processo}

Segundo TÖNSHOFF et al (2002), são empregados vários tipos de modelos físicos ou empíricos que utilizam relações conhecidas. Como resultado, o valor calculado é comparado com um limiar para avaliar o processo, conforme esquematizado na figura 3.11.

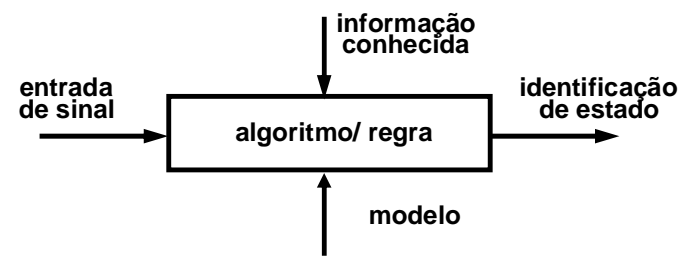

FIGURA 3.11 - Método por modelagem de processo para tomada de decisão (TÖNSHOFF et al, 2002 modificado)

Segundo o ponto de vista da engenharia de fabricação, modelo é uma representação abstrata de um processo de fabricação na qual serve para relacionar causas e efeitos, afirma TÖNSHOFF et al (1992) apud TÖNSHOFF et al (2002). 
Modelos podem ser divididos em duas origens: aqueles desenvolvidos baseando-se em relações físicas e aqueles baseados em médias empíricas (figura 3.12).

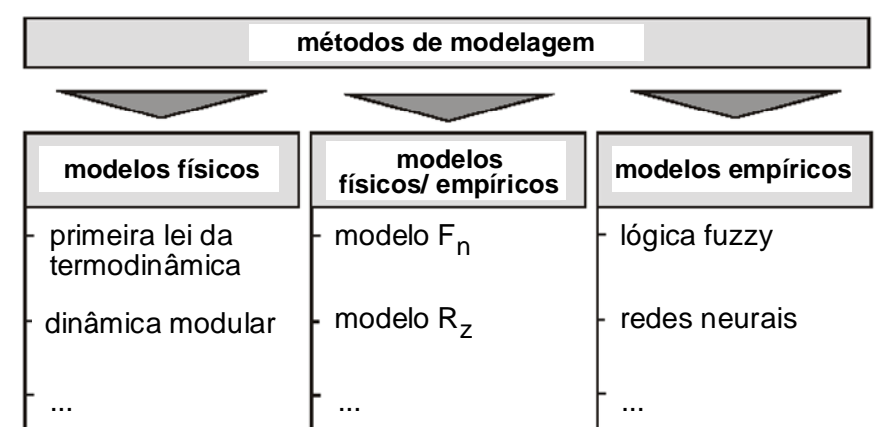

FIGURA 3.12 - Métodos de modelagem (TÖNSHOFF et al, 2002 - modificado)

Um modelo físico é desenvolvido a partir de uma compreensão dos princípios físicos fundamentais que estão envolvidos no processo. Assim, relevantes princípios físicos envolvidos no processo são selecionados, baseando-se no conhecimento do processo, para a obtenção de um modelo qualitativo. Em conformidade com as leis físicas, o modelo físico é estabelecido utilizando-se de uma função matemática desse modelo qualitativo. Modelos baseados na primeira lei da termodinâmica, dinâmica modular, etc, são alguns exemplos desse tipo de modelagem.

Quanto aos modelos empíricos, estes são obtidos através de médias de valores adquiridos através de experimentos de usinagem, com relevantes condições de entradas e saídas. Subseqüentemente, um tipo de método é escolhido, e as relações entre as entradas e saídas são identificadas utilizando-se dos dados experimentais, afirmam TÖNSHOFF et al (1992) e PAUL (1994), apud TÖNSHOFF et al (2002). Alguns exemplos de tipos de métodos para o processo de modelagem empírica são: correlações (coeficientes determinados por análises regressivas), redes neurais e lógicas fuzzy.

Adicionalmente, tem-se também a possibilidade de combinar modelos físicos e empíricos. Segundo TÖNSHOFF et al (2002), baseando-se nessa combinação, tem-se para o 
processo de retificação, por exemplo, modelos de topografia de rebolos, forças de retificação, rugosidades superficiais, etc.

\subsection{Integração de sistemas de monitoramento em máquinas ferramenta}

Basicamente, sistemas de monitoramento podem ser integrados às máquinas ferramentas em três níveis, conforme esquematizado na figura 3.13, com maior ou menor facilidade, dependendo do tipo de controle das mesmas:

1. ciclo de controle de processo ( monitoramento on-line):

monitoramento contínuo, durante o processo de usinagem. O benefício deste tipo de monitoramento dá-se diretamente na própria peça cujo ciclo foi monitorado.

2. ciclo de controle pós-processo ( monitoramento off-line):

sistema intermitente que examina os atributos periodicamente, como por exemplo, nos intervalos da usinagem de cada peça. O benefício desta técnica dá-se no próximo ciclo de usinagem a ser executado.

3. ciclo de controle superior (sistema de supervisão):

disponibiliza informações de chão de fábrica (dados da produção, processo e máquina), de maneira confiável e com um mínimo de atraso, para diversas áreas dentro da empresa (suporte, engenharia, etc) e, conforme o interesse, para clientes, cadeia de fornecedores, etc. Auxilia na integração do chão de fábrica com áreas técnicas, administrativas e corporativas, servindo de apoio para a 
gestão da produção, otimização de processos e manutenção/ suporte de equipamentos.

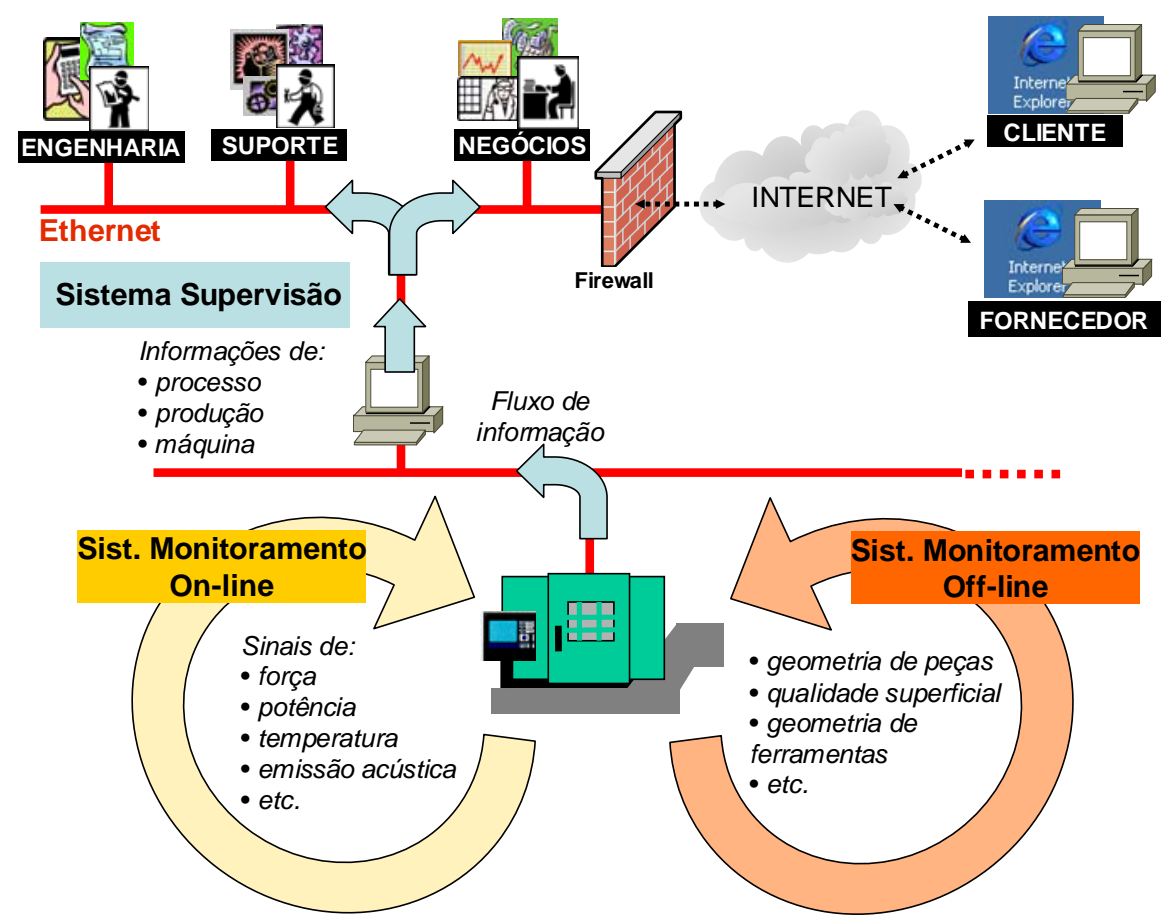

FIGURA 3.13 - Possibilidades de integração de sistemas de monitoramento em máquinas ferramenta

Partes do ciclo de controle de processo (sistema de monitoramento on-line) são sistemas de controle adaptativo (CA) (TÖNSHOFF et al, 2002). Informações provenientes de sensores são utilizadas para ajustes on-line de parâmetros do processo, com o objetivo de manter a qualidade de peças, bem como a redução de custos e tempos de ciclo.

\subsubsection{Controle de processos de usinagem}

Controles de máquinas ferramentas consistem de um CLP (Controlador Lógico Programável), que manuseia o seqüenciamento e a interface de operação, e de um 
microprocessador que coordena as funções de controle em tempo real (LIANG et al, 2004). A arquitetura do microprocessador pode ser geralmente dividida em três níveis: ciclo de controle de servomecanismo, ciclo de interpolação e ciclo de controle de processos, como esquematizado na figura 3.14.

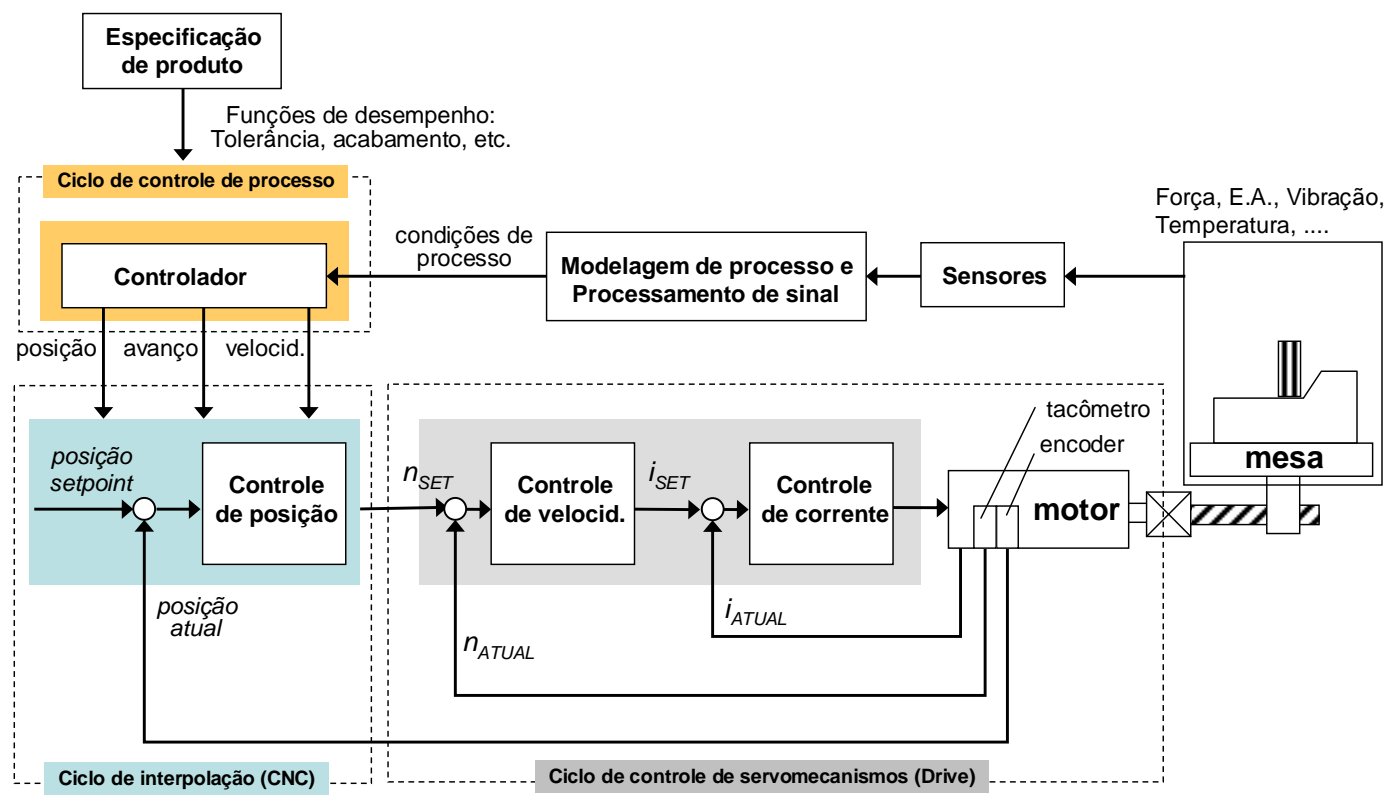

FIGURA 3.14 - Controle de máquina ferramenta e de processos (LIANG et al, 2004; SIEMENS, 2000 modificado)

O objetivo dos controles de servomecanismos é regular a velocidade e a posição dos eixos e do spindle, frente a distúrbios adversos, tais como as fricções, folgas, forças de usinagem, etc. Quanto ao ciclo de interpolação, este coordena múltiplos eixos para manter a ferramenta em um específico percurso e orientação. Finalmente, o ciclo de controle de processos é responsável pelo ajuste automático de parâmetros de usinagem (por exemplo, velocidades, avanços, etc.) para aumentar a produtividade e qualidade de produtos. O ciclo de controle de processos, também referido como controle adaptativo na terminologia de máquinas ferramentas, não é comumente integrado nas atuais máquinas ferramenta, enfatiza LIANG et al (2004). 
Segundo LIANG et al (2004), basicamente tem-se três tendências de sistemas de controle adaptativos, que são:

- controle adaptativo por limites

parâmetros de processo são manipulados em tempo real para manter uma específica variável do processo, tais como força ou potência, dentro de limites. Tipicamente é utilizado em processos de desbaste onde a produtividade é maximizada por manter a variável do processo em seu máximo valor.

- controle adaptativo por otimização neste tipo de controle, parâmetros de usinagem são configurados para otimizar um índice de desempenho, tais como tempo de produção, custo unitário, etc. Essas configurações são derivadas de modelos e da realimentação de sinais de processos.

- controle adaptativo geométrico

tem como objetivo maximizar a qualidade de operações de acabamento frente a distúrbios, tais como deflexões estruturais e desgastes de ferramentas. 


\section{SISTEMAS DE SUPERVISÃO E CONTROLE DE PROCESSOS}

Sistemas de controle eram inicialmente confinados para uma planta particular. As associações dos equipamentos de controle eram locais para a planta, e não conectados com uma rede de comunicação externa. Os primeiros sistemas de controle consistiam de um computador central, ou CLP, que comunicava com controles locais responsáveis pela interface com motores, bombas, válvulas, chaves, sensores, etc. A figura 4.1 ilustra esse tipo de estrutura.

Essa arquitetura é algumas vezes referenciada como um Sistema Distribuído de Controle (SDC), ou, do inglês, Distributed Control System (DCS). Como tais sistemas são geralmente confinados em localizações próximas um dos outros, normalmente utilizam redes locais de comunicação de alta velocidade, e geralmente envolvem ciclos fechados de controle. Como uma exigência necessária para a operação destes sistemas, companhias e vendedores desenvolveram seus próprios protocolos de comunicação, muitos dos quais eram proprietários.

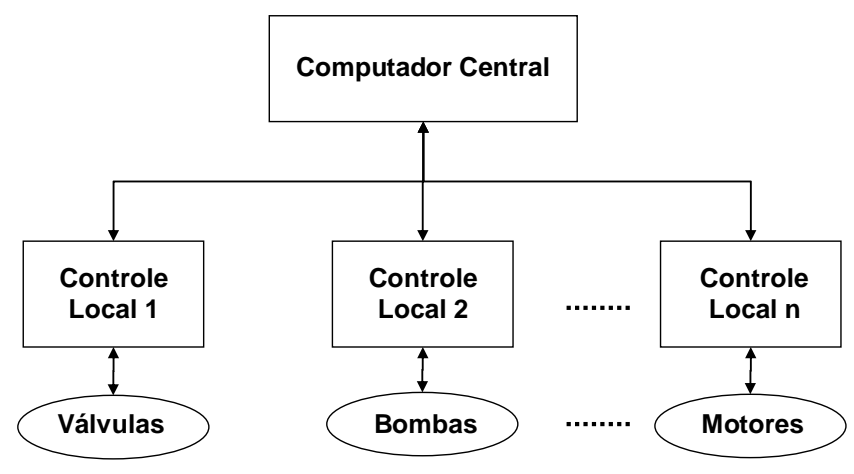

FIGURA 4.1 - Típico sistema de controle local 
Como as capacidades técnicas de computadores, sistemas operacionais e de redes de comunicação melhoraram, a administração organizacional pressionou para um aumento do conhecimento em tempo real dos estados de operações de plantas remotas. Também, a aquisição de dados, o controle, e a manutenção remota tornaram-se crescentemente atraentes do ponto de vista da administração e de custo em organizações com várias operações geograficamente separadas. Estas capacidades são atendidas por sistemas de supervisão e controle de processos, ou simplesmente sistemas SCADA (Supervisory Control and Data Acquisition).

\subsection{Definição}

Segundo AUTOMACAO.NET (2001) e DANEELS \& SALTER (1999), SCADA (Supervisory Control and Data Acquisition) são softwares que além de servirem como interface homem/ máquina, como os softwares HMI ou MMI (Human Machine Interfacing ou Man Machine Interfacing), podem também efetuar controles e distribuir informações entre estações via rede, com bom desempenho e segurança. São softwares robustos e confiáveis para aplicações de grande porte e para aplicações distribuídas em várias estações de trabalho.

São implementados no topo de sistemas de controle, formando centrais de controle (vide figura 4.2) que comunicam com equipamentos de campo através de redes e de unidades de terminais remotos (RTUs - Remote Terminal Units) e/ou de CLPs, propiciando uma visão geral de toda a planta de produção. 


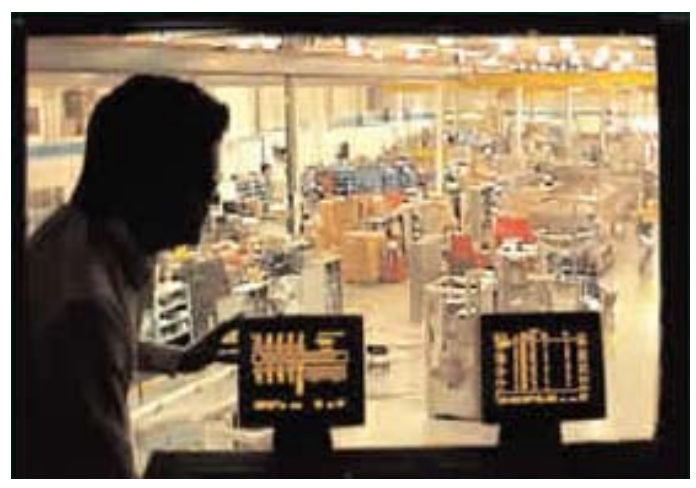

FIGURA 4.2 - Exemplo de central de controle de um sistema SCADA

Segundo TEK (1999) apud MEIRELES (2000), nestas centrais de controle (ou salas de controle), operadores podem acompanhar o funcionamento de equipamentos e o andamento da produção, com auxílio de interfaces gráficas especialmente desenvolvidas para auxiliar a visualização e a solução de problemas de chão de fábrica.

A seguir, têm-se algumas definições de sistemas SCADA:

- Tecnologia que permite usuários coletar dados de uma ou mais instalações e/ou enviar limitadas instruções de controle para as mesmas (Stuart A. Boyer, “SCADA: Supervisory Control and Data Acquisition”, ISA The Instruments, Systems, and Automation Society, $3^{\circ}$ edição).

- Sistema que opera com sinais codificados sob canais de comunicação para prover controle de equipamentos RTU (Remote Terminal Unit) (IEEE Standard C37.1-1994, Definition, Specification, and Analysis of Systems Used for Supervisory Control, Data Acquisition, ans Automatic Control).

- Categoria de programa de aplicação de software para controle de processos e aquisição de dados em tempo real de locais remotos, para controlar equipamentos e condições (ENDEAVORENG (2006)). 
Sistemas SCADA são comumente utilizados em indústrias de processos contínuos e por bateladas, como: processamento de aços, geração de energia (convencional e nuclear) e distribuição, processos químicos, indústrias de alimentos e bebidas, indústrias de açúcar e álcool, etc. O tamanho de cada planta pode variar de centenas à dezenas de milhares de canais input/output (I/O), afirma GERMAIN \& CLARKE (1998). Nos últimos anos, tais sistemas têm expandido também para processos discretos, possibilitando a supervisão de processos de usinagem através de uma comunicação direta entre centrais de controle e equipamentos controlados por CNC (máquinas ferramenta e linhas transfer).

\subsection{Arquitetura}

A arquitetura de um sistema SCADA pode ser dividida em duas categorias: hardware e software.

\subsubsection{Arquitetura de Hardware}

Segundo DANEELS \& SALTER (1999), uma arquitetura típica de um sistema de supervisão, ou sistema SCADA, é composta por estações clientes e estações servidoras de dados, conforme ilustrado na figura 4.3. Uma estação servidora de dados (SCADA Server) comunica-se com equipamentos de campo através de seus controladores, por exemplo CLP e CNC, que podem ser conectados diretamente ou via redes de campo (fieldbus). Através destas estações servidoras de dados pode-se armazenar e compartilhar informações do chão de fábrica para as estações clientes através de redes LAN/WAN. Assim, informações da estação servidora podem ser acessadas de qualquer ponto da rede corporativa através de softwares especiais (SCADA Client), ou através de navegadores de páginas HTML (browsers), tendo- 
se, neste último caso, algumas limitações de recursos. Adicionalmente, obedecendo-se as regras de seguranças da rede corporativa (firewall), pode-se até mesmo disponibilizar estas informações para a Internet.

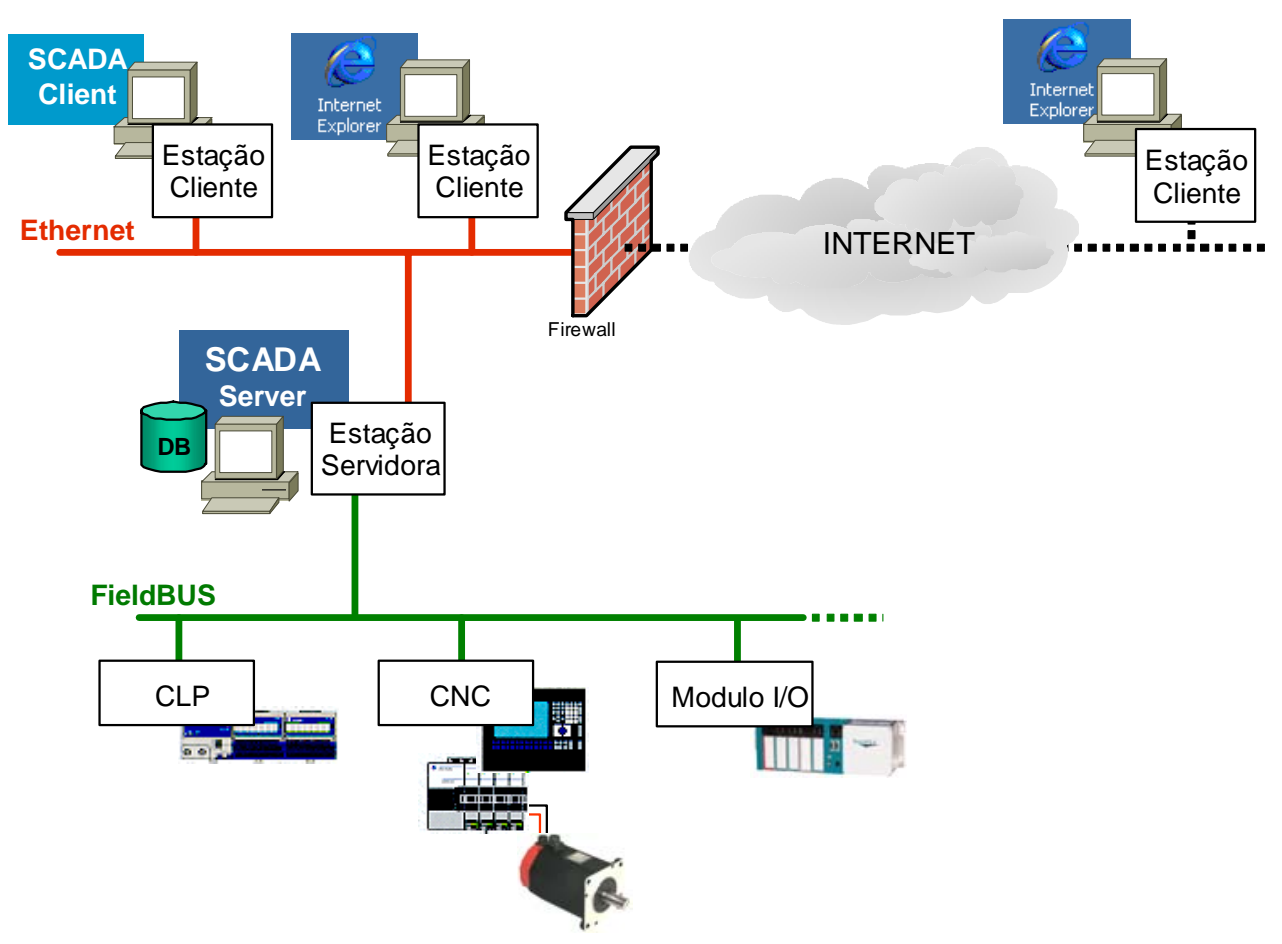

FIGURA 4.3 - Arquitetura de hardware típica de um sistema SCADA

\subsubsection{Arquitetura de Software}

Basicamente, a arquitetura de software de um sistema SCADA pode ser dividida nos seguintes módulos, conforme apresentado na figura 4.4:

- SCADA Server: responsável pela comunicação e troca de dados com equipamentos de campo, compartilhamento, processamento e armazenamento 
de informações, execução de tarefas em tempo real, gerenciamento de eventos e de alarmes, comunicação com aplicativos locais (por exemplo, Excel).

- SCADA Client: responsável pela interface homem-máquina, geração de gráficos de tendência, apresentação de alarmes e logs, integração com aplicativos locais.

- SCADA Development Environment: ambiente de desenvolvimento dos módulos de SCADA Server e Client.

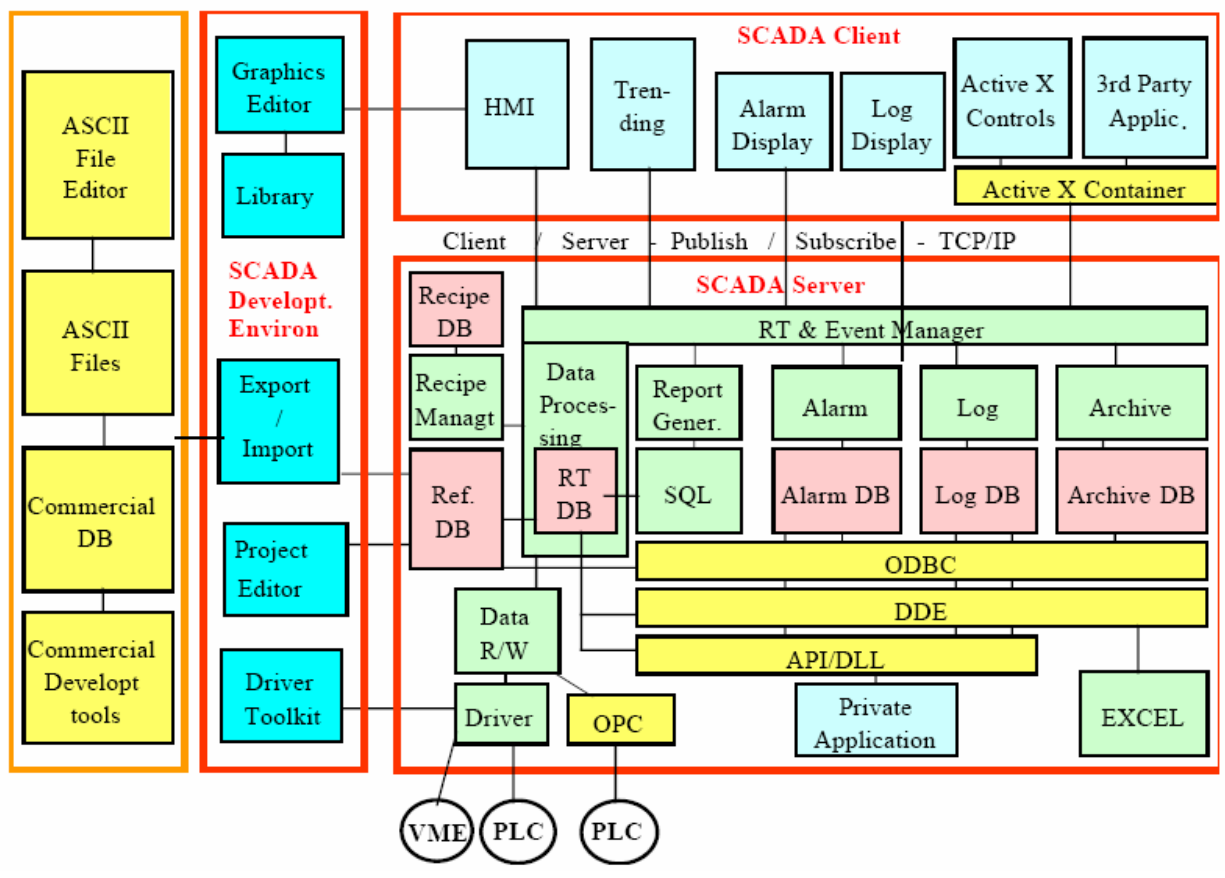

FIGURA 4.4 - Arquitetura de software genérica de um sistema SCADA (DANEELS \& SALTER, 1999) 


\subsection{Componentes}

Conforme ilustrado na figura 4.5, os principais componentes de um sistema SCADA são:

- Equipamentos de campo

o Sensores

o Módulos de aquisição de sinais (digitais e/ou analógicos)

o Controladores

o Atuadores

- Sistema de comunicação

- Estação SCADA Server

- Estações SCADA Client

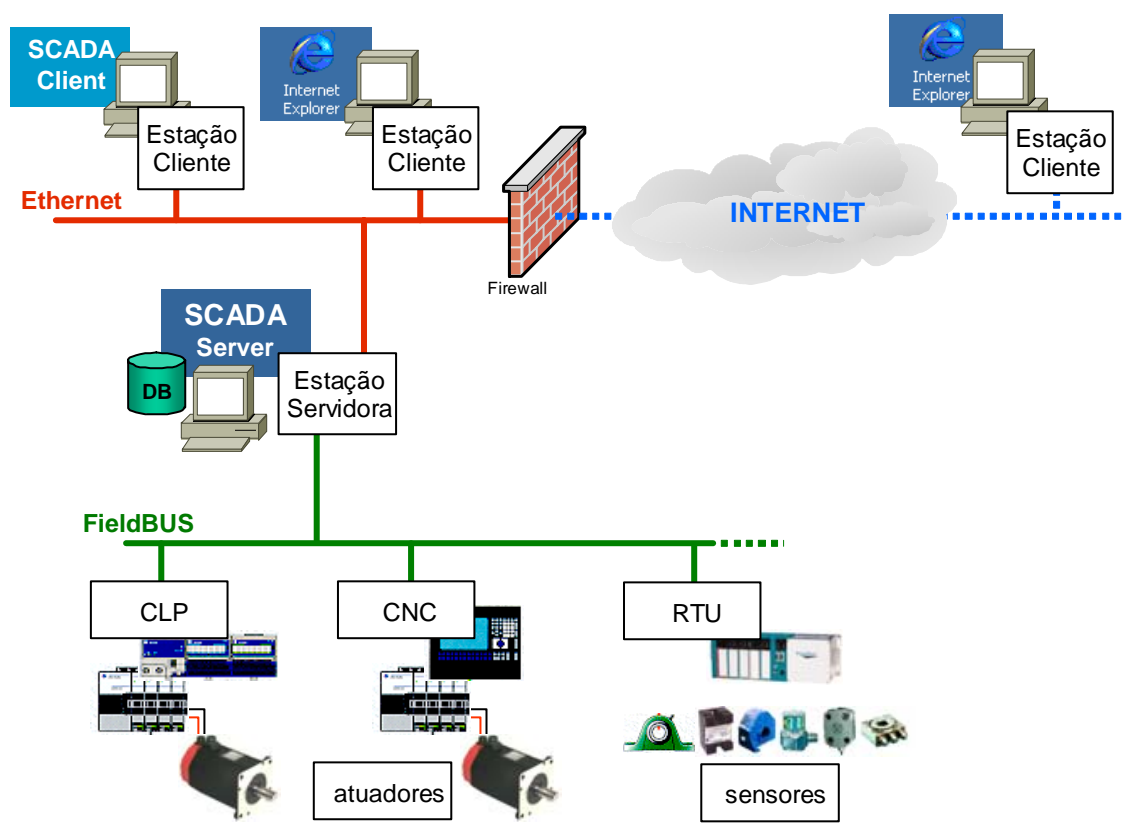

FIGRUA 4.5 - Principais componentes de um sistema SCADA 
A seguir, tem-se uma breve descrição desses componentes.

\subsubsection{Equipamentos de campo}

Trata-se de equipamentos de interface direta com plantas de produção e/ou máquinas. Responsáveis pela leitura de grandezas físicas, tomada de decisões e atuações no processo. Fazem parte:

o Sensores

o Módulos de aquisição de sinais digitais e/ou analógicos (RTU)

o Controladores (CLP, SoftLogic, CNC, painel de relés, etc.)

o Atuadores: equipamentos (motores, inversores de freqüência, contatores, relés, solenóides, etc) que efetivamente atuam no processo.

Na figura 4.6 tem-se em destaque colorido a localização destes equipamentos dentre todos os componentes típicos de um sistema SCADA.

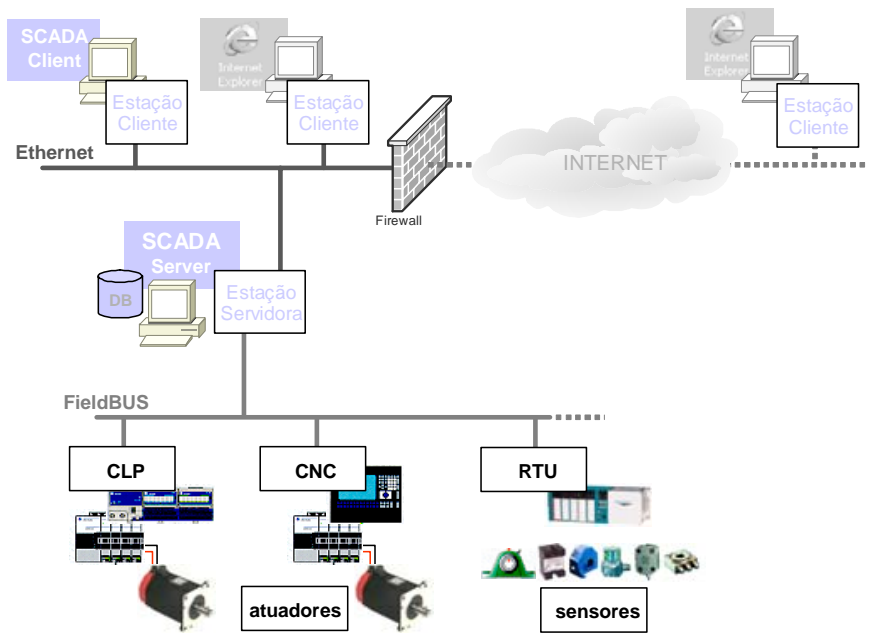

FIGURA 4.6 - Equipamentos de campo (em destaque) de um sistema SCADA 
Segundo ISA (2000), sensores são equipamentos que produzem sinais de tensão ou corrente, representando alguma propriedade física medida (temperatura, força, pressão, velocidade, vazão, etc). Fornecem informações necessárias para a percepção do que ocorre nas plantas de produção e/ou máquinas. Fazendo uma analogia ao corpo humano, os sensores formam os "olhos e ouvidos" de um sistema SCADA. Geralmente, os sinais de sensores requerem algum tipo de processamento antes de serem utilizados. Alguns padrões industriais de sinal de saída analógico de sensores são 0-5Volts ou 0-10Volts para curtas distâncias, e 420 mA ou 0-20 mA para longas distâncias com controladores. Saídas digitais binárias são normalmente empregadas por sensores para a indicação de status discretos de equipamentos, tais como nível “1” para indicar equipamento ligado e nível “0” para indicar desligado. Adicionalmente, utilizando-se da mesma analogia de um corpo humano, os atuadores elétricos de válvulas, drivers e inversores de freqüência de motores, dosadores eletrônicos, atuadores pneumáticos e hidráulicos, etc, são exemplos de atuadores de uma planta que formando as “mãos” de um sistema SCADA.

Contudo, antes de qualquer automação ou monitoramento remoto possa ser alcançado, a informação que é passada para e de um equipamento de campo deve ser convertida para um formato que seja compatível com a linguagem de um sistema SCADA. Para atender essa interface, tem-se os módulos de aquisição de sinais conhecidos como RTUs (Remote Terminal Units ou Remote Telemetry Units). Eles são primariamente utilizados para converter sinais eletrônicos, recebidos de equipamentos de campo, em linguagem (protocolo de comunicação) usada para transmitir dados em um canal de transmissão.

As instruções para a automação de algum equipamento de campo, tal como uma lógica para controle de uma bomba, são geralmente armazenadas localmente. Isto é largamente usual devido à limitação típica da taxa de comunicação entre uma estação SCADA e os equipamentos de campo. Essas instruções são tradicionalmente mantidas em CLPs 
(Controladores Lógicos Programáveis), que no passado eram fisicamente separados dos RTUs. CLPs são equipamentos de controle que tomam decisões baseando-se em sinais de outros hardwares e/ou transdutores (botões, chaves de fim de curso, sensores, CNCs, CLPs, computadores, etc) e em lógicas previamente programadas. Atualmente, CLPs já apresentam RTUs incorporadas, e até mesmo servidores WEB. São disponibilizados em módulos, tendo como os principais:

- módulo CPU

- módulo de entradas e saídas digitais e/ou analógicas

- módulo de interface de comunicação com redes de campo (RTUs)

- fonte de alimentação

Os CLPs podem ser utilizados separadamente ou em conjunto com sistemas SCADA ou outros sistemas. Eles têm sua origem na automação industrial e, portanto, são geralmente utilizados em aplicações de manufatura e plantas de processo. A necessidade de ter CLPs conectados a uma rede de comunicação não era grande para estas aplicações, pois eles eram geralmente requeridos somente para substituírem sistemas tradicionais de lógicas à relés ou controles pneumáticos (NCS TIB 04-1, 2004). Sistemas SCADA, por outro lado, tem sua origem nas aplicações remotas, onde eles eram somente necessários para obter informações básicas de fontes remotas. Assim, os RTUs utilizados nestes sistemas não tinham a necessidade de efetuarem controles porque o algoritmo de controle local eram mantidos em lógicas de chaveamento à reles, ou por CLPs. No entanto, com a necessidade de alterações do algoritmo e/ou de parâmetros de controle através de sinais remotos (a parte do "Controle” do acrônimo SCADA), surgiu a necessidade da utilização de equipamentos capazes de executarem tanto tarefas de controle, quanto de comunicações remotas. Assim, nota-se hoje uma fusão de funcionalidades dos CLPs e RTUs. Atualmente já é bastante comum 
encontrarmos CLPs com a capacidade de realizar comunicações remotos, bem como RTUs capazes de executarem funções de controle. Onde somente um simples controle local é desejável, tornou-se possível utilizar um RTU. Ao mesmo tempo, CLPs tradicionais com módulos de comunicação reportam seus estados de controle e recebem comandos de estações remotas. Como resultado desses desenvolvimentos, a diferença entre um CLP e um RTU tornou-se mínima, tendo suas terminologias virtualmente intercambiáveis.

Conforme mencionado anteriormente, os sistemas de supervisão têm expandido também para processos discretos, possibilitando a supervisão de processos de usinagem através de uma comunicação direta entre centrais de controle e equipamentos controlados por CNC (máquinas ferramenta e linhas transfer). Particularmente, a arquitetura de CNC baseada em PC traz uma infinidade de benefícios, destacando-se a flexibilidade, conectividade, integração, redução de custos, capacidade de armazenamento e recursos de multimídia. Através de um ambiente PC, tem-se no mundo do CNC um ambiente neutro para a utilização de softwares e hardwares que não necessitam obrigatoriamente serem provenientes do fabricante do CNC, reduzindo custos de atualizações e de mão de obra especializadas. Permitem a fácil conectividade e a integração com outros sistemas, máquinas e aplicações específicas.

\subsubsection{Sistema de comunicação}

Na figura 4.7 tem-se em destaque (colorido) a localização do sistema de comunicação dentre todos os componentes típicos de um sistema SCADA. 


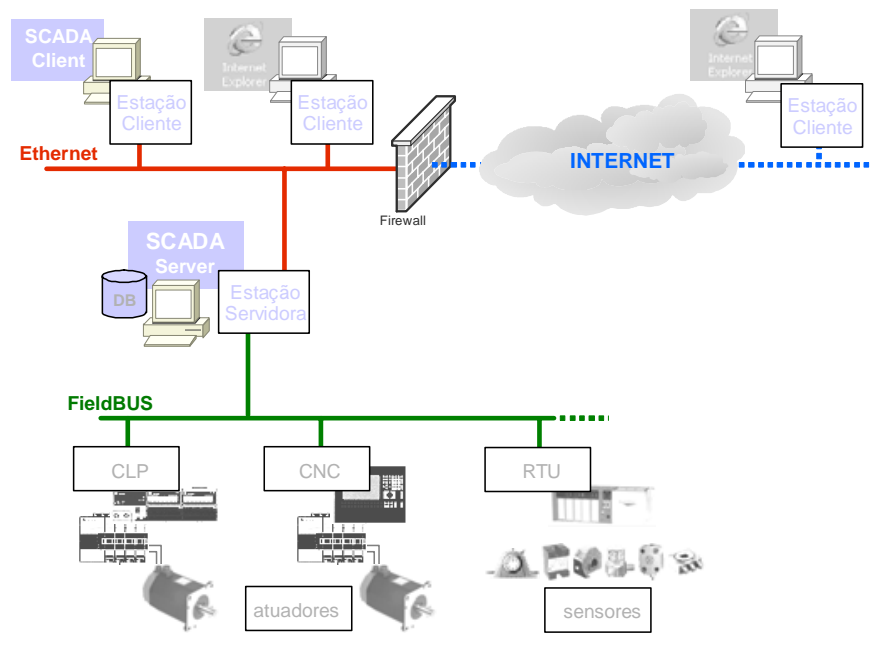

FIGURA 4.7 - Sistema de comunicação (em destaque) de um sistema SCADA

O sistema de comunicação é responsável pela troca de dados entre os equipamentos de campo e softwares. Suas principais funções são, segundo HONEYWELL (2000), ROCKWELL (2000), SIEMENS (2000), WONDERWARE (2000):

- Controlar: permite troca de dados em tempo real com os atuadores, através de uma variedade de métodos, tais como: taxas de refresh em I/O selecionados, compartilhamento de inputs, interlocking entre controladores, etc.

- Configurar: possibilita configurar todos os equipamentos que estão na rede, de qualquer localidade da mesma. Pode-se configurar equipamentos em start-up, modificar parâmetros com um clique de mouse ou através de um controlador lógico, sem ter qualquer impacto no desempenho do controle.

- Coletar Dados: permite a coleta de dados de equipamentos de campo, possibilitando a visualização em displays de IHMs, cálculos de tendências e análises, administração de manutenção e solução de problemas.

Atualmente existe uma grande quantidade de tecnologias de concepção aberta ou proprietária disponível no mercado em situação consolidada, sendo especificamente 
desenvolvidas para atender aos requisitos de cada um dos cinco níveis de dispositivos e equipamentos característicos de um sistema de automação. Contudo, há sobreposições de atuações, como vem ocorrendo com o uso do Ethernet TCP/ IP em áreas antes exclusivas da classe FieldBus (figura 4.8 - adaptada de ROCHA (1998)).

Quatro classes de redes de comunicação se destacam, segundo ROCHA (1998) :

- $\underline{\text { SensorBus }}$ : destinada para comunicação ao nível dos sensores e atuadores. Determinística e tempos de resposta extremamente curtos. Ex: AS-i, Seriplex, etc.

- DeviceBus : específico para dispositivos de controle e seus periféricos. Determinística e tempos de resposta curtos. Ex: DeviceNet, Interbus-S, ProfibusDP, etc.

- FieldBus : aplicada para comunicação entre unidades inteligentes (sistemas de supervisão e gerenciamento de produção). Determinístico, com alta performance. Ex: Fieldbus Foundation, Fieldbus WorldFIP, Modbus, Profibus-FMS, ProfibusPA, etc.

- DataBus : destinada para comunicação entre computadores. Estocástica, mas com capacidade de manipular grandes quantidades de informação em tempo não crítico. Ex: Ethernet TCP/IP, FDDI, etc.

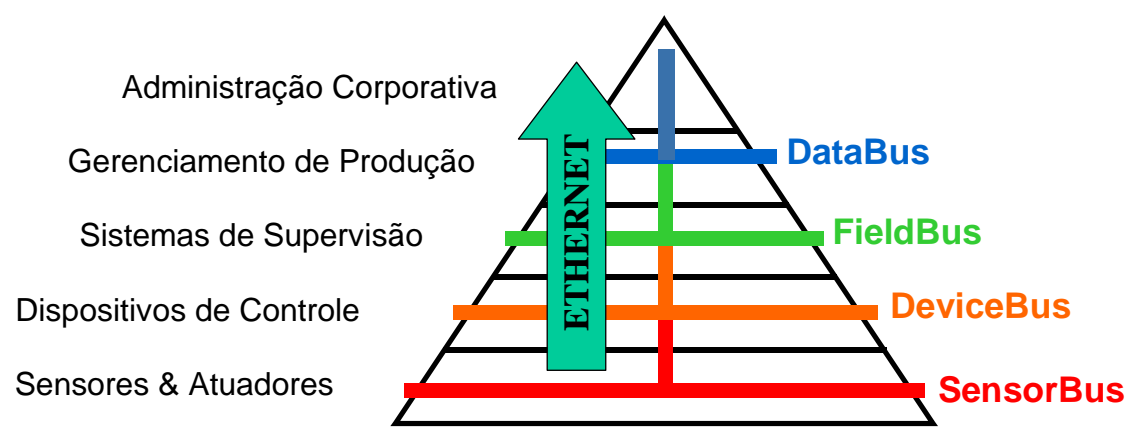

FIGURA 4.8 - Níveis de automação e tipos de redes 
Para aplicações de supervisão, utiliza-se, tipicamente, rede do tipo FieldBus que realiza a coleta de dados e controle de processos.

Segundo INTERBUSCLUB (2001), o aumento do grau de automação em máquinas e sistemas aumentou a necessidade de redes de cabos paralelos devido ao grande número de canais I/O (Inputs/Outputs). Como conseqüência dessa crescente utilização de redes de cabos paralelos, houve o aumento de esforços para sua configuração, instalação, start-up e manutenção. Além disso, cabos paralelos possuem freqüentemente custos elevados, principalmente os utilizados para a transmissão de dados analógicos. Como solução para este problema, surge em meados do final da década de 70 a primeira rede industrial de comunicações, comumente conhecida como Fieldbus. Trata-se de uma rede de comunicação serial, que com apenas um único cabo de comunicação conecta-se a vários I/Os, podendo ainda se comunicar com vários outros níveis de automação (desde os Sensores\&Atuadores até os níveis de Gerenciamento e Administração, dependendo do tipo de rede).

Dentre as diversas vantagens do Fieldbus em relação às redes de cabos paralelos, estão (ilustração na figura 4.9):

- redução de cabos, reduzindo custos e tempo para planejamento, instalação, configuração;

- redução de terminais e gabinetes de controle;

- capacidade de autodiagnóstico, reduzindo tempo de start-up, manutenção e tempos de paradas;

- melhor confiabilidade, com maiores proteções contra falhas em sinais analógicos ;

- possibilidade de comunicação com vários níveis de automação; 


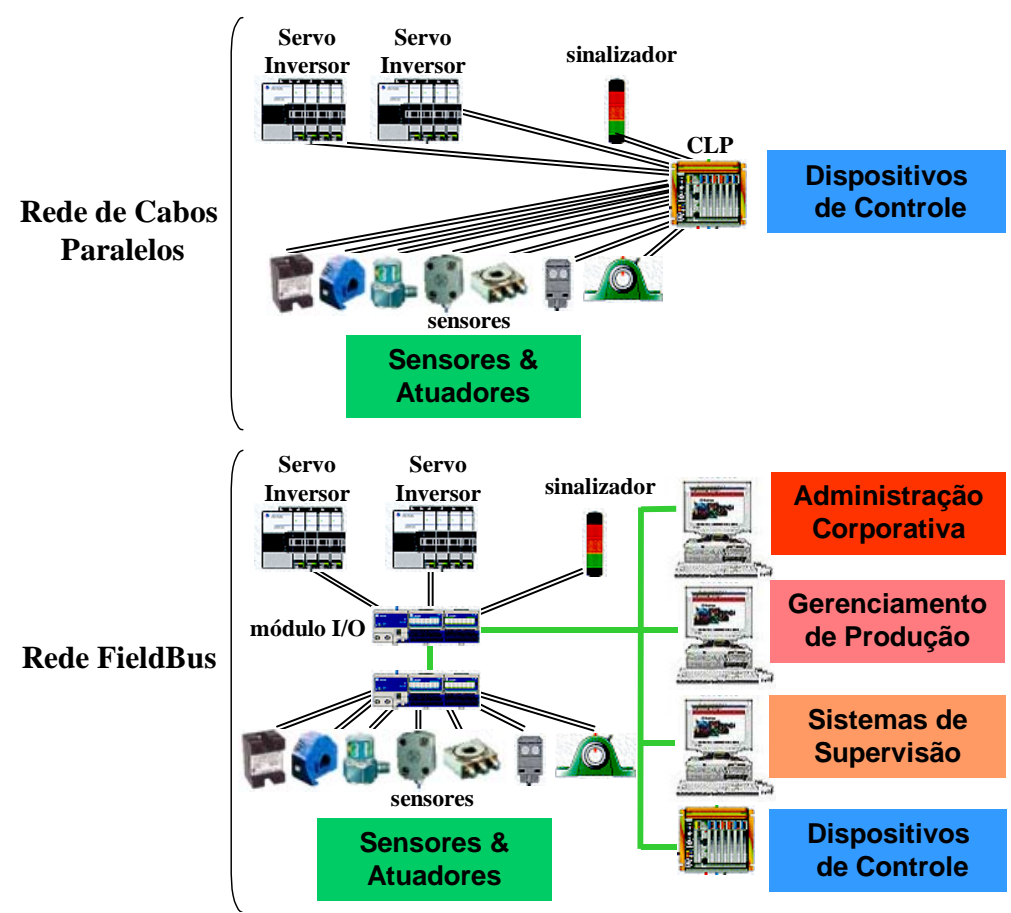

FIGURA 4.9 - Diferença entre redes de cabos paralelos e fieldbus (FERRAZ JR., 2002)

Segundo NCS TIB 04-1 (2004), redes de comunicação (fieldbus) com meio físico baseado em cabos são geralmente utilizadas em fábricas. Isto não é prático para sistemas que cobrem largas áreas geométricas devido ao alto custo de cabos, suportes e instalações. O uso de linhas telefônicas (alugada ou discada) é a solução mais econômica para sistemas de larga cobertura. Linhas telefônicas alugadas são utilizadas para sistemas que requerem conexões on-line com as estações remotas. $\quad$ Este método é de custo elevado já que uma linha por estação será locada indefinidamente. Linhas discadas (dial-up) podem ser utilizadas em sistemas que requerem atualizações de informações em intervalos reguladores (por exemplo, atualizações horárias). Nesta situação, as linhas entre as estações remotas são utilizadas apenas temporariamente. Uma estação pode discar um número particular de uma estação remota, receber informações e enviar comandos. Quando estações remotas não são acessíveis por linhas telefônicas, o uso de comunicação à rádio torna-se uma ótima solução. Conexões on-line também podem ser implementadas via sistemas à rádio. Para localizações onde uma 
conexão direta via rádio não é possível, um rádio repetidor é utilizado para interligar estes locais.

Para a comunicação entre equipamentos, há a necessidade de protocolos (regras) a serem seguidos, e tecnologias a serem utilizadas. Segundo AUTOMACAO.NET (2001) e OPC (2001), os principais protocolos e tecnologias para troca de dados entre hardwares de chão de fábrica e softwares aplicativos são:

COM (Component Object Model) : Disponibiliza uma interface padrão de comunicação entre componentes. Possibilita que uma aplicação utilize recursos de outra ou do sistema operacional.

DCOM (Distributed component object model) : É o COM para aplicações em Rede; disponibiliza objetos remotos e locais; criado para Windows NT.

OLE (Object Linking and Embedding) : Antecessor do COM. Disponibiliza integração entre aplicativos, permitindo troca de vários tipos de informações. Criado pela Microsoft em 1992, OLE é mais flexível, eficiente, e robusto do que o DDE, mas não possui a performance necessária para automação.

DDE (Dynamic Data Exchange) : Nasceu com o Windows 3.0; é um protocolo padrão de troca de dados entre aplicações Windows. Utilizando Driver DDE, é possível coletar dados do chão-de-fábrica em Planilhas Excel, por exemplo. É um protocolo lento, não confiável e foi desenvolvido para trabalhar em uma máquina e modificado para pequenas aplicações em rede (NetDDE). Possui variações como FastDDE e AdvancedDDE que possuem os 
mesmos problemas do DDE original - não foi desenvolvido para aplicações que necessitam de integridade de dados e alta velocidade. Deverá ser totalmente substituído pelo OPC.

NetDDE (Network Dynamic Data Exchange): protocolo para a troca dinâmica de dados entre quaisquer redes suportadas por Windows, como TCP/ IP, NET-BEUI, IPX/ SPX e entre aplicações Windows, como Excel, Word, etc.

OPC (OLE for Process Control) : protocolo padrão de interfaces, propriedades e métodos para o uso de aplicações em controle de processos e automação da manufatura. Baseado nas tecnologias OLE (Object Linking and Embedding) e DCOM (Distributed Component Object Model), o OPC permite uma interface comum de comunicação com diversos dispositivos de controle de processo, indiferentemente do software de controle ou dispositivos no processo.

DLL (Dynamic Linking Libraries) : tipo de tabela que várias aplicações com rotinas comuns podem acessar ao mesmo tempo. Possui velocidade e integridade conforme programação das rotinas de acesso; normalmente é utilizada por aplicativos na mesma máquina.

\subsubsection{Estação SCADA Server}

Na figura 4.10 tem-se em destaque (colorido) a localização da estação SCADA Server dentre todos os componentes típicos de um sistema SCADA. 


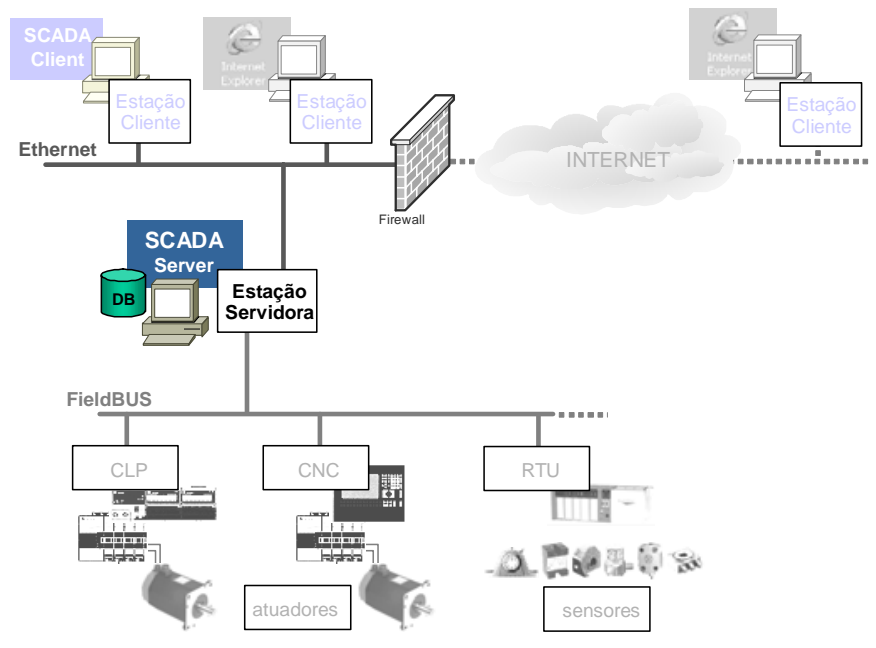

FIGURA 4.10 - Estação SCADA Server

A estação SCADA Server é geralmente constituída de um único computador, mas podendo também ser formada por uma rede de computadores servidores, afirma NCS TIB 041 (2004). As estações SCADA Server fornecem as interfaces homem máquina para os sistemas SCADA. Os computadores processam as informações enviadas e recebidas do chão de fábrica (de/para RTU, CLP, CNC, etc), apresentando-as de forma adequada para que usuários possam trabalhá-las. Diagramas de todo a planta e/ou processo podem ser exibidas em telas para facilitar a identificação com o sistema real. Cada ponto I/O de uma unidade remota pode ser mostrado com uma correspondente representação gráfica. Pode apresentar telas especiais de alarmes, com exibição de valores, descrições, datas/horas e freqüências de ocorrências, bem como telas de configurações de parâmetros de equipamentos de chão de fábrica com controle de acesso.

Segundo NCS TIB 04-1 (2004), historicamente, sistemas SCADA eram fornecidos com hardware, sistema operacional e software incompatíveis com sistemas de outros fornecedores. A expansão de um sistema só era possível através da contratação do fornecedor original. As plataformas de computadores eram caracteristicamente baseadas em arquitetura UNIX, e eram fisicamente removidas das redes de computadores dos outros domínios da companhia. Contudo, com o aumento e a evolução dos computadores pessoais, as redes de 
computadores de companhias cada vez mais se tornam uma só. Como resultado, atualmente muitos sistemas SCADA estão disponíveis para toda a rede de comunicação da empresa, e são implementados em servidores comumente empregados em aplicações de escritório, abrangendo as possibilidades de ampliação e integração com outros sistemas.

\subsubsection{Estações SCADA Client}

Na figura 4.11 tem-se em destaque (colorido) a localização de estações SCADA Clients dentre todos os componentes típicos de um sistema SCADA.

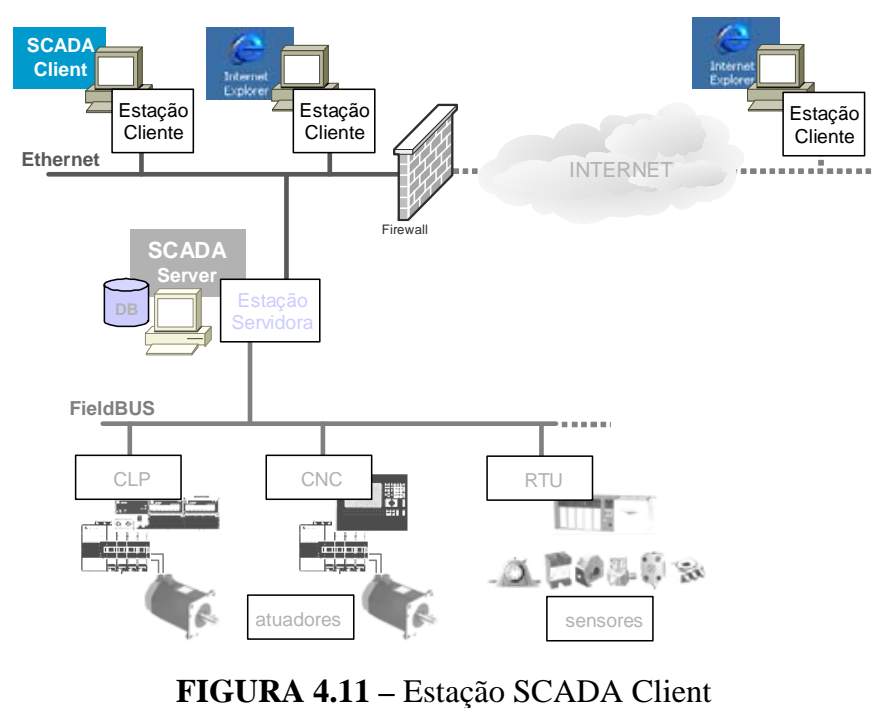

As estações SCADA Clients são geralmente terminais de computadores ligados em rede com a estação SCADA Server. Permitem, aos usuários, o envio e o acesso de informações da estação SCADA Server. A troca de informações entre as estações SCADA Clients e estação SCADA Server podem ser realizadas através de softwares especiais 
(SCADA Client), ou através de navegadores de paginas HTML (browsers), tendo-se, neste último caso, algumas limitações de recursos. Em algumas situações, obedecendo-se as regras de seguranças da rede corporativa (firewall), pode-se até mesmo disponibilizar estas informações para a Internet.

\subsection{Funcionalidades}

A funcionalidade de um sistema SCADA é similar para sistemas DCS (Distributed Control System) encontrados em soluções de automação, com exceção de que os sistemas SCADA geralmente contém aquisição de dados e controle de equipamentos geograficamente distribuídos, diferenciando-se dos sistemas DCS, afirma ENDEAVORENG (2006).

Resumidamente, suas principais funcionalidades são:

- Aquisição de dados: aquisição de dados das estações remotas de I/O e controladores via drivers de comunicação e/ou interfaces OPC e NetDDE.

- Controle: controle automático em malha fechada ou controle via atuação do operador.

- Displays de Processo: representações gráficas dos equipamentos de campo atualizadas automaticamente para retratar uma situação atual, e gráficos em geral, por exemplo de tendência, para acompanhamento de variáveis do processo (vide figura 4.12).

- Standby: sistemas duplicados em espera com a capacidade de tomar o controle no caso de falhas no sistema principal. 
- Integração: permite comunicação com sistemas corporativos, pois suporta SQL/ ODBC (Structured Query Language/ Open Database Connectivity). Integração com aplicativos locais via interfaces OPC, DDE, ActiveX, etc.

- Segurança: Controle de acesso por usuário aos vários componentes do sistema.

- Gerenciamento da Rede: Monitoramento das condições de comunicação da rede.

- Automação: permite automatizar tarefas via scripts, iniciando-as através de eventos.

- Outros: possui banco de dados proprietário, ferramentas de log de dados, relatórios formatados, históricos, receitas, alarmes e CEP (Controle Estatístico de Processos).

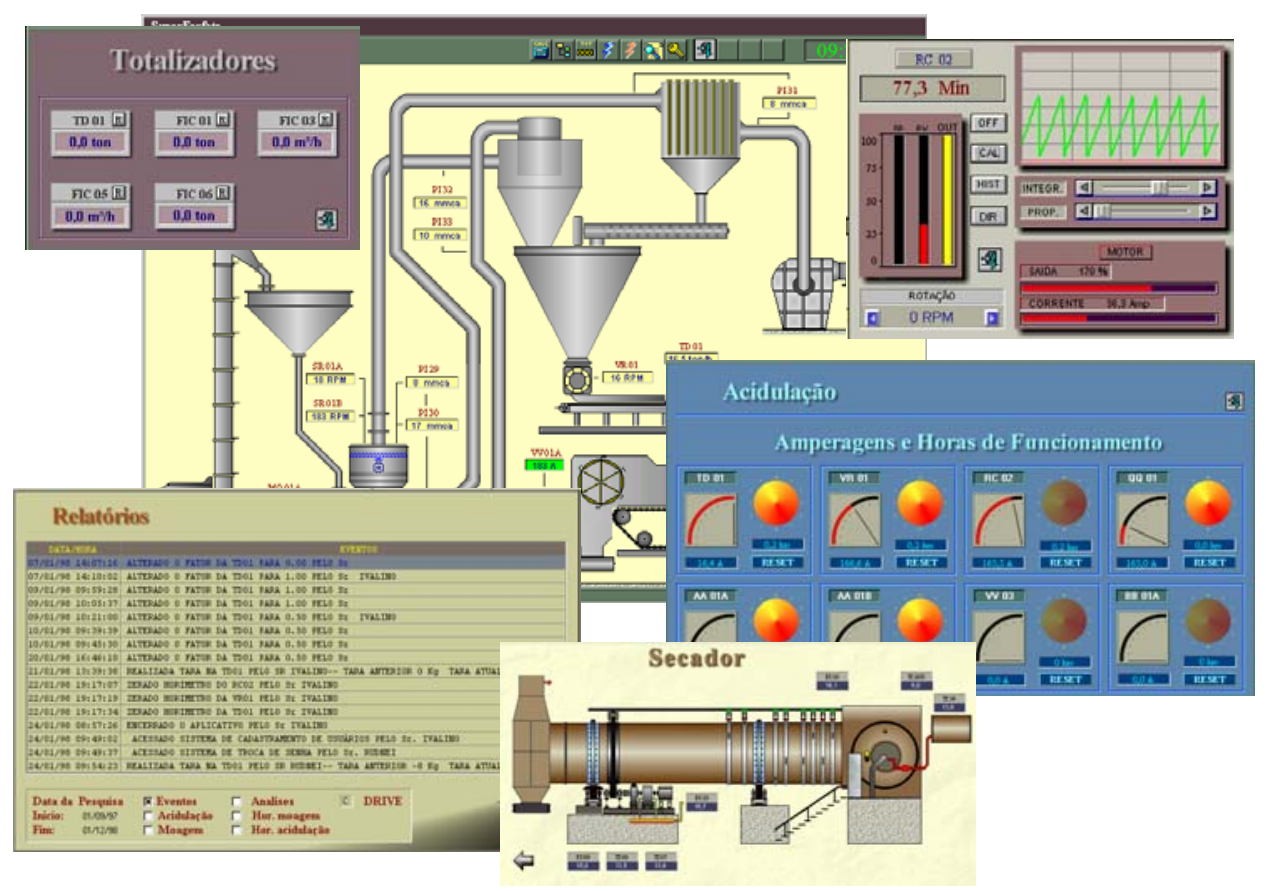

FIGURA 4.12 - Exemplos de telas de supervisão (FERRAZ JR., 2002) 


\subsection{Integração de sistemas}

O chão de fábrica pode ser composto de máquinas de diferentes configurações, com maior ou menor dificuldade de integração com o sistema SCADA e, como conseqüência, integração com os sistemas corporativos e de gestão da produção, tais como sistemas ERP e MES. Máquinas de ambiente PC facilitam esta integração por permitirem a captura de dados utilizando-se de protocolos padrões (por exemplo, OPC, DDE e NetDDE) já disponíveis nos sistemas SCADA, ou utilizando-se de protocolos proprietários, sendo neste caso necessário a compra ou o desenvolvimento de drivers para a comunicação. Quanto às maquinas que não apresentam ambiente PC (ambientes heterogêneos), quando o fabricante não disponibiliza recursos e drivers de comunicação, torna-se difícil a integração das mesmas com os sistemas SCADA, exigindo-se em muitos casos a utilização de módulos digitais e/ou analógicos para a aquisição de sinais (bits, words, sinais analógicos de sensores, etc) que podem ser convertidos em informações, como por exemplo uma combinação de bits (sinais) que indicam uma determinada situação da máquina (informação). Na figura 4.13, tem-se um esquema das possíveis configurações de máquinas de chão de fábrica: máquinas com ambiente PC e de arquitetura aberta ou parcialmente aberta, máquinas com ambiente PC e de arquitetura totalmente fechada e máquinas que não possuem ambiente PC. 


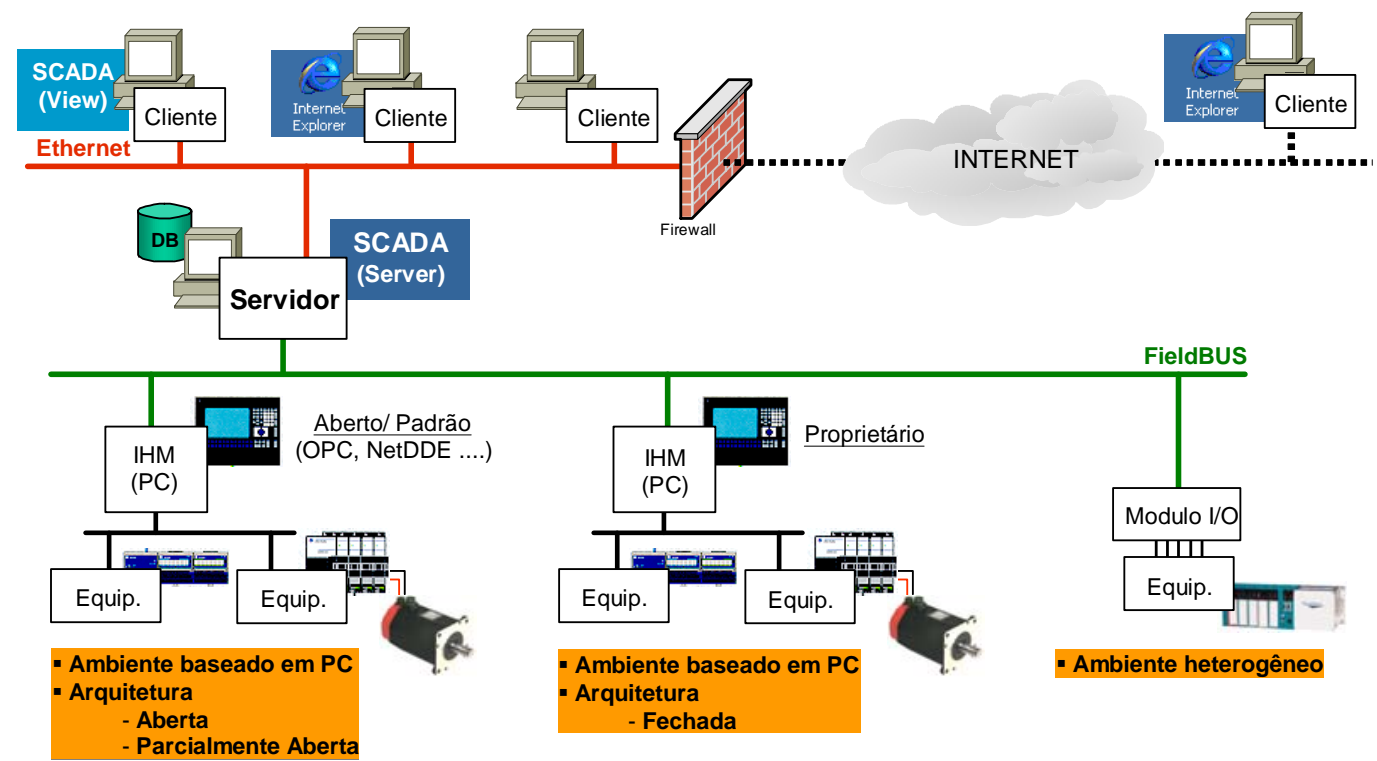

FIGURA 4.13 - Esquema das possíveis configurações de máquinas de chão de fábrica. 


\section{PROPOSTA DE ARQUITETURA DE MONITORAMENTO E SUPERVISÃO EM OPEN CNC}

Basicamente, pode-se classificar a aquisição de informações de chão de fábrica em dois propósitos de automação: sistema de supervisão da produção e sistema de monitoramento do processo, máquina e/ou da ferramenta de corte. Cada sistema de automação, de acordo com suas funcionalidades e informações a serem adquiridas, possui um nível específico de resolução de tempo de aquisição de dados. Sistemas de supervisão possuem, tipicamente, tal resolução da ordem de dias/horas/minutos. As informações oriundas de sistemas de supervisão alimentam desde sistemas de planejamento de atividades corporativas (sistemas ERPs - Enterprise Resource Planning) com base de tempo de 1 dia a 1 mês, até o gerenciamento da produção (sistemas MES - Manufacturing Execution Systems) com taxas de atualizações de informações de 1 a 10 minutos.

Os sistemas de monitoramento possuem normalmente uma resolução de tempo de frações de segundos. Podem ser executados durante o processo (on-line) ou periodicamente (off-line), como, por exemplo, nos intervalos de usinagem de cada peça. Podem ser empregados para o monitoramento do processo, da máquina e/ou da ferramenta de corte.

Na implementação de tais sistemas de automação, as indústrias utilizam diferentes arquiteturas de comunicação para cada nível de resolução de tempo, (vide figura 5.1). 


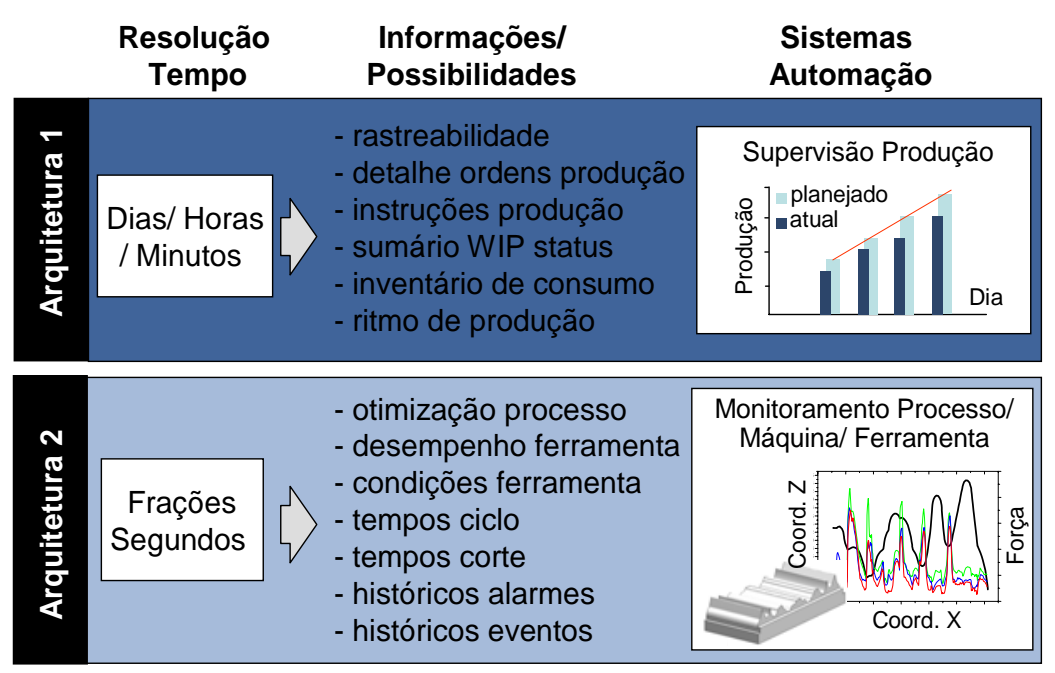

FIGURA 5.1 - Níveis de resolução de tempo para a aquisição de informações de chão de fábrica.

Em um sistema tradicional de monitoramento, a aquisição de informações sobre o processo, máquina e ferramenta de corte dá-se através de uma arquitetura composta por sensores externos (sensores não originalmente instalados nas máquinas ferramenta), unidades de processamento de sinal e um sistema computacional para a interpretação dos dados e geração de respostas (vide figura 5.2). Nesta arquitetura, os componentes de controle (IHM, CNC, CLP e Drivers) da máquina ferramenta são considerados “caixas pretas”, não disponibilizando qualquer informação para o sistema de monitoramento. As informações possíveis de serem adquiridas são oriundas de sensores externos instalados na máquina ferramenta, tais como sensores de emissão acústica, força, temperatura, corrente, etc. Conforme já mencionado anteriormente no capítulo 1, os sensores externos trazem diversas desvantagens, tais como custo, redução da área de trabalho, dificuldades de utilização, necessidade de hardwares adicionais (amplificadores, condicionadores de sinais, entre outros), etc. A instrumentação com tais sensores externos pode ser feita na área de trabalho da máquina (diretamente na peça , na mesa da máquina, no sistema de fixação, etc), na ferramenta de corte, e até mesmo no sistema de controle da máquina ferramenta (CNC, CLP e 
Drivers). Com esta arquitetura é possível a aquisição de informações do processo, da ferramenta, e algumas informações limitadas dos sistemas de controle da máquina ferramenta.

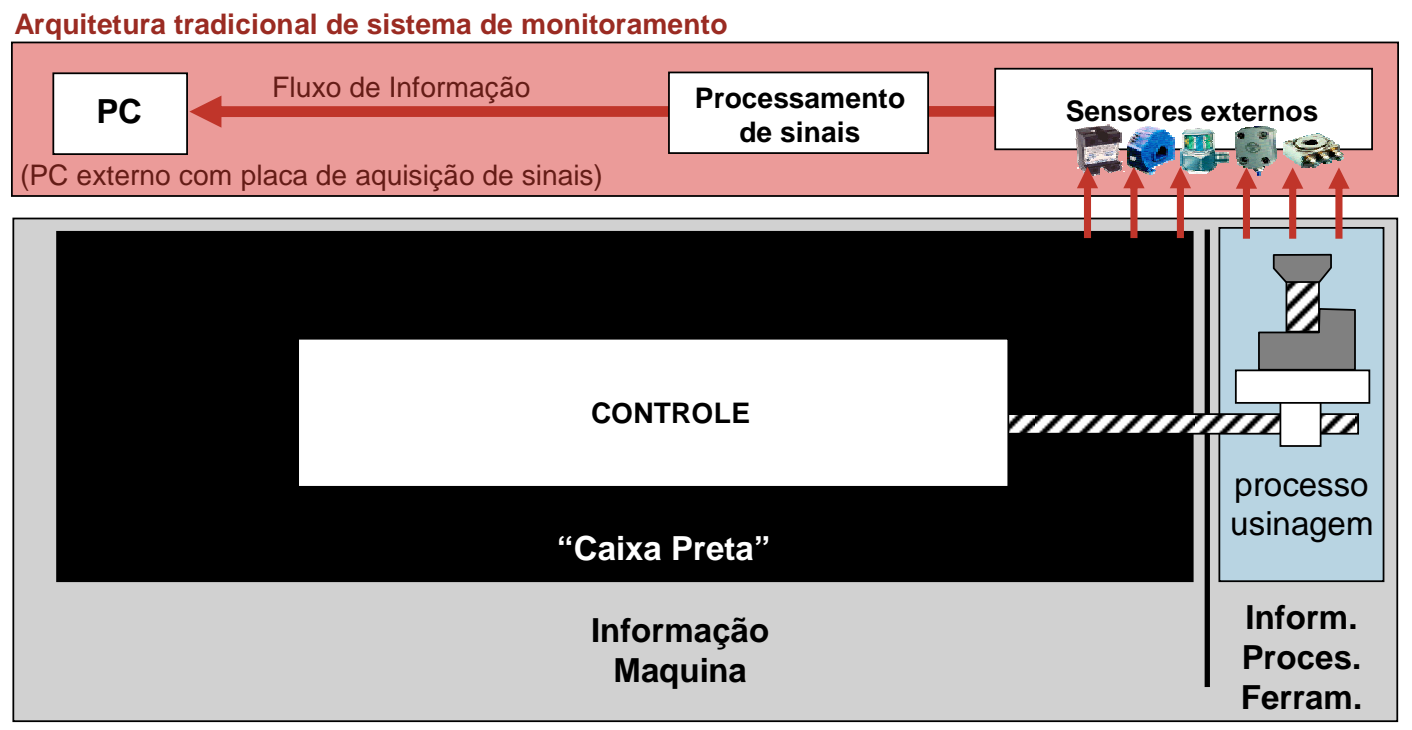

MÁQUINA FERRAMENTA

FIGURA 5.2 - Arquitetura tradicional de sistema de monitoramento.

Quanto aos sistemas de supervisão, estes são amplamente utilizados nos processos contínuos e por bateladas. No entanto, nos processos discretos eles são ainda considerados como novidade, tendo as informações da produção comumente adquiridas com uma resolução de tempo alta (dia, hora e minuto), de forma manual e muitas vezes isoladamente para cada máquina. Tem-se a aquisição automática de informações da produção em algumas situações particulares, tais como em linhas de alta produção de peças seriadas com sistemas automáticos de alimentação de peças controlados por CLPs, em linhas de produção transfer com identificação de peças via tags inseridos em paletes, e em máquinas ferramentas com recursos de registros de dados (datalog). No entanto, as informações da produção são normalmente adquiridas isoladamente para cada máquina através de bases de dados locais, ou de forma limitada quanto às possibilidades de informações possíveis de serem adquiridas quando utilizando resoluções de tempo menores e de forma integrada com as demais máquinas ferramenta que compõe o sistema de manufatura. Além disso, estas situações 
particulares não abrangem os sistemas de manufatura de peças variadas e/ou de lotes pequenos, em que normalmente não são utilizados sistemas automáticos de alimentação de peças e linhas transfer para a produção.

\subsection{Lacunas preenchidas por esta proposta}

Pode-se concluir que há lacunas a serem preenchidas nos sistemas atuais de monitoramento e supervisão de processos discretos. Inicialmente, há a necessidade de um melhor acompanhamento de informações da produção, devendo estas ser adquiridas de forma automática e com menores tempos de atualizações, bem como de forma integrada com todas as máquinas ferramenta que compõe o sistema de manufatura. Uma outra grande vantagem seria ter a possibilidade de desenvolver sistemas de monitoramento e supervisão utilizando somente os recursos já disponíveis nas máquinas ferramenta CNC, sem a necessidade de instalação de equipamentos adicionais (sensores, condicionadores, etc). Finalmente, nota-se a necessidade de uma arquitetura de comunicação em comum para ambos os sistemas de automação, possibilitando a integração dos dois níveis de resolução de tempo (o de supervisão e o de monitoramento), o que permitiria a supervisão e o monitoramento simultaneamente.

LÖDDING e OLIVEIRA (2005) definem micromonitoramento da produção como o monitoramento de peças (monitoramento do progresso da ordem de produção) respectivo ao monitoramento da máquina (monitoramento do estado de máquina), e com alta exatidão de medida de tempo. Aplicações convencionais de supervisão da produção tipicamente reúnem informações para um lote inteiro e as atribuem a dias ou horas. Um sistema de micromonitoramento pode avaliar peças individualmente, relacionando-as ao estado da máquina, com uma precisão de segundos (ou frações do mesmo). Permite uma integração dos dados coletados individualmente de cada máquina de uma linha de produção com os dados de 
cada peça de um lote. Assim, é possível avaliar a influência dinâmica de uma perturbação em uma máquina na produtividade de uma linha inteira de produção, concluem LÖDDING e OLIVEIRA (2005). Micromonitoramento combina um alto nível de detalhe com relação ao objeto monitorado, e um alto nível de exatidão de medida de tempo. Desta forma, com o micromonitoramento da produção define-se um novo nível de resolução de tempo para a aquisição de informações de chão de fábrica, o de minutos/segundos, com novas informações da produção e possibilidades de sistemas de automação, conforme exibido na figura 5.3. O conceito de micromonitoramento proposto recentemente lança mais um desafio no sentido de padronização de arquiteturas genéricas. Seria desejável uma arquitetura universal que atenda a todos os níveis de resolução temporal e de detalhamento de informações.

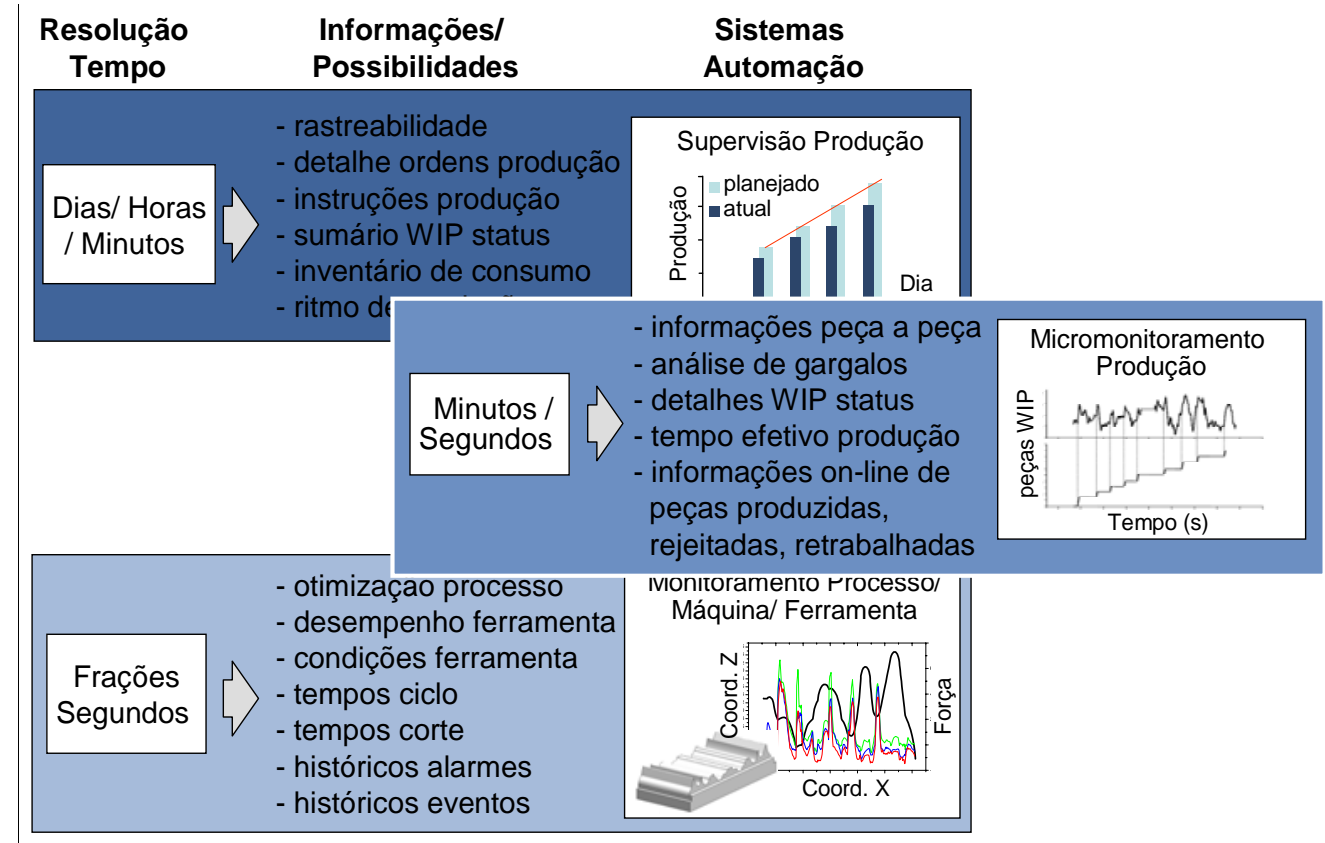

FIGURA 5.3 - Níveis de resolução de tempo para sistemas de supervisão, micromonitoramento da produção e sistemas de monitoramento.

A arquitetura sugerida neste trabalho busca atender de forma única a todos os níveis de resolução de tempo de aquisição de informações de acordo com os requisitos desejados, além 
de permitir a sua aplicação na produção de forma automática, integrada e com baixos tempos de atualizações (vide figura 5.4).

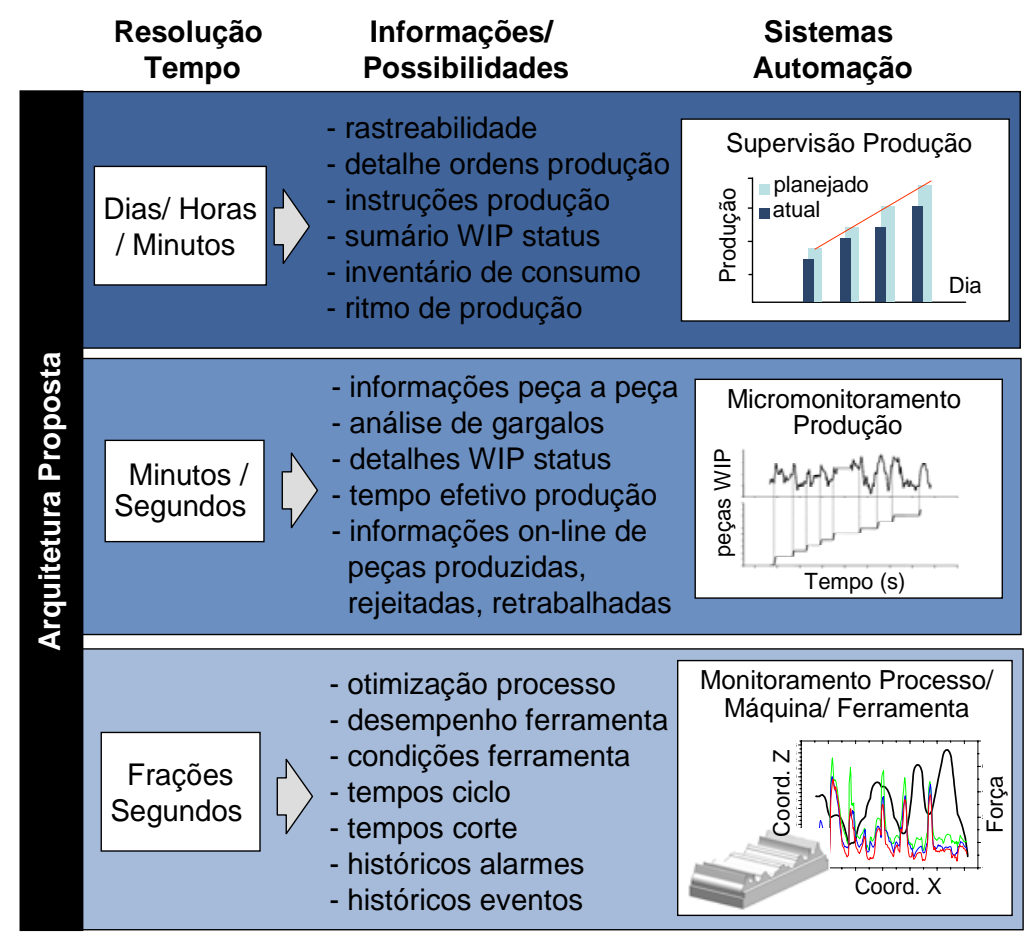

FIGURA 5.4 - Arquitetura proposta abrangendo todos os níveis de resolução de tempo de aquisição de informações.

\subsection{Descrição da arquitetura proposta}

Utilizando as vantagens dos controles de arquitetura aberta para a implementação de sistemas de automação e o conceito de micromonitoramento da produção, é apresentada uma proposta inovadora de arquitetura universal para explorar as potencialidades de ambas as tecnologias. Busca-se implementar e integrar sistemas de supervisão e de monitoramento (incluindo o micromonitoramento) em CNCs de arquitetura aberta baseado em open HMI, utilizando uma única arquitetura e somente os recursos já disponíveis na máquina ferramenta 
tais como: sensores, rede de comunicação, condicionadores/amplificadores de sinais, base de dados, softwares aplicativos, etc.

A arquitetura proposta é composta por um PC interligado à rede de comunicação dos componentes de controle da máquina ferramenta: IHM, CNC, CLP, Drivers de potência e painel de operação. Pode-se, deste modo, adquirir dados dos mesmos, bem como dos softwares aplicativos e base de dados da máquina ferramenta. Assim, evita-se o uso de sensores externos e de hardwares para o processamento e a aquisição de sinais. Através do acesso à rede de comunicação dos componentes de controle da máquina ferramenta é possível adquirir uma variedade de dados e informações, tais como: progresso da produção (provenientes da IHM, CNC e CLP), parâmetros tecnológicos do processo (provenientes de sensores, atuadores e Drivers de potência), e, a partir da combinação dessas duas informações, a rastreabilidade de informações tecnológicas de cada peça produzida. Baseando-se nesses dados, uma série de informações úteis, integrando os níveis de supervisão e monitoramento, pode ser obtida, como:

Produção: ritmo de produção, total de peças produzidas, rejeitadas e retrabalhadas, eventos de paradas, tempo efetivo de produção, status detalhados de WIP;

Processo: tempos de ciclo, tempos de corte, velocidades, avanços, consumo de potência, e demais condições de processo;

Ferramenta: número de peças produzidas por ferramenta ou por aresta de corte, condições da ferramenta;

Eventos de Máquina: histórico de alarmes, freqüência de ocorrências, tipos e descrições;

Esta arquitetura não requer o uso de sensores adicionais, além dos já instalados originalmente na máquina ferramenta. Contudo, sensores externos podem ser integrados na arquitetura proposta quando necessário, conforme exemplificado no item 7.2.2. apresentado a 
seguir. Para esta arquitetura proposta, o principal investimento requerido está no software. CNCs com ambientes homogêneos (PC) e com open HMI permitem ao usuário escolher a plataforma de desenvolvimento de aplicativos, tais como LabView, Visual Basic, Delphi, entre outras, evitando o uso obrigatório de softwares de fornecedores específicos, tais como alguns oferecidos por fabricantes de CNC com alto custo e limitações de recursos.

Utilizando-se dessa arquitetura, é possível a implementação integrada de sistemas de supervisão e monitoramento, conforme ilustrado na figura 5.5 .

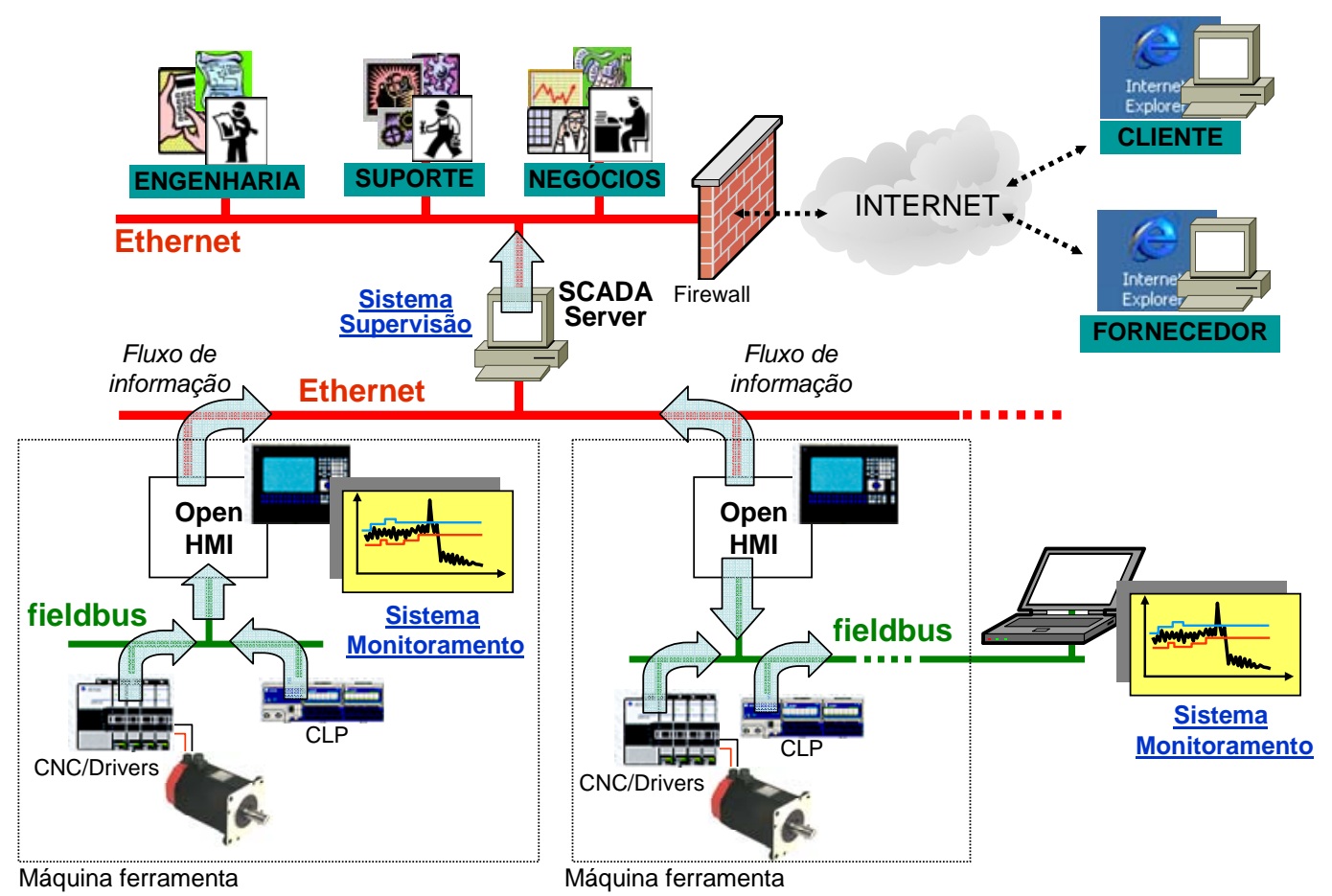

FIGURA 5.5 - Exemplos de aplicações da arquitetura proposta: sistema de monitoramento e supervisão.

No sistema de supervisão, tem-se uma estação SCADA Server adquirindo informações das máquinas ferramentas de um chão de fábrica através de uma comunicação direta com os mesmos. Torna-se possível a geração, registro e exibição de milhares de informações sobre a máquina ferramenta, produção e o processo de usinagem, o que é essencial para a integração com sistemas de gerenciamento da produção e administração corporativa, tais como sistemas MES (Manufacturing Execution Systems) e ERP (Enterprise Resource Planning). As 
informações podem ser compartilhadas para outros departamentos do sistema de manufatura (engenharia, suporte, negócios) através de redes locais Ethernet, e, obedecendo-se as regras de segurança da rede corporativa (firewall), até mesmo disponibilizar estas informações para a Internet.

Os sistemas de monitoramento podem ser implementados diretamente nos PCs das IHM’s das máquinas ferramenta, ou em PCs externos adicionados na rede interna (fieldbus) dos componentes de controle da máquina ferramenta. Com este tipo de arquitetura, pode-se desenvolver sistemas de monitoramento com aquisição on-line de informações provenientes da IHM, CNC, CLP e Drivers de potência, e até mesmo sincronizar a aquisição de tais informações com sinais provenientes de sensores adicionais instalados na máquina ferramenta (vide capítulo 7.2.2).

A seguir são descritas, com detalhes, cada opção de configuração da arquitetura proposta, possível de ser utilizada em CNCs de arquitetura aberta baseado em open HMI para a implementação dos sistemas de automação de supervisão e monitoramento. 


\subsubsection{Opção 1: Sistema de automação em PC externo interligado à rede interna de controle}

Nesta opção, o sistema de monitoramento e/ou supervisão é implementado em um PC externo (destaque em amarelo na figura 5.6). O PC externo, com hardware adequado (placa RS485), é configurado para tornar-se um ponto adicional da rede de comunicação interna (fieldbus) de controle da máquina ferramenta. Assim, obtem-se informações do processo, ferramenta, máquina e da produção através de trocas de informações diretas com os componentes desta rede de comunicação, tais como a IHM, CNC, CLP e Drivers de potência. Torna-se possível até mesmo o acesso de dados de aplicativos e da base de dados local do PC da IHM.

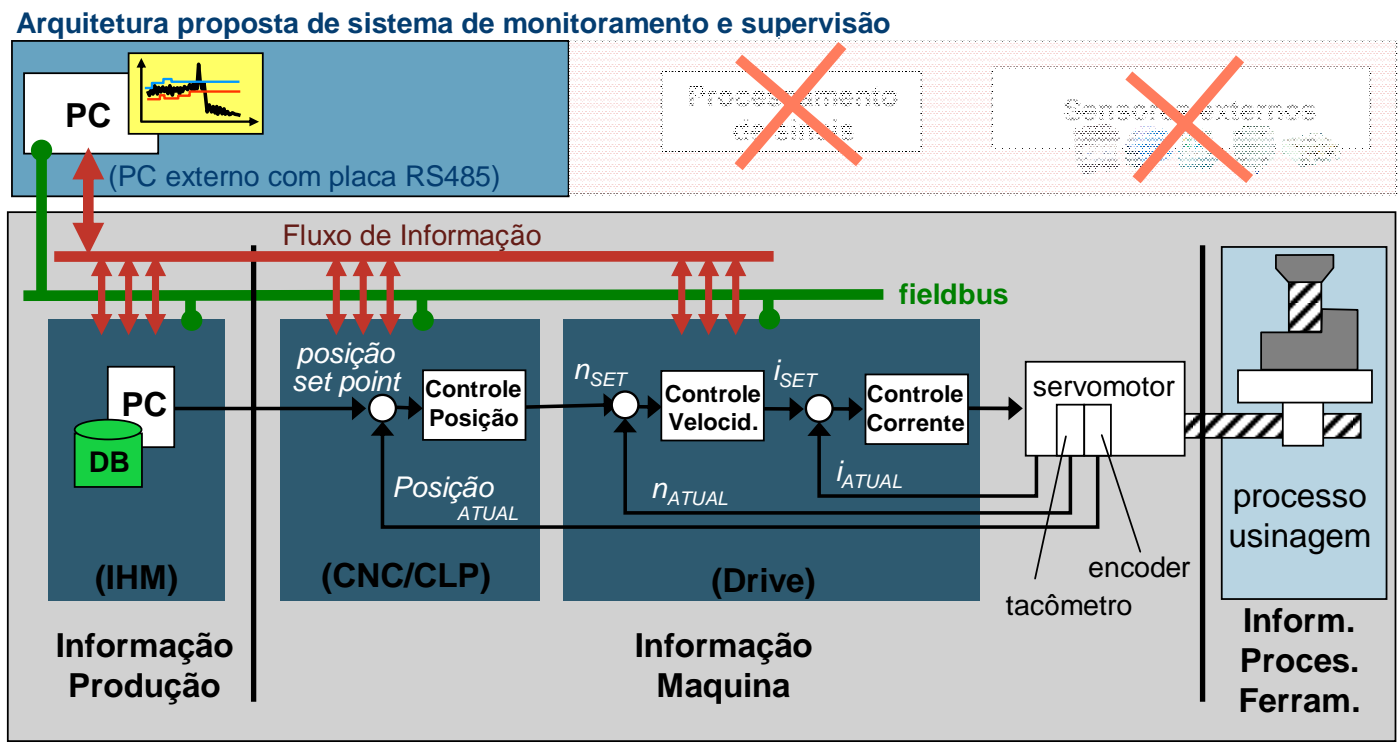

MÁQUINA FERRAMENTA

FIGURA 5.6 - Arquitetura proposta com sistema de automação em PC externo interligado à rede interna de controle. 


\subsubsection{Opção 2: Sistema de automação em PC externo interligado via PC da IHM}

Nesta opção, o sistema de monitoramento e/ou supervisão também é implementado em um PC externo (destaque em amarelo na figura 5.7). No entanto, a comunicação e a integração entre o PC externo e a máquina ferramenta dá-se através do PC da IHM via rede com padrão Ethernet TCP/ IP. Portanto, tendo-se o PC da IHM como intermediário, tem-se a comunicação do sistema de automação com a máquina ferramenta, obtendo-se dados da IHM, CNC, CLP, Drivers de potência, etc, e dos aplicativos e base de dados local do PC da IHM.

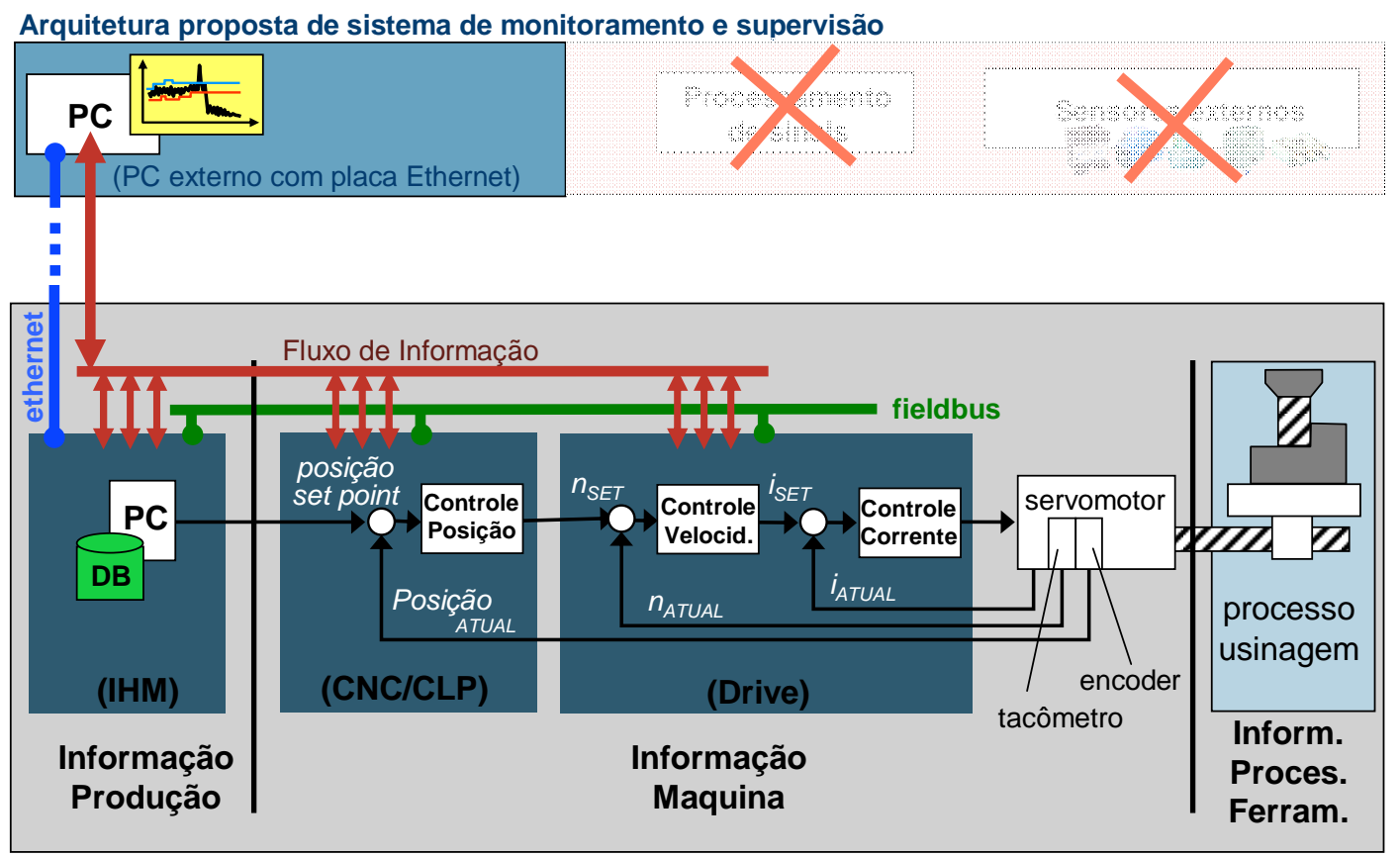

MÁQUINA FERRAMENTA

FIGURA 5.7 - Arquitetura proposta com sistema de automação em PC externo interligado via PC da IHM. 


\subsubsection{Opção 3: Sistema de automação no próprio PC da IHM}

Tendo o controle da máquina ferramenta uma IHM baseada em PC (open HMI), tornase possível a implementação de sistemas de automação no próprio PC da IHM (destaque em amarelo na figura 5.8). Com esta arquitetura, também se tem as mesmas possibilidades de aquisição de informações dos componentes de controle da máquina ferramenta. Evita-se o uso de PCs externos e de hardwares para a comunicação com a rede interna de controle. No entanto, deve-se ter o cuidado de desenvolver aplicativos que não excedam a capacidade de processamento do PC da IHM e não entrem em conflito com os aplicativos já existentes, evitando-se um comprometimento das funcionalidades da IHM.

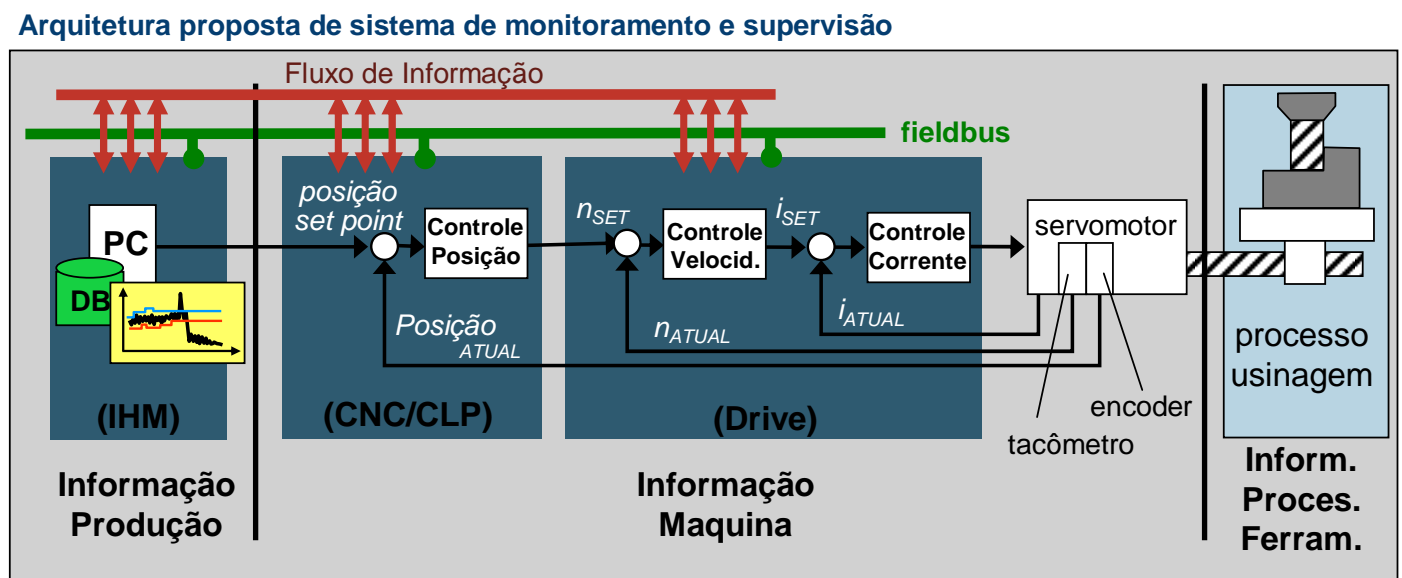

MÁQUINA FERRAMENTA

FIGURA 5.8 - Arquitetura proposta com o sistema de automação no próprio PC da IHM.

Foi apresentada, com detalhes, cada opção de configuração da arquitetura proposta, possível de ser utilizada em CNCs de arquitetura aberta baseados em open HMI. Todas as opções utilizam a mesma filosofia proposta que é a de desenvolver sistemas de monitoramento e supervisão de forma integrada, com um única arquitetura, utilizando somente os recursos disponíveis nas máquinas ferramentas e realizando a aquisição de informações de forma automática com resoluções de tempo compatíveis (frações de 
segundos). Adotando-se qualquer uma das opções apresentadas, é possível a implementação e a execução simultânea de sistemas de supervisão e monitoramento. 


\section{APLICAÇÕES DA ARQUITETURA PROPOSTA EM CNCS}

Conforme mencionado no capítulo 1, dentre as diversas técnicas de monitoramento e supervisão, o presente projeto de doutorado explora as vantagens das arquiteturas abertas de ambientes PCs de CNCs modernos. Quanto aos tipos de arquiteturas abertas, focou-se na arquitetura híbrida, ou open HMI, em que o cerne do CNC permanece fechado, no entanto apresentando uma IHM baseada em PC, com padrões e recursos abertos (não proprietários) para a integração e implementação de aplicativos.

Os sistemas de monitoramento e supervisão foram estudados e implementados nos dois modelos de CNCs mais utilizados pela indústria:

- SIEMENS (Sinumerik 810D e 840D): open HMI e de ambiente PC

- GE-FANUC (Serie 180i): open HMI e de ambiente PC

No entanto, outros tipos de controle foram estudados para uma melhor compreensão e abrangência de análise. Teve-se acesso ao comando CNC ECS (open HMI e de ambiente PC) através de trabalhos com a EMBRAER, e ao comando SIEMENS FM-NC (arquitetura fechada, sem ambiente PC) através da empresa TRW Fuji Valve (Tennessee - EUA). Apesar dos exemplos apresentados usarem como base dois modelos de CNCs, estes apresentam uma semelhança grande com outros tipos de CNCs disponíveis no mercado, tais como os ECS, MDSI, etc, em que se tem um ambiente PC nas suas interfaces homem-máquina e protocolos padrões e/ou bibliotecas proprietários para comunicação com aplicativos. Sendo assim, as arquiteturas e exemplos de aplicações de monitoramento e supervisão apresentados para estes dois tipos de CNCs servem de base para outros tipos de CNCs de arquitetura open HMI. 
A seguir, tem-se uma breve descrição dos CNCs SIEMENS (Sinumerik 810D e 840D)

e GE-FANUC (Serie $x x 0$ i), e posterior apresentação de propostas de arquitetura para a implementação de sistemas de monitoramento e supervisão em tais CNCs.

\subsection{Arquitetura de CNCs: SIEMENS e GE-FANUC}

Para facilitar a compreensão das arquiteturas CNCs da SIEMENS e GE-FANUC, pode-se dividi-las em:

1. IHM

2. CNC/ CLP

3. interface de comunicação

\subsubsection{SIEMENS (Sinumerik 810D/ 840D)}

\section{IHM}

A IHM dos comandos SIEMENS é basicamente composta por um PC (Personal Computer) e um sistema operacional Windows (Win95/ NT). Seu software de IHM é o MMC (Man Machine Interface) que possui uma aplicação OEM (Original Equipment Manufacturer) para a operação da máquina e a comunicação com outros PC via rede Ethernet.

\section{CNC/ CLP}

O CNC e o CLP são integrados, e possuem hardware e sistema operacional proprietários. 


\section{Interface de comunicação}

A interface de comunicação entre a IHM e o CNC/ CLP dá-se através de um meio físico RS-485 com uma comunicação proprietária: protocolo MPI (Multipoint Interface), para CNCs 810D, e OPI (Operator Panel Interface) para CNCs 840D; ou uma comunicação aberta: protocolo ProfiBus DP.

A integração entre a IHM e o CNC/ CLP é realizada através de um servidor DDE (Dynamic Data Exchange), o NCDDE-Server. Assim, o software da IHM (o MMC) realiza comunicação indireta com o CNC/ CLP através de um servidor DDE (NC-DDE Server) e protocolo DDE.

A IHM permite a instalação de placas de rede Ethernet/ Fast-Ethernet, suportando redes locais (LAN - Local Area Network) e sistemas DNC (Distributed Numerical Control) para o gerenciamento e distribuição de programas CN.

A interface de comunicação com os módulos I/O (Input / Output) dá-se por uma rede fieldbus de arquitetura aberta, o ProfiBus DP.

Quanto à comunicação com os drivers, tem-se uma comunicação proprietária fechada.

A seguir, na figura 6.1, tem-se um esquema da arquitetura de CNCs SIEMENS.

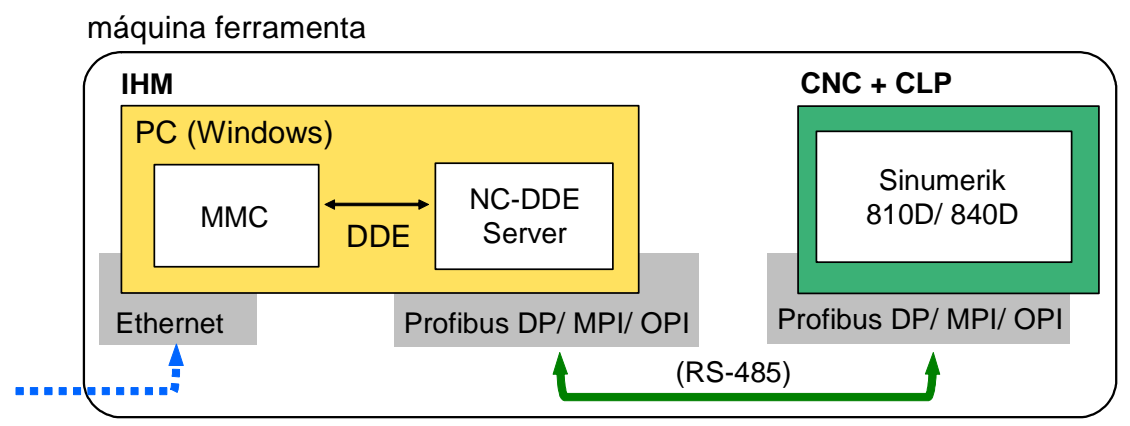

FIGURA 6.1 - Arquitetura de CNCs SIEMENS 


\subsubsection{GE-FANUC (Serie $X X 0 \mathrm{i})$}

\section{IHM}

A IHM dos comandos GE-FANUC também é, basicamente, composta por um PC (Personal Computer) e um sistema operacional Windows (WinCE/ NT). Seu software IHM é o BOP (Basic Operation Package).

\section{CNC/ CLP}

O CNC e o CLP são integrados, e possuem hardware e sistema operacional proprietários. A nomenclatura utilizada pela GE-FANUC para se referenciar ao CLP é PMC (Programmable Machine Control).

\section{Interface de comunicação}

A interface de comunicação entre a IHM e o CNC/ CLP dá-se através de uma comunicação proprietária: rede HSSB (High Speed Serial Bus) de fibra óptica ou rede Ethernet, e protocolo FOCAS1 (Fanuc OpenFactory CNC API Specification).

A interface de comunicação com os módulos I/O (Input / Output) dá-se por uma rede fieldbus.

Quanto à comunicação com os drivers, tem-se uma comunicação proprietária fechada: fibra óptica e protocolo FSSB (Fanuc Serial Servo Bus).

A IHM permite a instalação de placas de rede Ethernet/ Fast-Ethernet, suportando redes locais (LAN) e sistemas DNC para o gerenciamento e distribuição de programas CN. 
A figura 6.2 apresenta um esquema da arquitetura de CNCs GE-FANUC.

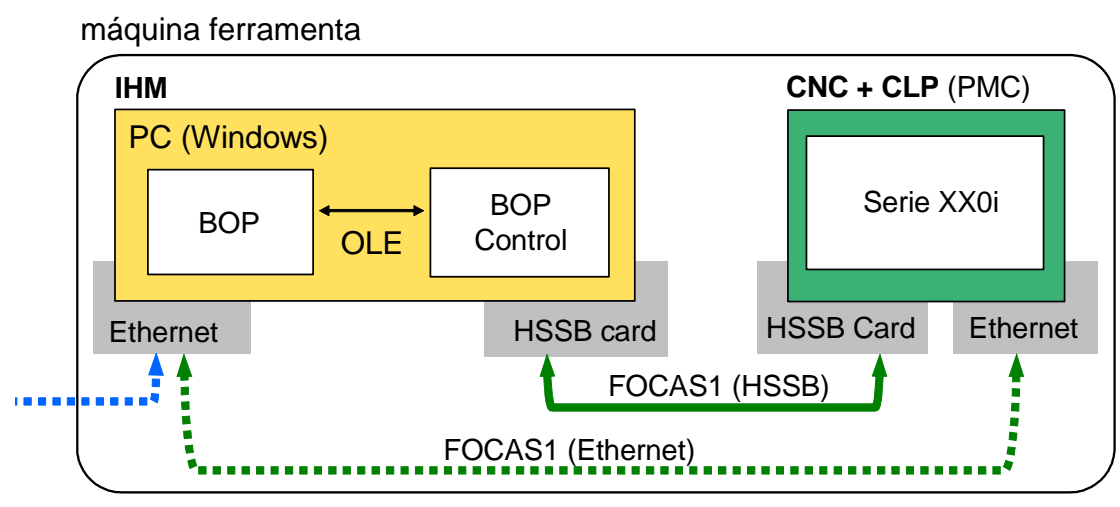

FIGURA 6.2 - Arquitetura de CNCs GE-FANUC

\subsection{Exemplos de Aplicação}

Nos sistemas de monitoramento, o tipo de arquitetura de comunicação é um fator crítico devido à necessidade de tempos curtos de resposta (alta velocidade na troca de dados), principalmente se os mesmos forem implementados como sistemas de monitoramento on-line, ou seja, execução durante o processo de usinagem. Além disso, se o monitoramento for realizar algum tipo de controle do processo, o fator determinístico (troca de dados em intervalo fixo de tempo) da rede de comunicação passa a ser imprescindível. Quanto aos sistemas de supervisão, em que somente coletam-se dados de processo, produção e dados tecnológicos da máquina, a velocidade e o intervalo de troca de dados (determinismo) não são tão críticos quanto nos sistemas de monitoramento. No entanto, o volume de informações trocadas, a possibilidade de comunicação simultânea com várias máquinas ferramentas, bem como os tipos de dados que podem ser coletados, são fatores decisivos para tal sistema. Assim, nesta condição, deve-se utilizar um tipo de rede de comunicação que suporte alto volume de tráfego de informações com comunicação simultânea entre máquinas e sem se 
preocupar com o fator determinístico da mesma, ou seja, podendo-se utilizar de redes probabilísticas.

Levando em consideração essas particularidades de características exigidas de redes de comunicação, têm-se, a seguir, propostas de arquiteturas de comunicação para sistemas de monitoramento e supervisão separados por cada tipo de CNC estudado (SIEMENS e GEFANUC), conforme exposto na tabela 6.1. abaixo.

TABELA 6.1 - Exemplos de arquiteturas de comunicação para sistemas de monitoramento e supervisão

\begin{tabular}{|c|c|c|}
\hline CNC & aplicação & Arquitetura \\
\hline \hline \multirow{2}{*}{$\begin{array}{c}\text { SIEMENS } \\
\text { (Sinumerik 810D/ 840D) }\end{array}$} & supervisão & rede Ethernet TCP/IP e protocolo NetDDE \\
\cline { 2 - 3 } & monitoramento & rede RS-485 MPI/OPI e protocolo DDE \\
\hline \multirow{2}{*}{$\begin{array}{c}\text { GE-FANUC } \\
\text { (Serie } X X 0 i)\end{array}$} & supervisão & rede Ethernet TCP/IP e protocolo FOCAS1 \\
\cline { 2 - 3 } & monitoramento & rede fibra óptica HSSB e protocolo FOCAS1 \\
\hline
\end{tabular}

As arquiteturas foram sugeridas de forma separada para garantir um melhor desempenho das mesmas em cada tipo de sistema de automação. No entanto, cada uma delas pode ser utilizada para ambos os sistemas de automação (monitoramento e supervisão) simultaneamente.

\subsubsection{SIEMENS (Sinumerik 810D e 840D)}

SISTEMA DE SUPERVISÃO: rede Ethernet TCP/ IP e protocolo NetDDE

Nessa arquitetura, tem-se um PC externo com um aplicativo de supervisão desenvolvido em qualquer plataforma que suporte o protocolo NetDDE (Network Dinamic 
Data Exchange), como por exemplo o LabView. Neste PC externo é executado o sistema de supervisão e a comunicação bilateral com a IHM da máquina ferramenta (vide figura 6.3).

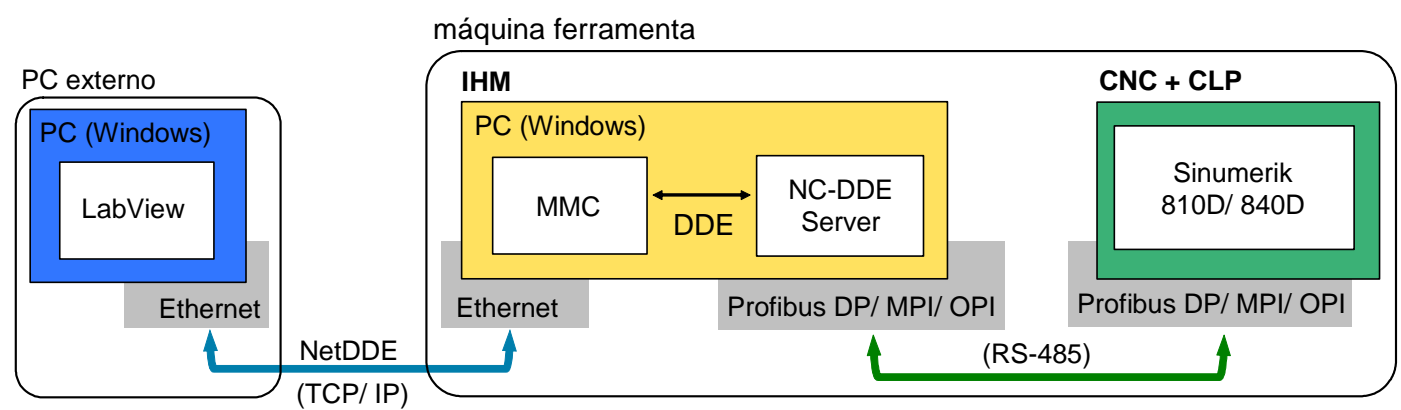

FIGURA 6.3 - Arquitetura de comunicação via rede Ethernet (TCP/ IP) e protocolo NetDDE

A comunicação e integração são realizadas entre o PC externo (com o sistema de supervisão e de comunicação) e o PC da IHM da máquina-ferramenta. A comunicação é efetuada via rede com padrão Ethernet TCP/ IP. A integração entre o PC externo e o CNC/ CLP é realizada através do servidor DDE, o NCDDE-Server, instalado no PC da IHM. Assim, o software de supervisão realiza comunicação indireta com o CNC/ CLP através desse servidor DDE e protocolo DDE adaptado para comunicação em rede, o NetDDE.

Esse tipo de arquitetura permite a comunicação simultânea e a longa distância entre um PC externo e várias outras máquinas ferramentas que possuem um DDE Server e uma rede Ethernet, ou seja, que permitam o uso do protocolo NetDDE para acesso a suas informações (vide esquema na figura 6.4). Assim, há uma comunicação e integração entre o PC externo, com o sistema de supervisão, e cada PC das IHMs das máquinas ferramenta. 


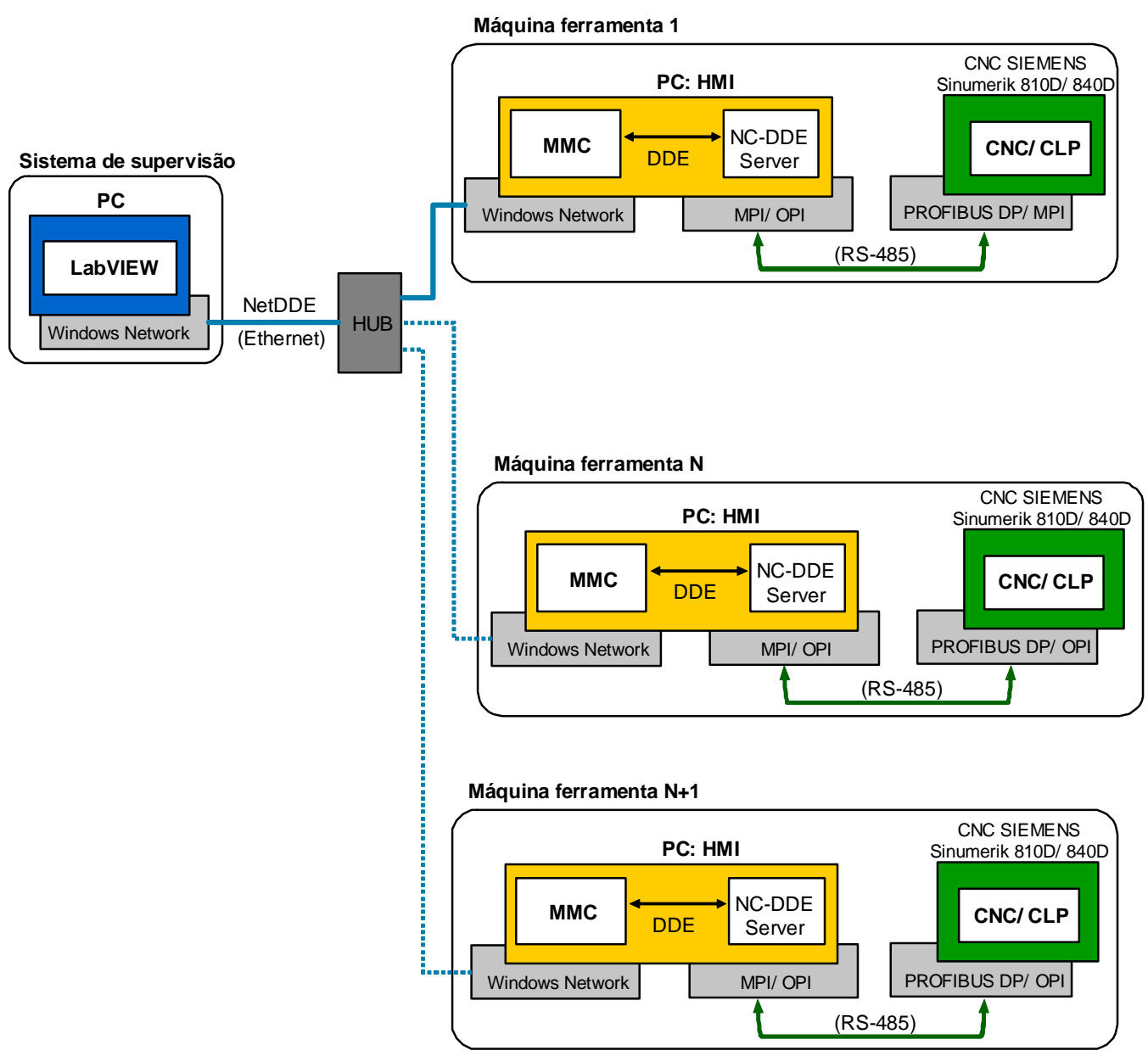

FIGURA 6.4 - Exemplo de arquitetura de supervisão com CNCs SIEMENS Sinumerik 810D/ 840D

SISTEMA DE MONITORAMENTO: rede RS-485 (MPI /OPI) e protocolo DDE

Nesta arquitetura, buscou-se obter uma comunicação determinística e de alta velocidade, sem a necessidade de longas distâncias entre os nós de comunicação e os altos volumes de informações trocadas. Assim, propõe-se uma comunicação direta entre um PC externo e o CNC/ CLP da máquina-ferramenta, evitando o PC da IHM como intermediário. O PC externo executa um aplicativo para o monitoramento e a comunicação, desenvolvido em LabView ou em qualquer outra linguagem que suporte o protocolo DDE. O PC externo é inserido como um ponto adicional na rede de comunicação interna da máquina ferramenta, que é composta por um meio físico RS-485 com protocolos MPI (MultiPoint Interface), para o CNC 810D, ou OPI (Operator Panel Interface), para o CNC 840D, e protocolo DDE, ao 
invés de uma rede Ethernet TCP/ IP e protocolo NetDDE como foi proposto para os sistemas de supervisão. Para tal, tem-se a necessitade de utilizar uma placa de comunicação Profibus (CP 5611 - SIEMENS) e um servidor DDE (NC-DDE Server) no PC externo. A placa de comunicação Profibus (CP 5611) gerencia toda a camada física e a camada de rede da comunicação MPI e/ou OPI. O servidor DDE (NC-DDE Server), na camada de aplicação, “encapsula” as particularidades dessa rede, permitindo uma comunicação através de um protocolo padrão, o DDE. Está configuração permite um aumento da taxa de aquisição e uma melhor estabilidade de comunicação (determinismo) em comparação com a comunicação via rede Ethernet TCP/ IP e protocolo NetDDE (vide figura 6.5).
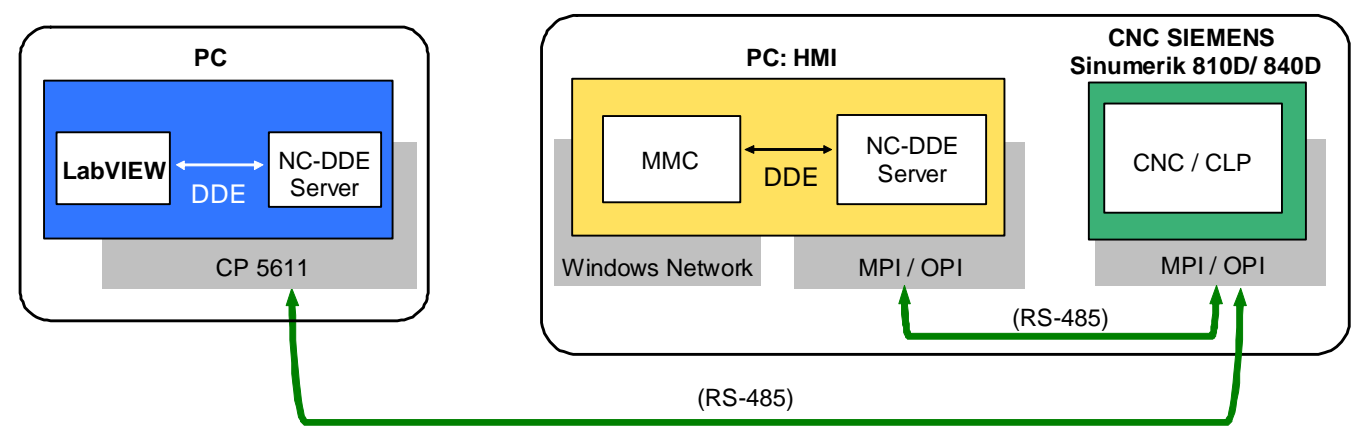

FIGURA 6.5 - Arquitetura de comunicação via rede RS-485 (MPI/ OPI) e protocolo DDE, utilizando um PC externo

Pode-se também implementar o sistema de monitoramento no próprio PC da IHM, eliminando-se o uso adicional do PC externo, da placa de comunicação Profibus (CP5611) e do servidor DDE (NC-DDE Server), conforme esquematizado na figura 6.6.

No entanto, conforme mencionado no capítulo anterior, deve-se ter o cuidado de desenvolver aplicativos que não excedam a capacidade de processamento do PC da IHM e não entrem em conflito com os aplicativos já existentes, evitando-se um comprometimento das funcionalidades da IHM. 


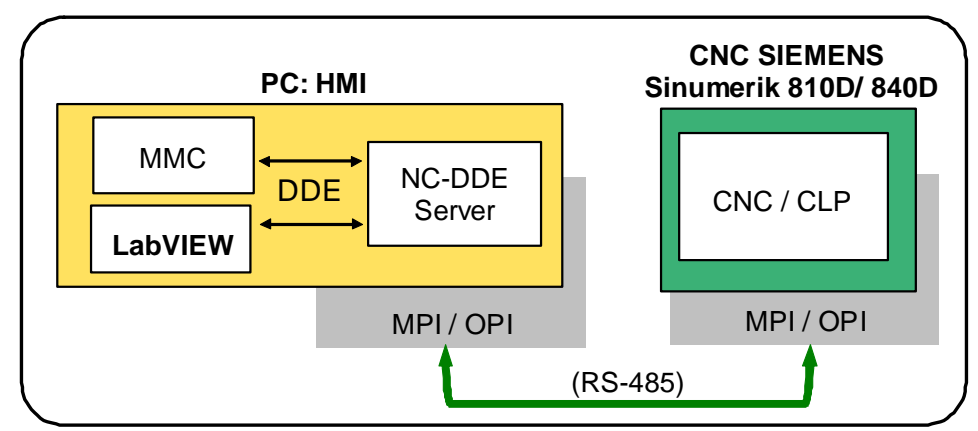

FIGURA 6.6 - Arquitetura de comunicação via rede RS-485 (MPI/ OPI) e protocolo DDE, no próprio PC da HMI

\subsubsection{GE-FANUC (Serie 180i)}

SISTEMA DE SUPERVISÃO: rede Ethernet TCP/IP e protocolo FOCAS1

Para esta configuração, tem-se uma comunicação e integração entre um PC externo e o CNC/ CLP da máquina ferramenta (vide figura 6.7). O PC externo executa um aplicativo de supervisão que pode ser desenvolvido em plataforma GE-FANUC (por exemplo, o SCADA Cimplicity) com integração direta com o CNC/ CLP via protocolo FOCAS1 (Fanuc OpenFactory CNC API Specification), ou em qualquer outro ambiente de programação (por exemplo, LabVIEW, Delphi, Visual Basic, softwares SCADA, etc). Neste último caso, a integração com o CNC/ CLP pode ser feita via drivers especiais que “encapsulam” o protocolo proprietário da GE-FANUC (FOCAS1 Ethernet) em um protocolo padrão aberto, tais como o DDE (Dynamic Data Exchange) ou o OPC (Ole for Process Control), ou até mesmo através da utilização direta das bibliotecas FOCAS1 Ethernet. A comunicação é realizada via rede com padrão Ethernet TCP/ IP, utilizando-se de um HUB para o compartilhamento da comunicação entre o CNC/ CLP e os PCs da HMI e do sistema de supervisão (PC externo). 


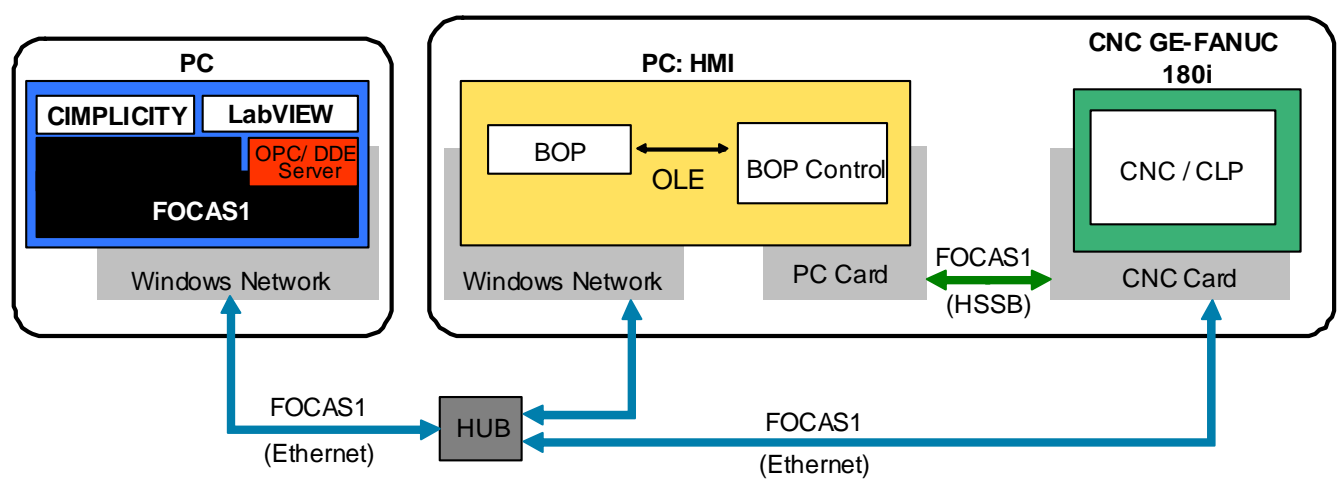

FIGURA 6.7 - Arquitetura de comunicação via rede Ethernet e protocolo FOCAS1 para sistema de monitoramento e/ou supervisão

Este tipo de arquitetura permite a comunicação simultânea de um PC externo com várias máquinas ferramenta que possuem um comando GE-FANUC Serie 0 com rede Ethernet, o que torna possível o desenvolvimento de sistemas de supervisão (vide figura 6.8).

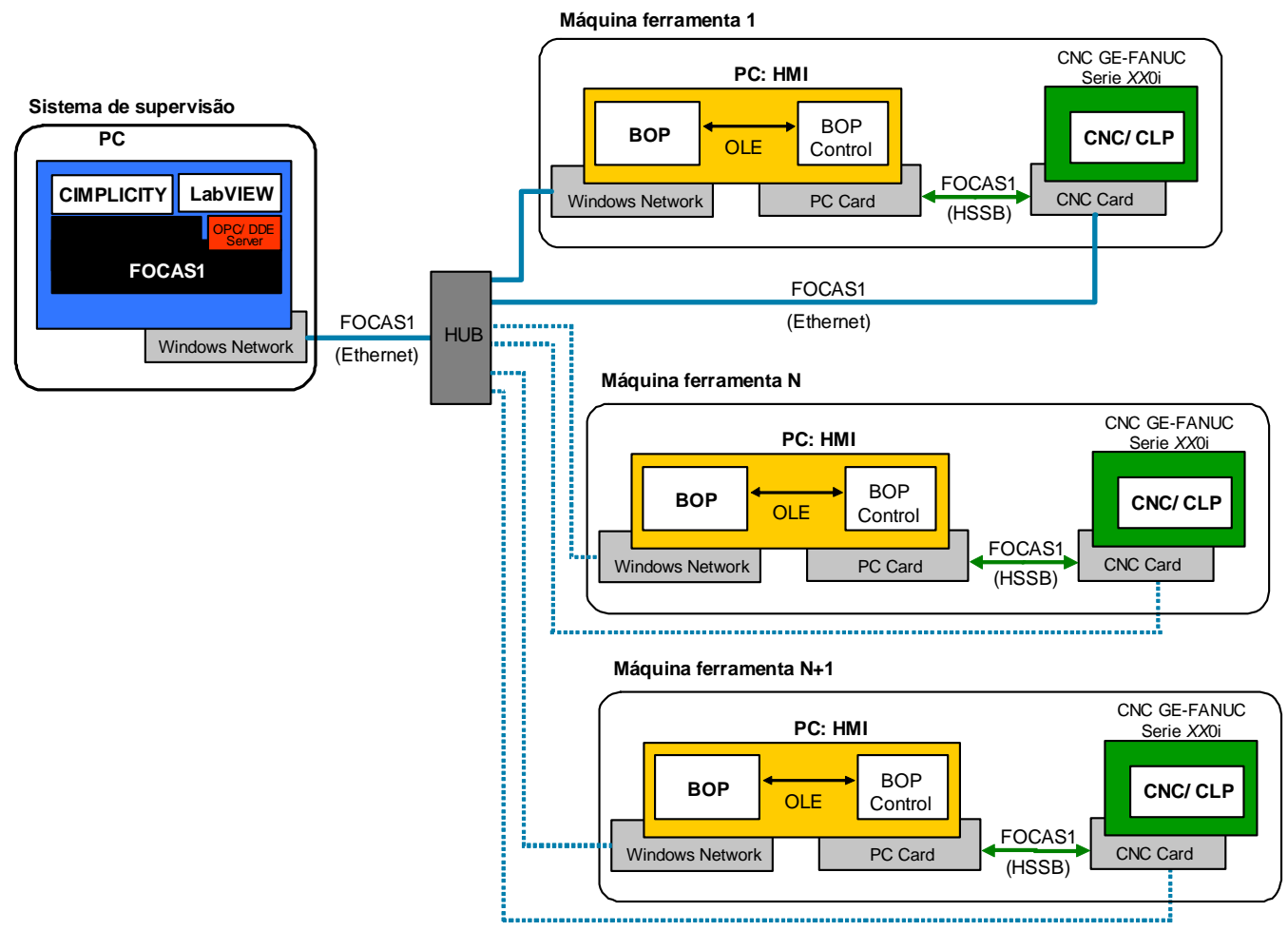

FIGURA 6.8 - Exemplo de arquitetura de supervisão com CNCs GE-FANUC serie $X X 0 \mathrm{i}$ 
SISTEMA DE MONITORAMENTO: rede HSSB de fibra óptica e protocolo FOCAS1

Assim como ocorre nos comandos SIEMENS Sinumerik (figura 6.6), pode-se também implementar o sistema de monitoramento no próprio PC da IHM, eliminando-se o uso adicional de PC e de HUB para o compartilhamento da comunicação com o CNC/ CLP (vide figura 6.9). Para tal, deve-se também tomar cuidado para evitar o uso excessivo do processador do PC da IHM, o que pode comprometer o seu desempenho. Nesta situação, tem-se uma comunicação via rede de fibra óptica HSSB (High Speed Serial Bus) e protocolo proprietário FOCAS1 HSSB. A integração com o software aplicativo do monitoramento dáse através de um OPC ou DDE Server que “encapsulam” as particularidades do protocolo FOCAS1 HSSB, ou até mesmo através do uso direto das bibliotecas FOCAS1 HSSB.

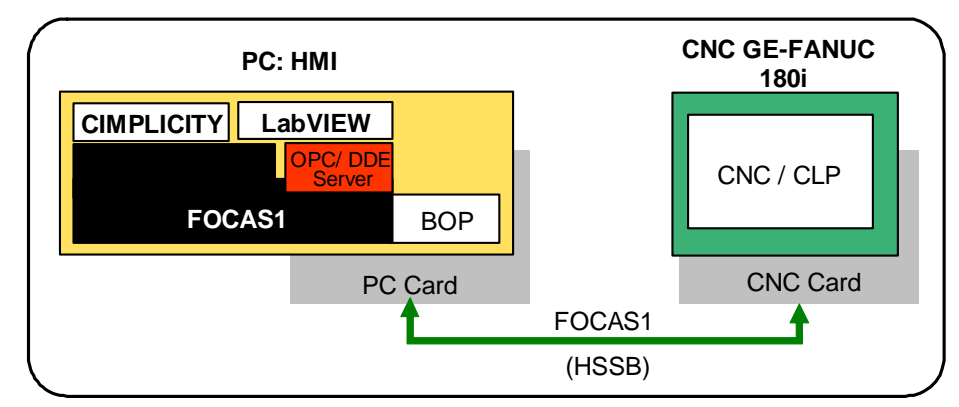

FIGURA 6.9 - Arquitetura de comunicação via rede HSSB de fibra óptica e protocolo FOCAS1, no próprio PC da IHM

\subsection{Avaliações de desempenho e limitações}

A seguir, são apresentadas algumas análises de desempenho e limitações das arquiteturas de redes de comunicação apresentadas anteriormente. 


\subsubsection{Comunicação com CNC SIEMENS (Sinumerik 810D/ 840D)}

1. rede Ethernet TCP/IP e protocolo NetDDE

resumo: comunicação entre um PC externo e o CNC/ CLP da máquina ferramenta, tendo o PC da IHM como intermediário, utilizando-se de uma rede Ethernet TCP/ IP e protocolo padrão NetDDE.

avaliação: este tipo de arquitetura é de fácil implementação e de baixo custo. Utilizase de um tipo de rede de comunicação (Ethernet TCP/ IP) bastante conhecida e difundida, e de baixo custo de manutenção e implementação, com a possibilidade de escolha de hardwares de diversos fabricantes. Possibilita a utilização de qualquer ambiente de programação que possua ferramentas de comunicação por protocolo NetDDE (por exemplo, o LabView, Delphi, Visual Basic, sistemas SCADA, etc), que é um protocolo padrão e aberto. Assim, não há necessidade de se desenvolver drivers de comunicação, ou ficar "preso" a softwares especiais exclusivamente fornecidos pelo fabricante do CNC. No entanto, por ser uma rede Ethernet, não possui a característica determinística, ou seja, não é possível garantir a disponibilidade de informações entre seus integrantes em um tempo determinado, o que prejudica no desenvolvimento de sistemas de monitoramento. Esta falta de determinismo é ainda mais agravada pelo uso do protocolo NetDDE, que varia a taxa de aquisição conforme o desempenho dos PCs externo e da IHM. Além disso, possui um taxa de aquisição menor do que a arquitetura com rede RS-485 e protocolo MPI/ OPI. Portanto, trata-se de um tipo de arquitetura adequada para o desenvolvimento de aplicações de supervisão, na qual a taxa de aquisição não é crítica, ou na aplicação de sistemas de monitoramento off- 
line, ou seja, após a interrupção da usinagem, através de medidas diretas de variáveis, como o desgaste e a detecção de quebra de ferramentas.

\section{2. rede RS-485 e protocolo MPI/ OPI}

resumo: comunicação direta entre um PC externo e o CNC/ CLP da máquinaferramenta, utilizando-se de um rede proprietário MPI/ OPI e protocolo padrão DDE.

avaliação: trata-se de arquitetura mais complexa e de custo mais elevado em relação à arquitetura anterior (rede Ethernet TCP/IP e protocolo NetDDE). A rede MPI/ OPI é de propriedade da SIEMENS, apesar de se basear em redes Profibus DP que são bastante difundidas na área de tecnologias de automação. Assim, têm-se poucas possibilidades na escolha de hardwares e softwares para este tipo de rede que não sejam produtos da SIEMENS. A rede MPI são empregadas nos CNCs 810D com taxas de 187,5 Kbps, e a rede OPI, uma evolução da MPI, é empregada nos CNCs 840D com taxas de 1,5 Mbps. Utiliza-se como protocolo de aplicação o DDE, ao invés do NetDDE. Com o protocolo DDE tem-se uma troca de dados local e não remota como ocorre com o NetDDE. Trata-se de um protocolo mais confiável do que o NetDDE, que é uma adaptação do DDE para a comunicação em rede. Isto melhora a troca de dados, além de evitar influências na taxa de aquisição pelo desempenho dos PCs externo e da IHM. Possuem taxas de aquisição mais elevadas que a arquitetura anterior, além de possuir características determinísticas. Assim, este tipo de arquitetura é recomendável para o desenvolvimento de sistemas de monitoramento on-line, ou seja, sistemas que realizam medições indiretas de variáveis durante a usinagem, como por 
exemplo, a medição de corrente do motor para a detecção de desgaste ou quebra de ferramentas.

A seguir, tem-se um dos testes realizados para a comparação entre os dois tipos de arquitetura de comunicação com o comando SIEMENS:

1. rede Ethernet TCP/IP e protocolo NetDDE

2. rede RS-485 MPI/ OPI e protocolo DDE

Realizou-se a usinagem de um perfil complexo (vide figura 6.10) em um centro de usinagem HERMLE, conforme as figuras abaixo, coletando simultaneamente as coordenadas dos eixos $\mathrm{Z}$ e $\mathrm{X}$ através dos dois tipos de arquitetura de comunicação com o comando SIEMENS Sinumerik 840D.

a-)

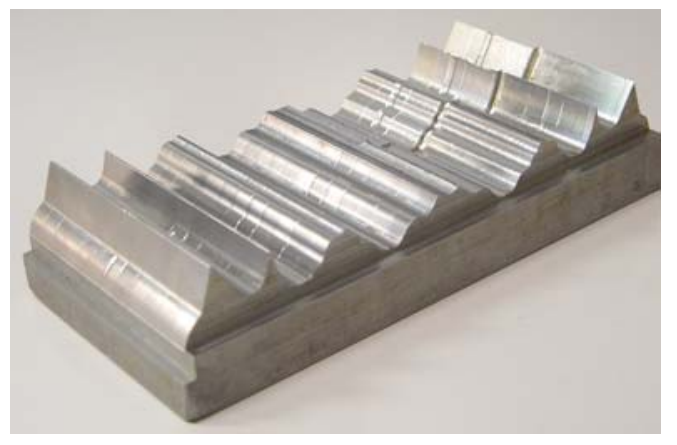

b-)

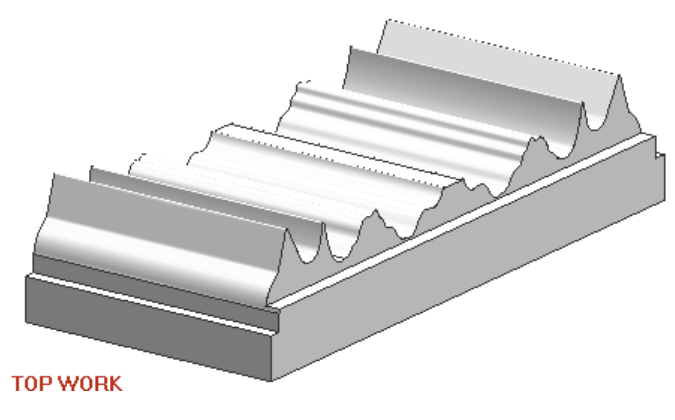

FIGURA 6.10 - Corpo de prova de perfil complexo: a-) foto do corpo de prova b-) modelo geométrica utilizado no CAM

A ferramenta partiu do início do corpo de prova, percorreu metade do perfil, e retornou novamente ao início do corpo de prova. As coordenadas capturadas pelas duas arquiteturas estão expostas na figura 6.11 . 


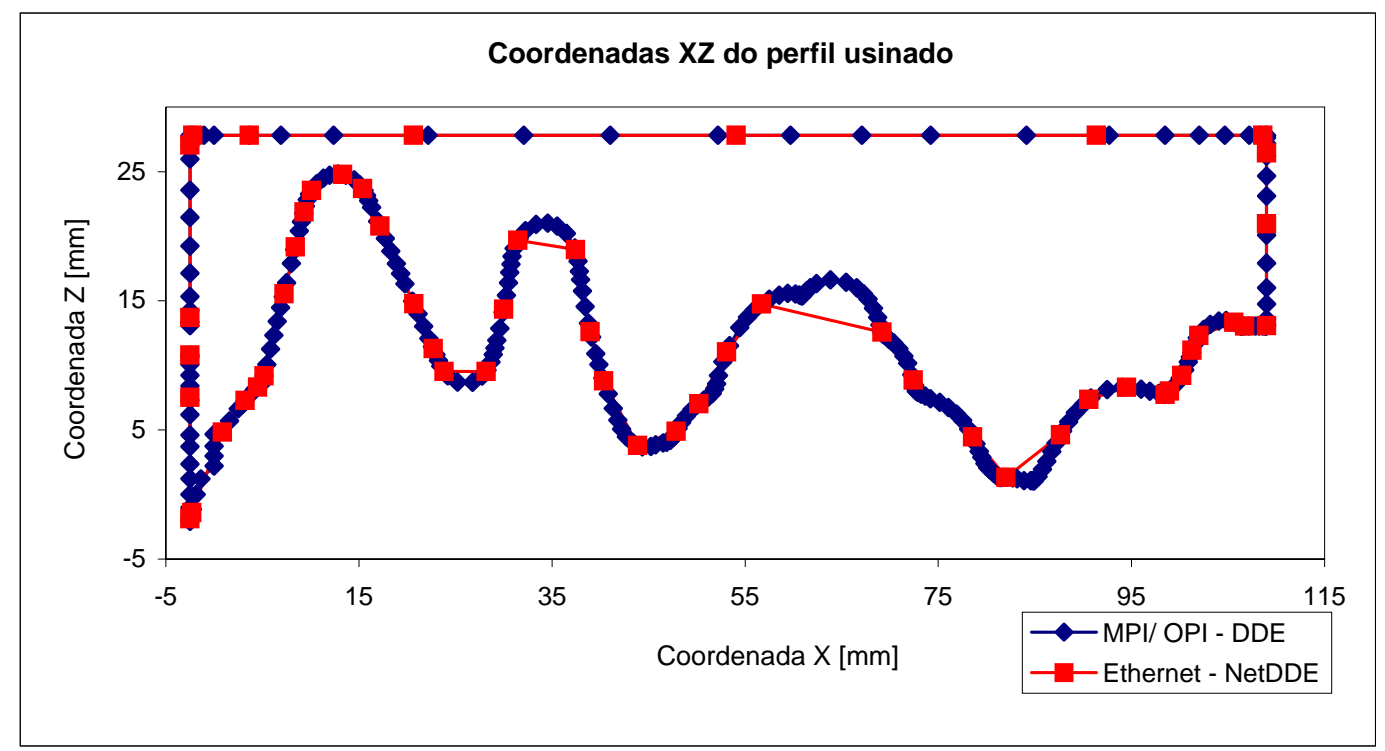

FIGURA 6.11 - Comparação entre arquiteturas de comunicação com CNC SIEMENS

Nota-se que a comunicação via rede MPI/ OPI e protocolo DDE reproduziu o perfil com maior quantidade de pontos do que a rede de comunicação Ethernet e protocolo NetDDE. Observou-se que a aquisição via rede MPI/ OPI e protocolo DDE alcançou taxas de aquisição superiores a três vezes a da arquitetura por rede Ethernet e protocolo NetDDE. Adicionalmente, pode-se observar que diferentemente do que ocorre com a rede Ethernet e protocolo NetDDE, a rede MPI/ OPI e protocolo DDE apresentou taxas constantes de aquisição, caracterizando-a como uma rede determinística.

\subsubsection{Comunicação com CNC GE-FANUC (serie 180i)}

1. rede Ethernet TCP/IP e protocolo FOCAS1

resumo: comunicação direta entre um PC externo e o CNC/ CLP da máquinaferramenta, utilizando-se de uma rede Ethernet TCP/ IP e protocolo proprietário (não aberto) FOCAS1 Ethernet da GE-FANUC. 
avaliação: utiliza-se de um tipo de rede de comunicação (Ethernet TCP/IP) bastante conhecida e difundida, e de baixo custo de manutenção e implementação, com a possibilidade de escolha de hardwares de diversos fabricantes. $\mathrm{O}$ desenvolvimento de aplicativos pode ser implementado através de softwares da GE-FANUC (por exemplo, o Cimplicity ou o Machine Monitor Status) ou através de outras plataformas de programação (por exemplo, o LabView, Visual Basic, Delphi, softwares SCADA, etc). Neste último caso, pode-se utilizar drivers especiais que “encapsulam” o protocolo FOCAS1 em outro protocolo aberto, tais como o DDE e o OPC, ou desenvolver aplicativos acessando diretamente as bibliotecas FOCAS1. Estes dois casos envolvem custos adicionais, tanto para a compra de drivers e da biblioteca do FOCAS1 quanto para as horas de trabalho de programadores para o desenvolvimento de aplicativos via bibliotecas FOCAS1.

Este tipo de arquitetura é recomendável para aplicações de supervisão e de monitoramento off-line.

\section{2. rede HSSB e protocolo FOCAS1}

resumo: sistema de monitoramento no próprio PC da IHM da máquina ferramenta, utilizando-se de uma rede de fibra óptica HSSB (High Speed Serial Bus) proprietária e protocolo proprietário FOCAS1 HSSB da GE-FANUC.

avaliação: trata-se de uma arquitetura de comunicação de alto custo e totalmente fechada quanto ao hardware, utilizando-se somente produtos da GE-FANUC. Exige placa especial de comunicação FOCAS1 HSSB no PC da IHM, além do cabeamento de fibra óptica entre este PC e o CNC/ CLP. É amplamente utilizada na comunicação entre o PC da IHM e o CNC/ CLP da máquina 
ferramenta por possuir alta taxa de comunicação, permitindo menores tempos de atualizações de telas do software da IHM. Em algumas situações, essa comunicação entre o PC da IHM e o CNC/ CLP pode ser realizada via rede Ethernet e protocolo FOCAS1 Ethernet. Em máquinas ferramenta que já possuem a configuração de comunicação FOCAS1 HSSB no PC da IHM, pode-se implementar o sistema de monitoramento neste próprio PC. No entanto, para as máquinas ferramenta que possuem uma comunicação FOCAS1 Ethernet no PC da IHM, torna-se inviável, economicamente, fazer um upgrade desse PC ou utilizar um PC externo adicional com comunicação FOCAS1 HSSB, devido ao alto custo de hardware. Como ocorre na arquitetura de comunicação via rede Ethernet TCP/ IP e FOCAS1 Ethernet, o desenvolvimento de aplicativos pode ser feito em softwares da própria GEFANUC, ou em outros ambientes, necessitando neste caso o uso de drivers “encapsuladores” do protocolo FOCAS1 HSSB, ou de uma programação mais elaborada para o uso direto das bibliotecas FOCAS1 HSSB. Adicionalmente, pode-se empregar tecnologia ActiveX para acessar objetos OLE do software básico da GE-FANUC (BOP - Basic Operation Package) que acompanha os CNCs da mesma. Neste caso, torna-se possível utilizar qualquer tipo de software para o desenvolvimento de aplicativos, desde que estes suportem tecnologia ActiveX. No entanto, por acessar objetos OLE do BOP, as aplicações ficam restritas aos mesmos, o que pode limitar as possibilidades de desenvolvimento de aplicações específicas. 


\section{TESTES EM LABORATÓRIO E INDÚSTRIA}

Neste capítulo, são apresentadas algumas rotinas de monitoramento e supervisão implementadas em CNCs de arquitetura híbrida (open HMI) e de ambiente PC, utilizando-se das arquiteturas de redes de comunicação descritas no capítulo anterior. Essas rotinas foram testadas em laboratório (Laboratório de Otimização de Processos de Fabricação, OPF, do Núcleo de Manufatura Avançada, NUMA, da USP de São Carlos) e na EMBRAER. CNCs com esta configuração permitem a escolha de ambientes de programação, tais como Visual Basic, Delphi, LabView, entre outros, evitando a obrigatoriedade de se utilizar softwares específicos fornecidos pelo próprio fabricante. Todas as rotinas utilizam os recursos já disponíveis nas máquinas ferramenta (sensores, rede de comunicação, condicionadores e amplificadores de sinais, CPU, etc), permitindo o desenvolvimento de sistemas de monitoramento e supervisão resistentes a sujeiras, cavacos, influências eletromagnéticas e mecânicas e sem custos adicionais e redução da área de trabalho.

\subsection{Rotinas de supervisão}

As rotinas de supervisão apresentadas a seguir tornam automática a aquisição de informações de chão de fábrica, compartilhando-as localmente e/ou remotamente, possibilitando um fluxo de informações entre os sistemas de tecnologia de informação (TI) dos altos níveis gerenciais e dos níveis de automação de chão de fábrica. 


\subsubsection{Rotina de supervisão de máquinas SIEMENS}

A seguir é apresentado um sistema de supervisão implementado em três máquinas ferramenta de open HMI, do laboratório OPF. Essas máquinas ferramenta utilizam CNC SIEMENS Sinumerik 8x0D, e são: um torno INDEX GU 600 (Sinumerik 810D), um centro de usinagem ROMI DISCOVERY 560 (Sinumerik 810D) e um centro de usinagem HERMLE C800U (Sinumerik 840D).

Nesta arquitetura, um PC externo é utilizado para executar o sistema de supervisão e a comunicação com os PCs das IHMs de cada máquina ferramenta, conforme esquematizado na figura 7.1 e detalhado no item 6.2.1. Este sistema foi desenvolvido em LabView 7.1.

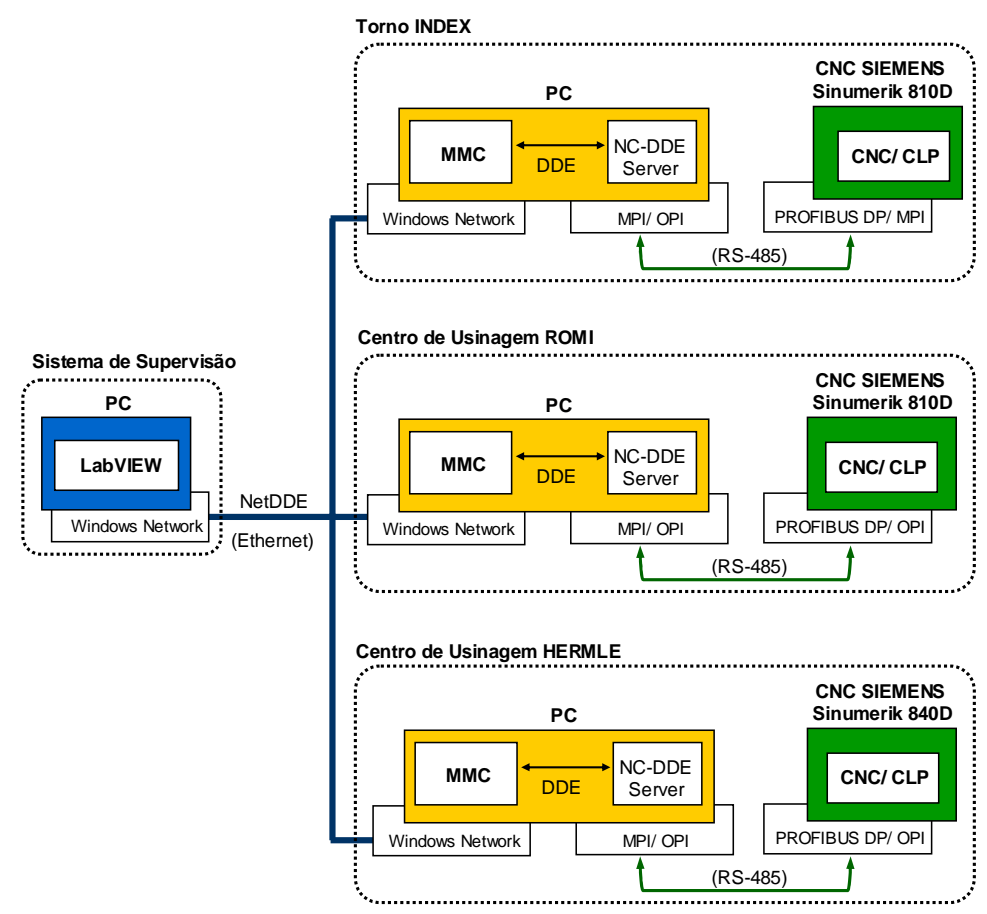

FIGURA 7.1 - Arquitetura de comunicação do sistema de supervisão com CNCs SIEMENS Sinumerik 8x0D 
Deste modo, há uma comunicação e integração entre o PC externo e cada PC das IHMs de cada máquina ferramenta. O sistema de supervisão utiliza esses PCs das IHMs para obter dados de todos os componentes da máquina ferramenta, tais como a IHM, CNC, CLP, drivers e painel de operação. Baseado nesses dados, uma série de informações úteis podem ser obtidas, tais como informações sobre a produção (ritmo de produção, total de peças produzidas, rejeitadas e retrabalhadas, eventos de paradas, tempo efetivo de produção), o processo (tempos de ciclo, tempos de corte, velocidades, avanços, etc), a ferramenta (número de peças produzidas por ferramenta e/ou por aresta de corte), e sobre históricos de alarmes (freqüência de ocorrência, tipos e descrições de alarmes), entre outras informações.

Alguns front ends desta aplicação de supervisão são mostrados nas figuras a seguir. A figura 7.2 mostra o front end principal do sistema, com informações gerais das máquinas ferramenta, tais como o nome e o número de identificação da peça e a ordem de produção (que podem ser inseridos, automaticamente, como linhas de comentário no próprio programa CNC através de um sistema DNC), o número total de peças produzidas, o tempo de ciclo atual, a média de tempos de ciclo, os tempos efetivos de produção e tempos de paradas, além de animações fotográficas que indicam se as portas das máquinas ferramenta estão abertas ou fechadas, através de leituras de bits (do módulo digital de entrada do CLP) correspondentes às chaves de tais portas. 


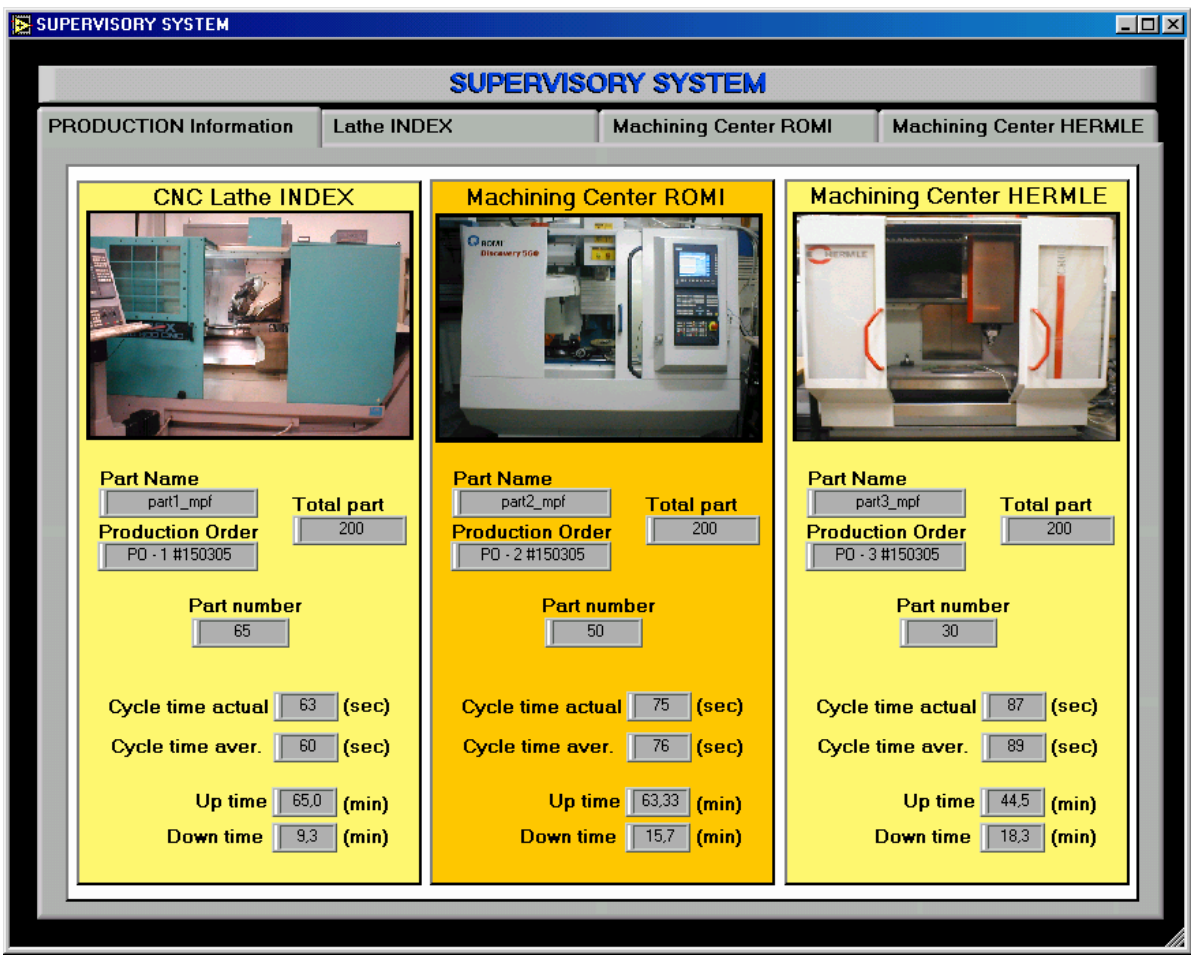

FIGURA 7.2 - Front end principal do sistema de supervisão (informações de produção das máquinas ferramenta)

Nas demais figuras (7.3, 7.4 e 7.5) são exibidas front ends específicos para cada máquina ferramenta, com algumas informações detalhadas das mesmas: nome do programa CNC em execução, coordenadas de posição e velocidades de avanço de cada eixo, velocidade de rotação do spindle, temperaturas dos servos-motores dos eixos de posicionamento e do spindle, condições de paradas e mensagens de alarmes e/ou de alertas, status da comunicação Ethernet TCP/IP e protocolo NetDDE. 


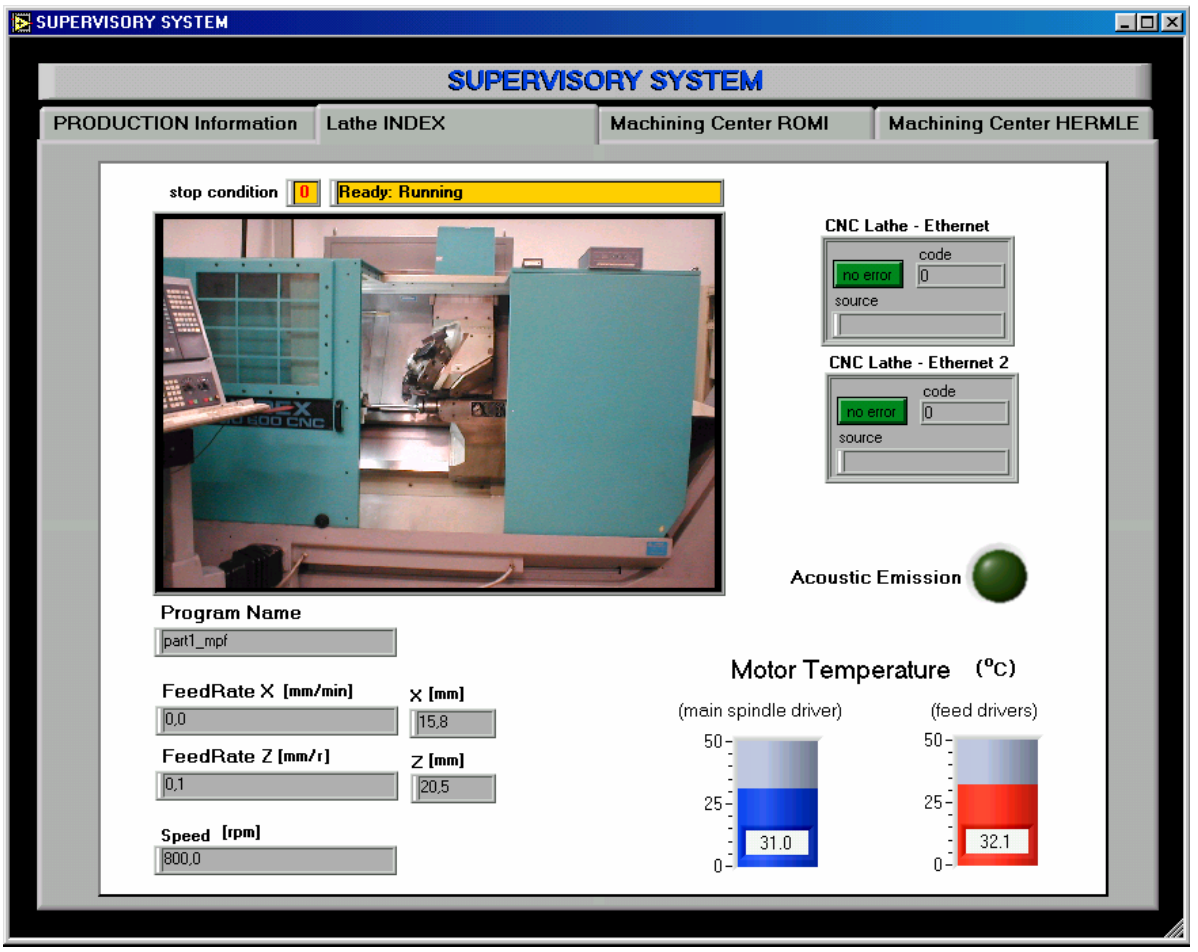

FIGURA 7.3 - Front end de informações do torno INDEX

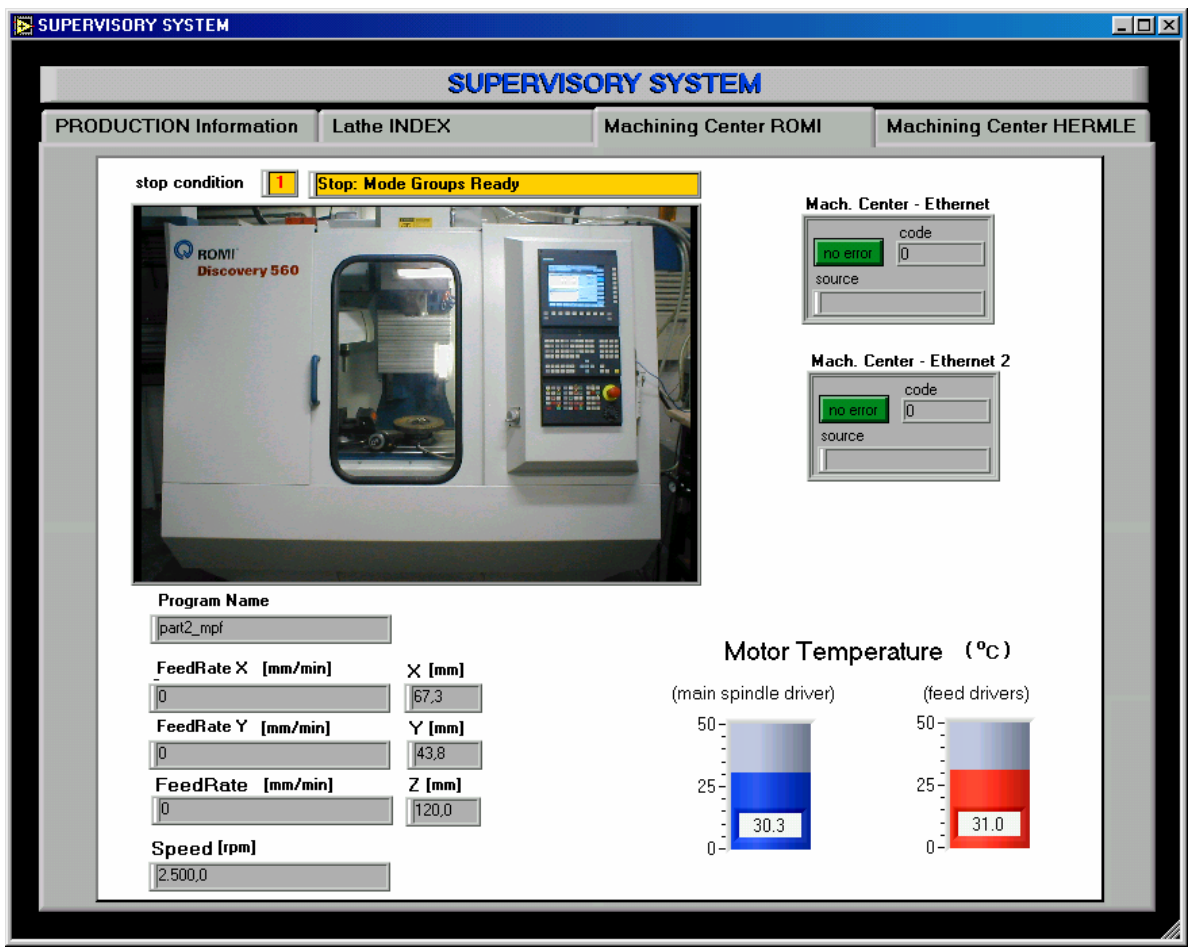

FIGURA 7.4 - Front end de informações do centro de usinagem ROMI 


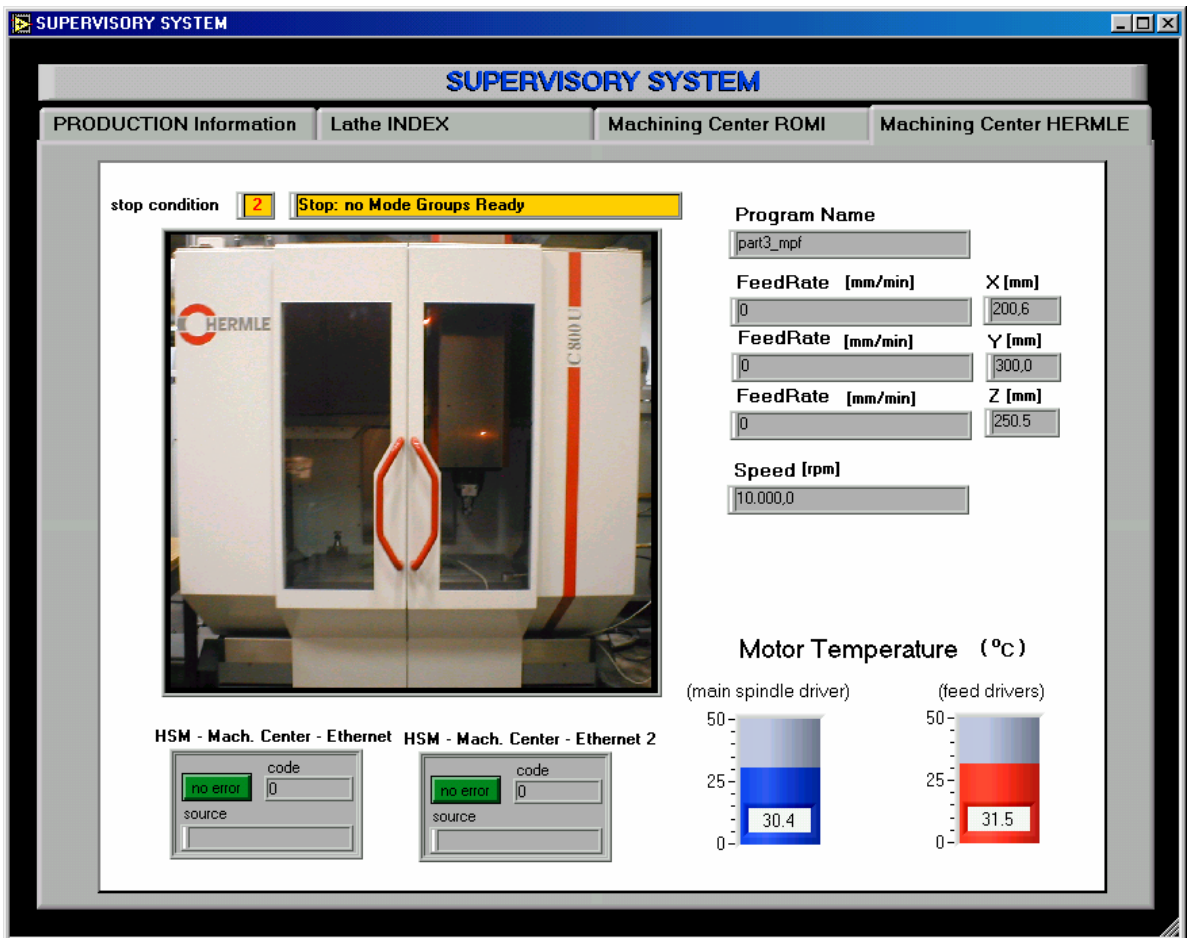

FIGURA 7.5 - Front end de informações do centro de usinagem HERMLE

\subsubsection{Rotina de supervisão de máquinas GE-FANUC}

Em conjunto com a empresa de automação SENSOFT e com o objetivo de se testar as idéias propostas nesse projeto de doutorado, foi desenvolvido um projeto piloto de supervisão de máquinas ferramenta (projeto EMBRAER-CEEHM - Coleta Eletrônica de Eventos e Horas Máquina) para a empresa EMBRAER, visando uma solução corporativa EMBRAER. Fizeram parte deste projeto quatro máquinas ferramenta com CNCs de ambiente PC, descritos na tabela abaixo. Tal projeto é inovador na indústria e foi a primeira iniciativa da EMBRAER no sentido de interligar as suas máquinas visando a supervisão dos processos. 
TABELA 7.1 - Máquinas ferramenta do projeto EMBRAER-CEEHM

\begin{tabular}{|c|c|}
\hline Máquina ferramenta & CNC \\
\hline Centro de usinagem MAKINO HSM 4 eixos A55E (1180) & GE- FANUC 160i - MA \\
\hline Centro de usinagem MAKINO HSM 5 eixos A55E (1190) & GE- FANUC 160i - MA \\
\hline Centro de usinagem GANTRY HSM 5 eixos (560) & ECS 4801 \\
\hline Centro de usinagem GANTRY HSM 3 eixos (580) & ECS 2801 \\
\hline
\end{tabular}

O projeto EMBRAER-CEEHM coleta, de forma automática, informações de tempos e eventos das máquinas ferramenta, tais como: tempos de fabricação, tempos de movimentos de interpolação (G1, G2, G3), tempos de aproximações rápidas (G0), alarmes, trocas e identificação de ferramentas, etc. Além dos tempos e eventos, também são adquiridos os status das máquinas, conforme a ilustração da figura 7.6. A partir do diagrama da figura 7.6, o sistema classifica o status atual da máquina em: desligada, executando, parada e alarme. Cada status é identificado no sistema através da numeração e descrição exposta na tabela 7.2.

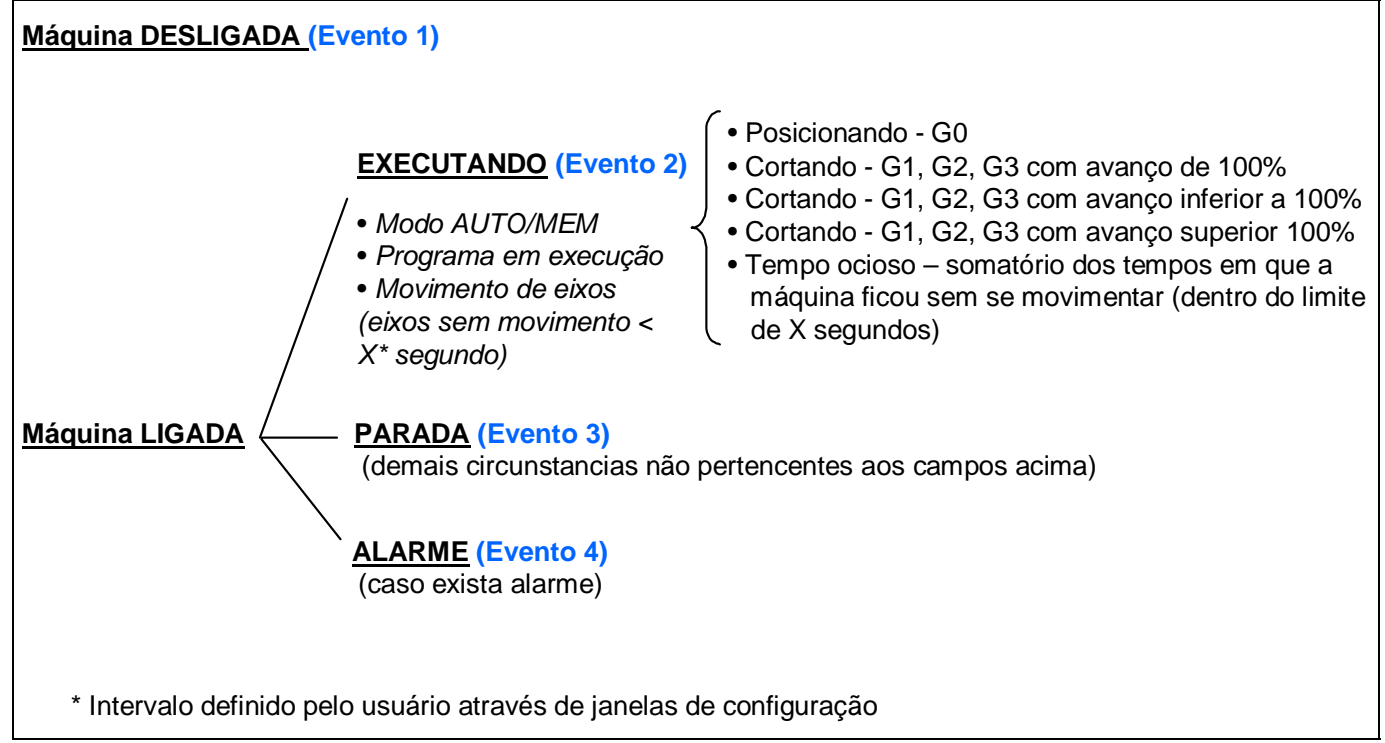

FIGURA 7.6 - Estratégia para definição de status a serem registrados 
TABELA 7.2 - Tabela de status do projeto EMBRAER-CEEHM

\begin{tabular}{|c|c|c|}
\hline Status & Identificação & Descrição \\
\hline DESLIGADA & 1 & Máquina desligada ou sem comunicação. \\
\hline EXECUTANDO & 2 & $\begin{array}{l}\text { Máquina em movimento, executando comandos de } \\
\text { posicionamento rápido (G0) ou interpolação (G1, G2 } \\
\text { e G3) no modo AUTO/MEM. Contudo, é permitido } \\
\text { que a máquina fique um determinado intervalo sem } \\
\text { se movimentar (caracterizado pelo valor da } \\
\text { velocidade de avanço igual a zero) para acomodar } \\
\text { pequenas paradas entre os movimentos } \\
\text { programados. Tal intervalo é definido através de } \\
\text { configurações do sistema feito pelo usuário. }\end{array}$ \\
\hline PARADA & 3 & $\begin{array}{l}\text { Este evento engloba todas as situações da máquina } \\
\text { que excluam as condições de evento executando ou } \\
\text { alarme. }\end{array}$ \\
\hline ALARME & 4 & $\begin{array}{l}\text { Este evento engloba a situação de máquina em } \\
\text { alarme e/ou botão emergência acionado. }\end{array}$ \\
\hline
\end{tabular}

A seguir, na figura 7.7, tem-se um esquema da arquitetura de comunicação empregada para cada máquina ferramenta. 


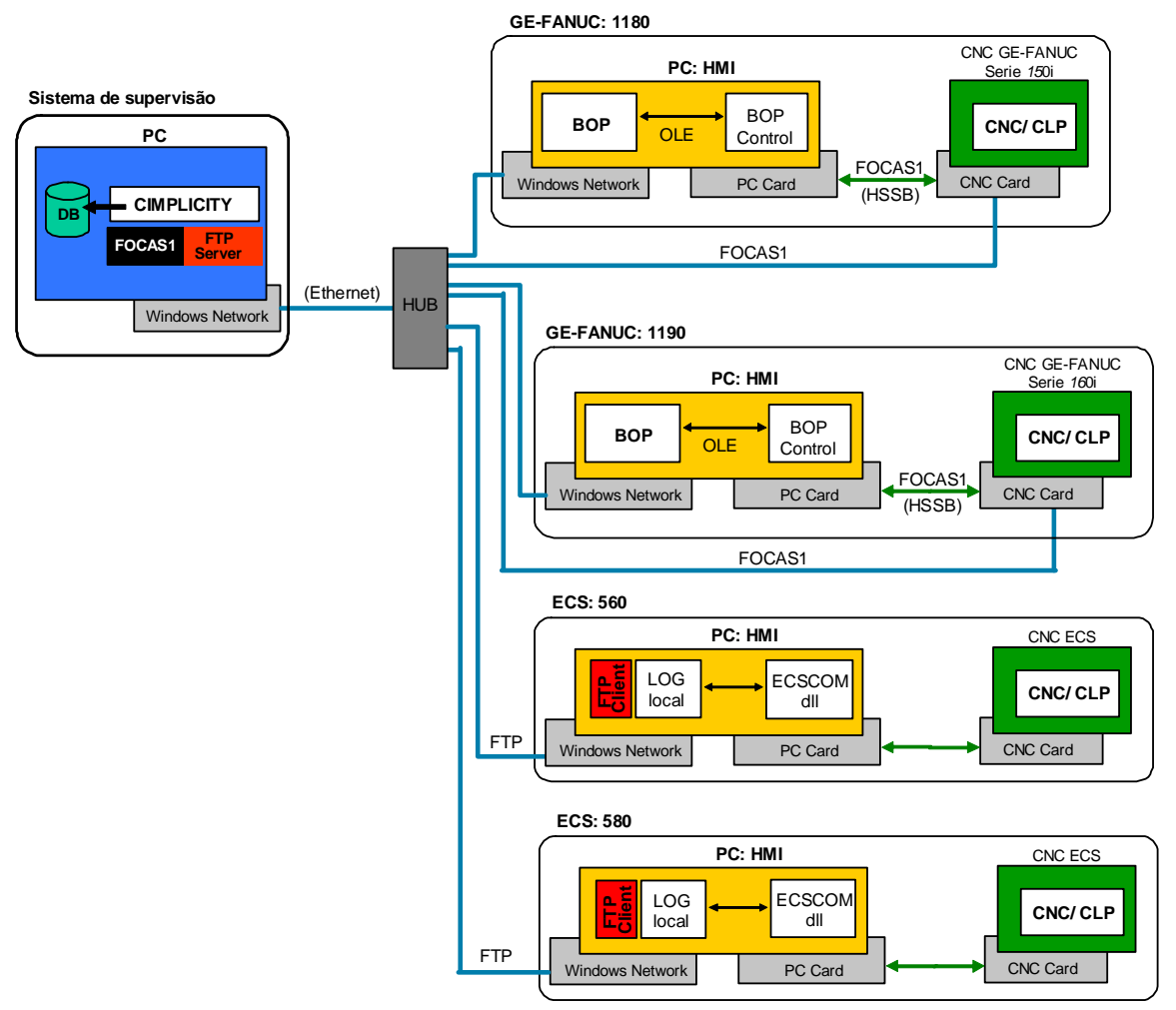

FIGURA 7.7 - Arquitetura de comunicação do projeto piloto EMBRAER-CEEHM

As máquinas ferramenta com CNC GE-FANUC são ligadas diretamente, através de rede Ethernet TCP/ IP e protocolo FOCAS1, ao aplicativo coletor de informações desenvolvido em Cimplicity (software proprietário da FANUC). Este aplicativo envia para o Banco de dados ACCESS somente os status e eventos que são modificados, ou seja, no banco de dados só são armazenados os status e eventos que sofrem mudanças de estado.

Quanto às máquinas ferramenta com CNC ECS, foi necessário desenvolver um aplicativo local (LOG LOCAL), em linguagem Delphi, para a coleta e armazenamento de dados de status e eventos. Periodicamente (conforme configuração feita pelo usuário), este aplicativo envia esses dados para a estação do sistema de supervisão via rede Ethernet TCP/ IP e protocolo FTP. Nessa estação do sistema de supervisão, um aplicativo desenvolvido em Cimplicity realiza a leitura dos dados provenientes das máquinas ferramentas com CNC ECS, e as envia para a base de dados Access. Adicionalmente, a estação do sistema de supervisão apresenta interfaces de operação, com informações gerais e detalhadas das máquinas em telas 
gráficas, possibilitando o acompanhamento on-line de informações de status e eventos, e configuração de parâmetros de coleta e envio de informações.

A seguir, são apresentados alguns front ends do projeto piloto EMBRAER-CEEHM. Na figura 7.8 é exibido a tela principal. Nesta, pode-se observar os status das máquinas (desligado, parado ou alarme, executando, sem comunicação) e ter acesso às informações detalhadas das mesmas.

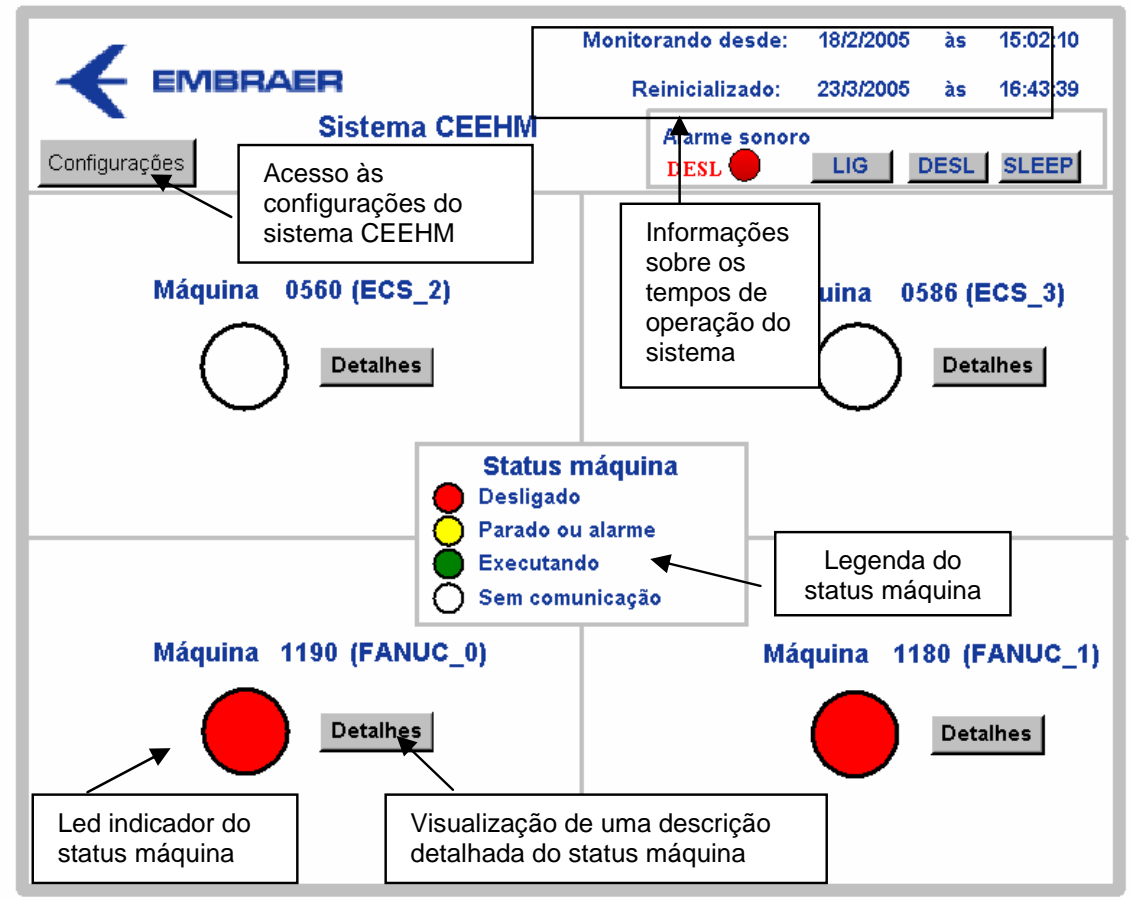

FIGURA 7.8 - Front end da tela principal do projeto EMBRAER-CEEHM (informações gerais das máquinas ferramenta) 


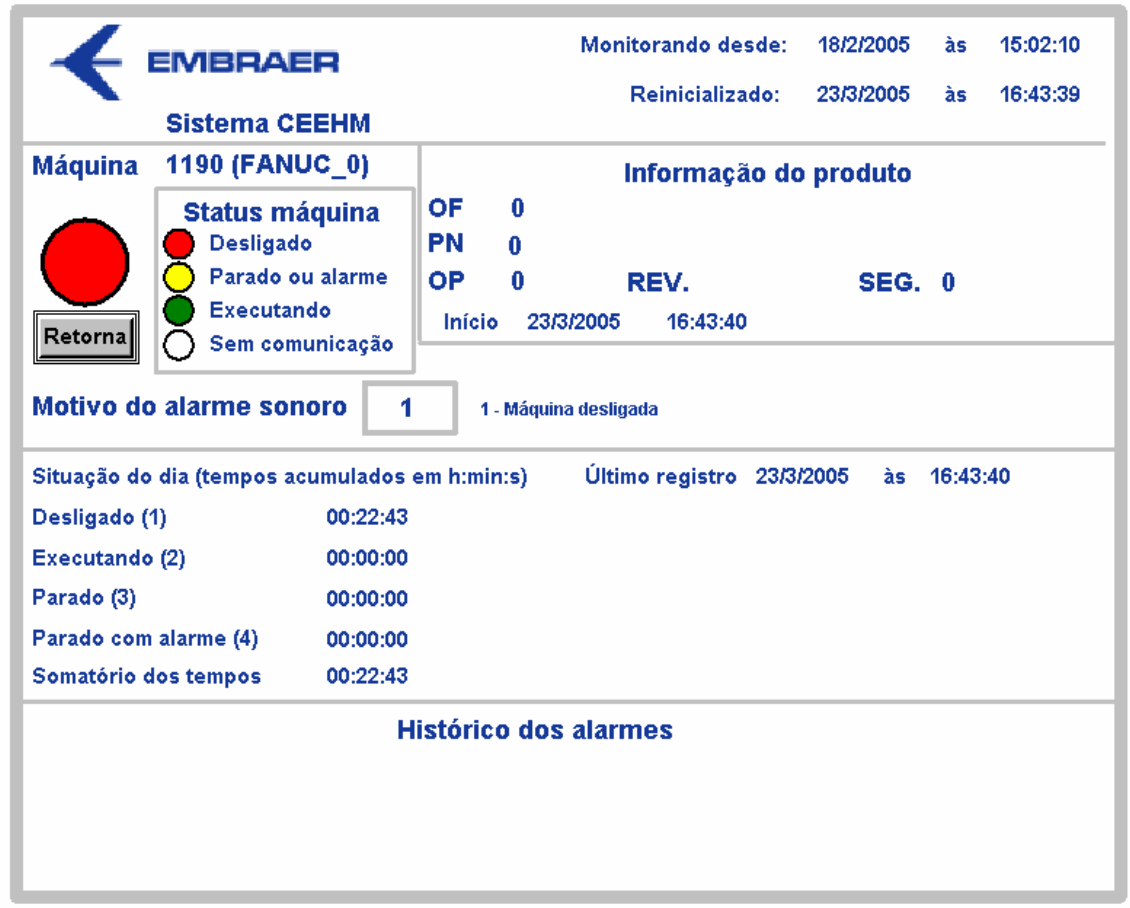

FIGURA 7.9 - Front end de uma das telas de informações detalhadas das máquinas ferramenta

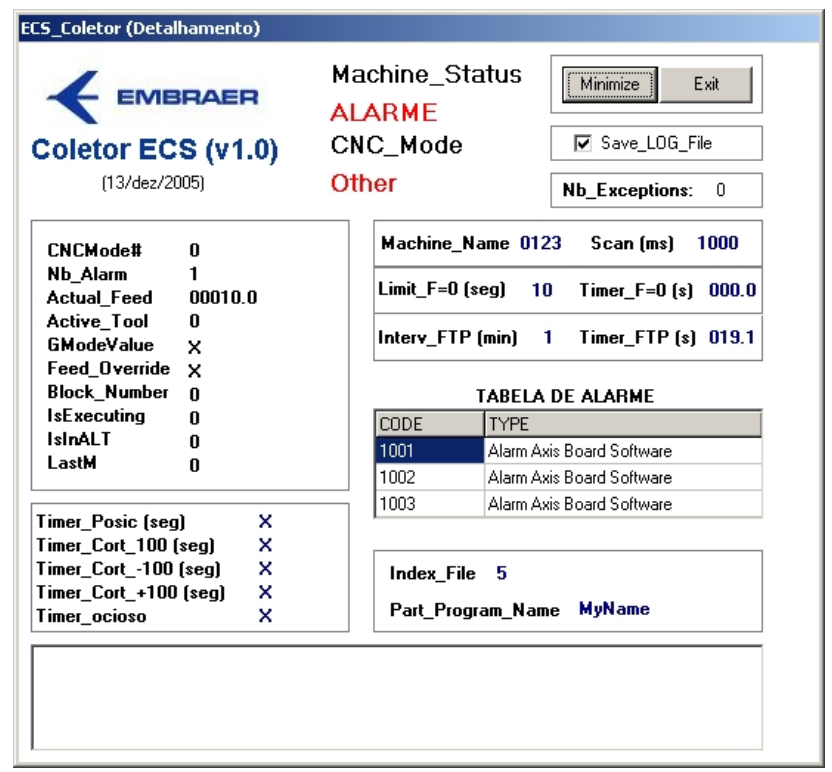

FIGURA 7.10 - Front end do aplicativo local (LOG LOCAL) das máquinas ferramenta com CNC ECS

Além de toda a arquitetura de hardware e software para a aquisição e o armazenamento de informações, fez parte também do projeto EMBRAER-CEEHM o desenvolvimento de aplicativo para a execução de consultas de informações da base de dados e a apresentação das mesmas em gráficos e tabelas. Este aplicativo, chamado de Visibilidade, 
foi implementado em ambiente EXCEL através de macros desenvolvidas em linguagem

Visual Basic. Podem-se fazer quatro tipos de consultas:

- Consulta de Eventos

- Consulta Diária

- Consulta Semanal

- Consulta de 7-30 dias

A seguir, são apresentadas algumas consultas de dados realizadas através do aplicativo

Visibilidade.

Consulta de Eventos:

Exibição de todos os dados da base de dados selecionada pelo botão “Base de dados”.

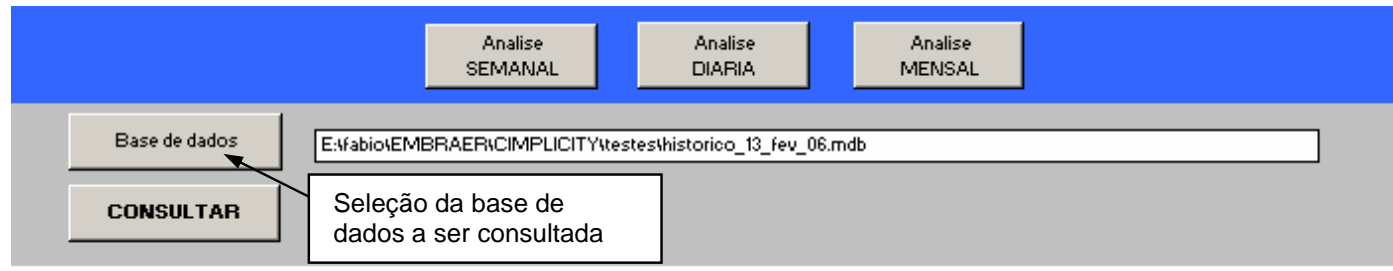

\begin{tabular}{|c|c|c|c|c|c|c|c|c|c|c|c|c|}
\hline Registro & Maquiea & Data & Hora & Erento & of & PH & OP & RT & $s g$ & Ferranenta & TeDpo_posic & TeEpo \\
\hline 1 & 1190 & $03+11105$ & 10:17:16 & 6 & 0 & 0 & 0 & 0 & 0 & 0 & 0 & \\
\hline 2 & 1190 & $04 / 11105$ & $06: 36: 31$ & 5 & 0 & 0 & 0 & 0 & 0 & 0 & 0 & \\
\hline 3 & 1180 & $03+11105$ & 10:17:16 & 6 & 0 & 0 & 0 & 0 & 0 & 0 & 0 & \\
\hline 4 & 1180 & $04+111105$ & $06: 36: 31$ & 5 & 0 & 0 & 0 & 0 & 0 & 0 & 0 & \\
\hline 5 & 1190 & $04 / 11105$ & $06: 36: 34$ & 3 & \multirow{3}{*}{\multicolumn{3}{|c|}{$\begin{array}{l}\text { Tabela dos dados } \\
\text { armazenados }\end{array}$}} & 0 & 0 & 6 & 0 & \\
\hline 6 & 1180 & $04 / 11105$ & $06: 36: 34$ & 3 & & & & 0 & 0 & 0 & 0 & \\
\hline 7 & 1190 & $04 / 11105$ & $06: 41: 48$ & 6 & & & & 0 & 0 & 0 & 0 & \\
\hline 8 & 1190 & $04 / 11105$ & 07:06:11 & 5 & ए & ए & 0 & 0 & 0 & 0 & 0 & \\
\hline 9 & 1180 & $04+11105$ & $06: 41: 48$ & 6 & 0 & 0 & 0 & 0 & 0 & 0 & 0 & \\
\hline 10 & 1180 & $04 ; 11 \% 05$ & 07:06:11 & 5 & 0 & 0 & 0 & 0 & 0 & 0 & 0 & \\
\hline 11 & 1190 & $04 i 11105$ & 07:06:14 & 3 & 0 & 0 & 0 & 0 & 0 & 6 & 0 & \\
\hline 12 & 1180 & $04 / 11105$ & $07: 06: 14$ & 3 & 0 & 0 & 0 & 0 & 0 & 0 & 0 & \\
\hline 13 & 1190 & $04 i 11 \% 05$ & $07: 19: 46$ & 2 & 0 & 145-03257-401-PP1 & 40 & 1 & $\mathrm{~B} 01$ & 47 & 0 & \\
\hline 14 & 1190 & 0411105 & 07:19:58 & 3 & 0 & 145-03257-401-PP1 & 40 & 1 & $\mathrm{~B} 01$ & 47 & 0 & \\
\hline 15 & 1190 & $04 / 11105$ & $07: 20: 06$ & 2 & 0 & 145-03257-401-PP1 & 40 & 1 & $\mathrm{~B} 01$ & 34 & 21 & \\
\hline 16 & 1190 & $04+11105$ & $07: 25: 32$ & 3 & 0 & 145-03257-401-PP1 & 40 & 1 & $\mathrm{~B} 01$ & 34 & 0 & \\
\hline 17 & 1190 & $04 / 11105$ & $07: 25: 36$ & 2 & 0 & 145-03257-401-PP1 & 40 & 1 & $\mathrm{~B} 01$ & 11 & 25 & \\
\hline 18 & 1190 & $04 i 11105$ & 07:27:54 & 3 & 0 & 145-03257-401-PP1 & 40 & 1 & $\mathrm{~B} 01$ & 11 & 0 & \\
\hline 19 & 1190 & $04 ; 11105$ & 07:27:58 & 2 & 0 & 145-03257-401-PP1 & 40 & 1 & $\mathrm{~B} 01$ & 36 & 11 & \\
\hline
\end{tabular}

FIGURA 7.11 - Consulta de eventos 


\section{Consulta Diária:}

Através desta consulta, é possível visualizar informações diárias de até quatro máquinas simultaneamente. Para cada máquina, é gerado uma escala temporal (de 0 à 24 horas) com indicações em cores do status em que se encontra a máquina (vermelho: desligada; verde: executando; amarelo: parada; branco: sem monitoramento). No lado direito dessa escala temporal tem-se indicações dos momentos em que foram gerados alarmes (linha vermelha) e eventos realizados pela máquina (linha azul), tais como troca de ferramenta, mudança de ordem de produção, etc (vide figura abaixo). Adicionalmente, têm-se gráficos de pizza e de barra dos status para cada máquina.

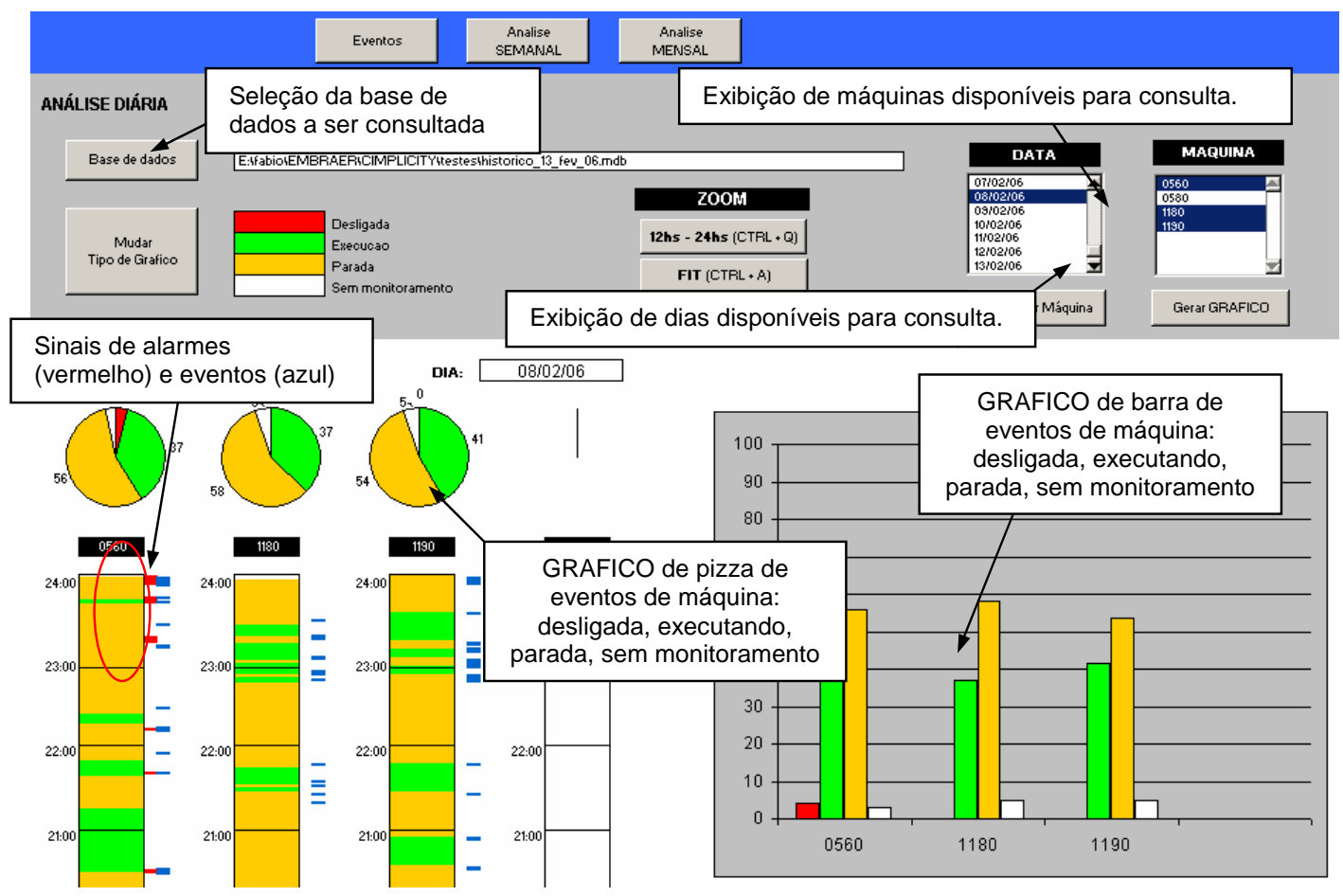

FIGURA 7.12 - Consulta diária 


\section{Consulta Semanal:}

Através desta consulta, é possível visualizar informações semanais de cada máquina, individualmente. Apresenta os mesmos tipos de visibilidades da consulta diária (vide figura abaixo).

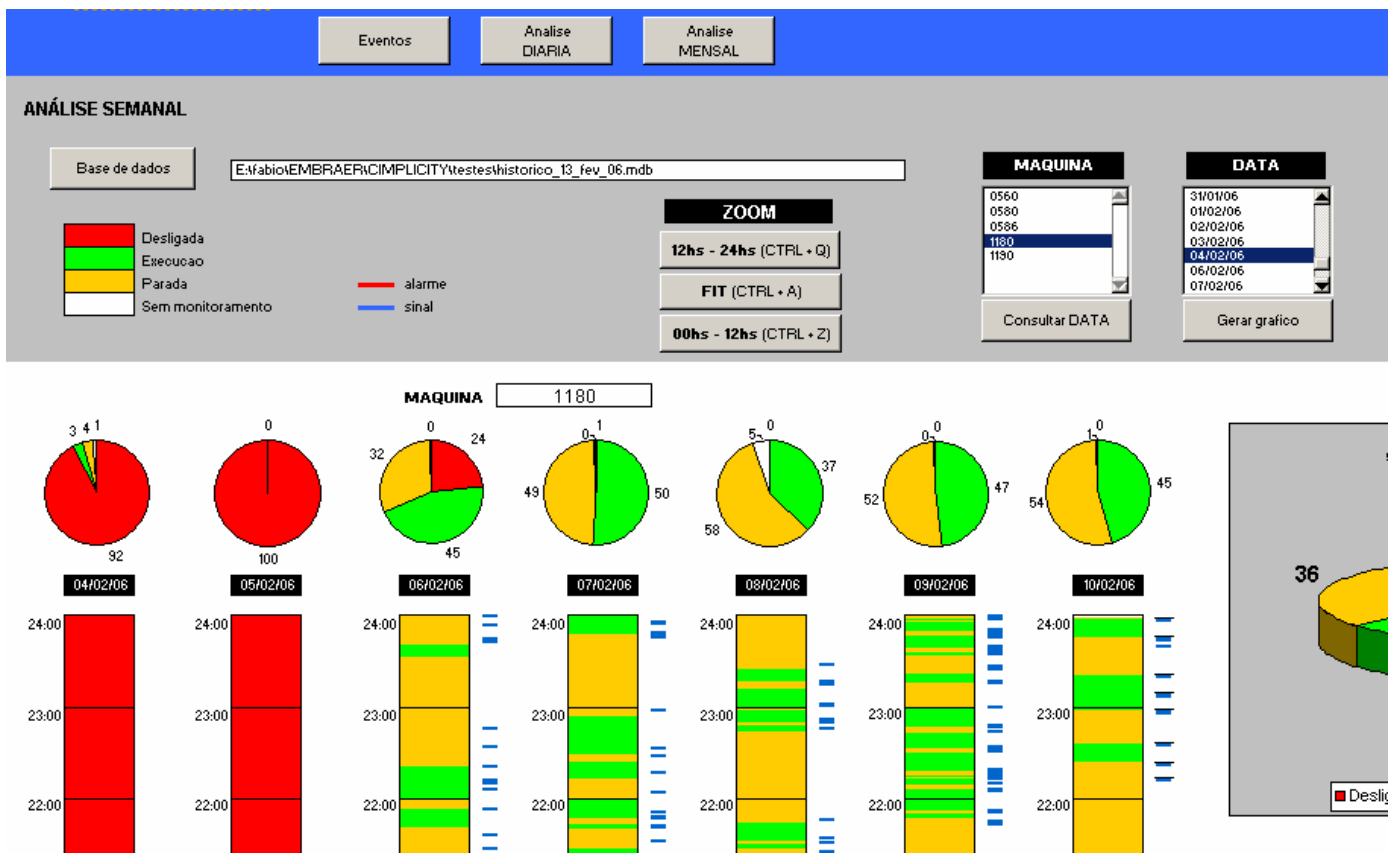

FIGURA 7.13 - Consulta semanal

Consulta de 7-30 dias:

Através desta consulta, é possível visualizar informações de 7 à 30 dias para a máquina selecionada. A figura a seguir exibe uma breve descrição do procedimento desta consulta. 


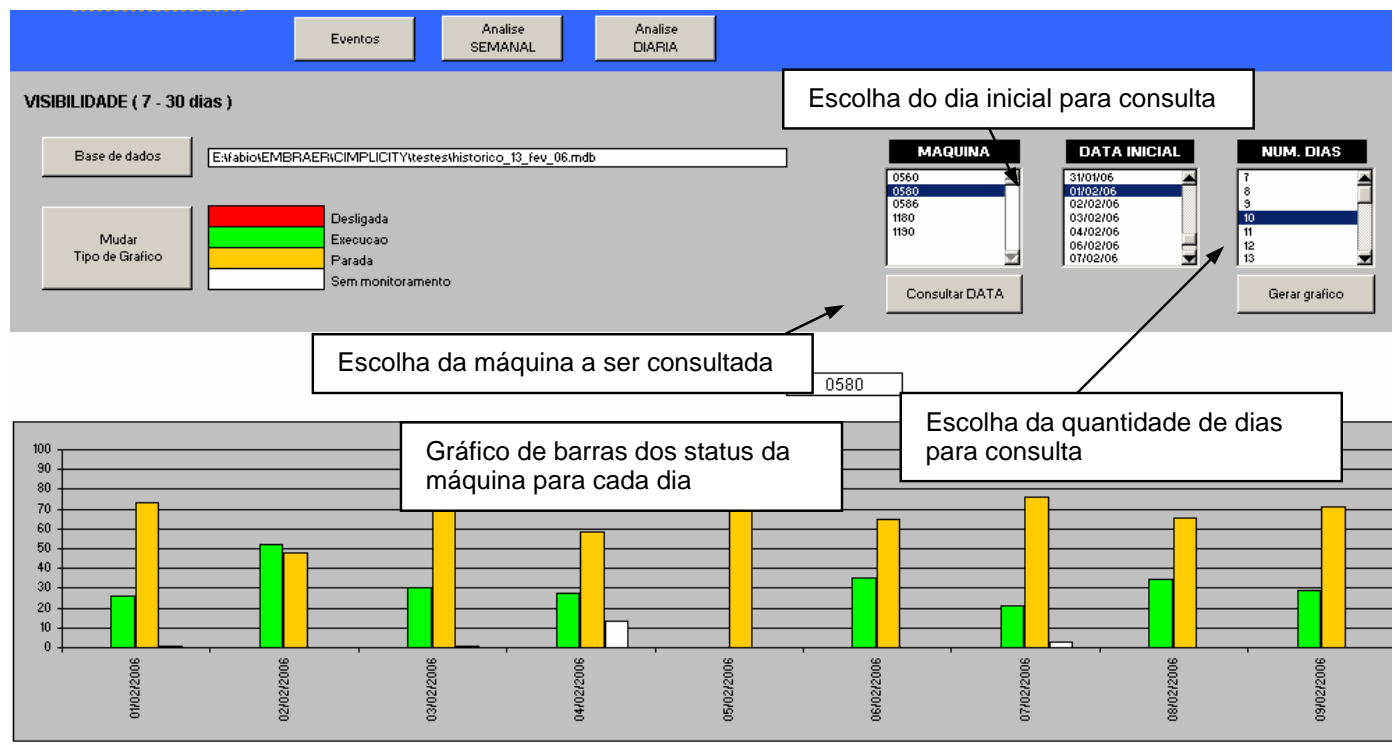

FIGURA 7.14 - Consulta de 7-30 dias

A implementação do projeto piloto de supervisão das máquinas ferramenta na EMBRAER foi bem sucedida e será efetivamente utilizada pela empresa. Através do sistema, a Embraer passou a ter um melhor gerenciamento da produção, da manutenção de máquinas e da otimização de seus processos de usinagem. A gerência concluiu que o sistema proporciona ganhos de produtividade, por conta da automatização de um processo de coleta de dados que antes era manual. Além dessas vantagens, o sistema estimulou os funcionários a melhorarem. Hoje eles podem, em tempo real, ter uma avaliação de seus desempenhos individuais na produção. A partir desses resultados, possíveis graças à arquitetura proposta, o projeto EMBRAER-CEEHM está sendo expandido para as demais máquinas ferramenta de 4 à 5 eixos, tornando-se hoje um sistema coorporativo padrão na empresa. A expansão do sistema será interligada com os demais departamentos do sistema produtivo da EMBRAER. 


\subsection{Rotinas de monitoramento}

As rotinas de monitoramento visam não somente servirem como fonte de informações para posteriores otimizações de processos de usinagem, mas também detectar possíveis falhas de funcionamento de seus componentes (máquina, peça-obra, ferramenta e processo) e executar ações de prevenção e/ou correção. Todas as rotinas de monitoramento foram testadas no laboratório OPF.

\subsubsection{Rotina de monitoramento da ferramenta de corte para processos de} fresamento

A seguir é apresentado um sistema de monitoramento para a detecção automática de desgastes de ferramenta de corte, desenvolvido em LabView 7.1. O sistema de monitoramento foi implementado em um PC externo com comunicação direta com um CNC/CLP SIEMENS Sinumerik 840D, via rede RS-485 MPI/OPI e protocolo DDE (vide figura abaixo, e mais detalhes no item 6.2.1).

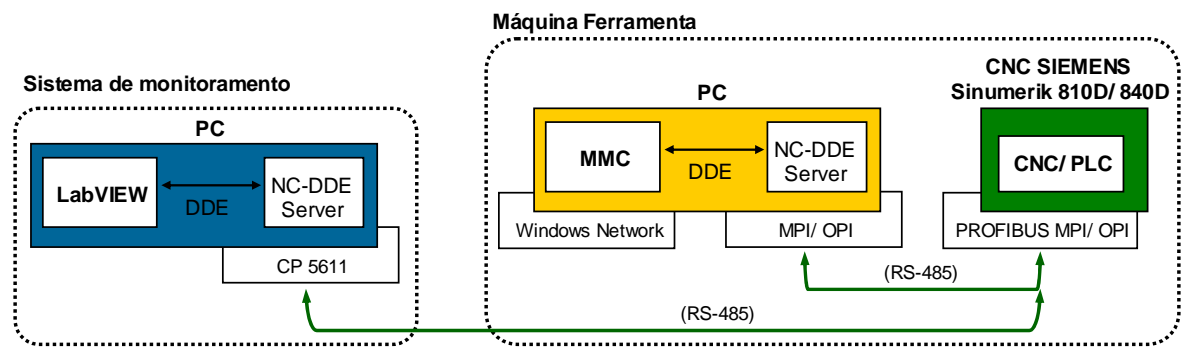

FIGURA 7.15 - Arquitetura de comunicação do sistema de monitoramento com CNC SIEMENS Sinumerik $8 \mathrm{x} 0 \mathrm{D}$

O processo monitorado foi o de fresamento de um bloco retangular (300 x $400 \times 50$ mm) de aço H13 com dureza de 52 HRc, em um centro de usinagem vertical de alta 
velocidade, HERMLE modelo C800. Utilizou-se de dois insertos de corte de $20 \mathrm{~mm}$ de diâmetro, classe 4040 R08 (Sandvik), com as condições de usinagem descritas na tabela a seguir.

TABELA 7.3 - Parâmetros de usinagem

\begin{tabular}{|c|c|c|c|}
\hline ap & ae & $\mathbf{f z}$ & Vc \\
\hline $2 \mathrm{~mm}$ & $2 \mathrm{~mm}$ & $0,07 \mathrm{~mm} /$ volta & $160 \mathrm{~m} / \mathrm{min}$ \\
\hline
\end{tabular}

Sinal adquirido do CNC/CLP:

Foi adquirida do CNC uma variável referente ao spindle, chamada "LOAD”. Através de ensaios pré-liminares, percebeu-se que essa variável é proporcional à potência exercida pelo eixo árvore. Assim, utilizando-se dessa variável e de outras para o auxílio na determinação do momento exato do início de corte (por exemplo, linha do programa CN em execução, posições dos eixos, variáveis R utilizadas na parametrização de programa CN, etc) pôde-se desenvolver o sistema de monitoramento.

\section{Estratégia de monitoramento:}

Sabendo que o sinal de "LOAD” do spindle é proporcional à potência consumida e que as avarias e desgastes de ferramentas levam à alterações das forças de corte, conclui-se que os valores do sinal de "LOAD” do spindle alteram de acordo com a situação em que se encontram as ferramentas de corte. Adicionalmente, sabe-se que a combinação de desgastes e avarias de ferramentas de corte, as possíveis diferenças de dureza ao longo do material usinado, entre outros fatores, podem gerar valores médios de forças de corte similares para ferramentas novas e para ferramentas com avarias e/ou desgastes, o que dificulta na determinação dos estados das mesmas. Sendo assim, nota-se uma grande importância não só do acompanhamento das forças de corte, mais também da sua evolução ao longo dos ciclos de usinagem, contribuindo para a detecção de avarias e desgastes de ferramentas de corte. 
Foi adotado um monitoramento off-line de cada passe do processo de fresamento, com a utilização de ciclos iniciais para o aprendizado do sistema. Para cada passe de fresamento, o sistema adquire o sinal de "LOAD" spindle ao longo de toda a usinagem, e ao final do passe calcula-se a média desse sinal e compara-se com limites proporcionais a uma média de referência. A média de referência é determinada nos primeiros passes quando a ferramenta está em condições normais de corte, ou seja, sem desgastes e/ou avarias. O usuário do sistema de monitoramento é quem define a quantidade de ciclos iniciais necessários para o cálculo dessa média de referência a ser utilizada nas comparações com os demais ciclos de corte. Após os ciclos de aprendizado do sistema, é calculada a média de referência e uma janela de comparação com seus limites inferiores e superiores é mostrada. Estes limites são proporcionais à média de referência segundo valores pré-definidos pelo usuário, como por exemplo, limite inferior igual a 20\% menor e limite superior igual a $20 \%$ maior do que a média de referência. Assim, se após um passe de fresamento há uma média de "LOAD” spindle fora da janela definida pelos limites inferior e superior, o sistema de monitoramento automaticamente gera alertas para o operador da máquina ferramenta (por exemplo, via alarmes e/ou mensagens), podendo até mesmo executar ações, tais como parar o programa CN e/ou trocar ferramenta de corte e continuar a execução da usinagem.

\section{Procedimento experimental:}

Para testar o sistema de monitoramento de detecção de desgaste da ferramenta de corte, foram feitos quatro ensaios de usinagem com uma ferramenta de corte em situações distintas quanto ao seu desgaste de flanco (VB), conforme exposta na tabela a seguir.

TABELA 7.4 - Desgastes da ferramenta de corte nos quatro ensaios de usinagem

\begin{tabular}{|c|c|c|c|c|}
\hline Ensaios : & $\mathbf{1}$ & $\mathbf{2}$ & $\mathbf{3}$ & $\mathbf{4}$ \\
\hline $\begin{array}{c}\text { Desgaste da ferramenta } \\
\text { ( VB [mm] ) }\end{array}$ & 0 & 0,25 & 0,4 & 0,7 \\
\hline
\end{tabular}


$\mathrm{Na}$ figura 7.16 tem-se o front end do sistema de monitoramento com alguns comentários das suas funcionalidades, gráfico e valores (médio e máximo) do sinal de “LOAD” spindle para cada ensaio. O sistema de monitoramento foi utilizado durante esses quatro ensaios. Os dois primeiros ensaios foram empregados na aprendizagem do sistema para o cálculo do valor de referência do “LOAD” spindle, obtendo um valor de 1,08 (vide figura 7.16). Para a determinação da janela de monitoramento, adotou-se $20 \%$ do valor de referência do "LOAD” spindle, para cima e para baixo, para os valores de limite superior e inferior, respectivamente (vide quadro de “MONITORING SETUP” na figura 7.16). Como pode ser notado, foi empregada então uma janela de monitoramento com o limite superior de 1,3, e limite inferior de 0,86. No quadro "CYCLE SETUP” é informado para o sistema a linha $\mathrm{N}$ do programa $\mathrm{CN}$ quando inicia e termina o ciclo de corte. Assim, detecta-se automaticamente o inicio e fim do ciclo de corte, capturando o sinal de "LOAD” spindle somente no momento da usinagem. Adicionalmente, no quadro "FILTRO DE SINAL" encontra-se as constantes de configuração do filtro de sinal. À direita do front end são apresentadas as informações de saída do sistema, tais como valores de limites da janela de monitoramento e indicadores quando os mesmos são ultrapassados, e valores de média e máximo do sinal de “LOAD” spindle para cada ensaio. 


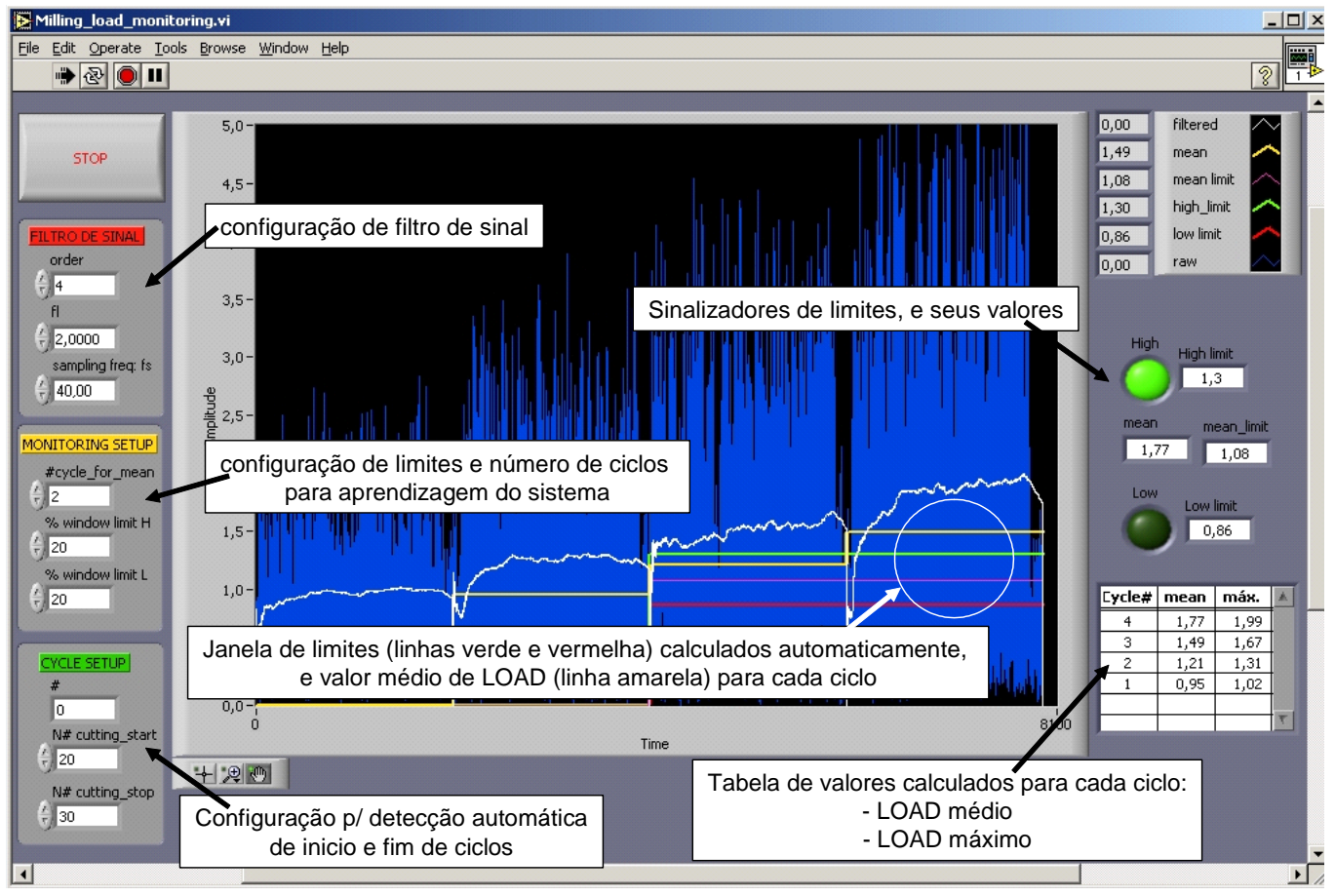

FIGURA 7.16 - Front end do sistema de monitoramento do processo de fresamento

Na figura a seguir tem-se detalhes do sinal de "LOAD” spindle ao longo de cada ensaio, seus valores médios e janela de monitoramento.

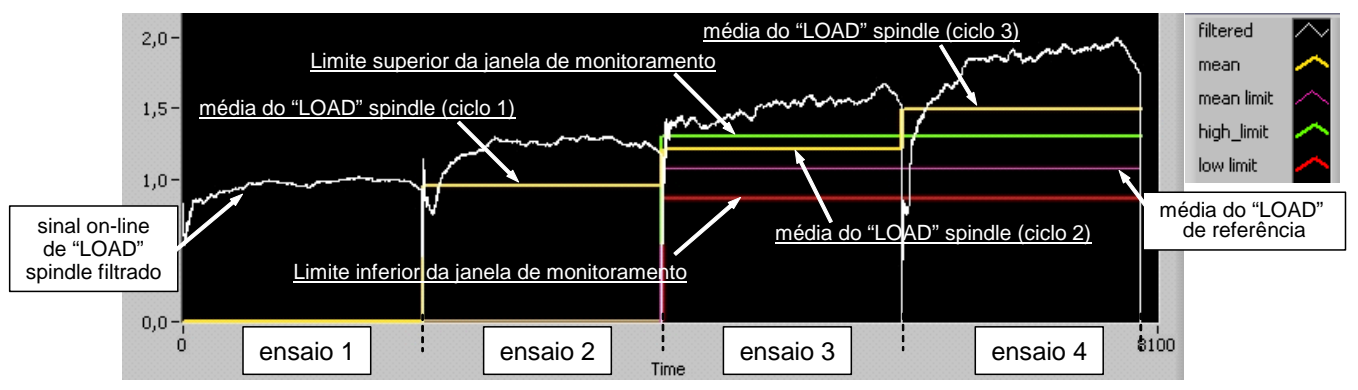

FIGURA 7.17 - Front end do sistema de monitoramento do processo de fresamento

Nota-se no gráfico da figura 7.17 que após cada ensaio tem-se o cálculo da média do sinal de “LOAD” spindle, sendo plotado no próximo ciclo (linha amarela). Como foi préconfigurado o uso de dois ciclos iniciais para o aprendizado do sistema, percebe-se que após o $2^{\circ}$ ensaio surge a janela de monitoramento com os seus limites (linha verde e vermelha) proporcionais à média de referência (linha roxa), calculada como a média dos dois primeiros ensaios. 


\section{Resultados:}

Na figura 7.18 é exposto um gráfico dos valores do sinal de “LOAD” spindle adquirido pelo sistema de monitoramento ao longo do processo de fresamento para cada ensaio.

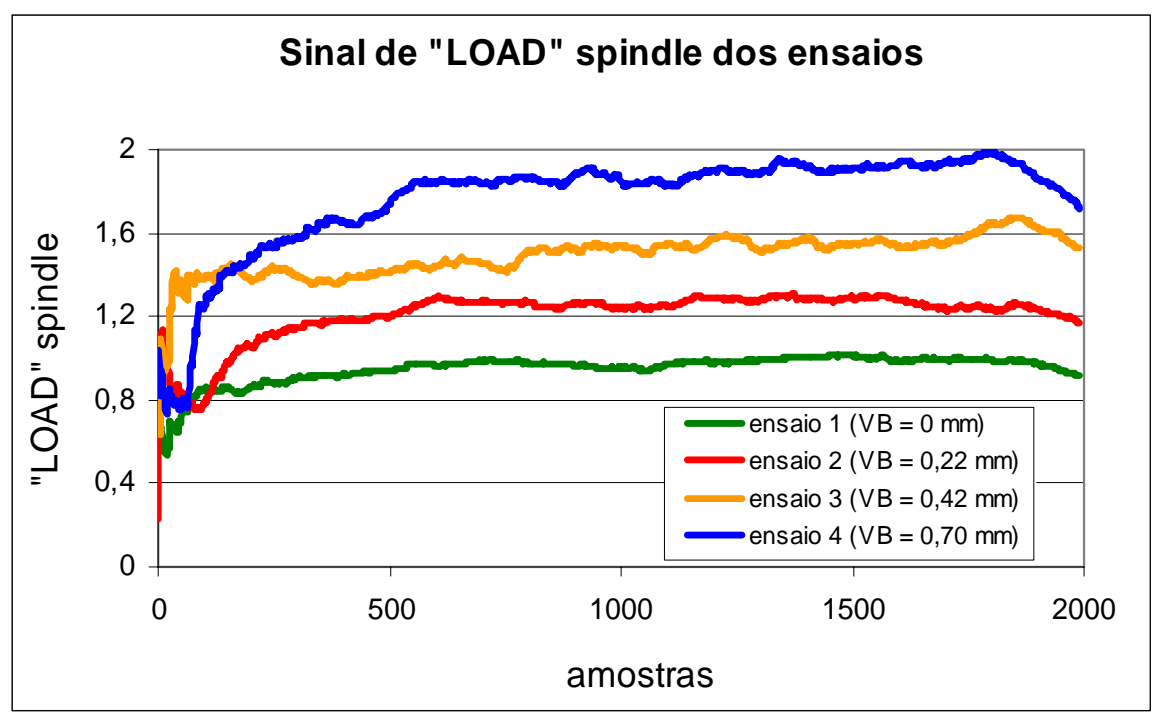

FIGURA 7.18 - Gráfico do sinal de "LOAD” spindle ao longo do processo de fresamento para cada ensaio

Nota-se, neste gráfico, que há variações do sinal de "LOAD” spindle em cada ensaio, ou seja, em cada situação de desgaste da ferramenta de corte. O sinal de "LOAD” spindle aumentou com o aumento do desgaste de flanco, variando desde valores em torno de 0,8 para a ferramenta sem desgaste, até valores em torno de 1,8 para a ferramenta com um desgaste de flanco de VB = 0,70 mm. Adicionalmente, pode-se concluir que o sinal de "LOAD” spindle permite uma sensibilidade do sistema de monitoramento para variações de desgaste de flanco de pelo menos 0,20 mm, como pode-se observar nos ensaios 2 e 3 .

Na figura 7.19 é apresentado um gráfico dos valores médios do sinal de "LOAD” spindle para cada ensaio, bem como detalhes dos desgastes da ferramenta de corte. 


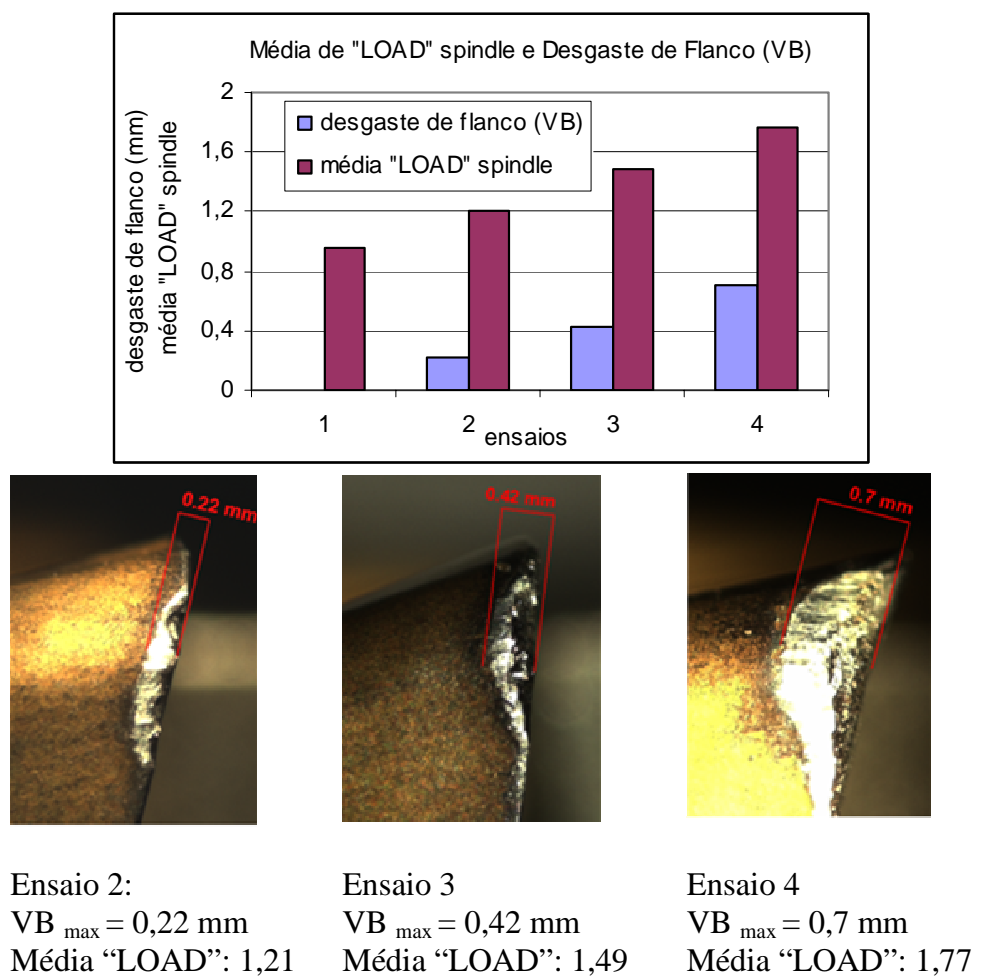

FIGURA 7.19 - Gráfico da média do sinal de “LOAD” spindle em cada ensaio de usinagem

Assim como foi observado para o sinal de "LOAD” spindle, nota-se que os valores de suas médias são também bastante distintos para cada situação de desgaste da ferramenta de corte; média do "LOAD” spindle de 0,95 para a ferramenta sem desgaste, de 1,21 para um desgaste de $\mathrm{VB}=0,22 \mathrm{~mm}$, de 1,49 para um desgaste de $\mathrm{VB}=0,42 \mathrm{~mm}$, de 1,77 para um desgaste de $\mathrm{VB}=0,70 \mathrm{~mm}$.

Baseando-se nas configurações iniciais para a definição da janela de monitoramento, percebe-se que o sistema de monitoramento detectou um desgaste da ferramenta de corte acima de seu limite à partir do $3^{\circ}$ ensaio (vide figura 7.20). 


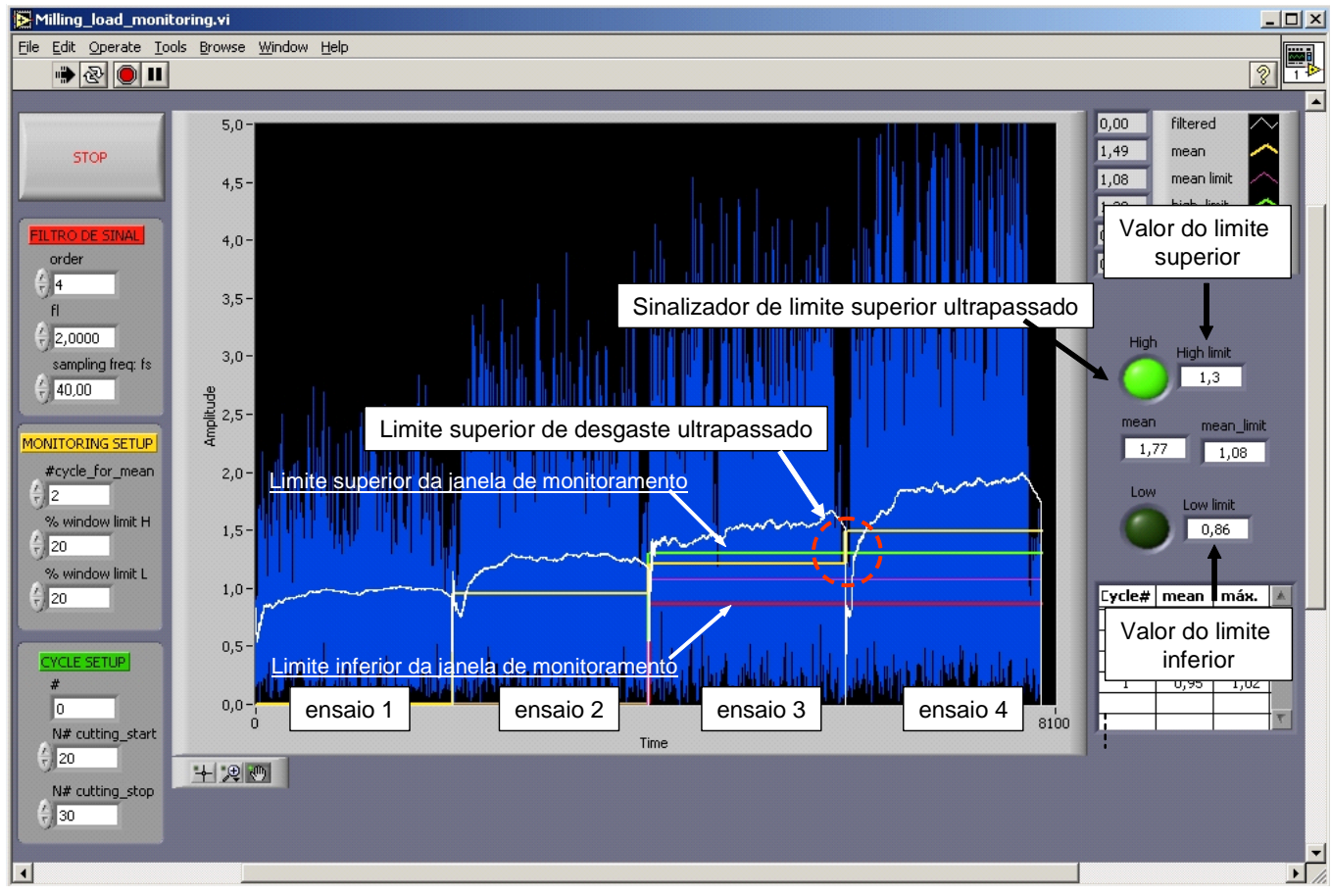

FIGURA 7.20 - Detalhe da detecção de limite de desgaste da ferramenta de corte ultrapassado

\section{Conclusão:}

À partir dos resultados apresentados, pode-se concluir que a arquitetura de comunicação proposta é perfeitamente viável para o desenvolvimento de sistemas de monitoramento, bem como o emprego das variáveis que são possíveis de serem adquiridas através da mesma; no caso, a variável “LOAD” spindle e a variável de leitura de bloco do programa CN em execução. Em particular, a variável “LOAD” spindle mostrou-se útil na determinação indireta dos desgastes da ferramenta de corte, apresentando valores muito distintos para cada situação do desgaste da ferramenta, facilitando a implementação da estratégia de monitoramento. Todo o sistema de monitoramento foi implementado utilizando-se somente os recursos disponíveis na máquina-ferramenta, sem alterações da área de trabalho e sem sensores adicionais. 


\subsubsection{Rotina de aquisição de sinais para o estudo de fenômenos de usinagem}

A seguir, são apresentados alguns exemplos de estudos de fenômenos de usinagem utilizando como ferramenta a arquitetura de comunicação proposta para as máquinas ferramenta com CNCs SIEMENS Sinumerik 810D/840D: PC externo com comunicação direta com um CNC/CLP SIEMENS Sinumerik 810D/840D, via rede RS-485 MPI/OPI e protocolo DDE.

Com esta arquitetura de comunicação torna-se possível a aquisição on-line de informações do CNC, CLP e drivers, e até mesmo sincronizá-las com sinais de sensores adicionalmente instalados na máquina ferramenta, possibilitando, por exemplo, análises da relação entre velocidades de avanço (reais e programadas), forças de corte e tipos de interpolações em geometrias complexas.

A figura 7.21 mostra a aquisição de velocidades de avanço real e programada (setpoint), e respectivas coordenadas Z e X durante um processo de fresamento. Com estas informações, podem-se fazer análises on-line das variações de velocidades de avanço ao longo do corpo de prova. Torna-se possível conferir as diferenças entre as velocidades de avanço real e programada, que podem ser fontes de variações de acabamentos superficiais.

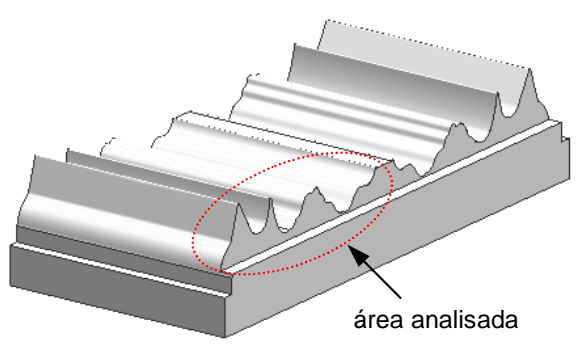

corpo de prova

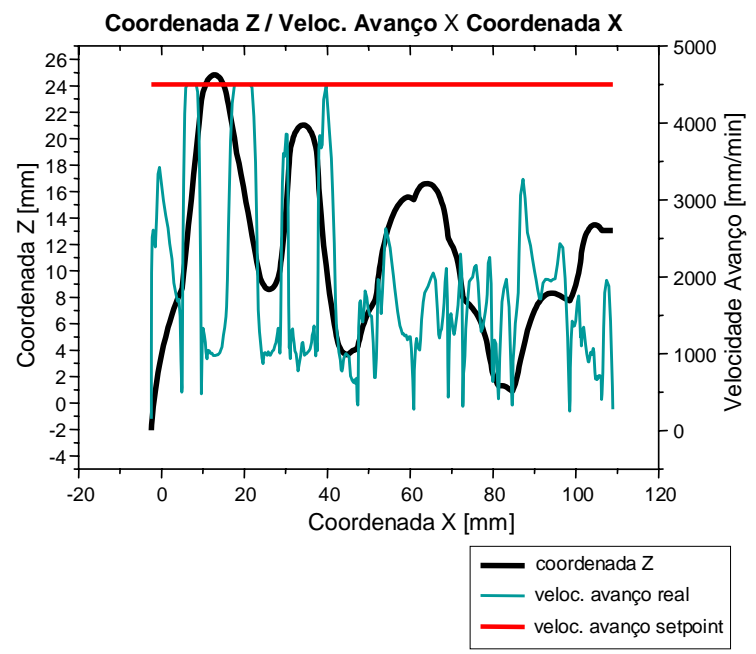

FIGURA 7.21 - Análise de velocidades de avanço (real e de setpoint) ao longo do corpo de prova 
A figura 7.22 apresenta o sincronismo on-line da aquisição de sinais obtidos diretamente do CNC (coordenadas X e Z), e de sinais de um dinamômetro (força na direção Z) instalado na máquina ferramenta. Desta forma, pode-se analisar detalhadamente as variações de forças de usinagem de acordo com os tipos de interpolações do CNC, bem como detectar pontos críticos, ao longo do corpo de prova, com relação às forças de usinagem e acabamentos/qualidades de peças usinadas, entre outras possibilidades.

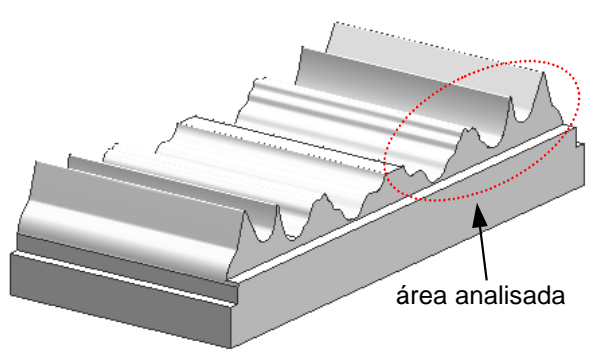

corpo de prova

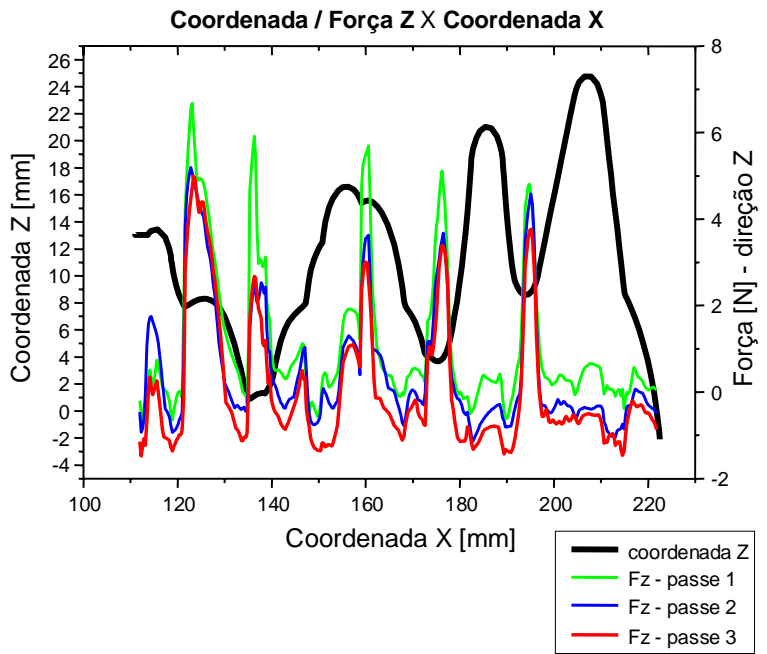

FIGURA 7.22 - Análise de forças de corte ao longo do corpo de prova

A implementação das soluções de monitoramento e supervisão, utilizando a arquitetura proposta pelo presente projeto de doutorado, demandaram, praticamente, apenas o desenvolvimento de software e o cabeamento da rede de comunicação com as máquinas. Portanto, nos exemplos dos sistemas de supervisão (desenvolvidos no laboratório OPF e na EMBRAER), os custos principais foram referentes ao cabeamento da rede de comunicação, a licença de um software SCADA (LabView e Cimplicity) e a programação para o desenvolvimento do sistema. Particularmente para o caso da EMBRAER, até mesmo o custo de cabeamento da rede de comunicação foi eliminado, pois foi utilizada toda a infra-estrutura (cabeamento de rede Ethernet TCP/IP, eletro calhas, etc) já existente do sistema DNC de gerenciamento de programas CN. Caso esse projeto fosse solucionado através de métodos 
convencionais, deveria ser utilizado um novo cabeamento de comunicação de rede para os módulos remotos de aquisição de sinais digitais e analógicos (RTUs) a serem empregados na captura de dados da máquina, para o posterior processamento e conversão dos mesmos em informações. Ter-se-iam também custos adicionais em instalações (painéis elétricos para instalação dos RTU’s, ou CLPs), hardware (placas controladoras RS485 e os módulos RTU) e na programação dos mesmos. A solução tradicional, além apresentar maiores custos, teria restrições quanto às possibilidades de informações possíveis de serem acessadas. Não seria possível, por exemplo, a leitura de alarmes e mensagens presentes nas máquinas, o programa CN em execução, o número da ordem de produção, a identificação da peça, os tempos de utilização de cada ferramenta de corte, entre outras informações.

Quanto aos exemplos de monitoramento testados em laboratório, estes se mostraram eficientes e possíveis de serem implementados utilizando a arquitetura proposta. Permitiu a aquisição de sinais provenientes de sensores já instalados nas máquinas ferramentas, o que garantiu robustez do sistema e menores custos de instalação. Adicionalmente, foi evitado o uso de placas de aquisição e condicionadores de sinais. Através da arquitetura proposta, tornaram-se possíveis algumas rotinas de aquisição de sinais, tais como a aquisição de valores de avanço de setpoint e reais sincronizados com as coordenadas de interpolação, além do sincronismo de leitura dessas coordenadas com sinais provenientes de sensores externos, como sinais de um dinamômetro conforme exposto no item 7.2.2. Através de métodos convencionais, seria necessário o uso de sensores de posição (réguas óticas lineares, encoders, etc) para cada eixo da máquina, cálculos e instalações complexas que poderiam comprometer a robustez do sistema e a área de trabalho. O custo de um sistema externo seria muito mais elevado.

Pode-se ter as seguintes conclusões quanto aos sistemas de supervisão e monitoramento implementados com a arquitetura proposta: 
- envolveram mínimos gastos com infra-estrutura;

- reduziram ou eliminaram o uso de sensores externos, além de placas e condicionadores de sinais;

- garantiram robustez e funcionalidade por utilizarem sistemas (redes de comunicação, sensores, etc) provenientes da própria máquina-ferramenta. 


\section{CONCLUSÃO}

O presente trabalho é multidisciplinar nas áreas de automação e usinagem e objetiva a apresentação de propostas de arquiteturas para a integração das mesmas. Abrangeu tanto os elementos tecnológicos dos CNCs de arquitetura aberta, bem como os sistemas de monitoramento e supervisão dos processos de usinagem.

A respeito dos CNCs de arquitetura aberta e de sistemas de monitoramento e supervisão, pode-se concluir que:

- $\quad$ CNC de IHM baseada em PC apresenta ambientes de hardware e software que auxiliam o desenvolvimento e integração de sistemas de supervisão e monitoramento, contribuindo para a integração de todo o sistema de manufatura, melhorias na qualidade de produtos, otimização dos processos de fabricação e redução de custos da produção.

- CNC de arquitetura aberta dispõe de protocolos padrões para a comunicação e integração de aplicativos, permitindo a livre escolha de ambientes de programação, reaproveitamento de softwares e redução de mão de obra especializada.

- Sistemas de supervisão e monitoramento podem ser implementados utilizando-se de todos os recursos (sensores, redes de comunicação, servidores, base de dados, aplicativos, etc) já disponíveis nas máquinas-ferramenta, reduzindo, ou até mesmo eliminando, a necessidade de hardware e software adicionais, sendo estes muitas vezes de altos custos e intrusivos nos processos de fabricação. 
Utilizando as vantagens dos controles de arquitetura aberta para a implementação de sistemas de automação e o conceito de micromonitoramento da produção, foi apresentada uma proposta inovadora de arquitetura universal para explorar as potencialidades de ambas as tecnologias, expondo exemplos de implementações em laboratório e em empresa (EMBRAER). Buscou-se implementar e integrar os sistemas de supervisão e de monitoramento em CNC's de arquitetura aberta baseados em open HMI, utilizando-se somente os recursos já disponíveis na máquina ferramenta.

Os resultados mostraram que o uso de CNC's abertos para monitoramento e supervisão de processos com a arquitetura proposta é viável e proporciona funções de monitoramento/supervisão que não eram possíveis, ou seriam muito dispendiosas, com os sistemas convencionais. Usando-se a arquitetura proposta, algumas lacunas nos sistemas atuais de monitoramento e supervisão de processos discretos foram preenchidas, tais como:

- A aquisição de informações (da produção, máquina, processo e da ferramenta) de forma automática e integrada, com menores tempos de atualizações e envolvendo diversas máquinas ferramentas que compõe um sistema de manufatura.

- A possibilidade de desenvolver sistemas de monitoramento e supervisão utilizando somente os recursos já disponíveis nas máquinas ferramenta CNC, sem a necessidade de instalação de equipamentos adicionais (sensores, condicionadores, etc);

- A utilização de uma arquitetura de comunicação única para ambos os sistemas de automação, possibilitando a supervisão e o monitoramento simultaneamente. 
Foi apresentada com detalhes cada uma das opções de configuração da arquitetura proposta, possível de ser utilizada em CNC's de arquitetura aberta baseados em open HMI. Todas as opções utilizam a mesma filosofia que é a de desenvolver sistemas de monitoramento e supervisão de forma integrada através de uma única arquitetura, utilizando somente os recursos disponíveis nas máquinas ferramenta e realizando a aquisição de informações de forma automática e à baixas resoluções de tempo (frações de segundos). Adotando-se algumas das opções, foi possível a implementação, o teste e a execução simultânea de funções de sistemas de supervisão e monitoramento.

A implementação do projeto piloto de supervisão das máquinas ferramenta na EMBRAER foi bem sucedida. Através deste projeto, foi possível à Embraer um melhor gerenciamento da produção, da manutenção de máquinas e da otimização de seus processos de usinagem, proporcionando ganhos de produtividade por conta da automatização de um processo que antes era manual. Baseando-se na arquitetura proposta no projeto piloto, o projeto EMBRAER-CEEHM está expandindo para as demais máquinas ferramenta, tornandose um sistema coorporativo e interligado com os demais departamentos do sistema produtivo da EMBRAER.

As opções de configuração da arquitetura proposta contribuíram, não somente para a implementação de sistemas de monitoramento e supervisão em máquinas CNC de arquitetura aberta, como também para o estudo de fenômenos de usinagem através da aquisição direta de sinais provenientes do CNC, CLP e Drivers das máquinas, tais como potência, posições dos eixos, etc, e sincronismo dos mesmos com sinais provenientes de sensores externos. Os experimentos e funcionalidades apresentados como exemplo são inovadoras, não foram encontradas em trabalhos anteriores e representam um avanço na forma de utilização de máquinas ferramentas modernas. 


\section{REFERÊNCIAS BIBLIOGRÁFICAS}

\section{Referências Bibliográficas Citadas}

ALTINTAS, Y.; MUNASINGHE, W. K. (1994). A Hierarchical Open-Architecture CNC System for Machine Tools, Annals of the CIRP, v. 43, n. 1, p. 349-354.

ASATO, O. L. et al (2002). Analysis of open CNC architecture for machine tools. Journal Brazilian Society of Mechanical Sciences, v. 24, n. 3, p.208-212.

AUTOMACAO.NET (2001). SCADA/ HMI. http://www.automacao.net/scada.htm (4 mar.)

BLUM, T.; SUZUKI, I.; INASAKI, I. (1988). Development of a Condition Monitoring System for Cutting Tools Using an Acoustic Emission Sensor. Bulletin of theJapan Society of Precision Engineering, v. 22, n.4, p.301-8.

BUZATTO, W. T. (1999). Open CNC. Controle \& Instrumentação, p.70-71, jan.

BYRNE, G. et al (1995). Tool Condition Monitoring (TCM) - The Status of Research and Industrial Application. Annals of the CIRP, v. 44, n.2, p.541-67.

DANEELS, A.; SALTER, W. (1999) What is SCADA? International Conference on Accelerator and Large Experimental Physics Control Systems. p.339-43.

DINIZ, A. E.; PIGARI, A. (1995). Monitoramento do processo de torneamento em desbaste via emissão acústica. Congresso Brasileiro de Engenharia Mecânica - COBEM.

DU, R.; ELBESTAWI, M. A.; WU, S. M. (1995). Automated monitoring of manufacturing process, part 1: monitoring methods. ASME Journal of Engineering of Industry, v.117, n.2, p.121-32. 
ENDEAVORENG (2006). SCADA

Details.http://www.endeavoreng.com/endeavor/scada_details.html (25 jan).

FERRAZ JR., F. (2002). Desenvolvimento de um sistema de monitoramento e supervisão para o processo de torneamento. São Carlos, 2002. 94p. Dissertação (Mestrado) - Escola de Engenharia de São Carlos, Universidade de São Paulo.

GERMAIN, G. L.; CLARKE, T. W. (1998). A.R.T. of supervisory control and data acquisition. In: INTERNATIONAL PIPELINE CONFERENCE, Calgary, 1998. Proceedings, Fairfield, ASME, p 895-902.

GONÇALVES FILHO, E. V. (1994). Comando Numérico de Máquinas Ferramentas. São Carlos. 45p. Apostila - Escola de Engenharia de São Carlos, Universidade de São Paulo.

HERRIN, G. E. CIM Perspectives - Who Benefits from Open Architecture. MMSonline. Disponível em: <http://www.mmsonline.com/articles/0698cim.html>. Acesso em: 4 de abril de 2001.

HONEYWELL (2000). http://www.iac.honeywell.com-plantscape.com (4 mar).

INSTITUT FÜR ANGEWANDTE ORGANISATIONSFORSCHUNG (1984). Comando Numérico CNC: técnica operacional: curso básico. Editora Pedagógica e Universitária Ltda, São Paulo.

INTERBUSCLUB (2001). http://interbusclub.com (4 jun).

ISA - The Instrumentation, Systems, and Automation Society (2000). Sensors Guide. http://www.isa.org ( 4 mar).

JEMIELNIAK, K. (1999). Comercial tool condition monitoring systems. The Internacional Journal of Advanced Manufacturing Technology, v.15, p.711-21.

KLUFT, W. (1983). Werkzeugüberwachungssysteme für die Drehbearbeitung, doctoral thesis, RWTH Aachen.

KLUFT, W. (1994). A monitoração dos processos reduz custos e desperdícios. Máquinas e Metais, n.345, p.60-80, outubro. 
KRAR, S.; GILL, A. (2002). Exploring Advanced Manufacturing Technology - Part 2: Open Architecture CNC. Advanced Manufacturing, March. Disponível em: $<$ http://www.advancedmanufacturing.com/March02/exploringamt.htm>. Acesso em: 22 de janeiro de 2003.

LANDERS, R. G.; ULSOY, G. A. (1998). Supervisory Machining Control: Design Approach and Experiments. Annals of the CIRP, v. 47, n.1, p.301-306.

LIANG, S. Y. et al (2002). Machining Process Monitoring and Control: The State-of-the-art. ASME International Mechanical Engineering Congress \& Exposition, n. IMECE2002MED-32640, November.

LIANG, S. Y. et al (2004). Machining Process Monitoring and Control: The State-of-the-art. Journal of Manufacturing Science and Engineering, v.126, p.297-310.

LÖDDING, H., OLIVEIRA, J.F.G. (2005). Micromonitoring: An Advanced Method for Production Control and Improvement. The 38th CIRP - International Seminar on Manufacturing Systems, Florianópolis - Brazil.

MATHEW, J.; DAN, L. (1990). Tool wear and failure monitoring techniques for turning: a review. Internacional Journal of Machine Tools Manufacturing, v.30, n.4, p.579-98.

MDSI - Manufacturing Data Systems, Inc. When is open architecture machine control really open? Disponível em: <http://www.mdsi2.com/products/openarch.htm>. Acesso em: 12 de maio de 2003.

MEIRELES, G. S. C. (2000). Desenvolvimento de sistema de aquisição de dados em operações de usinagem visando o monitoramento de linhas ou células de produção. São Carlos, 2000. 97p. Dissertação (Mestrado) - Escola de Engenharia de São Carlos, Universidade de São Paulo.

MINTCHELL, G. A. (1998). New at IMTS PCs Boost CNC Capability. Control Engineering Online, $\quad$ November, $1998 . \quad$ Disponível em: $<$ http://www.controleng.com/archives/1998/ctl1101.98/ 11d955.htm> . Acesso em: 5 de abril de 2001.

MINTCHELL, G. A. (2000). CNC Technology: Another weapon in integrated manufacturing's arsenal. Control Engineering, v. 47, n. 12, November, p. 62-70. 
MINTCHELL, G. A. (2001) Control, MES Partner for C-Manufacturing Solutions. Control Engineering. http://www.manufacturing.net.

MMSonline. Scanning the horizon: Control Builder says Open Architecture should mean Open Architecture. Disponível em: <http://www.mmsonline.com/articles/0496scan2.html>. Acesso em: 5 de abril de 2001.

NCS TIB 04-1 (2004). Supervisory Control and Data Acquisition (SCADA) Systems. National Communications System, Technical Information Bulletin 04-01, October.

NOURSE, B. E. Achieving Hard Real-Time for CNC on Windows NT. Disponível em: $<$ http://www.mdsi2.com/products/MDSIRealTimeCNC.htm>. Acesso em: 4 de abril de 2001.

OPC Foundation (2001). OPC Techical Overview. http://www.opcfoundation.org (4 mar).

OSACA (2004). http://www.osaca.org/_pdf/OSACA_part1_v20.pdf - Part I : Basic of OSACA, v. 2.0

PRITSCHOW, G. et al (1993). Open System Controllers - A Challenge for the Future of the Machine Tool Industry. Annals of the CIRP, v. 42, n. 1, p. 449-453.

PRITSCHOW, G. et al (2001). Open Controller Architecture - Past, Present and Future. Annals of the CIRP, v. 50, n.2, p. 1-7.

ROCHA, I. R. (1998). Redes de comunicação industriais: solução ou opção ?. Revista InTech Brasil, ano 1, n. 4, p. 26-30, maio.

ROCKWELL (2000). http://www.software.rockwell.com (4mar).

ROCKWELL (2004). Making Sense of e-Manufacturing: A Roadmap for UK Industry. http://www.rockwellautomation.co.uk

SANTOCHI, M. et al. (1997). A sensor-integrated tool for cutting force monitoring. Annals of the CIRP, v. 46, n.1, p.49-52.

SCHOFIELD, S. (1996). Open Architecture Controller for Advanced Machine Tools, Ph.D. Thesis, University of California, Berkeley apud ASATO, O. L. et al (2002). Analysis of 
open CNC architecture for machine tools. Journal Brazilian Society of Mechanical Sciences, v. 24, n. 3.

SIEMENS (2000). The SINUMERIK System DOC ON CD. 04/2000 Edition, electronic manual (CD)

SIEMENS (2000). http://www.siemens.com (4 mar).

SOKOLOWSKI, A.; KOSMOL, J. (2001). Selected examples of cutting process monitoring and diagnostics. Journal of Materials Processing Technology, v.113, p.322-330.

SOUZA, A. J. (1999). Desenvolvimento e implementação de funções de automação inteligentes num torno CNC utilizando técnicas de monitoramento por emissão acústica. São Carlos,. 82. Tese (Mestrado) - Escola de Engenharia de São Carlos, Universidade de São Paulo.

TANGUY, J.-C. (1993). Monitoração automática da usinagem: como e por quê. Máquinas e Metais, n.325, p.78-90, fev.

TEK Soft Consulting (1999). SCADA Introduction. http://www.iinet.net.au/intro.html (25 agosto).

TÖNSHOFF, H. K. et al (1992). Modelling and Simulation in Grinding Processes. Annals of the CIRP, v. 41, n.2, p.677-688.

TÖNSHOFF, H. K. et al (2002). Process Monitoring in Grinding. Annals of the CIRP, v. 51, n.2, p.551-671.

TÖNSHOFF, H. K.; INASAKI, I. (2002). Roles of sensors in manufacturing, edited by Tönshoff, H.K., Inasaki, I., Wiley-VCH.

TURNER, J. M. Evaluating CNC Technology: Fact Vs. Rhetoric. Reprinted from Production Magazine, October, 1994.

ULSOY, KOREN; RASMUSSEN (1983). Principle development in the adaptive control of machine tools. ASME Journal of Dynamic Systems, Measurement, and Control, v. 105, p.107-112. 
USHER, M. J. (1985). Sensors and transducers. MacMillan Publisher Ltd., Houndsmills, Basingstoke, Hampshire and London.

WHEELWRIGHT, S. C. (1978). Reflecting corporate strategy in manufacturing decisions. Business Horizons, p.57-66, Feb.

WIENDAHL, H. -P.; LUTZ, S. (2002). Production in Networks. Annals of the CIRP, v. 51, n. 2, p.573-586.

WONDERWARE (2000). http://www.microsoft.com/industry/man (4 mar).

WRIGHT, P.; SCHOFIELD, S.; WANG, F. C. (1996). Open Architecture Control for Machine Tools. Integrated Manufacturing Laboratory, University of California, Berkeley, nov. apud ASATO, O. L. et al (2002). Analysis of open CNC architecture for machine tools. Journal Brazilian Society of Mechanical Sciences, v. 24, n. 3.

ZHOU, Z. D. et al (2000). Integrated condition monitoring and fault dignosis for modern manufacturing systems. Annals of the CIRP, v. 49, n.1, p.387-390.

\section{Referências Bibliográficas Consultadas}

ARNOLD, J. R. T.; CHAPMAN, S.T. (2001). Introduction to Materials Management. $4^{\text {th }}$ ed. Prentice-Hall.

CORRÊA, H. L.; GIANESI, I. G. N. (1993). Just in time, MRPII e OPT - um enfoque estratégico. $2^{\mathrm{a}}$ ed., São Paulo: Atlas.

CORRÊA, H. L.; CORRÊA, C. A. (2004). Administração de produção e operações: manufatura e serviços: uma abordagem estratégica. $1^{\text {a }}$ ed., São Paulo: Atlas.

DINIZ, A. E.; PIGARI, A. (1996). Monitoramento do desgaste da ferramenta no processo de torneamento usando emissão acústica. Journal of the Braz. Soc. Mechanical Sciences, v.18, n. 3, September, p.227-238. 
KIM, G. D.; CHU, C. N. (2001). In-Process Tool Fracture monitoring in Face Milling Using Spindle Motor Current and Tool Fracture Index. The Internacional Journal of Advanced Manufacturing Technology, v.18 , n. 6, p.383-389.

KLOCKE, F.; KRATZ, H. (2001). Process Monitoring in Mould and Die Milling with Accelerometer Signals. Production Engineering, v. VIII, n.2, p.45-48.

LI, X. (2001). Real-Time Prediction of Workpiece Errors for a CNC Turning Centre, Part1. Measurement and Identification. The Internacional Journal of Advanced Manufacturing Technology, v.17, p.649-653.

LIU, Z.-Q. (1999). Real-Time Monitoring of Tool Fracture in Turning Using Sensor Fusion. The Internacional Journal of Advanced Manufacturing Technology, v.15, p.305-310.

LIU, Z.-Q. (2001). Methodology of Parametric Programming for Error Compensation on CNC Centres. The Internacional Journal of Advanced Manufacturing Technology, v.17, p.570-574.

MINTCHELL, G. A. (2001) “Technology advances power integrated control”, Control Engineering, p.24-31, July.

MU, Y. H.; HUNG, N. P.; NGOI, K. A. (2000). Monitoring a Sub-Newton Cutting Force for Ultra-Precision Machinig. The Internacional Journal of Advanced Manufacturing Technology, v.16, p.229-232.

NOVAK, A. (1996). On-Line Prediction of the Tool Life. Annals of the CIRP, v. 45, n.1, p.93-96.

NEELY, A.; GREGORY, M.; PLATTS, K. (1995). Performance Measurement System Design - a literature review and research agenda. International Journal of Operations \& Production Management, v.15, n.4, p. 80-116.

OMAC (2004) http://www.arcweb.com/omac - OMAC_Architecture_Final.pdf Functional Requirements, version 1.0, Release Date: 1/25/02

RYABOV, O.; MORI, K.; KASASHIMA, N. (1996). An In-Process Direct Monitoring Method for Milling Tool Failures Using a Laser Sensor. Annals of the CIRP, v. 45, n.1. 
SHINNO, H.; HASHIZUME, H. (1997). In-Process Monitoring Method for Machining Environment based on Simultaneous Multiphenomena Sensing. Annals of the CIRP, v. 46, n.1, p.53-56.

SLACK, N. et al. (1995). Administração da Produção. São Paulo: Atlas.

SLACK, N. (2002). Vantagem competitiva em manufatura: atingindo competitividade nas operações industriais. $2^{\text {a }}$ ed., São Paulo: Atlas.

WARDANY, T. I.; ELBESTAWI, M. A. (1997). Prediction of Tool Failure Rate in Turning Hardened Steels. The Internacional Journal of Advanced Manufacturing Technology, v.13, p.1-16. 


\section{APÊNDICE}

\section{CONFIGURAÇÃO PARA COMUNICAÇÃO VIA REDE MPII OPI (SIEMENS)}

Para que um PC seja anexado a uma rede MPI ou OPI de uma máquina ferramenta, devese seguir os seguintes passos:

1. Instalar a placa CP 5611 SIEMENS de comunicação PROFIBUS, e configurar os drivers e parâmetros de interface à rede através do aplicativo "Setting the PG/PC interface”. A placa deverá ser configurada para uma comunicação MPI (“CP5611(MPI)”). Na configuração da comunicação MPI deve-se definir o PC como o único master da rede, e taxa de comunicação de acordo com o CNC a ser conectado: 187.5Kbaud para CNC 810D, e 1.5Mbaud para CNC 840D. O timeout pode ser definido como 1segundo, e máximo endereço de rede de 31 (vide figura abaixo).
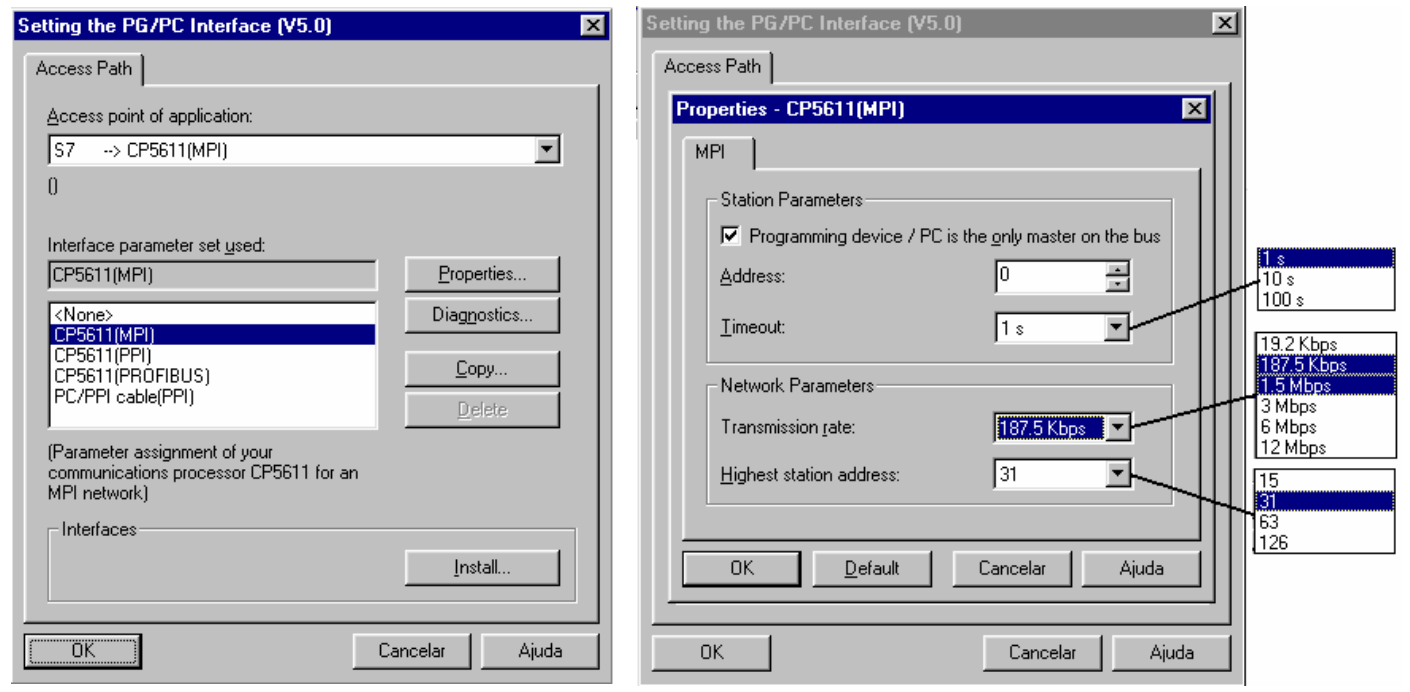

Configuração dos parametros de rede MPI e OPI. 
2. O passo seguinte deve ser a conexão das duas estações, o módulo NCU do CNC e o PC, através de cabeamento RS-485, nos terminais de acordo com o tipo de CNC, conforme indicados nas figuras a seguir. Para conectá-los, manter preferencialmente o PC e o centro de usinagem desligados, com a justificativa de evitar quaisquer danos que possam ser causados pelo acúmulo de cargas eletrostáticas.
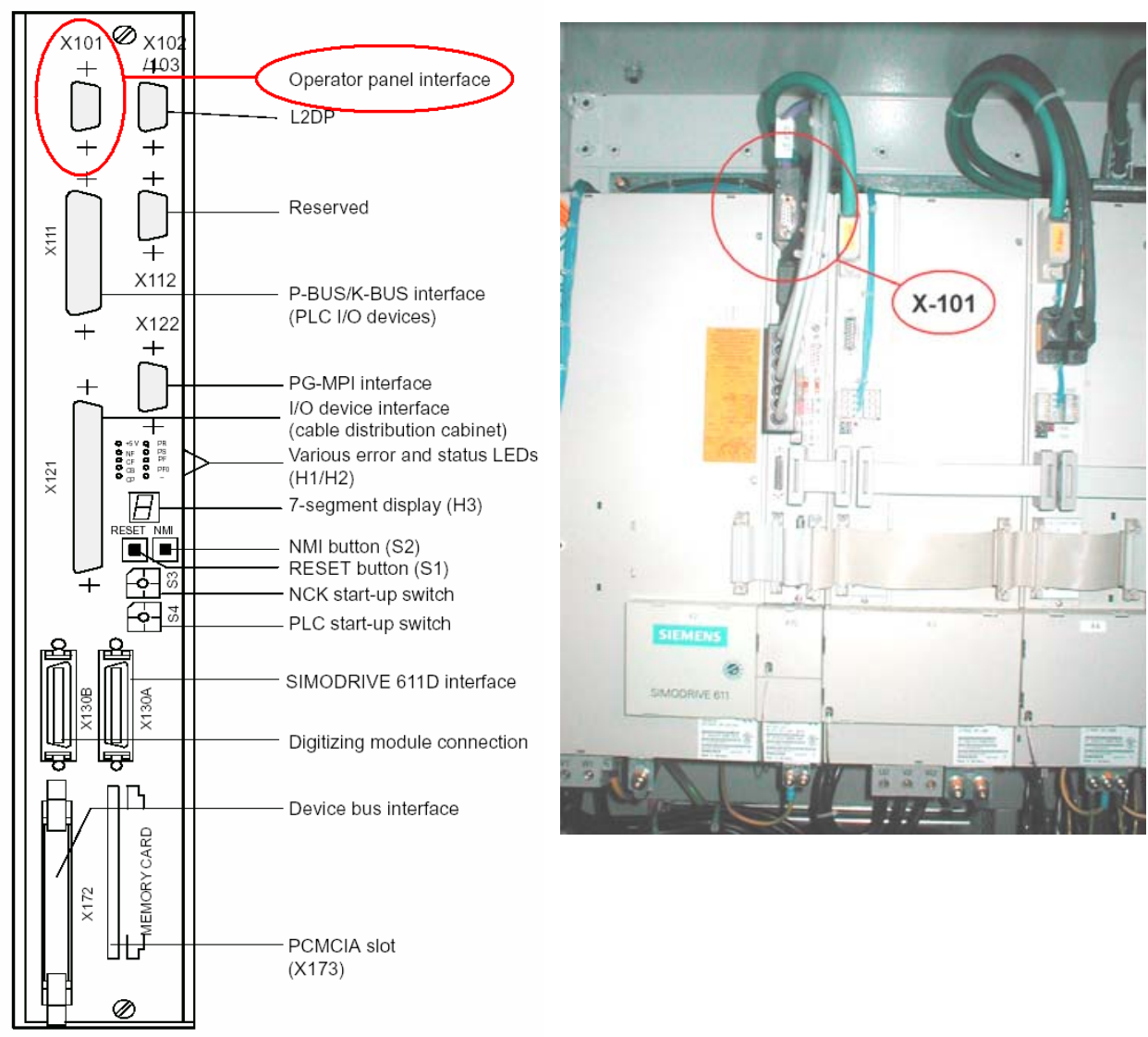

Conector $(\mathrm{X101})$ de interface à rede OPI, comando Sinumerik 840D 

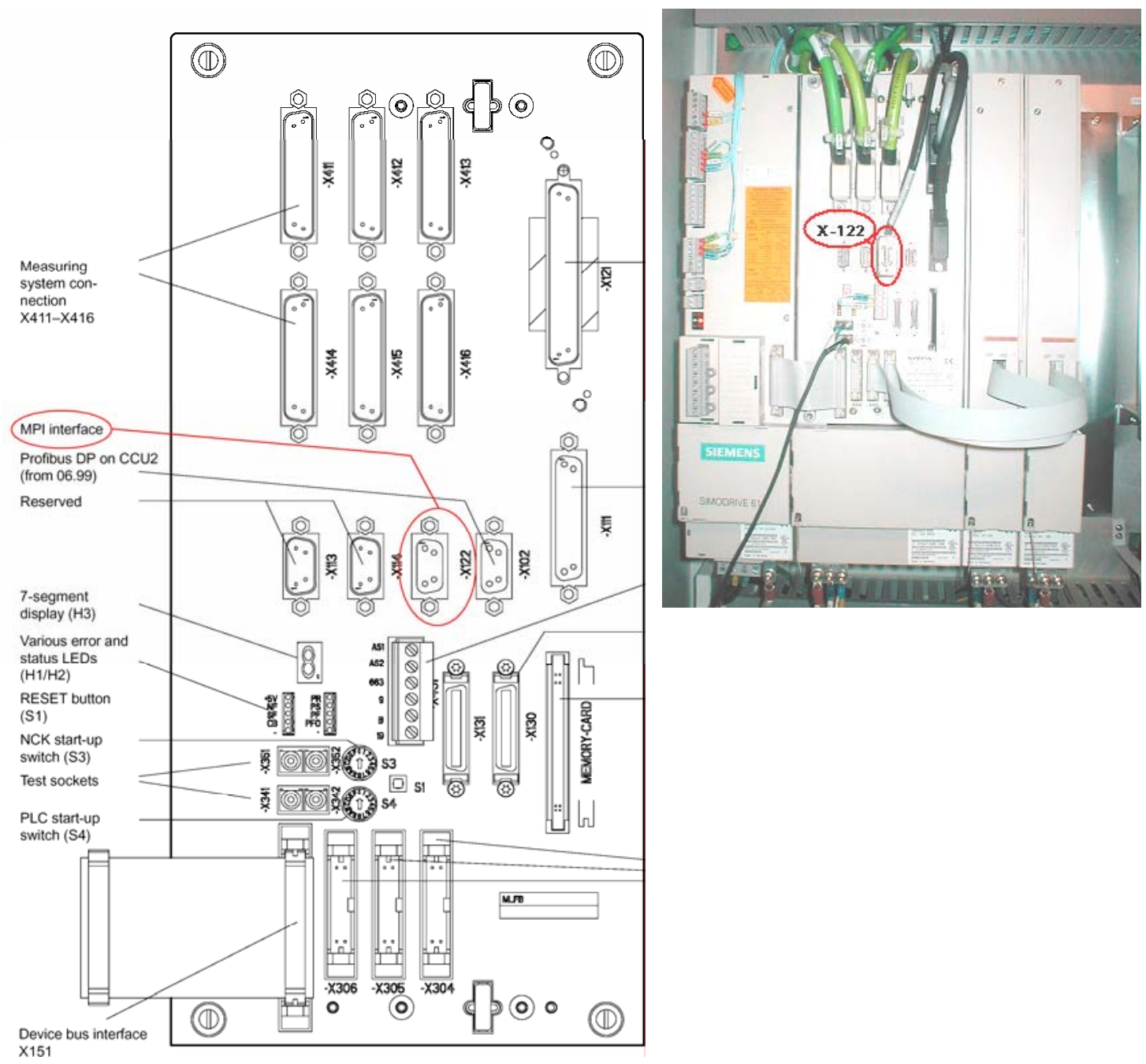

Conector (X122) de interface à rede MPI, comando Sinumerik 810D

3. Ligar o centro de usinagem e o PC, para realizar através do "Setting PG/PC Interface” um diagnóstico da comunicação, onde deverão constar todas as estações ativas da rede MPI ou OPI (vide próxima figura). 


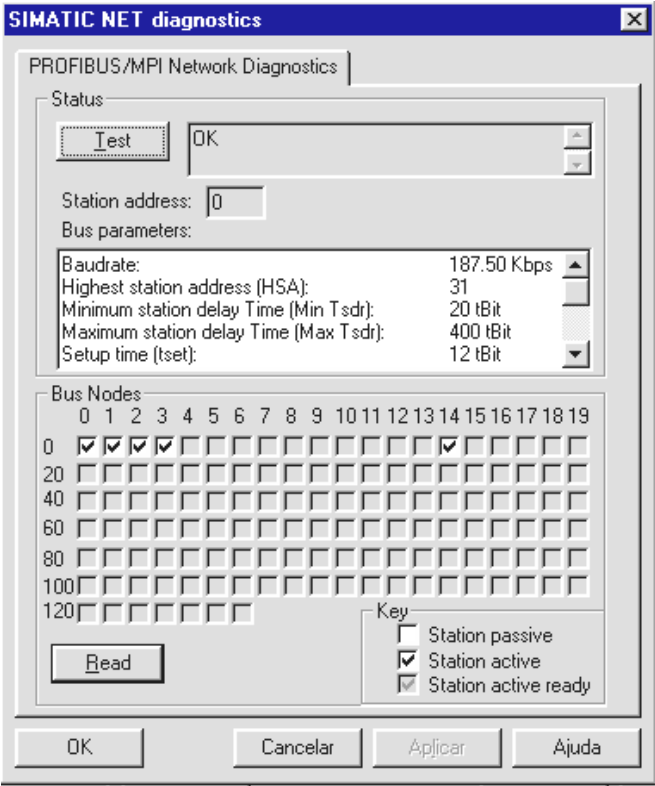

(a)

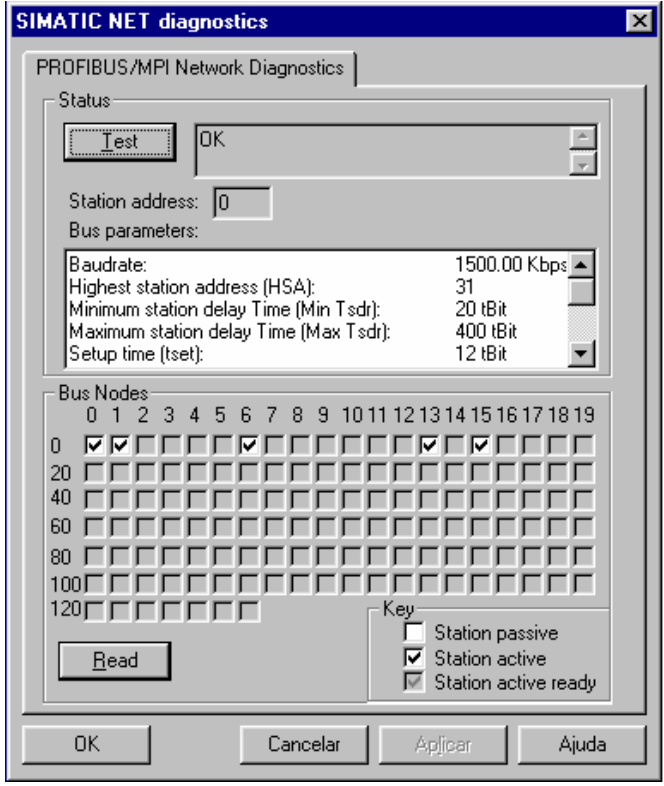

(b)

Diagnóstico de comunicação das redes MPI(a) e OPI(b).

\begin{tabular}{|c|c|c|}
\hline $\begin{array}{l}\text { MPI/OPI } \\
\text { address }\end{array}$ & $\begin{array}{c}\text { Equipamento padrão associado ao } \\
\text { endereçamento para o comando } \\
\text { Siemens } 810 \mathrm{D}\end{array}$ & $\begin{array}{l}\text { Equipamento padrão associado } \\
\text { ao endereçamento para o } \\
\text { comando Siemens } 840\end{array}$ \\
\hline \multicolumn{3}{|c|}{ 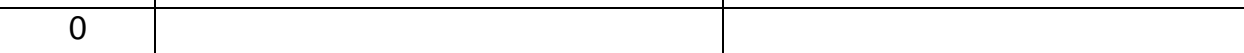 } \\
\hline 1 & MMC $100,102 / 103$ ou OP030 & MMC100, 102/103 ou OP030 \\
\hline 2 & Modulo PLC (AS314) & \\
\hline 3 & NCK (SW 3.5 ou superior) & \\
\hline \multicolumn{3}{|l|}{4} \\
\hline \multicolumn{3}{|l|}{5} \\
\hline 6 & & Painel de Controle (MCP) \\
\hline \multicolumn{3}{|l|}{7} \\
\hline 8 & $\begin{array}{c}2^{\circ} \text { Painel de Controle da Máquina } \\
(\mathrm{MCP})\end{array}$ & \\
\hline \multicolumn{3}{|c|}{ 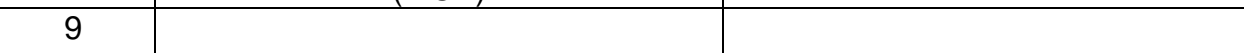 } \\
\hline \multicolumn{3}{|l|}{10} \\
\hline \multicolumn{3}{|l|}{11} \\
\hline 12 & Interface do painel e controle & \\
\hline 13 & NCK (Superior ao SW 3.4) & NCK/PLC \\
\hline 14 & $\begin{array}{l}1^{\circ} \text { Painel de controle ou unidade de } \\
\text { programação portátil }\end{array}$ & \\
\hline 15 & Unidade de controle manual (HHU) & \\
\hline
\end{tabular}

Endereços padrões dos dispositivos pertencentes às rede MPI e OPI dos CNCs SINUMERIK 810D e 840D. 
4. Com o endereçamento correto, todos os nós da rede estarão disponíveis para comunicação; 


\section{ROTINA DE SUPERVISÃO DE MÁQUINAS FERRAMENTA COM CNC SIEMENS 8X0D}

A seguir é apresentado a programação LabView 7.1 de um exemplo de sistema de supervisão implementado em três máquinas ferramenta de open HMI, do laboratório OPF. Essas máquinas ferramenta utilizam CNC SIEMENS Sinumerik 8x0D, e são: um centro de usinagem HERMLE C800U (Sinumerik 840D), um centro de usinagem ROMI DISCOVERY 560 (Sinumerik 810D) e um torno INDEX GU 600 (Sinumerik 810D).

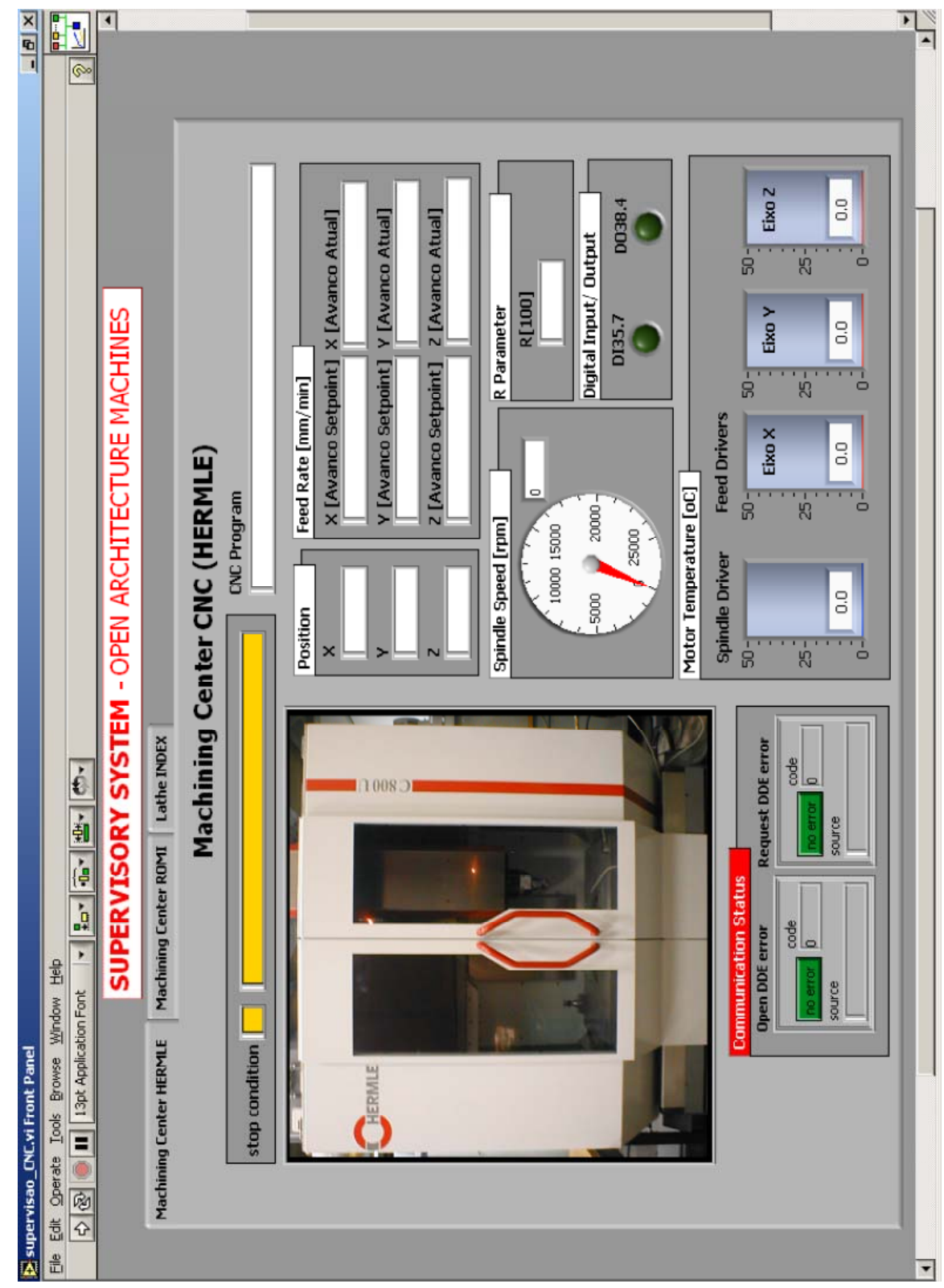

Figura 1 - Front end do sistema de supervisão: informações do centro de usinagem HERMLE. 


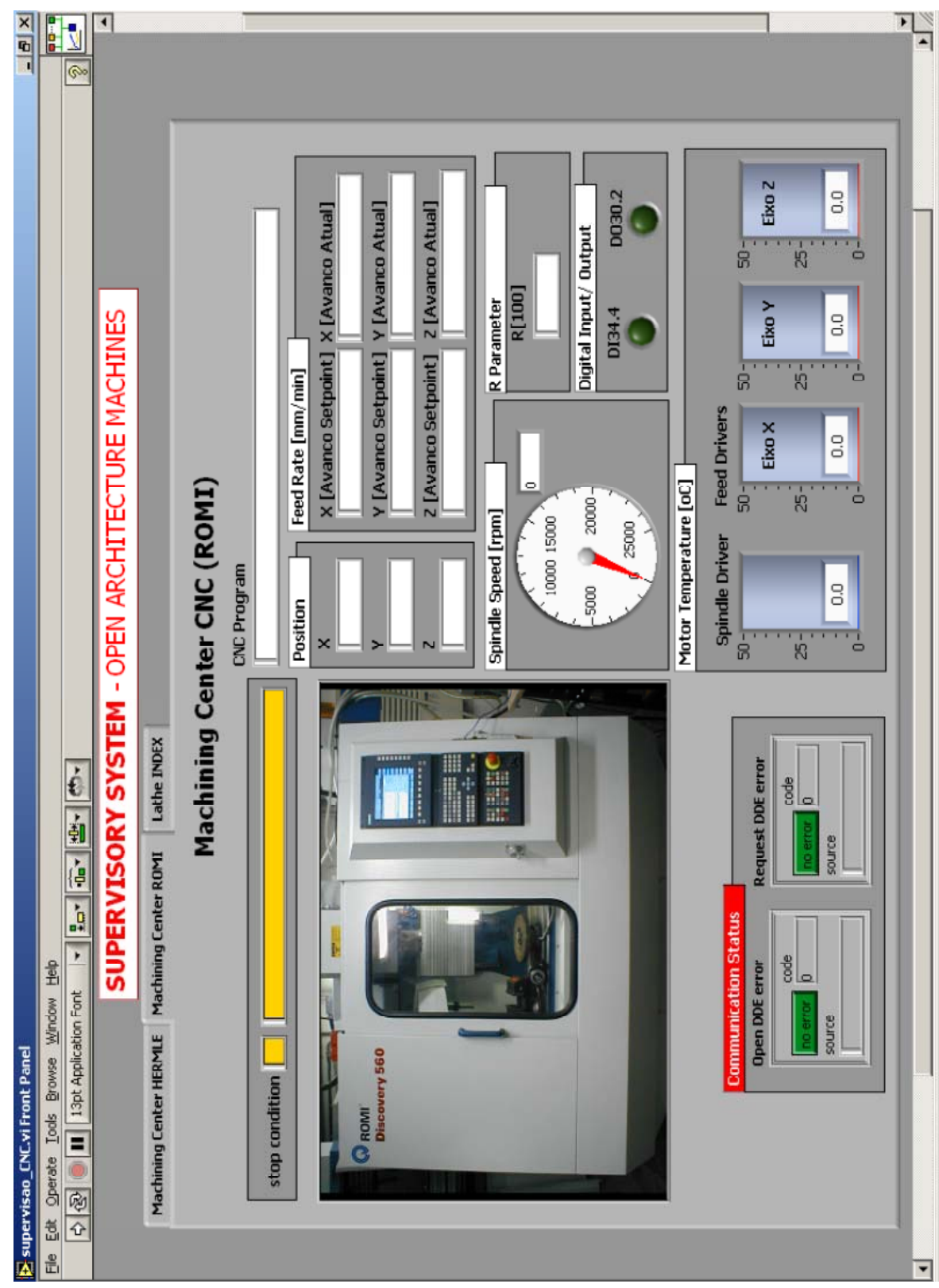

Figura 2 - Front end do sistema de supervisão: informações do centro de usinagem ROMI. 


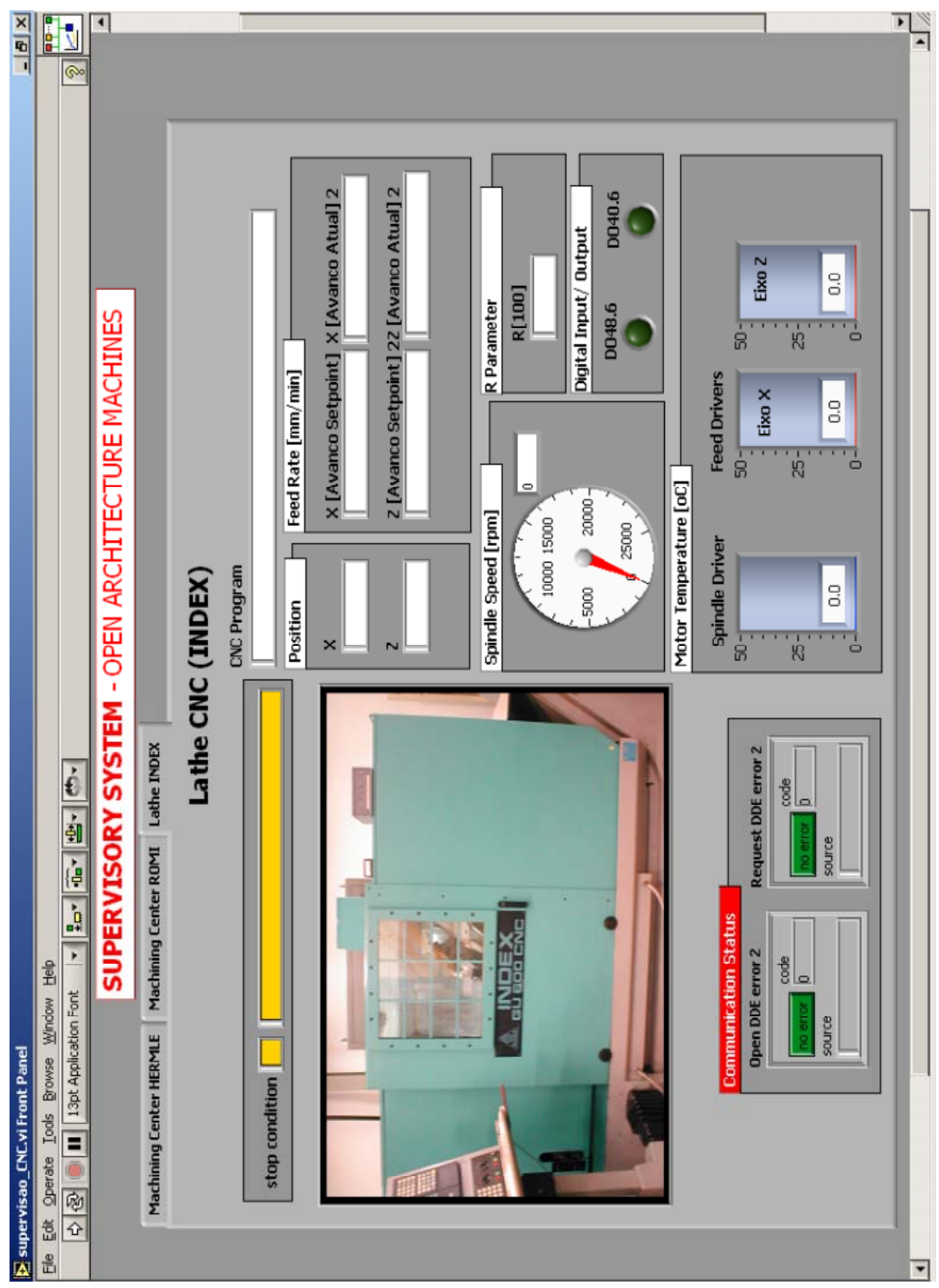

Figura 3 - Front end do sistema de supervisão: informações do torno CNC INDEX. 


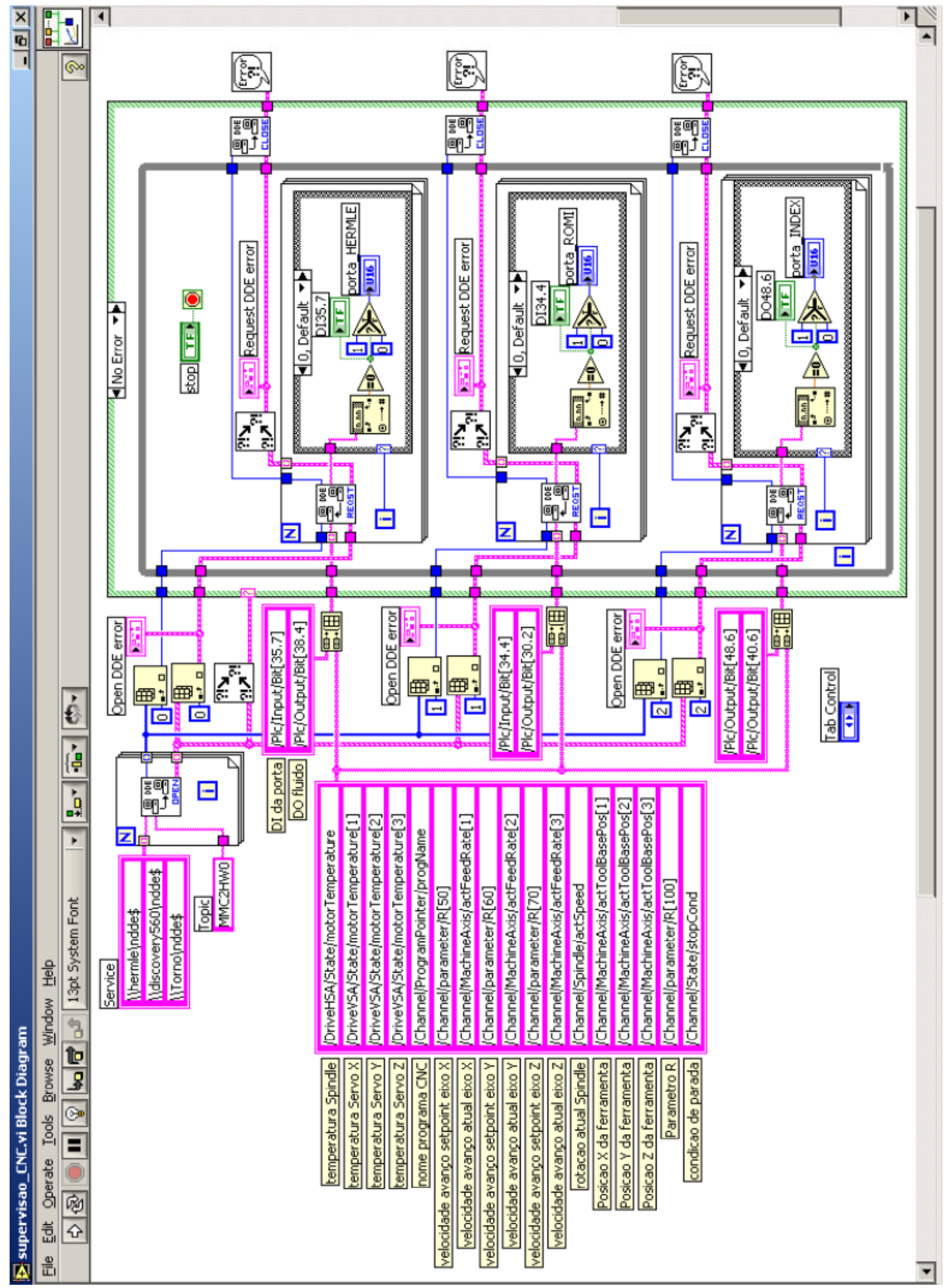

Figura 4 - Diagrama de programação: visão geral. 


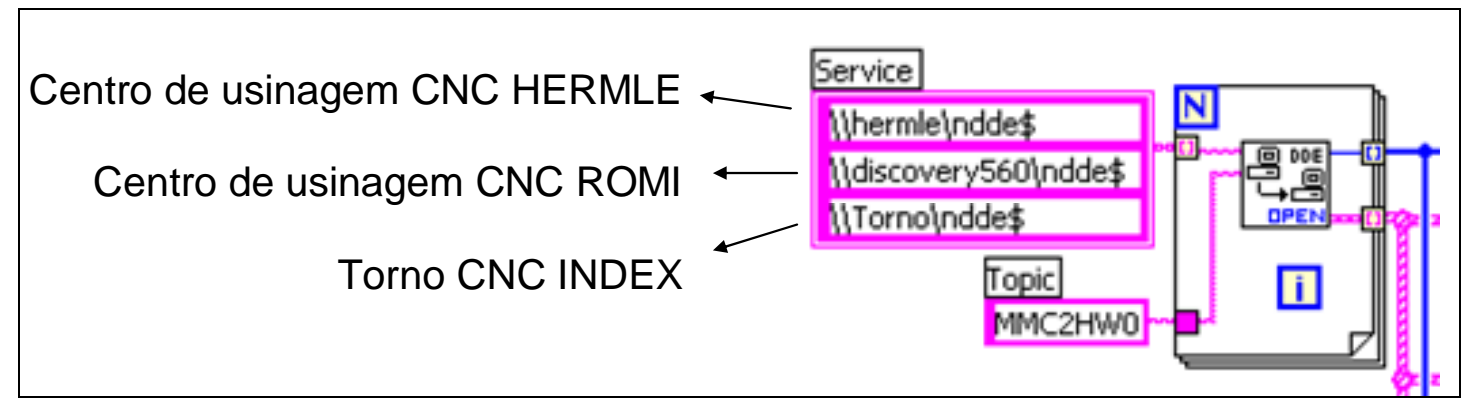

Figura 5 - Diagrama de programação: detalhe da configuração da comunicação Ethernet NetDDE com as três máquinas ferramenta CNC.

\begin{tabular}{|c|c|}
\hline temperatura Spindle & DriveHSA/State/motorTemperature \\
\hline temperatura Servo $\mathrm{X}$ & DriveVSA/State/motorTemperature[1] \\
\hline temperatura Servo Y & DriveVSA/State/motorTemperature[2] \\
\hline temperatura Servo Z & IDriveVSA/State/motorTemperature[3] \\
\hline nome programa CNC & IChannel,'ProgramPointeriprogName \\
\hline velocidade avanço setpoint eixo $\mathrm{X}$ & IChannel/parameter/R[50] \\
\hline velocidade avanco atual eixo $\mathrm{X}$ & IChannel/MachineAxis/actFeedRate[1] \\
\hline velocidade avanco setpoint eixo $\mathrm{Y}$ & IChannel/parameter/R[60] \\
\hline velocidade avanco atual eixo $\mathrm{Y}$ & /Channel//MachineAxis/actFeedRate[2] \\
\hline velocidade avanço setpoint eixo Z & IChanneliparameter/R[70] \\
\hline velocidade avanco atual eixo Z & Vhannel/MachineAxis/actFeedRate[3] \\
\hline rotacao atual Spindle & IChannel/Spindle/actSpeed \\
\hline Posicao X da ferramenta & IChannel/MachineAxis/actToolBasePos[1] \\
\hline Posicao Y da ferramenta & IChannel/MachineAxis/actToolBasePos[2] \\
\hline Posicao $\mathrm{Z}$ da ferramenta & IChannel/MachineAxis/actToolBasePos[3] \\
\hline Parametro R & IChannel/parameter/R[100] \\
\hline condicao de parada & IChannel/State/stopCond \\
\hline DI da porta & /Plc/Input/Bit[35.7] \\
\hline DO fluido & /Plc/Output/Bit[38.4] \\
\hline
\end{tabular}

Figura 6 - Diagrama de programação: itens lidos das máquinas ferramenta CNC via comunicação Ethernet NetDDE. 


\section{ROTINA DE MONITORAMENTO DA FERRAMENTA DE CORTE PARA PROCESSOS DE FRESAMENTO}

A seguir é apresentado a programação LabView 7.1 do sistema de monitoramento para a detecção automática de desgastes de ferramenta de corte.

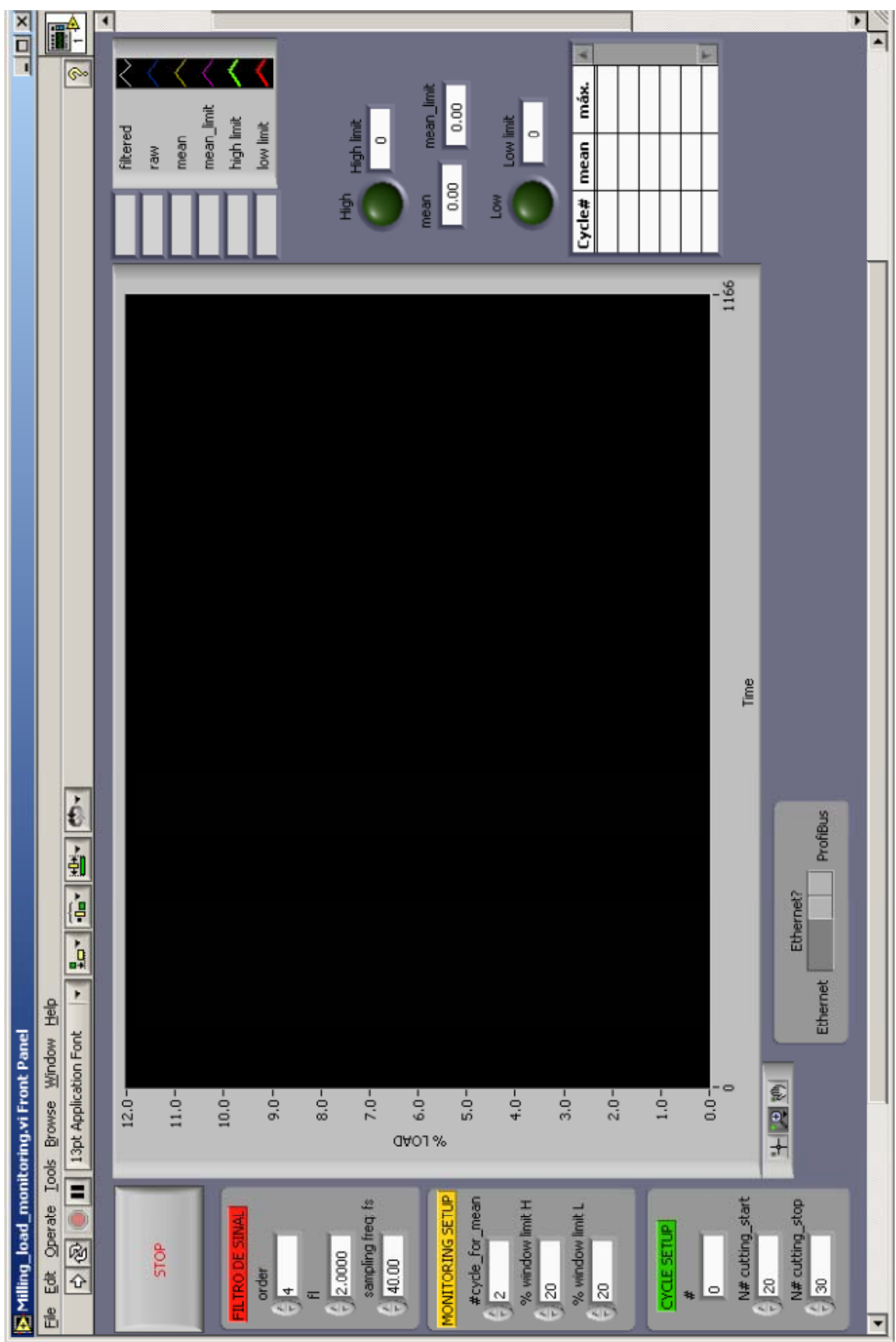

Figura 1 - Front end do sistema de monitoramento. 


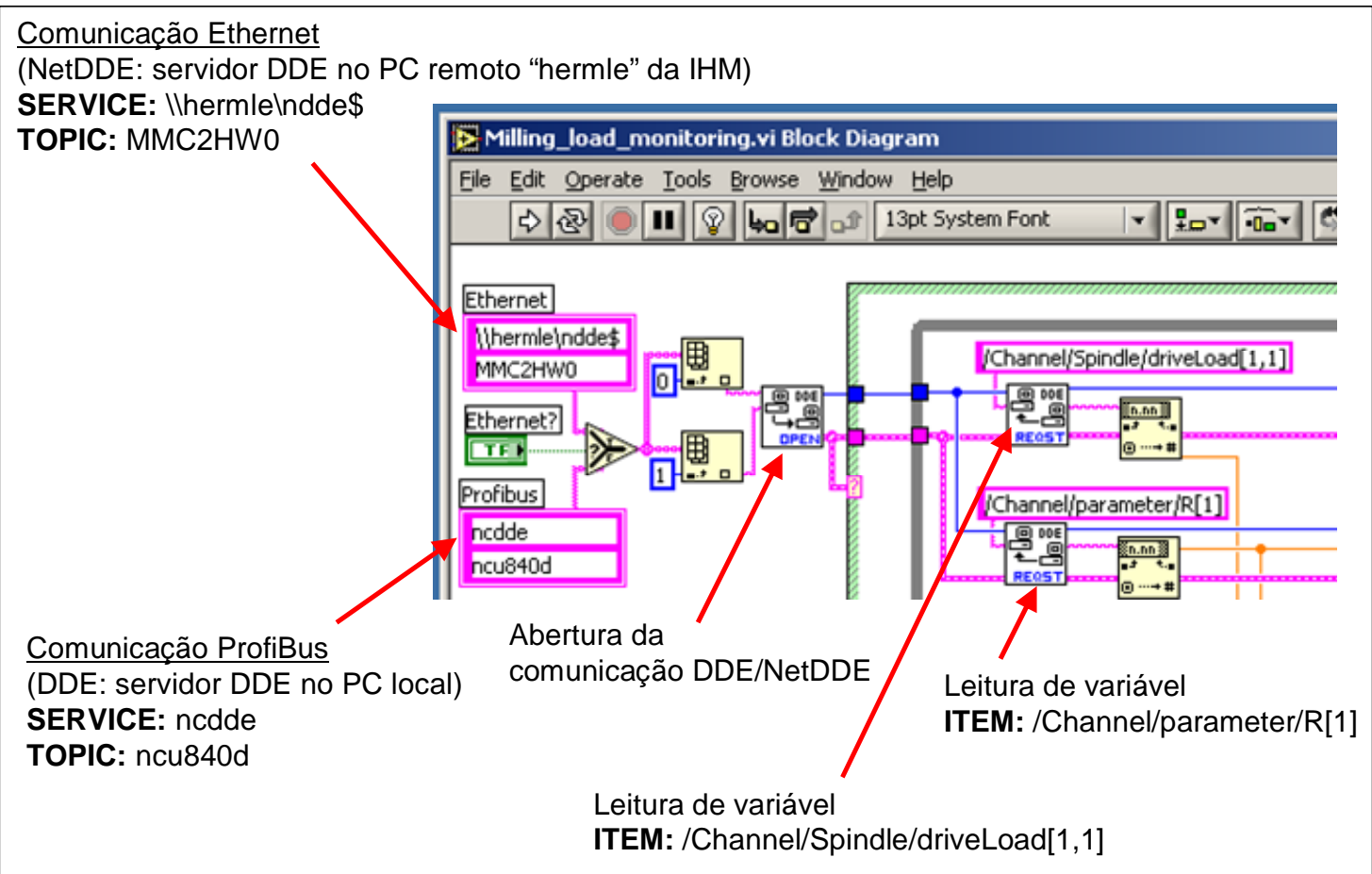

Figura 2 - Diagrama de programação: Detalhe das configurações de comunicação:

- Ethernet NetDDE

- Profibus DDE 


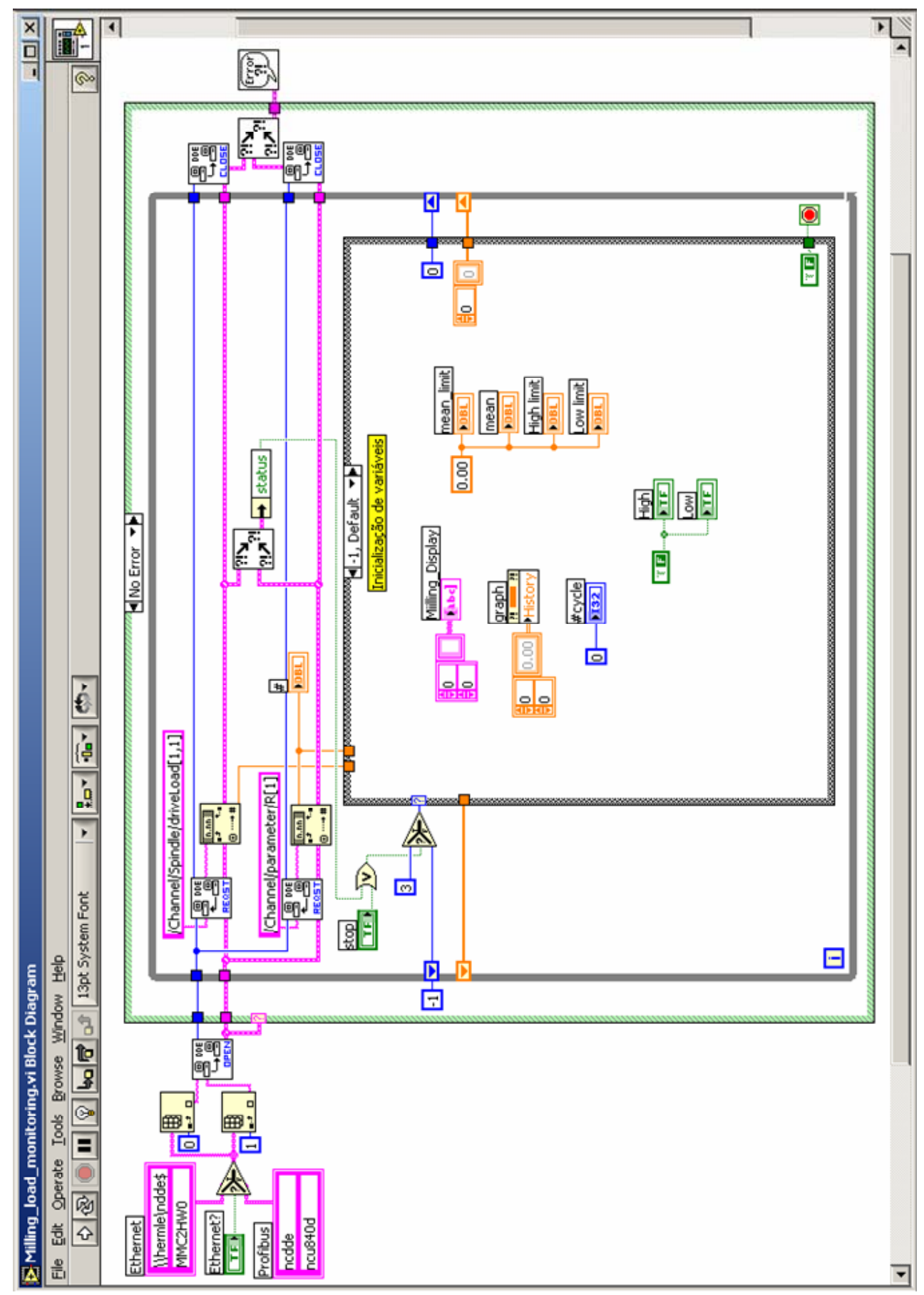

Figura 3 - Diagrama de programação: estado -1: inicialização de variáveis. 


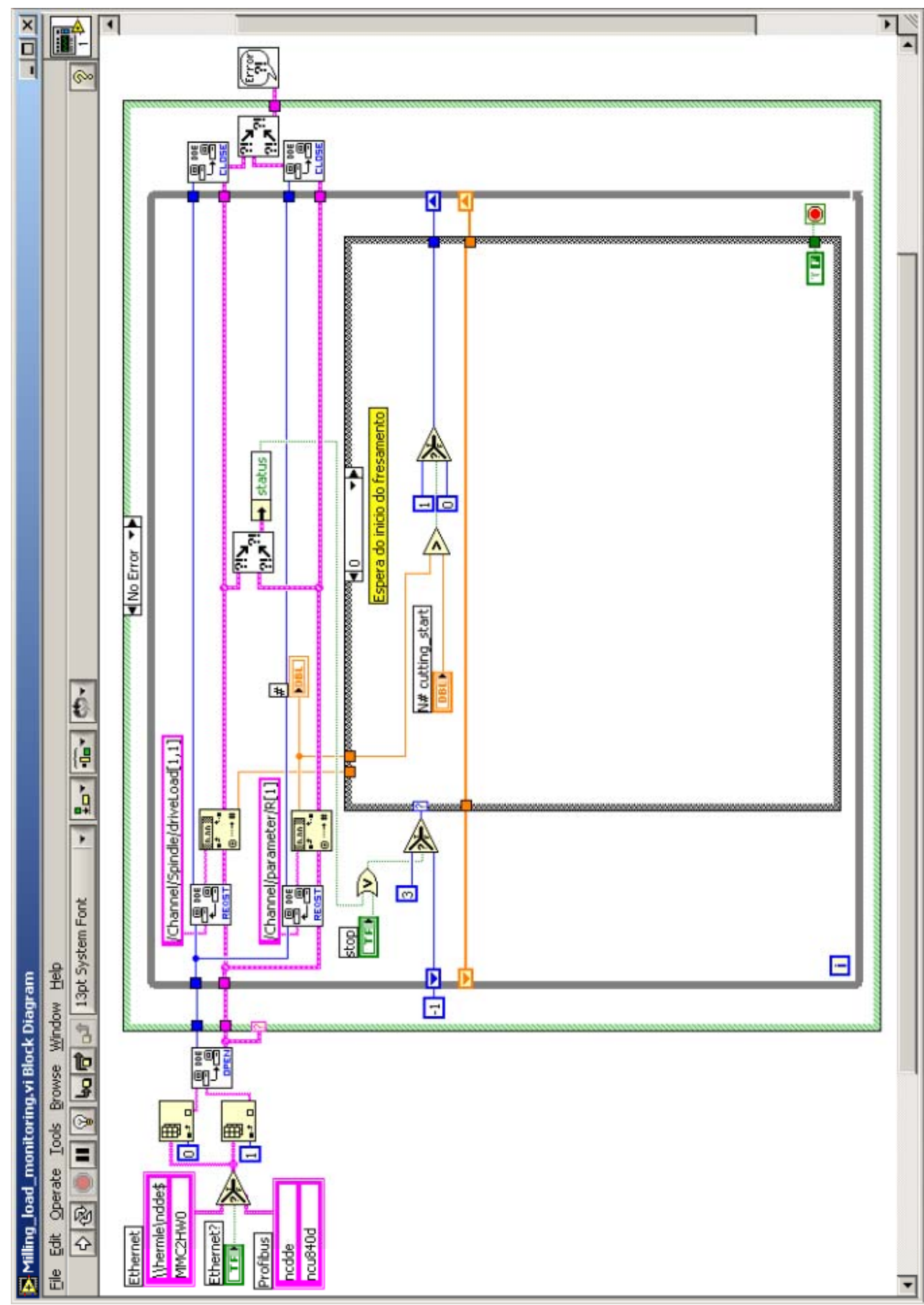

Figura 4 - Diagrama de programação: estado 0: espera do inicio do ciclo de fresamento. 


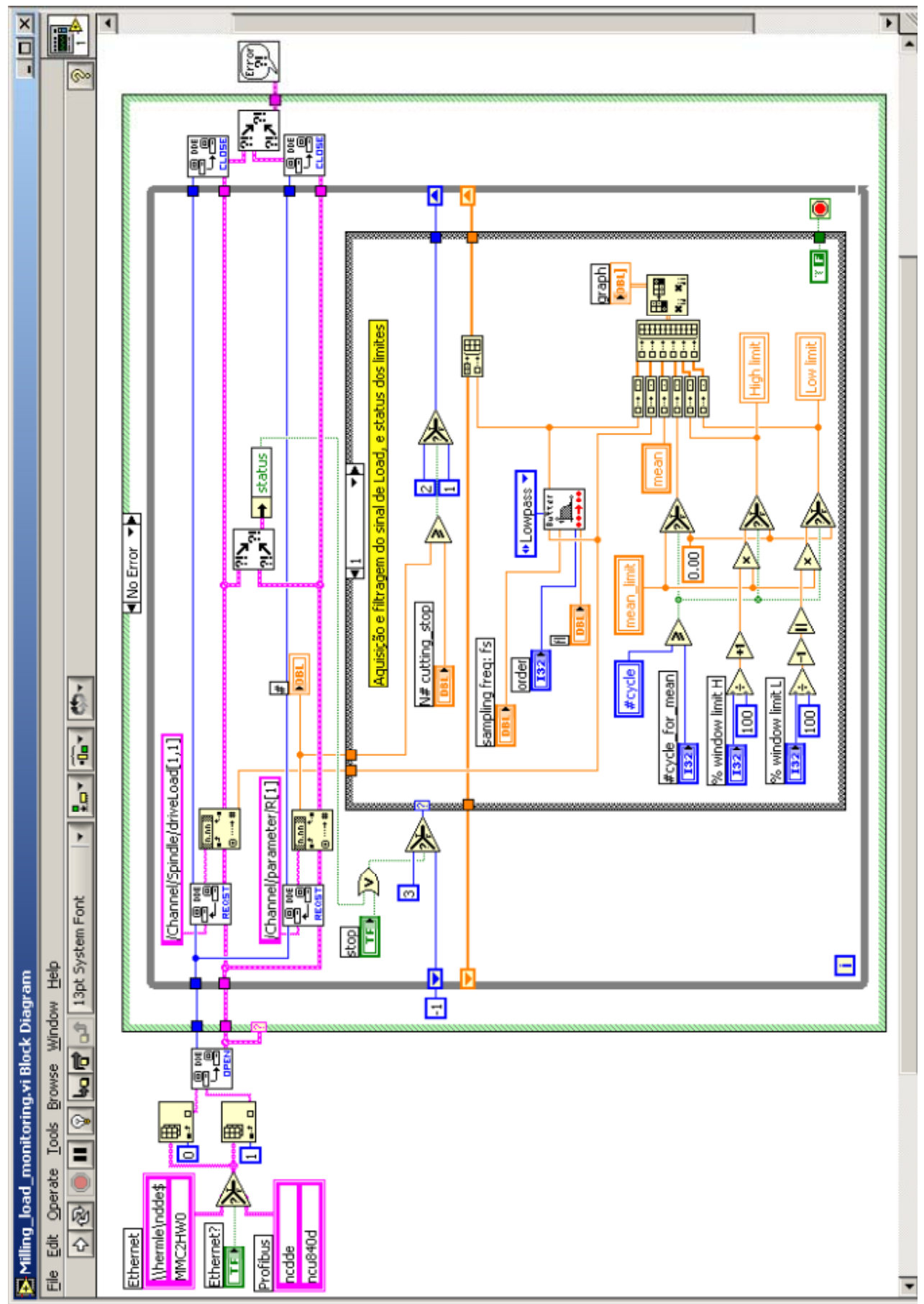

Figura 5 - Diagrama de programação: estado 1: aquisição e filtragem do sinal de Load, e status dos limites. 


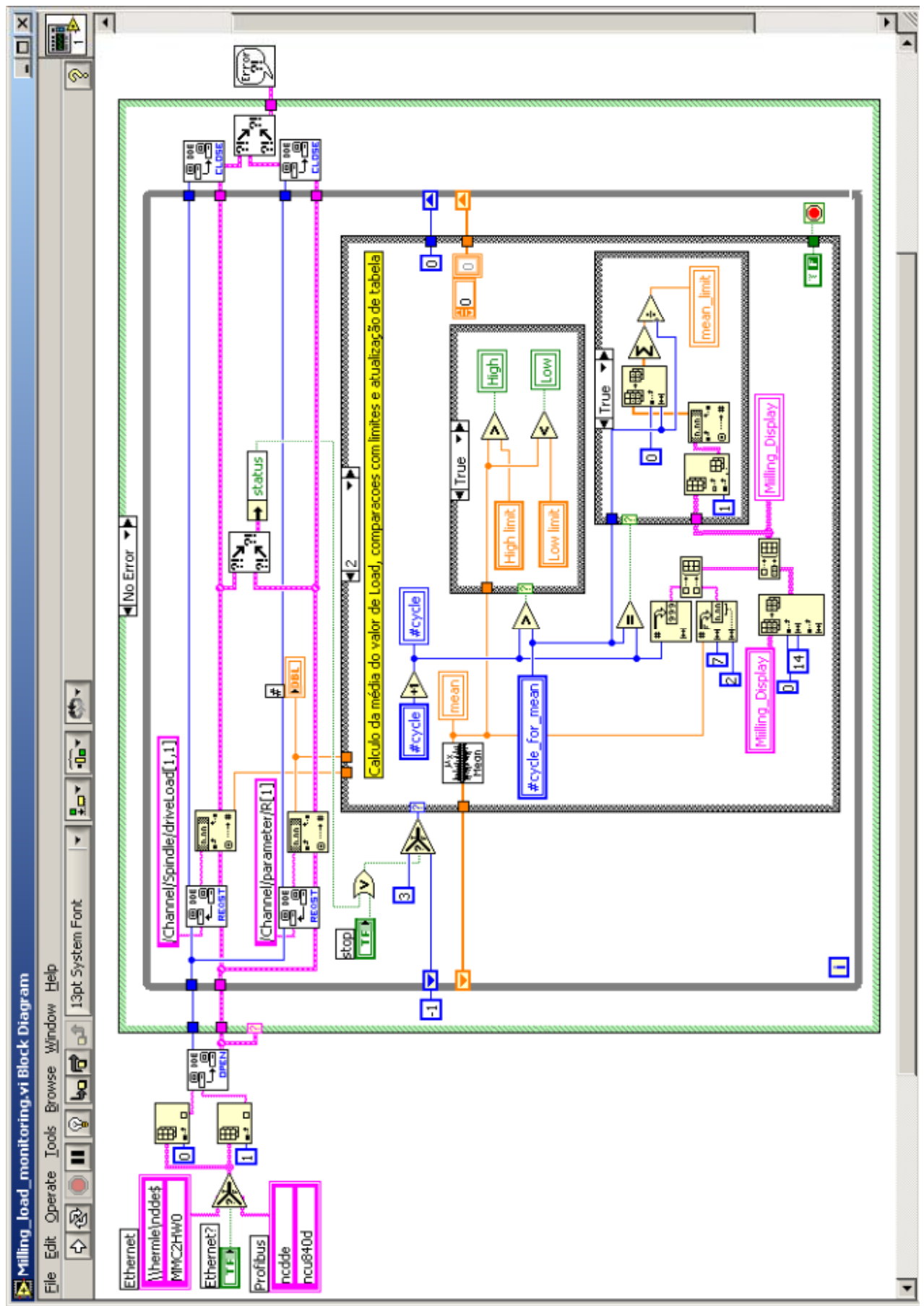

Figura 6 - Diagrama de programação: estado 2: cálculo da média do sinal LOAD, comparação com limites e atualização da tabela de informações dos ciclos. 


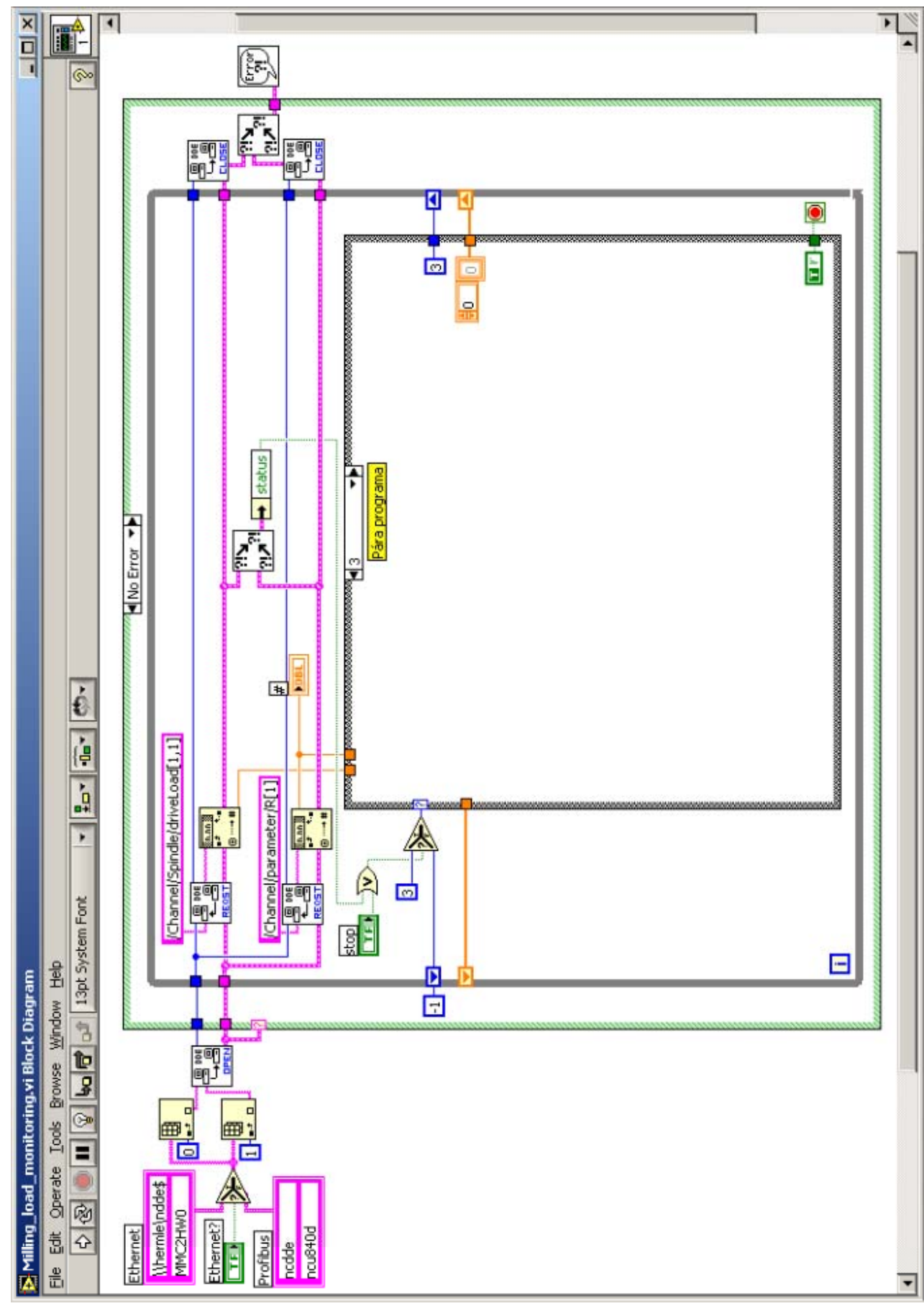

Figura 7- Diagrama de programação: estado 3: pára programa. 


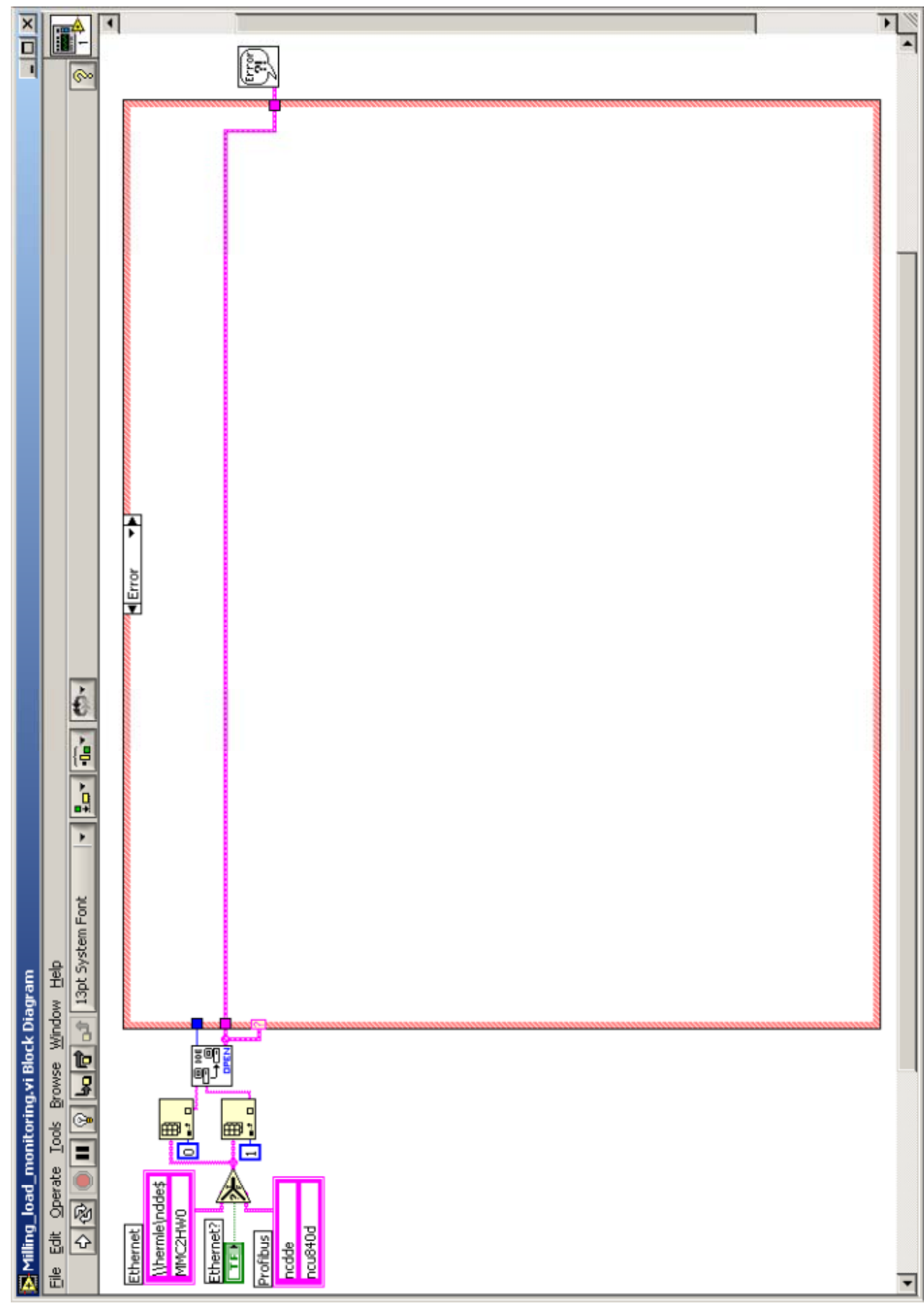

Figura 8 - Diagrama de programação: estado Error. 